\title{
Metagenomanalysen von zwei Habitaten mit (hemi-)cellulolytischen mikrobiellen Gemeinschaften
}

\author{
Dissertation \\ zur Erlangung des Doktorgrades \\ der Mathematisch-Naturwissenschaftlichen Fakultäten \\ der Georg-August Universität zu Göttingen
}

vorgelegt von

Silja Wittenberg

aus Goslar

Göttingen 2009 
D7

Referent:

Prof. Dr. W. Liebl

Korreferent:

PD. Dr. R. Daniel

Tag der mündlichen Prüfung: $\quad$ 22.01.2010 
Meinen Eltern gewidmet 


\section{Inhaltsverzeichnis}

Abkürzungsverzeichnis

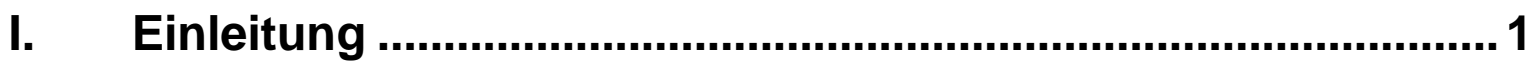

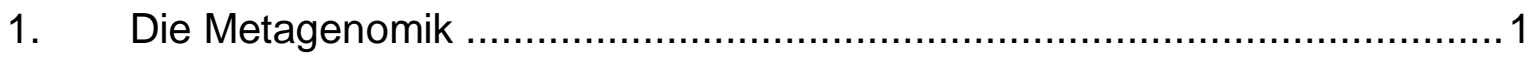

2. Der mikrobielle Abbau von pflanzlichen Polysacchariden .......................4

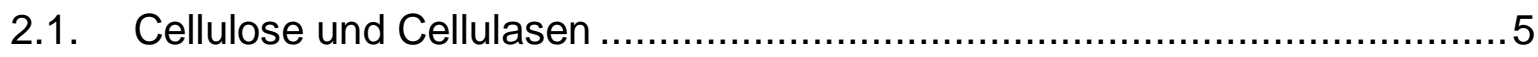

2.2. Hemicellulose, Xylan und Xylanasen ........................................ 6

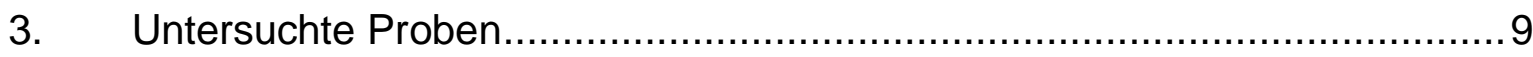

3.1. Fosmidgenbank aus Umweltproben des Avachinsky Kraters, Sibirien .........9

3.2. Der Elbebiber (Castor fiber albicus) ........................................... 10

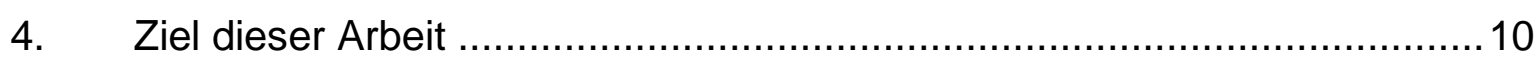

II. Material und Methoden ...................................................... 12

1. Organismen, Plasmide und Oligonukleotide .................................. 12

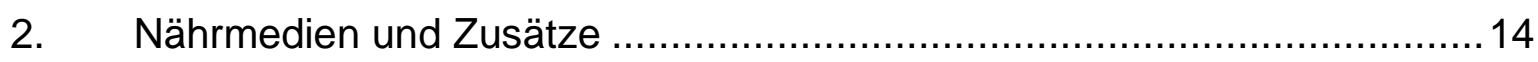

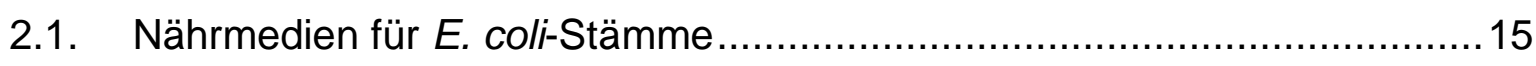

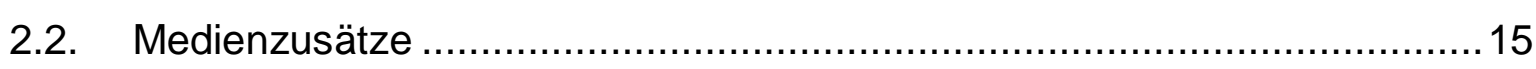

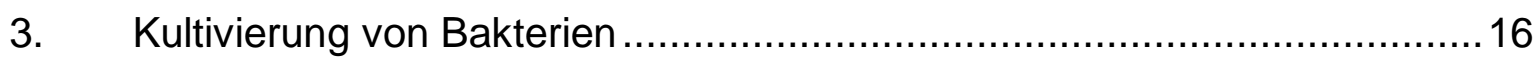

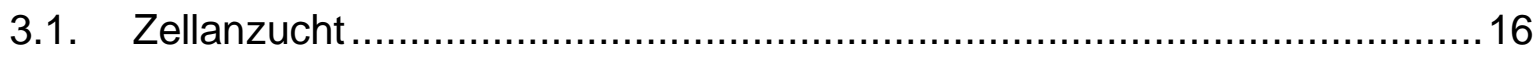

3.2. Bestimmung der Zelldichte ................................................... 16

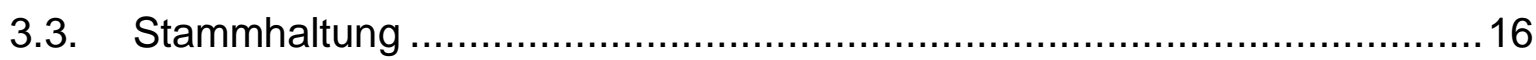

4. Zellernte und Gewinnung von Zellextrakten.................................... 17

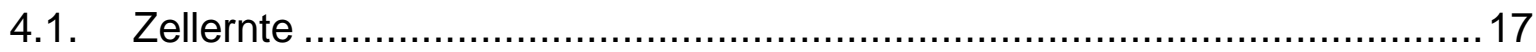

4.2. Zellaufschluss durch Ultraschall .................................................. 17

4.3. Zellaufschluss durch French Pressure Cell....................................... 17

5. Molekulargenetische Arbeitstechniken ........................................ 18

5.1. Behandlung von Materialien und Lösungen für das Arbeiten mit Nukleinsäuren

5.2. Bestimmung der DNA Konzentration einer Probe mittels NanoDrop® ....... 18 
5.3. Isolierung von DNA und Aufreinigung ............................................. 19

5.3.1. Phenol-Chloroform-Extraktion ............................................... 19

5.3.2. DNA-Fällung mit Isopropanol und Ethanol ...................................... 19

5.3.3. Reinigung von DNA-Fragmenten mittels „SureClean“ von Bioline ......... 19

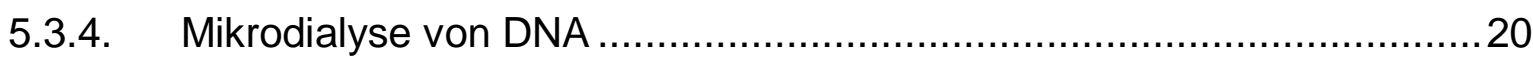

5.3.5. Plasmidisolierung durch alkalische Lyse ...................................... 20

5.3.6. Plasmidisolierung mit dem QiaPrep ${ }^{\circledR}$ Miniprep (Qiagen, Hilden) ............21

5.4. Isolierung von Umwelt-DNA ........................................................ 22

5.4.1. Isolierung mit dem „ExtractMaster ${ }^{\mathrm{TM}}$ Fecal DNA Extraction Kit“ ............22

5.4.2. Isolierung mit dem SoilMaster ${ }^{\mathrm{TM}}$ DNA Extraction Kit............................22

5.4.3. Isolierung von DNA mittels „PowerSoil ${ }^{\mathrm{TM}}$ DNA Isolation Kit“.................23

5.4.4. Isolierung von DNA aus Umweltproben (Zhou et al., 1996) .................23

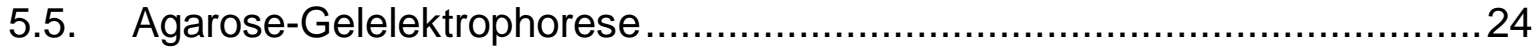

5.5.1. Analytische Agarose-Gelelektrophorese ..................................... 24

5.5.2. Größen- und Konzentrationsbestimmung von DNA-Fragmenten in

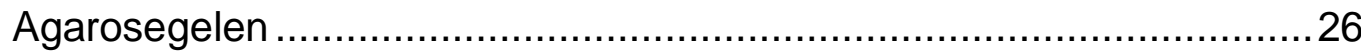

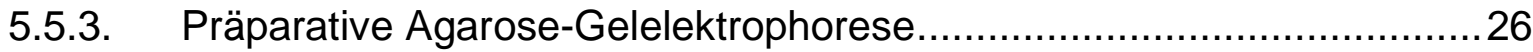

5.5.4. Präparative Gelelektrophorese mit Low Melting Point - Agarose ..........27

5.6. Polymerasekettenreaktion (PCR) …........................................... 27

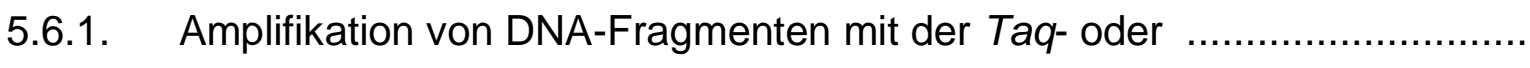
Pfu-DNA- Polymerase .......................................................... 27

5.6.2. Amplifikation von DNA-Fragmenten mit der KOD Hifi .............................. DNA Polymerase ....................................................................... 29

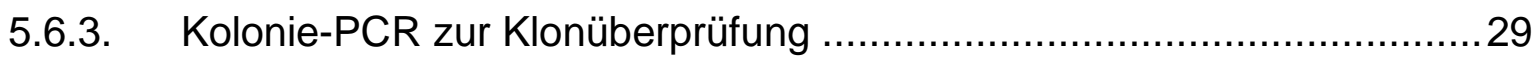

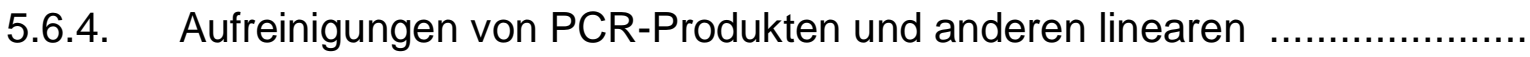
DNA- Fragmenten ..................................................................... 30

5.7. Mechanische Modifikation von DNA ............................................... 31

5.7.1. DNA-Scherung mittels Nebulizer ............................................. 31

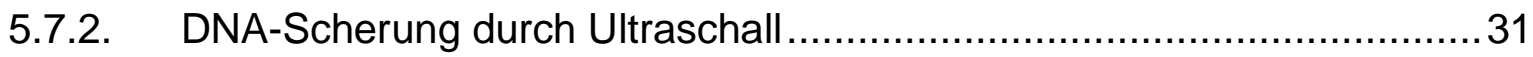

5.8. Enzymatische Modifikation von DNA ….......................................... 32

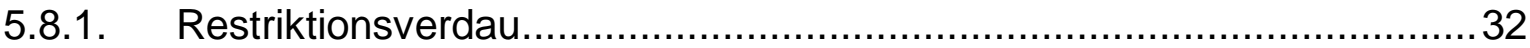

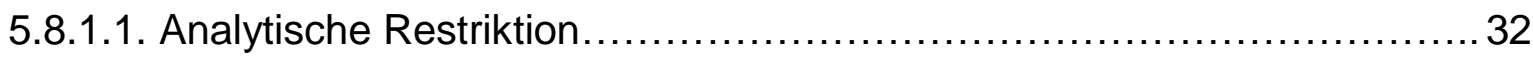

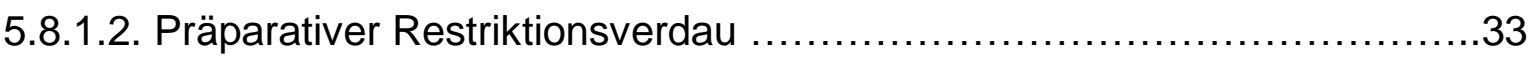

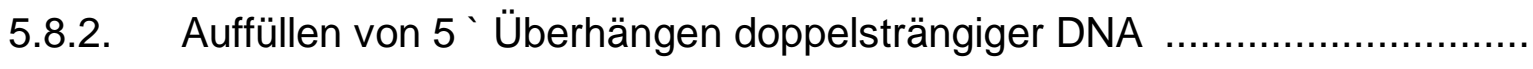
mittels T4-DNA-Polymerase 
5.8.3. Anhängen von dATP an „blunt-end-DNA“. .34

5.8.4. Dephosphorylierung linearer DNA mit „Antarctic Phophatase“ .............34

5.8.5. Ligation von DNA Fragmenten in Plasmidvektoren ............................ 34

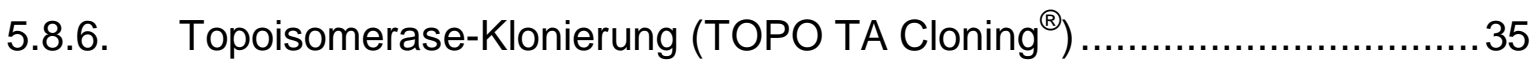

5.8.7. Klonierung von PCR-Produkten zur heterologen Expression in E. coli mit dem pET Directional TOPO ${ }^{\circledR}$ Expression“-Kit 36

5.9. Transformation von E. coli-Zellen ................................................. 36

5.9.1. Transformation durch Elektroporation........................................... 36

5.9.2. Transformation von E. coli durch Hitzeschock (Inoue et al., 1990) .........37

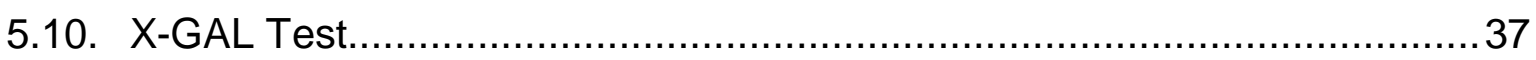

5.11. Konstruktion von Genbanken aus Umwelt-DNA ................................ 38

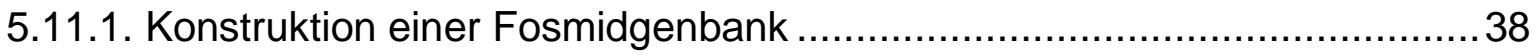

5.11.2. Konstruktion einer Plasmidgenbank mit dem TOPO ${ }^{\circledR} \mathrm{XL}$ PCR Cloning-Kit (Invitrogen ${ }^{\circledR}$, Carlsbad) ..................................... 41

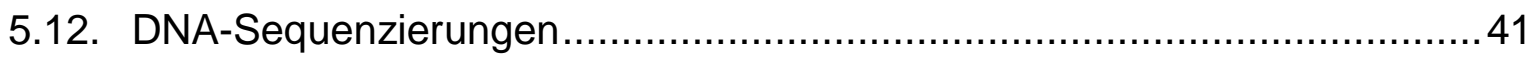

5.12.1. Shotgun-Sequenzierung von Fosmid-DNA ........................................ 41

5.12.2. 454-Sequenzierung von 16S rRNA-Gensequenzen ........................... 42

6. Proteinbiochemische Methoden................................................ 43

6.1 Quantitative Proteinbestimmung (Bradford, 1976) ................................ 43

6.2. Polyacrylamid-Gelelektrophorese ............................................... 44

6.2.1. SDS- Polyacrylamid-Gelelektrophorese (Laemmli, 1970) ...................44

6.2.2. Nativ-Polyacrylamidgelelektrophorese (Nativ-PAGE) .......................46

6.2.3. Coomassie-Färbung von Proteinen in Polyacrylamid-Gelen .................4 47

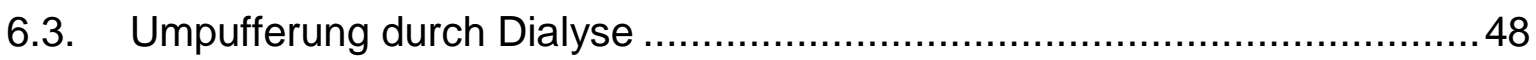

6.4. Einkonzentrierung und/oder Umpufferung von Proteinlösungen mittels Mikrokonzentratoren .............................................................. 48

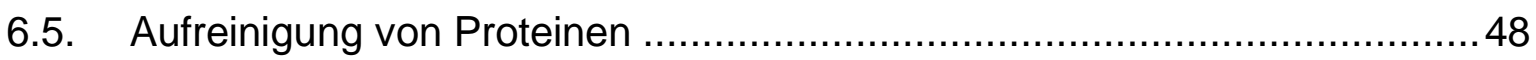

6.5.1. Abtrennung thermolabiler Proteine durch Hitzedenaturierung ...............48

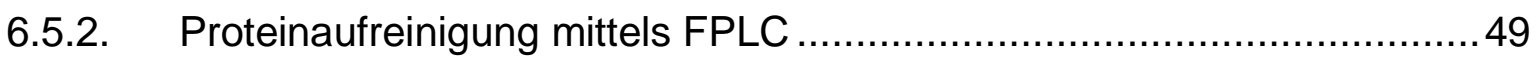

6.5.3. Reinigung löslicher Proteine mit Protino ${ }^{\circledR}$ Ni-TED-Säulen .....................50

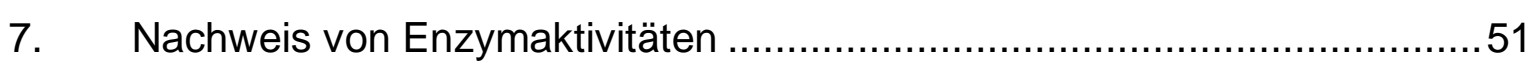

7.1. DNSA-Test zur Bestimmung der Menge reduzierender Zucker .................51

7.2. Nachweis der Hydrolyse von Polysacchariden durch Enzyme nach

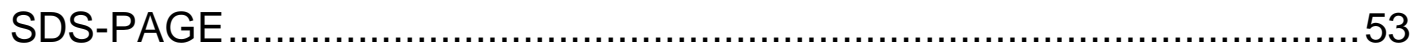

7.3. Produktanalyse durch Dünnschichtchromatographie (TLC) ...................54 
8. Nachweis (hemi-)cellulolytischer Aktivität von E. coli-Klonen....................55

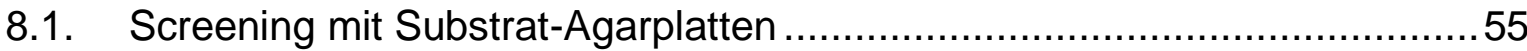

8.2. Screening mit selbst angefärbten Substraten ..................................... 56

8.3. Screening mit 4-Methylumbelliferyl- $\beta$-D-cellobiosid .............................. 58

9. Die Prozessierung von DNA-Rohsequenzen ................................... 58

9.1. Die Prozessierung von DNA-Sequenzen mit Hilfe des STADEN-

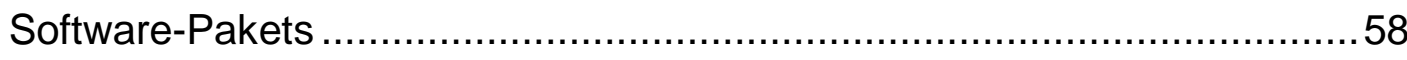

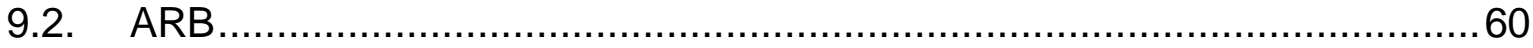

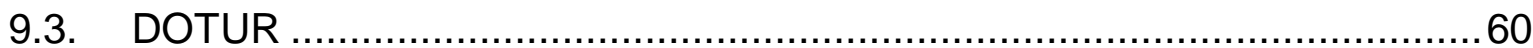

9.4. Untersuchung von 16S rRNA-Gensequenzen auf die Existenz chimärer Sequenzen

III. Experimente und Ergebnisse

1. Teil 1: Identifizierung und Charakterisierung von neuen (hemi-) cellulolytischen Enzymen aus einer metagenomischen FosmidDNA- Genbank aus Umweltproben des Avachinky Kraters 62

1.1. Ergebnis des Screenings und Sequenzierung der Fosmid-DNA. 63

2. Analyse und heterologe Expression von zwei ausgewählten ORFs und Charakterisierung der Genprodukte. 65

2.1. Analyse des ORFs $x y n 1015$ 65

2.1.2. Amplifikation des ORFs $x y n 1015$ und Ligation in den Vektor pET101

2.1.3. Heterologe Expression des ORFs xyn1015 in E. coli BL21(DE3) und Aufreinigung von Xyn1015 68

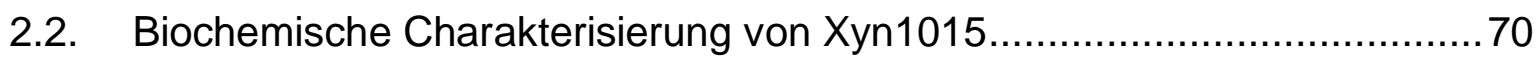

2.2.1. Bestimmung des Temperaturspektrums ..................................... 70

2.2.2. Bestimmung der Thermostabilität ................................................... 71

2.2.3. Bestimmung des pH-Optimums ................................................ 72

2.2.4. Einfluss verschiedener Additive auf die Aktivität............................... 73

2.2.5. Einfluss von $\mathrm{NaCl}$ auf die Aktivität................................................ 75

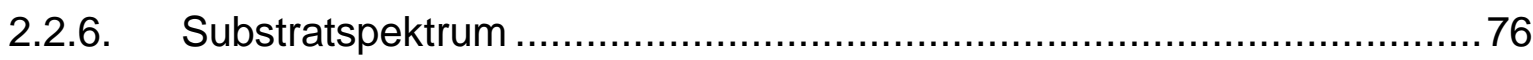

2.2.7. Qualitative Untersuchung der Produktbildung und des Spaltungsmechanismus von Xyn1015 beim Abbau von Buchenholz- Xylan 


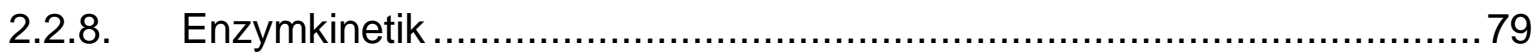

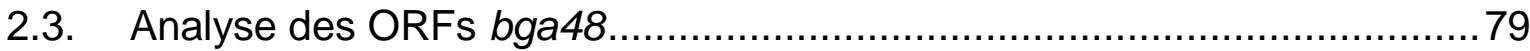

2.3.1 Klonierungen des ORFs bga48 und heterologe Expression in E. coli BL21(DE3).

2.3.2. Heterologe Expression und Aufreinigung von Bga48 …....................... 83

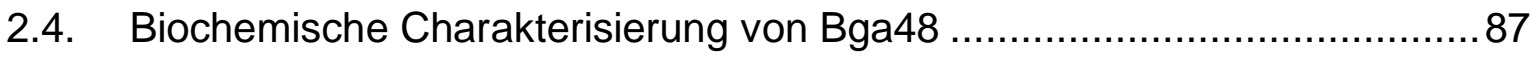

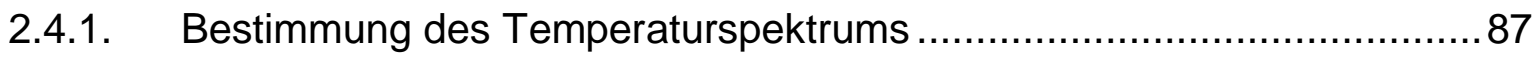

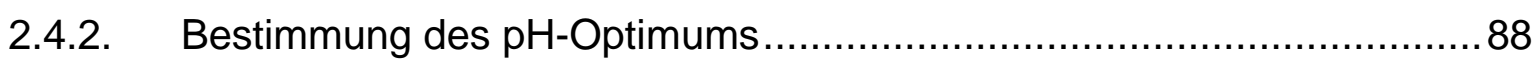

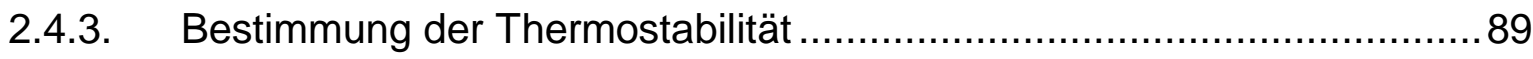

2.4.4. Einfluss verschiedener Additive auf die Aktivität...................................90

2.4.5. Untersuchung des Substratspektrum ............................................. 92

2.4.6. Qualitative Untersuchung der Produktbildung und des Spaltungsmechanismus von Bga48 beim Abbau von B-Glucan ............94

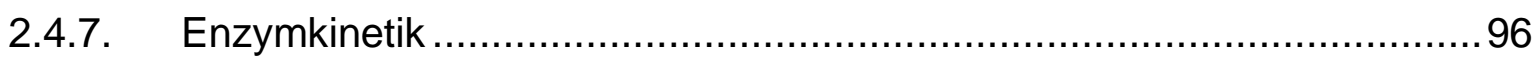

3. Teil 2: Untersuchung der Diversität in unterschiedlichen Teilen des Intestinaltraktes des europäischen Bibers (Castor fiber albicus)........97

3.1. Sektion der Biber und Isolierung des Inhalts der unterschiedlichen Darmabschnitte

3.2. Methoden zur Untersuchungen der mikrobiellen Diversität in den

Darmabschnitten des Bibers mittels 16S rRNA-Genanalysen .98

3.3. Untersuchung der phylogenetischen Diversität unterschiedlicher Darmabschnitte des Bibers.

3.3.1. Analyse der 16S rRNA Gensequenzen aus der Probe des vorderen Bereiches des Blinddarmes.

3.3.1.1. Konstruktion phylogenetischer Stammbäume der bakteriellen Diversität im vorderen Abschnittes des Blinddarmes.

3.3.2. Analyse der 16S rRNA Gensequenzen aus der Probe des hinteren Bereiches des Blinddarmes.

3.3.2.1. Konstruktion phylogenetischer Stammbäume des hinteren Abschnittes des Blinddarmes

3.3.3. Analyse der 16S rRNA Gensequenzen aus der Probe des Dickdarms des männlichen Tieres.

3.3.3.1. Konstruktion phylogenetischer Stammbäume des Inhaltes des Endbereiches des Dickdarmes. 
3.4. Vergleich der bakteriellen Diversität in den hinteren Abschnitten des Blinddarms des weiblichen und männlichen Tieres

3.5. Konstruktion von Genbanken mit metagenomischer DNA aus dem hinteren Caecumbereich

IV. Diskussion

1: Durchmusterung der metagenomischen Fosmidgenbank aus Umweltbodenproben des Avachinsky Kraters in Kamchatka/Sibirien auf cellulolytische und hemicellulolytische Enzyme

2. Sequenzanalyse, Expression und biochemische Charakterisierung von Xyn1015 und Bga48

2.1. Sequenzanalyse des ORFs xyn1015.

2.2. Biochemische Charakterisierung von Xyn1015

2.3. ORF bga48.

2.4. Biochemische Charakterisierung von Bga48

3. Phylogenetische Untersuchung des Intestinaltraktes des Elbebibers (Castor fiber albicus....

3.1. Vergleich zwischen der klassischen 16S rRNA-Genanalyse und der 16S rRNA-Genanalyse von 454-Pyrosequenzdaten partiell amplifizierter 16S rRNA-Genen

3.2. Die mikrobielle Diversität im Darm des Bibers

3.3. Vergleich der bakteriellen Diversität in verschiedenen Bereichen des Darmtraktes des Bibers

3.4. Vergleich der bakteriellen Diversität im Caecum von zwei Individuen mit unterschiedlicher Nahrungsaufnahme.

3.5: Konstruktion von metagenomischen Genbanken aus Proben des hinteren Caecumbereiches

3.6. Ausblick

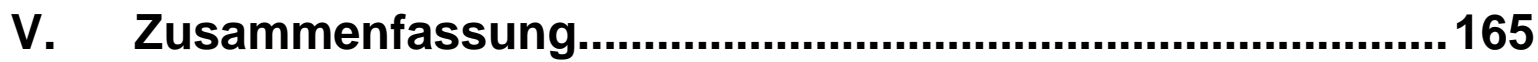

VI. Literaturverzeichnis .......................................................... 168

VII. Anhang ........................................................................... 180 


\section{Abkürzungsverzeichnis}

A

AA

Abb.

Amp

bidest.

bp

BLAST

BSA

${ }^{\circ} \mathrm{C}$

CDD

$\mathrm{Cm}$

C-terminal

$\mathrm{Da}$

dest.

d. h.

DMSO

DNA

DNase

dNTP

EC

E-cup

E. coli

EDTA
Ampere

Acrylamid

Abbildung

Ampicillin

bidestilliert

Basenpaar

Basic Local Alignment Search Tool

Bovines Serumalbumin

Grad Celsius

conserved domain database

Chloramphenicol

carboxyterminal

Dalton

Destilliert

das heißt

Dimethylsulfoxid

Desoxyribonukleinsäure

Desoxyribonuklease

Desoxyribonukleotid-5'-triphosphat

Enzyme Commission

Eppendorf Gefäß

Escherichia coli

Ethylendiamintetraacetat 
et al.

Fa.

g

h

HEPES

Kan

KOD-Polymerase

k

$\mathrm{kb}$

$\mathrm{kDa}$

$\mathrm{kg}$

I

LacZ

LB

m

M

$\mu$

MCS

$\min$

n

NCBI

$\mathrm{N}$-terminal

OD

ORF und weitere (et alii)

Firma

Gramm

Stunde

N-2-Hydroxyethylpiperazin-

N'-2-ethansulfonsäure

Kanamycin

Polymerase aus Thermococcus kodakaraensis

Kilo $\left(10^{3}\right)$

Kilobasen

Kilodalton

Kilogramm

Liter

$\beta$-Galactosidase

Luria Bertani

milli- $\left(10^{-3}\right)$

$\operatorname{Molar}(\mathrm{mol} / \mathrm{l})$, Mega- $\left(10^{6}\right)$

Mikro- $\left(10^{-6}\right)$, Wachstumsrate

Multiklonierungsstelle (multiple cloning site)

Minute

Nano- $\left(10^{-9}\right)$

National Center for Biotechnology Information

aminoterminal

Optische Dichte

offener Leserahmen (open reading frame) 


\begin{tabular}{|c|c|}
\hline $\mathrm{Pa}$ & Pascal \\
\hline PCR & $\begin{array}{l}\text { Polymerasekettenreaktion (polymerase chain } \\
\text { reaction) }\end{array}$ \\
\hline Pfu-Polymerase & Polymerase aus Pyrococcus furiosus \\
\hline $\mathrm{pH}$ & $\begin{array}{l}\text { negativer dekadischer Logarithmus der } \\
\text { Protonenkonzentration }\end{array}$ \\
\hline PIPES & Piperazin-1,4-bis(2-ethansulfonsäure) \\
\hline$r$ & resistent/Resistenz \\
\hline RDP & Ribosomal Database Project \\
\hline RNA & Ribonukleinsäure \\
\hline RNAse & Ribonuklease \\
\hline RT & Raumtemperatur/Reverse Transkription \\
\hline s & Sekunden, sensitiv \\
\hline SDS & Natriumdodecylsulfat \\
\hline ssDNA & einzelsträngige DNA \\
\hline SV & Säulenvolumen \\
\hline Tab. & Tabelle \\
\hline TAE & Tris-Acetat-EDTA-Puffer \\
\hline Taq-Polymerase & Polymerase aus Thermus aquaticus \\
\hline TE & Tris-EDTA-Puffer \\
\hline TEMED & $\mathrm{N}, \mathrm{N}, \mathrm{N}^{\prime}, \mathrm{N}^{\prime},-$ Tetramethylethylen-diamin \\
\hline Tris & Tris-(hydroxymethyl)-aminomethan \\
\hline U & Einheit der Enzymaktivität (unit) \\
\hline ÜN & über Nacht \\
\hline UV & Ultraviolett \\
\hline $\mathrm{V}$ & Volt \\
\hline
\end{tabular}


$\mathrm{v} / \mathrm{v}$

Vol.

$\mathrm{w} / \mathrm{v}$

X-Gal

Nukleotidbasen
A Purinbase Adenin
G Purinbase Guanin
C Pyrimidinbase Cytosin
$\mathrm{T} \quad$ Pyrimidinbase Thymidin

Volumen

Masse pro Volumen

5-Bromo-4-Chloro-3-indolyl- $\beta$-D-galactosid

\section{Aminosäuren}
A Alanin
M Methionin
C Cystein
$\mathrm{N} \quad$ Asparagin
D Aspartat
P Prolin
E Glutamat
Q Glutamin
F Phenylalanin
R Arginin
G Glycin
S Serin
H Histidin
T Threonin
I Isoleucin
V Valin
K Lysin
W Tryptophan
L Leucin
Y Tyrosin 


\section{Einleitung}

\section{Die Metagenomik}

Die Biosphäre enthält eine hohe Anzahl verschiedener Habitate, die von Mikroorganismen als Lebensraum besiedelt werden können. Sie haben Fähigkeiten entwickelt, um auch unter extremsten Bedingungen zu leben und sich zu teilen. So konnten Prokaryoten in den unterschiedlichsten Habitaten nachgewiesen werden. Sie sind z.B. in der Antarktis ebenso zu finden, wie in heißen Quellen und können extreme Temperaturen, pH-Werte, Drücke, Strahlungen und hohe Salzkonzentrationen tolerieren.

Schätzungen gehen davon aus, dass auf der Erde bis zu 100 Millionen unterschiedliche bakterielle Arten existieren (Strickeberger, 1996, Wilson, E. O., 1992). Unter Laborbedingungen ist es jedoch nur möglich, einen geringen Anteil von angenommenen $1 \%$ dieser Arten zu kultivieren und somit für die biologische Forschung zugänglich zu machen (Amann et al., 1995, Ellis et al., 2003). Dieses stellt einen hohen Verlust dar, da die genetische Information dieser unkultivierbaren Organismen ein hohes Potential für die Grundlagenforschung und für biotechnologische Anwendungen birgt.

Um diese Problematik zu umgehen, wird seit einigen Jahren ein alternatives Verfahren angewendet, in dem auf die Kultivierung der Mikroorganismen verzichtet wird. Hierbei wird die gesamte DNA einer Standortprobe direkt isoliert und funktionellen und DNA-basierten Analysen unterzogen. In diesem Zusammenhang wurde der Begriff "Metagenom" eingeführt, der die gesamte genetische Information eines Standortes beschreibt (Handelsman et al., 1998).

Hierbei wird das Metagenom eines Habitats für unterschiedliche Analysen genutzt (Abbildung 1). Zum einen können Aussagen über die mikrobielle Diversität getroffen werden, zum anderen bietet sich zudem die Möglichkeit, neuartige Biokatalysatoren oder bioaktive Substanzen zu identifizieren (Daniel, 2004, Handelsman, 2004). 


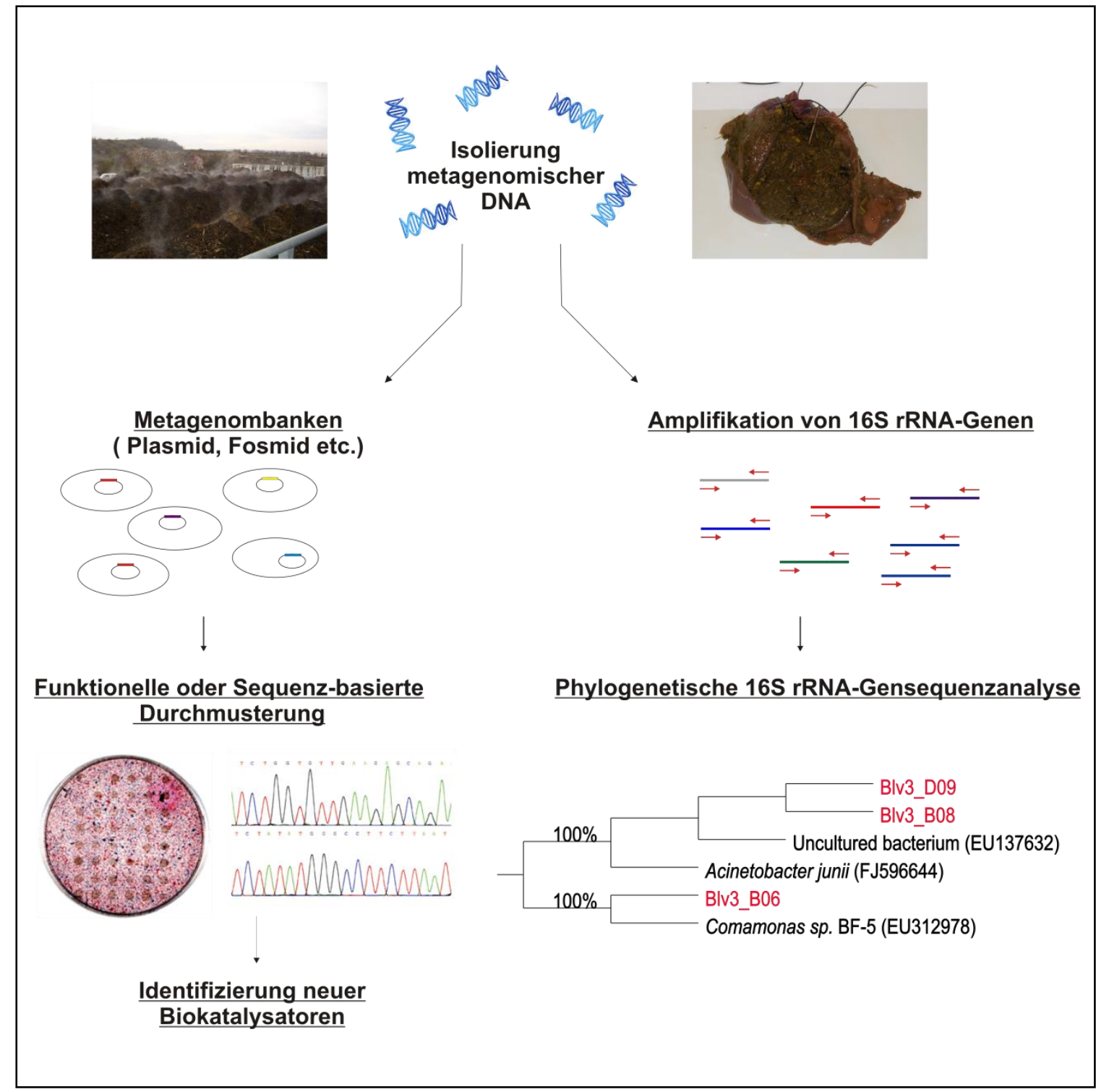

\section{Abbildung 1: Strategien zur Analyse und Charakterisierung von Metagenomen}

Nach der Isolation der gesamten DNA einer Standortprobe wird diese verwendet, um phylogenetische 16S rRNA-Gensequenzanalysen durchzuführen und Metagenombanken zu konstruieren. Die Metagenombanken können mit funktionellen oder DNA-basierten Methoden bezüglich neuer Biokatalysatoren oder bioaktiven Substanzen durchgemustert werden.

Zur Untersuchung der mikrobiellen Diversität hat sich die Methodik der 16S rRNAGensequenzanalyse etabliert. Den Grundstein hierfür legte im Jahr 1987 Woese mit seinen Mitarbeitern. Er erstellte den ersten bakteriellen Stammbaum kultivierter Bakterien auf Grundlage von 16S rRNA-Genen (Woese, 1987). Bei der 16S-rRNA handelt es sich um einen Teil der 30S ribosomalen Untereinheit, die 
ubiquitär in allen Prokaryoten vorkommt. Das entsprechende Gen enthält sowohl stark konservierte Bereiche, als auch variable Regionen und eignet sich daher als phylogenetisches Markergen. Während von den konservierten Bereichen Oligonukleotide für die zur partiellen oder vollständigen Amplifikation des 16SrRNA-Gens mittels PCR abgeleitet werden können, dienen die variablen Regionen der 16S-rRNA zur phylogenetischen Differenzierung der einzelnen Arten (Amann et al., 1995, Riesenfeld et al., 2004). Carl Woese erstellte 1987 einen bakteriellen Stammbaum mit zwölf unterschiedlichen Phyla. Durch die Einführung metagenomischer Methoden ist die Anzahl der bakteriellen Phyla und Arten enorm angestiegen. Mittlerweile befinden sich in der NCBI-Datenbank an die 1,3 Millionen bakterielle 16S-rRNA-Gensequenzen, wobei es sich nur bei etwa 170.000 Sequenzen um 16S-rRNA-Gensequenzen kultivierter Bakterien handelt. Die gesamten Sequenzdaten werden zur Zeit in 100 verschiedene Phyla bzw. candidate devisions eingeteilt (Stand August 2009) (DeSantis et al., 2006). Dieses zeigt das hohe Potential der Metagenomforschung.

Ein weiterer Aspekt der Metagenomik ist die Identifizierung neuer Biokatalysatoren oder bioaktiver Substanzen wie z. B Antibiotika oder Immunosuppressiva in Metagenombanken (Schmeisser et al., 2007). Hierfür wird zunächst die gesamte DNA einer Standortprobe isoliert, in geeignete Vektoren wie z.B. Plasmide oder Fosmide kloniert und in Wirtsbakterien, meist E. coli, transformiert. Während Plasmidgenbanken eine maximale Insertgröße von ca $10 \mathrm{~kb}$ erlauben, können in Fosmid-Genbanken DNA-Fragmenten bis zu $40 \mathrm{kbp}$ kloniert werden. Die Verwendung von Fosmidgenbanken hat den Vorteil, dass Gene im Zusammenhang betrachtet werden können. Häufig sind die Gene komplexer Stoffwechselswege des Metabolismus, Katabolismus und Anabolismus in Genclustern angelegt.

Die generierten Metagenombanken können nun nach biotechnologisch interessanten Genen mittels DNA-Sequenz- oder Funktions-basierten Methoden durchgemustert werden. Die Sequenz-orientierte Methode basiert auf DNA-Sequenzähnlichkeiten schon bekannter Gene. Diese Methode erfordert die Erstellung von degenerierten Primern auf der Grundlage konservierter DNARegionen zur Identifizierung neuartiger Gene durch direkte Amplifikation oder durch Kolonie-Hybridisierung (Bell et al., 2002). Aufgrund der sinkenden Kosten werden jedoch immer häufiger die gesamten Metagenombanken auf der 
Grundlage des „whole genome shotgun sequencing“ sequenziert. Eine Methode, die zuvor nur an isolierten Einzelorganismen durchgeführt wurde (Venter et al., 2004). Mit den erhaltenen Sequenzdaten können anschließend BLAST-Analysen durchgeführt werden und somit Ähnlichkeiten zu schon bekannten Genen detektiert werden. Auf diese Weise können jedoch nur Enzyme schon bekannter Proteinfamilien oder funktionellen Klassen detektiert werden. Bei der funktionellen Enzymaktivitäts-basierten Durchmusterung, z.B. durch Verwendung von Plattentests, können vollkommen neue Enzyme detektiert werden. Dieses wird jedoch dadurch limitiert, dass die metagenomischen Gene heterolog im Wirtsstamm exprimierbar sein müssen. Viele Gene benötigen spezielle Expressionsvorraussetzungen, die der klassische Wirtsstamm E. coli oft nicht erfüllen kann.

\section{Der mikrobielle Abbau von pflanzlichen Polysacchariden}

Besonders in den letzten Jahren hat sich angesichts des sinkenden Erdölvorkommens, der erhöhten $\mathrm{CO}_{2}$-Emmissionen und der starken Preiserhöhung für Erdöl-basierte Kraftstoffe das Interesse für alternative Wege der Kraftstoffherstellung aus erneuerbaren Ressourcen gesteigert. Hier bietet sich die Verwertung von pflanzlicher Biomasse an, deren in diversen Struktur-oder Speicherpolysacchariden enthaltende Zucker von Hefen und anderen Mikroorganismen zu Ethanol fermentiert werden. Während in den ersten Jahren der Bioethanol-Forschung als Grundlage zuckerhaltige Rohstoffe wie Zuckerrohr, Mais oder Weizen verwendet wurden (Mielenz, 2001), liegt der heutige Forschungsfokus auf der Verwertung von Cellulose-haltigen Rohstoffen, wie zum Beispiel Ernte- oder Holzabfälle oder Pflanzen, die unter anspruchslosen Anbaubedingungen kultivierbar sind (Li, L. L. et al., 2009). Damit diese Rohstoffe für die Ethanolproduktion verwendet werden können, müssen jedoch zunächst die (Hemi-)Cellulosebestandteile dieser Pflanzen durch chemische oder enzymatische Prozesse zu Zucker gespalten werden, um sie für die Fermentation durch Mikroorganismen zugänglich zu machen (Carere et al., 2008). Für die Spaltung des Cellulose und Hemicellulosehaltigen Materials bietet sich die Verwendung von mikrobiellen Cellulasen und Hemicellulasen an. 
In den folgenden Kapiteln werden die Eigenschaften von Cellulose und Hemicellulose und deren Abbau durch mikrobielle Cellulasen und Hemicellulasen erläutert. Des Weiteren wird über die Anwendbarkeit dieser Enzyme, die weit über die Verwendung in der Bioethanolproduktion hinaus geht, berichtet.

\subsection{Cellulose und Cellulasen}

Die pflanzliche Zellwand besteht zu $35 \%$ bis $50 \%$ aus Cellulose. Damit stellt Cellulose das am häufigsten vorkommende Biopolymer der Erde dar (Lynd et al., 2002). Es handelt es sich um ein Homopolysaccharid aus B-1,4 glycosidisch verknüpften Glucose-Einheiten, die Ketten aus bis zu 15.000 Molekülen bilden können. Die strukturelle Grundeinheit ist Cellobiose, die aus zwei zu $180^{\circ}$ gedrehten Glucosemolekülen besteht. Etwa 30 Glucoseketten bilden eine Elememtarfibrille, in der Wasserstoffbrücken sowohl innerhalb der Ketten, als auch zwischen den Ketten für Stabilität sorgen. Mehrere Elementarfibrillen werden zu Mikrofibrillen angeordnet, die letztendlich die Cellulosefasern bilden (Lynd et al., 2002). So wird innerhalb der Cellulosefaser eine stabile kristalline Struktur erreicht, die jedoch durch amorphe Bereiche, in denen fehlende Wasserstoffbrücken eine verminderte Stabilität verursachen, unterbrochen wird. In der Natur variiert der Grad der Kristallisation zwischen $40 \%$ und $90 \%$ (Hildén und Johansson, 2004).

Aufgrund der Komplexität der Cellulosestruktur entwickelten Cellulose-abbauende Mikroorganismen eine Anzahl von spezialisierten Enzymen. Cellulasen werden in die Familie der Glycosidhydrolasen eingeordnet und hydrolysieren B-1,4-glycosidische Bindungen. Für den vollständigen Abbau von mikrokristalliner Cellulose sind drei große Enzymgruppen nötig. Endoglucanasen schneiden innerhalb der amorphen Bereiche der Elementarfibrille und produzieren so Oligosaccharide unterschiedlicher Länge. Die Exo-Glucanasen, d.h. Cellodextrinasen und Cellobiohydrolasen, wirken an den Enden der Cellulosekette und spalten Glucose bzw. Cellobiose ab. Als dritte Gruppe hydrolysieren die B-Glucosidasen Cellobiose und lösliche Cellodextrine zu Glucose. Der Reaktionsmechanismus erfolgt in allen Fällen über den Mechanismus der sauren Hydrolyse der glycosidischen Bindungen (Lynd et al., 2002). 
Der mikrobielle Abbau erfolgt über zwei verschieden Enzymsysteme. Aerobe Pilze und Bakterien sekretieren in der Regel die unterschiedlichen freien cellulolytischen Enzyme, die die Cellulose synergistisch hydrolysieren. Häufig besitzen diese Enzyme sogenannte Kohlenhydratbindedomänen (CBMs, carbohydrate binding modules), die für die Enzymstabilität und für die Substratbindung sorgen (Wang, Y. et al., 2009, Zhang und Lynd, 2004).

Anaerobe Bakterien organisieren mit wenigen Ausnahmen die cellulolytischen Enzyme in sogenannten Cellulosomen, die als Ausstülpungen auf der Zellwand ausgebildet werden (Schwarz, 2001). Cellulosomen bestehen aus einem nichtkatalytischen scaffolding-Protein mit verschiedenen Cohesin-Domänen, an die unterschiedliche Enzyme des Cellulose- und Hemicelluloseabbaus über DockerinDomänen binden können. Somit ist eine optimale Verwertung und Bindung des Substrats gewährleistet (Lynd et al., 2002, Schwarz, 2001).

Cellulasen finden nicht nur in der zuvor beschriebenen Bioethanolproduktion Anwendung (Carere et al., 2008), sondern in zahlreichen anderen industriellen Gebieten. In der Nahrungsmittelindustrie werden Cellulasen in der Fruchtsaft-, Bier-, und Weinherstellung zur Aufklarung der Getränke verwendet. Zudem werden sie in der Herstellung von Sojaprodukten eingesetzt. In der Textilindustrie werden Cellulasen verwendet, um den so genannten „stone-wash"-Effekt zu erzielen. Des Weiteren finden Cellulasen Anwendungen in der Futtermittel- und Papierindustrie, aber auch in vielen anderen Gebieten (Bhat, 2000).

\subsection{Hemicellulose, Xylan und Xylanasen}

Der Begriff „Hemicellulosen“ beinhaltet die Heteropolymere Xylan, Mannan, Galaktan und Arabinan. Die Klassifizierung dieser Polymere beruht auf der Art des Zuckers, aus dem die Hemicellulosen hauptsächlich aufgebaut sind (D-Xylose, D-Mannose. D-Galaktose und D-Arabinose) (Beg et al., 2001). Hemicellulosen sind flexible Polysaccharide, die sich auf die Oberfläche von Cellulosefasern legen und häufig als Verbindungschicht zum Lignin dienen.

Xylan ist die am häufigste vorkommende Hemicellulose und das zweithäufigste Biopolymer auf der Erde. Es kommt als Strukturpolysaccharid in den Zellwänden aller Landpflanzen und in einigen Algen vor. Es handelt sich um ein heterogenes Polysaccharid, das auf einem homopolymeren Rückgrat aus B-1,4-verknüpften 
D-Xylose-Einheiten besteht (Kulkarni et al., 1999). An diesem Rückgrat können sich, je nach Syntheseort des Xylans, verschiedene Substituenten wie AcetylGruppen am O-2 oder O-3, oder a-1,3 -verknüpfte L-Arabinofuranosen, welche

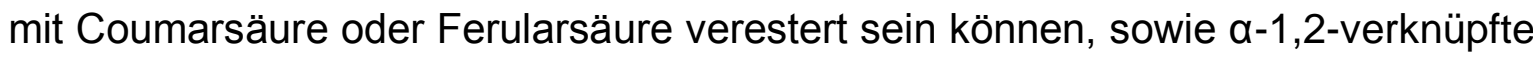
4-O-Methyl-D-Glucuronsäuren befinden (Coughlan und Hazlewood, 1993). Die Anzahl und Art der Seitenketten kann je nach Pflanzenart stark variieren (Warren, 1996). So sind in Hartholzxylanen etwa 70 \% der Xylosereste acetyliert, in Weichholzxylanen liegt nur eine etwa 12 \%ige Acetylierung vor. In Gehölzen ist das Xylan über aromatische Seitenketten der Cumarylsäuren und Ferularsäure kovalent mit dem Lignin verbunden und liegt den Cellulosefasern in nicht kovalenter Verbindung auf. So schützt Xylan die Cellulose vor enzymatischen Abbau (Beg et al., 2001).

Aufgrund der zahlreichen Seitenketten ist eine kristalline Struktur, wie sie bei Cellulose vorkommt nicht oder kaum ausgebildet. Ein weiterer Unterschied zur Cellulose ist die wesentlich kürzere Kettenlänge der Xylosereste, die in Hartholzxylanen normalerweise maximal einen Polymerisierungsgrad von 200, bei Weichholzxylanen von 75 beträgt (Kulkarni et al., 1999).

Für den enzymatischen Abbau von Xylan ist aufgrund der komplexen Zusammensetzung ein Zusammenspiel verschiedener Enzyme notwendig, die sowohl von xylanabbauenden Pilzen, als auch xylanverwertenden Bakterien produziert werden. Für die Abspaltung der verschiedenen Seitenketten werden Hydrolasen wie $\alpha$-L-Arabinofuranosidasen, $\alpha$-Glucuronidasen, AcetylXylan-Deacetylase und Phenolsäure-Esterasen benötigt. Das Xyloserückgrat wird von $\beta$-1,4 -Endoxylanasen innerhalb der Kette zu Xylose und Xylooligomeren gespalten, während $\beta$-Xylosidasen Xylooligomere zu Xylose hydrolysieren (Abbildung 2). 
a-Glucuronidasen

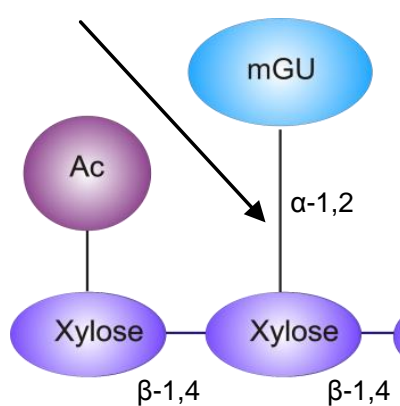

Endo-Xylanasen
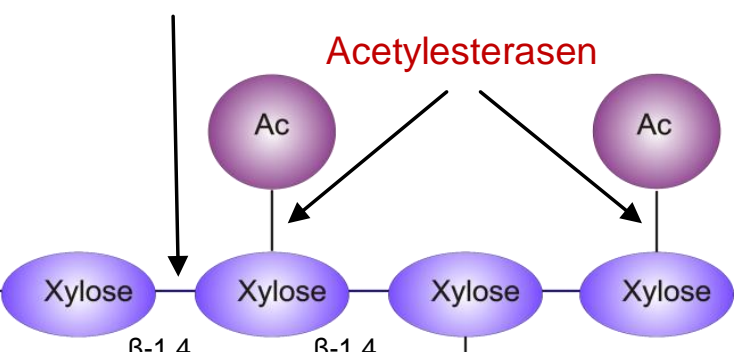

a- Arabinofuranosidasen

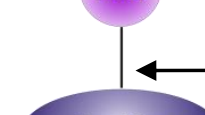

Phenolsäure-

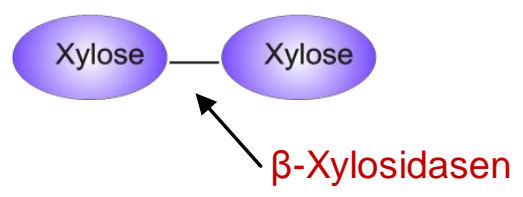

Fer/Cou Esterasen

\section{Abbildung 2: Schematische Übersicht über die Struktur von Xylan und die am} Abbau beteiligten Enzyme. $A c=$ Acetylgruppe, Ara $=$ Arabinofuranose, Cou $=$ Coumarsäure, Fer $=$ Feruloylsäure, $\mathbf{m G U}=4-\mathrm{O}-$ Methyl-D-Glucuronsäure Quelle: Beg et al., 2001, vereinfacht

Xylanasen werden in vielen industriellen Bereichen angewendet. Zurzeit werden sie hauptsächlich in der Bleichung von Papier eingesetzt, sie helfen jedoch auch in der Fruchtsaft-, Bier- und Weinherstellung und finden Anwendungen in der Herstellung von Backwaren. Zudem werden sie in der Textilindustrie und Futtermittelherstellung verwendet (Collins et al., 2005). Eine weitere zukunftsorientierte Anwendung ist der Einsatz in der Bioethanolproduktion. Hemicellulosen eignen sich weniger als Rohstoff für die Ethanolproduktion, da bei dem Abbau vorwiegend Pentosen gebildet werde, die von den am häufigsten verwendeten Hefen nicht verwertet werden können (Pauly und Keegstra, 2008). Dennoch könnte der Einsatz von Hemicellulasen in der Bioethanolproduktion sinnvoll sein, da die Hemicellulosen den eigentlichen Rohstoff Cellulose vor dem enzymatischen Abbau schützen. Durch den Abbau dieser schützenden Schicht durch Hemicellulasen könnte das Substrat Cellulase für cellulolytische Enzyme, aber auch für chemische und mechanische Prozesse zugänglicher gemacht 
werden. Ein weiterer Ansatz ist die Verwendung von alternativen Ethanolproduzierenden Mikroorganismen, die die Abbauprodukte von Hemicellulose im Gegensatz zu den momentan vorwiegend eingesetzten Hefen verwerten können (Sommer et al., 2004).

\section{Untersuchte Proben}

\subsection{Fosmidgenbank aus Umweltproben des Avachinsky Kraters, Sibirien}

In dieser Arbeit wurde eine metagenomische Fosmidgenbank, die aus Umweltbodenproben des Avachinsky Kraters in Kamchatka (Sibirien) erstellt wurde, funktionell bezüglich cellulolytischer und hemicellulolytischer Enzyme durchgemustert.

Die Metagenombank wurde von Jörg Schuldes (Institut für Mikrobiologie und Genetik, Universität Göttingen) im Rahmen einer Doktorarbeit konstruiert. Zudem wurde die Umweltprobe mittels 16S-rRNA-Analysen auf ihre phylogenetische Diversität hin analysiert.

Die Umgebung der Probenentnahme war natürlich auf $67^{\circ} \mathrm{C}$ erhitzt und hatte einen pH-Wert von 9-9,3. Die phylogenetischen Analysen zeigten die Existenz von Vertretern zweier archaeller Phyla und 18 bakterieller Phyla. Etwa $50 \%$ aller 16S-rRNA-Gensequenzen wurden den Proteobacteria zugeordnet. Es konnten aber auch Vertreter der Bacteroidetes (8\%) und Acidobacteria (7,5\%) sowohl in geringen Anteilen Vertreter der Cyanobacteria, der Nitrospira, der Planctomycetes und der Gemmatimonadetes detektiert werden. Die archaellen 16S-rRNA Gensequenzen wurden den Phyla Crenarchaeota und Euryarchaeota zugeordnet. Ein Anteil von 95,5 \% aller 16S-rRNA-Gensequenzen zeigten keinerlei Identität zu schon kultivierten Mikroorganismen und bildeten zum Teil neue Cluster innerhalb der verschiedenen Phyla.

Die metagenomische „large insert“ Genbank enthielt 5200 Klone mit einer Gesamtgröße von 182 Mbp klonierter Umwelt-DNA. Im Rahmen der Doktorarbeit von Jörg Schuldes konnten vier Gene für neuartige lipolytische und drei Gene für proteolytische Enzyme detektiert werden und diese teilweise charakterisiert werden (Schuldes, 2008). 


\subsection{Der Elbebiber (Castor fiber albicus)}

Der Biber gehört zur Ordnung der Rodentia und wird hier in die Familie der Castoridae eingeordnet. Zur Familie der Castoridea gehören nur zwei Arten: Der kanadische (C. canadensis) und europäische Biber (C. fiber). Der Elbebiber (C. fiber albicus) ist eine Unterart des europäischen Bibers und kommt in Deutschland in wenigen Regionen entlang der Elbe vor.

Der europäische Biber kann eine Körperlänge von bis zu 110 Zentimetern und ein Körpergewicht bis zu $30 \mathrm{~kg}$ erlangen und ist daher weltweit das zweitgrößte Nagetier.

Während des Sommers ernähren sich europäische Biber vorwiegend von weichen und unverholzten Pflanzen, wie Kräutern, Gräsern oder Trieben von Wasserpflanzen. Da der Biber keinen Winterschlaf betreibt, ist er gezwungen, in der kalten Winterzeit seine Nahrung umzustellen. In dieser Zeit ernährt er sich hauptsächlich von Rinde von Weichhölzern wie Espen, Weiden, Eschen oder Pappeln (Nolet et al., 1994). Diese nährstoffarme und schwer verdauliche Nahrung wird mit Hilfe von spezialisierten Mikroorganismen in dem stark ausgeprägten Blinddarm aufgeschlossen (Hoover und Clarke, 1972). Der Blinddarminhalt wird in sogenannten „Pillen“ ausgeschieden, erneut gefressen und verdaut. Diese Pillen enthalten neben dem aufgeschlossenen Pflanzenmaterial zudem von Bakterien produzierte wichtige Vitamine und Eiweiße. Dieses Verhalten ist bei vielen Vertreter der Rodentia bekannt und wird Caecotrophie genannt (Hirofumi, 2001). Da sich die mikrobielle Flora nicht auf ständig wechselnde Rindenarten einstellen können, bevorzugt der einzelne Biber nur wenige verschiedene Baumarten und ändert vorzugsweise die Baumwahl zeitlebens nicht.

\section{Ziel dieser Arbeit}

Im Rahmen dieser Doktorarbeit sollten in der metagenomischen Fosmidgenbank aus Umweltproben des Avachinsky-Kraters Gene für neuartige cellulolytische und hemicellulolytische Enzyme identifiziert werden. Die Gene sollten anschließend heterolog in E. coli exprimiert und biochemisch charakterisiert werden. Des Weiteren sollte die mikrobielle Diversität in unterschiedlichen Bereichen des Intestinaltraktes des Elbebibers mittels 16S-rRNA-Analyse ermittelt werden und 
eine Genbank aus dem Metagenom der Mikroorganismen im Blinddarm erstellt werden. 


\section{Material und Methoden}

\section{Organismen, Plasmide und Oligonukleotide}

Die in der vorliegenden Arbeit verwendeten Bakterienstämme, Plasmide und Oligonukleotide sind in Tabelle 1 bis 3 aufgeführt.

Tabelle 1: Verwendete E. coli-Stämme

\begin{tabular}{|c|c|c|}
\hline Stamm & Beschreibung & Herkunft/Referenz \\
\hline $\begin{array}{l}\text { Escherichia coli } \\
\text { Top10 }\end{array}$ & $\begin{array}{l}\text { F- mcrA_(mrr-hsdRMS-mcrBC) } \\
\varphi 80 l a c Z \text { M15_lacX74 nupG recA1 } \\
\text { araD139_(ara-leu)7697 galE15 } \\
\text { galK16rpsL(StrR) endA1 } \lambda \text { - }\end{array}$ & $\begin{array}{l}\text { Invitrogen, } \\
\text { Carlsbad, } \\
\text { USA }\end{array}$ \\
\hline $\begin{array}{l}\text { Escherichia coli } \\
\text { BL21(DE3) }\end{array}$ & $\begin{array}{l}\text { F- ompT gal dcm lon hsdSB( } r B-m B-) \\
\lambda(D E 3 \text { [lacl lacUV5-T7 gene } 1 \text { ind1 } \\
\text { sam7 nin5]) }\end{array}$ & $\begin{array}{l}\text { Invitrogen, } \\
\text { Carlsbad, } \\
\text { USA }\end{array}$ \\
\hline $\begin{array}{l}\text { Escherichia coli } \\
X L 1 \text {-blue }\end{array}$ & $\begin{array}{l}\text { thi1, endA1, gyrA96 (Nalr), supE } \\
44, \text { recA1, hsdR17, } \lambda-\text {-, lac, -rpsL(Smr), } \\
\text { [F'traD36, proAB,laclq, } \\
\text { lacZ } \triangle M 15, T n 10(T c r)]\end{array}$ & Bullock et al., 1987 \\
\hline $\begin{array}{l}\text { Escherichia coli } \\
\text { EPI300-T1 }{ }^{\circledR}\end{array}$ & $\begin{array}{l}\text { F- mcrA } \Delta(m r r-h s d R M S-m c r B C) \\
\Phi 80 d l a c Z \Delta M 15 \Delta l a c X 74 \text { recA1 endA1 } \\
\text { araD139 } \Delta(\text { ara,leu }) 7697 \text { galU } \\
\text { galK } \lambda \text { rpsL nupG trfA tonA dhfr }\end{array}$ & $\begin{array}{l}\text { Epicentre, } \\
\text { Madison, WI } \\
\text { USA }\end{array}$ \\
\hline
\end{tabular}

Tabelle 2: Verwendete Plasmide

\begin{tabular}{lll}
\hline Plasmid & Beschreibung & Referenz \\
\hline pCR2.1-TOPO & Amp $^{r}$, Kan', pMB1-Replikon & Invitrogen, Carlsbad, USA \\
pET101/D-TOPO & $\begin{array}{l}\text { Amp }{ }^{r} \text {; His6-tag C-terminal, } \\
\text { V5-Epitop-tag }\end{array}$ & Invitrogen, Carlsbad, USA
\end{tabular}


Fortsetzung Tabelle 2

\begin{tabular}{|c|c|c|}
\hline Plasmid & Beschreibung & Referenz \\
\hline pCR-XL-TOPO & $\mathrm{Kan}^{\mathrm{r}}$, Zeor; pMB1-Replikon & Invitrogen, Carlsbad, USA \\
\hline pCC1Fos & $\mathrm{Cm}^{\mathrm{r}}$, oriV, & Epicentre, Madison, WI,USA \\
\hline pET101::1015sp & Amp ${ }^{r}$, His6-tag & Diese Arbeit \\
\hline pET101::1015 & Ampr, His6-tag & Diese Arbeit \\
\hline pET101::48H1 & Amp ${ }^{r}$, kein His6-tag & Diese Arbeit \\
\hline pET101::48H2 & Amp ${ }^{r}$, kein His6-tag & Diese Arbeit \\
\hline pET101::48H3 & Amp $^{r}$, kein His6-tag & Diese Arbeit \\
\hline pET101::48H4 & Amp ${ }^{r}$, kein His6-tag & Diese Arbeit \\
\hline pET101::48H5 & Amp $p^{r}$, kein His6-tag & Diese Arbeit \\
\hline pET101::48H6 & Amp ${ }^{r}$, kein His6-tag & Diese Arbeit \\
\hline
\end{tabular}

Tabelle 3: Verwendete Oligonukleotide

\begin{tabular}{lll}
\hline Oligonukleotid & Sequenz & Referenz \\
\hline 8.f & GGATCCAGACTTTGATYMTGGCTCAG & $\begin{array}{l}\text { Ben-Dov et al., } \\
2006\end{array}$ \\
1114.r & GGGTTGCGCTCGTTRC & $\begin{array}{l}\text { Reysenbach und } \\
\text { Pace, 1995,mod. } \\
\text { Diez et al , } 2001\end{array}$ \\
349.f & AGGCAGCAGTGGGGAAT & Sorensen et al, \\
Arch8F & TCCGGTTGATCCTGCCGG & 2004, modifiziert \\
Arch958R & YCCGGCGTTGAMTCCAATT & DeLong, 1992 \\
Abi.for & ACGACGTTGTAAAACGACGGCCAG & $\mathrm{G}_{2} \mathrm{~L}$, Göttingen \\
Abi.rev & TTCACACAGGAAACAGCTATGACC & $\mathrm{G}_{2}$ L, Göttingen
\end{tabular}


Fortsetzung Tabelle 3

\begin{tabular}{lll}
\hline Oligonukleotid & Sequenz & Referenz \\
\hline 454V2.for & $\begin{array}{l}\text { GCCTCCCTCGCGCCATCAGAGTGGCGGACG } \\
\text { GGTGAGAA }\end{array}$ & Diese Arbeit \\
Xyl1015.F & CACCATGAACGAAGGGATTCGTGGCAATGG & Diese Arbeit \\
Xyl1015.F1 & CACCATGGCTCAGCAAGAGCAACTGCTCG & Diese Arbeit \\
Xyl1015.R & TCCCGGCAGTCGGATTTCAACGATG & Diese Arbeit \\
48H1.F & CACCATGCGATGGTGGTTGGTTG & Diese Arbeit \\
$48 \mathrm{H} 1 . \mathrm{R}$ & GAGAAGCCTTGCCTCACAC & Diese Arbeit \\
$48 \mathrm{H} 2 . \mathrm{F}$ & CACCATGCGTTGCGGTCTGACACAGGAAG & Diese Arbeit \\
$48 \mathrm{H} . \mathrm{F}$ & CACCATGGGCGAAGAGATGTTGCG & Diese Arbeit \\
$48 \mathrm{H} 4 . \mathrm{F}$ & CACCATGCGCAAAGAAGACGCCGAAAAG & Diese Arbeit \\
$48 \mathrm{H} 4 . \mathrm{R}$ & TCAAACGCCCCAAGCCTTTCGCAGTTTCTCCG & Diese Arbeit \\
$48 \mathrm{H} 5 . \mathrm{R}$ & TCAATACTCGCGCCATTCTTGCGTC & Diese Arbeit \\
$48 \mathrm{H} 6 . \mathrm{F}$ & CACCATGCGCTACGGTGGCATCGTC & Diese Arbeit \\
\hline
\end{tabular}

\section{Nährmedien und Zusätze}

Das Ansetzen der Medien erfolgte mit bidestilliertem Wasser. Bei Festmedien erfolgte eine Zugabe von 1,5\% (w/v) Bacto-Agar. Die Medien wurden für 20 Minuten bei $121^{\circ} \mathrm{C}$ autoklaviert. Zusätze, die bei hohen Temperaturen zerfallen oder zerstört werden, wurden mittels $0,2 \mu \mathrm{m}$ Filter (Minisart $\AA$, Sartorius, Göttingen) sterilfiltriert und den autoklavierten Medien nach Abkühlung auf $50^{\circ} \mathrm{C}$ zugesetzt. Die Lagerung der Medien erfolgte bei $4^{\circ} \mathrm{C}$. 


\subsection{Nährmedien für E. coli-Stämme}

LB-Medium (Sambrook et al., 1989, modifiziert)

$\begin{array}{lr}\text { Trypton } & 10 \mathrm{~g} \\ \text { Hefeextrakt } & 5 \mathrm{~g} \\ \mathrm{NaCl} & 10 \mathrm{~g} \\ \mathrm{H}_{2} \mathrm{O}_{\text {bidest. }} & \mathrm{ad} 1 \mathrm{I}\end{array}$

2x LB-Medium (für die Anzucht in 96 well Blöcken)

$\begin{array}{ll}\text { Trypton } & 20 \mathrm{~g} \\ \text { Hefeextrakt } & 10 \mathrm{~g} \\ \mathrm{NaCl} & 10 \mathrm{~g} \\ \mathrm{H}_{2} \mathrm{O}_{\text {bidest. }} & \mathrm{Ad} 1 \mathrm{I}\end{array}$

\subsection{Medienzusätze}

Falls erforderlich wurden den Medien Zusätze in der in Tabelle 4 angegebenen Konzentrationen hinzugegeben:

Tabelle 4: Medienzusätze

\begin{tabular}{lclc}
\hline Zusatz & Abkürzung & Stammlösung & Endkonzentration \\
\hline Ampicillin & Amp & $100 \mathrm{mg} / \mathrm{ml}$ in $\mathrm{H}_{2} \mathrm{O}$ & $100 \mu \mathrm{g} / \mathrm{ml}$ \\
Kanamycin & $\mathrm{Kan}$ & $25 \mathrm{mg} / \mathrm{ml}$ in $\mathrm{H}_{2} \mathrm{O}$ & $25 \mu \mathrm{g} / \mathrm{ml}$ \\
$\begin{array}{l}\text { Chloramphenicol } \\
\text { Isopropyl-ß-d- }\end{array}$ & $\mathrm{Cm}$ & $20 \mathrm{mg} / \mathrm{ml}$ in Ethanol & $20 \mu \mathrm{g} / \mathrm{ml}$ \\
$\begin{array}{l}\text { Thiogalactopyranosid } \\
\text { 5-Brom-4-chlor-3- }\end{array}$ & IPTG & $24 \mathrm{mg} / \mathrm{ml}$ in $\mathrm{H}_{2} \mathrm{O}$ & $24 \mu \mathrm{g} / \mathrm{ml}$ \\
$\begin{array}{l}\text { indolyl-ß-D- } \\
\text { galactopyranosid }\end{array}$ & X-Gal & $20 \mathrm{mg} / \mathrm{ml}$ in & \\
\hline
\end{tabular}




\section{Kultivierung von Bakterien}

\subsection{Zellanzucht}

Die Anzucht von E. coli in Flüssigmedium erfolgte, gegebenenfalls unter dem Zusatz selektiver Antibiotika, in Reagenzgläsern oder Erlenmeyerkolben aerob bei $37^{\circ} \mathrm{C}$ im Rundschüttler (Infors $\mathrm{HT}$, Bottmingen, $\mathrm{CH}$ ) bei $150 \mathrm{Upm}$ über Nacht. Hierfür wurden die Nährmedien zuvor entweder mit einer einzelnen Kolonie von einer Agar-Platte oder $2 \%$ ig mit einer Vor- oder Stammkultur beimpft.

Die Anzucht auf festen Medien erfolgte bei $37^{\circ} \mathrm{C}$ über Nacht im Brutschrank (Brutschrank HT TR 225, Infors AG).

\subsection{Bestimmung der Zelldichte}

Die optische Dichte einer Zellsuspension wurde durch eine photometrische Messung (Ultraspec 3300 pro, Pharmacia Biotec) bei einer Wellenlänge von $600 \mathrm{~nm}\left(\mathrm{OD}_{600}\right)$ quantifiziert. Als Leerwert diente unbeimpftes Nährmedium. Wenn nötig, wurden die Zellsuspensionen verdünnt, um die lineare Abhängigkeit von Zelldichte und Zellanzahl zwischen $\mathrm{OD}_{600}$ von 0,1 - 0,5 zu bewahren. Eine OD von 0,1 entspricht etwa einer Zellkonzentration von $1 \times 10^{8}$ Zellen $/ \mathrm{ml}$.

\subsection{Stammhaltung}

E. coli-Stämme wurden bis zu vier Wochen auf LB-Platten bei $4{ }^{\circ} \mathrm{C}$ gelagert. Für eine langfristige Konservierung wurden Glycerinkulturen angelegt. Dazu wurden frische Übernachtkulturen mit sterilem Glycerin $(50 \%(\mathrm{v} / \mathrm{v}))$ im Verhältnis 1:1 gemischt und bei $-70^{\circ} \mathrm{C}$ eingefroren. 


\section{Zellernte und Gewinnung von Zellextrakten}

\subsection{Zellernte}

Die Zellernte erfolgte bei Kulturen kleinerer Volumina mithilfe der HeraeusTischzentrifuge (Biofuge pico, Kendro, Osterode) bei 13000 Upm und Raumtemperatur. Die Ernte größerer Zellvolumina erfolgte in einer Kühlzentrifuge (Sorvall RC-5B-Zentrifuge, Fa. Du Pont de Nemours GmbH) bei 6000 Upm und $4{ }^{\circ} \mathrm{C}$ für 15 Minuten. Nach der Zentrifugation wurden Reste des Kulturmediums entfernt, indem das Zellpellet in dem gewünschten Puffer resuspendiert und die Zellsuspension erneut zentrifugiert wurde. Nach einem weiteren Zentrifugationsschritt wurden die pelletierten Zellen abschließend in dem gewünschten Puffer resuspendiert.

\subsection{Zellaufschluss durch Ultraschall}

Kulturvolumina von weniger als $5 \mathrm{ml}$ wurden durch Ultraschallaufschluss unter Verwendung einer Ultraschall-Sonde (Ultraschallprozessor UP 200S, 24 kHz, 200 W, Fa. Dr. Hielscher GmbH, Teltow; Sonotrode S2, $2 \mathrm{~mm}$ ) lysiert. Die Zellsuspension wurde in einem Eppendorf-Cup 5 min beschallt (35\%ige Amplitude, Cycle 0,5). Obwohl mit thermostabilen Enzymen gearbeitet wurde, wurden die Zellen beim Aufschluss mit Eis gekühlt. Das Abzentrifugieren der Zelltrümmer erfolgte bei 13000 Upm für 15 min in einer Tischzentrifuge (Biofuge fresco, Heraus Christ, Osterode). Der Überstand mit löslichen, intrazellulären Proteinen wird als Rohextrakt bezeichnet.

\subsection{Zellaufschluss durch French Pressure Cell}

Der Aufschluss von Zellen in der „French Pressure Cell“ (Fa. SLM Aminco, Urbana, USA), ) erfolgt dadurch, dass die Zellen zunächst einem hohen Druck (140 $\mathrm{MPa}$ ) ausgesetzt werden, der anschließend rapide abgesenkt wird, indem ein Ventil geöffnet wird, durch das die Zellen gepresst werden. Der plötzliche Druckabfall bewirkt das Platzen und somit die Lyse der Zellen. Das zähflüssige 
Lysat wurde aufgefangen und es erfolgte erneut eine Passage durch die French Pressure Cell. Anschließend wurde das Lysat $30 \mathrm{~min}$ bei 13000 Upm in SS34 Zentrifugationsgefäßen zentrifugiert (Sorvall RC-5B-Zentrifuge, Fa. Du Pont de Nemours $\mathrm{GmbH}$ ), wobei Zelltrümmer sedimentieren und von dem cytoplasmatischen Überstand getrennt werden. Der Überstand mit löslichen, intrazellulären Proteinen wird als Rohextrakt bezeichnet. Diese Methode wurde ausschließlich bei größeren Kulturvolumina eingesetzt.

\section{Molekulargenetische Arbeitstechniken}

\subsection{Behandlung von Materialien und Lösungen für das Arbeiten mit Nukleinsäuren}

Um eine Kontamination durch Nukleasen zu vermeiden, wurden alle thermostabilen Lösungen, Glaswaren und andere Materialien, die für das Arbeiten mit Nukleinsäuren notwendig waren, autoklaviert oder gegebenenfalls abgeflammt. Thermolabile Lösungen wurden sterilfiltriert.

\subsection{Bestimmung der DNA Konzentration einer Probe mittels NanoDrop ${ }^{\circledR}$ ND-1000}

Die Konzentration von DNA in einer Probe wurde mit dem NanoDrop® ND-1000 (Fa. Thermo Scientific, Wilmington, DE, USA) bestimmt. Der Gebrauch des Gerätes ermöglicht sowohl die Bestimmung der DNA Konzentration in der Probe, als auch Ermittlung der Reinheit. Ein weitere Vorzug des Gerätes ist, dass nur ein geringes Probenvolumen von 1,5-3 $\mu \mathrm{l}$ eingesetzt werden muss (s. ND-1000 Spektrophotometer V3.3 User`s manual). 


\subsection{Isolierung von DNA und Aufreinigung}

\subsubsection{Phenol-Chloroform-Extraktion}

Zur Entfernung von Proteinen und anderen Verunreinigungen aus DNA-Lösungen wurden diese 1:1 mit einem Phenol/Chloroform/lsoamylalkohol-Gemisch $(25: 24: 1(\mathrm{v} / \mathrm{v} / \mathrm{v}))$ versetzt und kräftig gemischt. Zur Phasentrennung wurden die Proben 10 min bei 13000 Upm zentrifugiert (Biofuge pico, Heraus Christ, Osterode) und die wäßrige, DNA-haltige Phase vorsichtig abgehoben. Zur Entfernung von Phenolresten wurde anschließend die Extraktion mit Chloroform/lsoamylalkohol $(24: 1,(\mathrm{v} / \mathrm{v}))$ wiederholt.

\subsubsection{DNA-Fällung mit Isopropanol und Ethanol}

Die Fällung von DNA mit Ethanol oder Isopropanol dient der Konzentrierung der DNA und der Entfernung von Proteinen, Salzen und freien Nukleotiden.

Die DNA-Lösungen wurden mit 0,1 Vol. einer 3 M Natrium-Acetat-Lösung $(\mathrm{pH} 5,2)$ und 0,7 Vol. Isopropanol oder 3,5 Vol. eiskaltem, unvergälltem Ethanol (96\% $(\mathrm{v} / \mathrm{v})$ ) versetzt. Die DNA wurde dann mit Isopropanol 15 min bei RT bzw. mit Ethanol $30 \mathrm{~min}$ bis $12 \mathrm{~h}$ bei $-20^{\circ} \mathrm{C}$ gefällt. Die gefällte DNA wurde anschließend durch 30 minütige Zentrifugation bei $13000 \mathrm{Upm}$ und $4^{\circ} \mathrm{C}$ pelletiert (Biofuge fresco, Heraus Christ, Osterode). Das Pellet wurde anschließend mit $70 \%$ igem (v/v) Ethanol gewaschen, in der Vakuumzentrifuge (Speed Vac® Plus SC110A, Savant) getrocknet und in 30-50 $\mu$ sterilem $\mathrm{H}_{2} \mathrm{O}_{\text {bidest }}$ aufgenommen.

\subsubsection{Reinigung von DNA-Fragmenten mittels „SureClean“ von Bioline}

Zur Reinigung von DNA wurde "SureClean“ von Bioline (Fa. Bioline GmbH, Luckenwalde) verwendet. Die Durchführung erfolgte nach Angabe des Herstellers. Der Vorteil dieser Methode ist, dass die Aufreinigung ohne den Einsatz von Säulen erfolgt und somit die Scherung der DNA reduziert wird. 


\subsubsection{Mikrodialyse von DNA}

Die Mikrodialyse dient der Entfernung von Salzen aus DNA-Lösungen. Die Dialyse wurde in einer Petrischale gegen steriles $\mathrm{H}_{2} \mathrm{O}_{\text {bidest }}$ als Dialysepuffer durchgeführt. Zunächst wurden Membranfilterscheiben (Porengröße 0,025 $\mu \mathrm{m}$, Fa. Millipore,Eschborn) mit der glänzenden Seite nach oben auf die Wasseroberfläche gegeben. Dann wurden mit einer Pipette vorsichtig 5 bis $20 \mu l$ der Probe auf die Dialysemembran aufgetragen. Die Dialyse war nach 30 Minuten abgeschlossen.

\subsubsection{Plasmidisolierung durch alkalische Lyse}

Grundlegend für diese Methode der Plasmidisolierung (nach BIRNBOIM und DOLY,1979, mod.) ist, dass chromosomale DNA in einem pH-Bereich zwischen 12 und 12,5 denaturiert, während die als ccc-Form vorliegende Plasmid-DNA weitestgehend erhalten bleibt. Unter Einwirkung von SDS und $\mathrm{NaOH}$ (LysisPuffer) erfolgt bei niedrigen Temperaturen eine Lyse der Bakterienzellwand und Denaturierung der hochmolekularen chromosomalen DNA. DNase-Aktivität wird durch den hohen pH-Wert sowie durch das EDTA im TE-Puffer verhindert. Durch Zugabe von Neutralisationspuffer erfolgt eine Neutralisierung, welche eine Aggregation der chromosomalen DNA bewirkt. Weiterhin kommt es zur Präzipitation von Protein-SDS-Komplexen und hochmolekularer RNA. Durch Zentrifugation sedimentieren die Makromoleküle und hochmolekularen Komplexe, während die Plasmid-DNA im Überstand bleibt, aus dem sie mit Hilfe von Isopropanol oder Ethanol gefällt werden kann. Für die Gewinnung von Plasmid DNA wurde eine bei $37^{\circ} \mathrm{C}$ gewachsene $5 \mathrm{ml}$ Kultur benutzt, deren Zellen durch Zentrifugation (13000 Upm, 2 min, RT) geerntet wurden. Das Zellpellet wurde in $250 \mu \mathrm{l}$ TE- Puffer resuspendiert, anschließend erfolgte die Zugabe von $250 \mu \mathrm{l}$ Lysispuffer, welches durch leichtes Schwenken und damit Vermischen der Puffer zu einer Lyse der Zellen führte. Nach einer kurzen Inkubation der Mischung von max. 5 Minuten, erfolgte die Neutralisierung des Lysates durch die Zugabe von $350 \mu \mathrm{l}$ Neutralisationspuffer. Die chromosomale DNA und die Proteine konnten dann durch Zentrifugation (13000 Upm, $10 \mathrm{~min}, 4^{\circ} \mathrm{C}$ ) abgetrennt werden. Zur 
Konzentrierung der Plasmid- DNA wurde der Überstand einer Fällung mit Ethanol oder Isopropanol unterzogen.

\section{Lösungen:}

\section{TE-Puffer:}

Tris- $\mathrm{HCl} \quad 50 \mathrm{mM}$

EDTA $\quad 10 \mathrm{mM}$

RNase A $200 \mu \mathrm{g} / \mathrm{ml}$ (Stammlösung $10 \mathrm{mg} / \mathrm{ml}$ )

$\mathrm{pH} 8,0$

Zugabe der RNase-Lösung nach dem Autoklavieren, Lagerung bei $4{ }^{\circ} \mathrm{C}$

\section{Lysis-Puffer:}

$\begin{array}{ll}\mathrm{NaOH} & 0,2 \mathrm{M} \\ \text { SDS } & 1 \%(\mathrm{w} / \mathrm{v})\end{array}$

\section{Neutralisationspuffer:}

Kaliumacetat $\quad 3 \mathrm{M}$

$\mathrm{pH} 5,5$

\section{RNase Stammlösung (50x):}

RNase A $10 \mathrm{mg} / \mathrm{ml}$ gelöst in Tris-HCl $10 \mathrm{mM}$

Tris- $\mathrm{HCl} \quad 50 \mathrm{mM}$

EDTA $\quad 10 \mathrm{mM}$

$\mathrm{pH} 8,0$

Die RNase Stammlösung wurde $15 \mathrm{~min}$ im Wasserbad gekocht. Nach dem Abkühlen erfolgte die Lagerung bei $-20^{\circ} \mathrm{C}$.

\subsubsection{Plasmidisolierung mit dem QiaPrep ${ }^{\circledR}$ Miniprep (Qiagen, Hilden)}

Das Plasmidisolierungskit der Firma Qiagen (Hilden) ermöglicht die Präparation hochreiner DNA, die unter anderen auch für Sequenzierungsreaktionen verwendet werden kann. Diese Methode basiert ebenfalls auf der alkalischen Lyse, 
verbunden mit der Verwendung einer Säule, an welche während der Aufreinigung die Plasmid-DNA selektiv bindet. Proteine und andere zelluläre Verunreinigungen können nicht binden und werden somit abgetrennt. Die Durchführung dieser Plasmid-Isolierung erfolgte gemäß der vom Hersteller mitgelieferten Versuchsvorschrift.

\subsection{Isolierung von Umwelt-DNA}

Zur Isolierung von hochmolekularer DNA aus den Inhalt verschiedener Abschnitte des Verdauungstraktes des Bibers wurden unterschiedliche Methoden verwendet.

\subsubsection{Isolierung mit dem „ExtractMaster ${ }^{\mathrm{TM}}$ Fecal DNA Extraction Kit“ (Epicentre, Madison, WI, USA)}

Das „ExtractMaster ${ }^{\mathrm{TM}}$ Fecal DNA Extraction Kit” verspricht die Isolierung hochmolekulare DNA aus fäkalen Ausgangsproben, einhergehend mit der Entfernung von störenden Inhibitoren, die häufig koextrahiert werden. Diese Inhibitoren können folgende Reaktionen wie zum Beispiel eine PCR negativ beeinflussen. Es erfolgen eine chemische und enzymatische Lyse der Zellen und ein anschließender chromatografischer Aufreinigungsschritt über eine Säule.

Für die Isolierung wurden jeweils $250 \mathrm{mg}$ Ausgangsprobe verwendet. Die Durchführung erfolgte laut Angaben des Herstellers. Die DNA wurde in $\mathrm{H}_{2} \mathrm{O}$ aufgenommen und bis zur weiteren Verwendung bei $4{ }^{\circ} \mathrm{C}$ oder $-20{ }^{\circ} \mathrm{C}$ gelagert.

\subsubsection{Isolierung mit dem SoilMaster ${ }^{\mathrm{TM}}$ DNA Extraction Kit (Epicentre, Madison, WI, USA)}

Das „SoilMasterTM DNA Extraction Kit“ soll bei der Aufreinigung der DNA die Entfernung von organischen Inhibitoren wie Humin- oder Fulvinsäuren ermöglichen. Des Weiteren wird eine hohe Ausbeute an hochmolekularer DNA mit nur geringer Scherung versprochen. Die Lyse der Zellen erfolgt unter Zusatz von Detergenzien bei einer Temperatur von $65^{\circ} \mathrm{C}$, so dass keine mechanische Lyse 
der Zellen notwendig ist. Es folgt ein chromatografisches Aufreinigungsverfahren über ein Säule.

Die Durchführung erfolgte laut Herstellerangaben, wobei 250 mg Ausgangsprobe eingesetzt wurde. Die DNA wurde in $\mathrm{H}_{2} \mathrm{O}$ aufgenommen und bis zur weiteren Verwendung bei $4^{\circ} \mathrm{C}$ oder $-20^{\circ} \mathrm{C}$ gelagert.

\subsubsection{Isolierung von DNA mittels „PowerSoil ${ }^{\mathrm{TM}}$ DNA Isolation Kit“}

Zur Isolierung größerer Mengen DNA aus Proben des Verdauungstrakt des Bibers wurde das „PowerSoil ${ }^{\mathrm{TM}}$ DNA Isolation Kit“ von Mobio (Fa. MoBio Laboratories, Inc., Carlsbad USA) verwendet. Dieses Kit ermöglicht eine effiziente DNAIsolierung aus stark Huminsäure haltigen Standorten wie Kompost, Sedimenten oder fäkalen Proben. Die Zellen werden durch chemische sowie durch mechanische Einwirkung lysiert. Hierbei wird die Probe für eine schnelle und gründliche Homogenisierung in ein „bead beating“-Röhrchen gegeben und die Zellen mittels mechanischer und chemischer Lyse aufgeschlossen. Die so freigewordene DNA wird an einer Silica-Membran gebunden und über mehrere Waschschritte gereinigt.

Für die DNA-Isolierung wurde $5 \mathrm{~g}$ der Ausgangsprobe eingesetzt. Die Durchführung erfolgte laut Herstellerangaben, mit den Ausnahmen, dass das „bead beating“ auf $30 \mathrm{~s}$ verkürzt wurde, sowie die Elution mit $\mathrm{H}_{2} \mathrm{O}_{\text {bidest. (5 Mal je }}$ $1 \mathrm{ml}$ ) vorgenommen wurde. Durch die Modifikationen konnte der Ertrag sowie die Größe der isolierten DNA-Fragmente erhöht werden. Falls nötig, wurde die isolierte DNA mit einer Vakuumzentrifuge (Speed Vac® Plus SC110A, Savant) aufkonzentriert.

\subsubsection{Isolierung von DNA aus Umweltproben (Zhou et al., 1996)}

Diese Methode der DNA-Isolierung beruht auf der direkten Lyse der Zellen, so dass sie vor dem Aufschluss nicht von festen Partikeln abgetrennt werden müssen. Weiterhin wird so die zusätzlich in der Probe frei vorliegende DNA erhalten. 
Zur DNA-Isolierung wurden $2 \mathrm{~g}$ Umweltprobe mit 5,4 $\mathrm{ml}$ DNA-Extraktionspuffer (DEP) und $40 \mu \mathrm{l}$ Proteinase $\mathrm{K}(10 \mathrm{mg} / \mathrm{ml})$ versetzt und für $30 \mathrm{~min}$ bei $37^{\circ} \mathrm{C}$ horizontal geschüttelt (225 Upm). Nach der Zugabe von $600 \mu \mathrm{l} 20 \%$ SDS (oder 30 $\mathrm{ml} 10 \%$ ) wurde das Gemisch für $2 \mathrm{~h}$ bei $65^{\circ} \mathrm{C}$ inkubiert und dabei alle 15 bis 20 min vorsichtig geschüttelt.

Zur Trennung der bereits gelösten DNA von festen Partikeln folgte anschließend ein Zentrifugationsschrittt (10 min, 7000 Upm, Rotor GS3, Sorvall Zentrifuge, Fa. Du Pont Instruments, Newton, USA, RT), der Überstand wurde in einen SS34-Zentrifugenbecher überführt. Das Pellet wurde noch zweimal in je 1,8 ml DEP und $200 \mu \mathrm{l} 20 \%$ SDS suspendiert und nach einer 10-minütigen Inkubation bei $65^{\circ} \mathrm{C}$ wie oben beschrieben zentrifugiert.

Zur Extraktion der DNA wurde den gesammelten Überständen 1 Vol. Chloroform/Isoamylalkohol (24:1) zugesetzt und für $10 \mathrm{~min}$ bei 7000 Upm (Rotor GS3, Sorvall Zentrifuge, Fa. Du Pont Instruments, Newton, USA) und RT zentrifugiert. Die Fällung der DNA erfolgte durch Zugabe von 0,6 Vol. Isopropanol für $1 \mathrm{~h}$ bei RT. Nach einer Zentrifugation bei $9000 \mathrm{Upm}$ für $20 \mathrm{~min}$ bei RT wurde das Pellet mit eiskaltem Ethanol $(70 \% \mathrm{v} / \mathrm{v})$ gewaschen und in $1 \mathrm{ml}$ sterilem $\mathrm{H}_{2} \mathrm{O}_{\text {bidest. }}$ aufgenommen.

\section{DNA-Extraktionspuffer (DEP)}

$\begin{array}{ll}\text { Tris } & 100 \mathrm{mM} \\ \text { EDTA } & 100 \mathrm{mM} \\ \mathrm{Na}_{2} \mathrm{HPO}_{4} & 100 \mathrm{mM} \\ \mathrm{NaCl} & 1,5 \mathrm{M} \\ \mathrm{CTAB} & 1 \% \\ \mathrm{pH} 8,0 & \end{array}$

\subsection{Agarose-Gelelektrophorese}

\subsubsection{Analytische Agarose-Gelelektrophorese}

Die Auftrennung von DNA Fragmenten nach ihrer Größe erfolgte mittels AgaroseGelelektrophorese. Negativ geladene Nukleinsäuren wandern im elektrischen Feld 
zur Anode, wobei die Migrationsgeschwindigkeit der DNA-Fragmente von mehreren Faktoren abhängt, wie z.B. der Größe der Gelporen (bestimmt durch die Agarosekonzentration, der angelegten Spannung und der Salzkonzentration des Puffers. Es erfolgt eine Auftrennung der DNA-Fragmente entsprechend ihrer Größe, da deren Laufgeschwindigkeit umgekehrt proportional zu ihrer Molekularmasse ist.

Für die gelelektrophoretische Auftrennung von Nukleinsäuren wurden horizontale Elektrophoresekammern (Hoefer® HE33 Mini Horizontal Submarine Unit; Pharmacia Biotech, Uppsala, Schweden) verwendet. Die Agarose-Gele bestanden aus $0,8 \%(w / v)$ Agarose in 1 x TAE Puffer, welcher auch als Elektrophoresepuffer benutzt wurde. Die DNA-Proben wurden 5:1 mit DNA-Auftragspuffer gemischt, der sowohl zur Beschwerung der Proben als auch zur Markierung der Lauffront bei etwa 500 bp diente. Die Auftrennung erfolgte bei einer konstanten Spannung von 70-100 V. Nach Beendigung der Gelelektrophorese wurden die Nukleinsäuren im Gel in einer wässrigen Ethidiumbromid-Lösung $(1 \mu \mathrm{g} / \mathrm{ml})$ 10-20 min gefärbt und anschließend im Wasserbad kurz entfärbt. In der Gel- Dokumentationsanlage (ImageQuant 100 Imager (GE Healthcare Europe GmbH, Freiburg, Germany). wurde die DNA bei UV-Licht durch das eingelagerte Ethidiumbromid sichtbar gemacht, fotografisch dokumentiert und eventuell nachträglich bearbeitet (MultiAnalyst-V.1.1.1.-Dokumentationsprogramm).

\section{Lösungen:}

\section{Ethidiumbromid-Färbebad:}

$250 \mu \mathrm{l}$ einer $2 \mathrm{mg} / \mathrm{ml}$ Ethidiumbromidlösung in $500 \mathrm{ml} \mathrm{H}_{2} \mathrm{O}_{\text {bidest }}$

\section{0x TAE-Puffer:}

Tris- $\mathrm{HCl}$

Eisessig

$\mathrm{Na}_{2}$ EDTA $\times 2 \mathrm{H}_{2} \mathrm{O}$

$\mathrm{H}_{2} \mathrm{O}_{\text {bidest }}$

$\mathrm{pH} 8,5$
$242 \mathrm{~g}$

$57,1 \mathrm{ml}$

$37,2 \mathrm{~g}$

ad $1000 \mathrm{ml}$ 


\section{0x DNA-Auftragspuffer (Beschwerlösung):}

Ficoll 400

Bromphenolblau

$\operatorname{EDTA}(0,5 \mathrm{M})$

$\mathrm{H}_{2} \mathrm{O}_{\text {bidest }}$
$7,5 \mathrm{~g}$

$50 \mathrm{mg}$

$10 \mathrm{ml}$

ad $50 \mathrm{ml}$

\subsubsection{Größen- und Konzentrationsbestimmung von DNA-Fragmenten in Agarosegelen}

Die Bestimmung der Größe von DNA-Fragmenten erfolgte nach Auftrennung im Agarosegel an Hand der Laufstrecken eines ebenfalls mit aufgetrennten internen Standards. Als Größenstandard diente dabei eine $1 \mathrm{~kb}$-Leiter (Gene Ruler ${ }^{\mathrm{TM}} 1 \mathrm{kB}$ DNA Ladder, MBI Fermentas, St Leon-Rot)

\subsubsection{Präparative Agarose-Gelelektrophorese}

Die präparative Agarose-Gelelektrophorese ermöglicht die Isolation von DNAFragmenten aus Restriktions- und PCR-Reaktionen mit definierter molekularer Größe aus einer Mixtur linearer Fragmente.

Prinzipiell wurde bei der präparativen Gelelektrophorese wie bei dem unter II.5.5.1. beschriebenen analytischen Verfahren vorgegangen. Um Interkalationsund UV induzierte Schäden zu minimieren, wurden der Färbeschritt und die anschließende UV-Exposition möglichst kurz gehalten oder es wurde auf eine Anfärbung mit Ethidiumbromid komplett verzichtet, indem nur die die Markerspuren und Referenzspuren gefärbt wurden. Nach der Elektrophorese wurden definierte Banden mit einem Skalpell aus dem Gel herausgeschnitten. Zur Präparation der DNA aus dem Gelstück wurde das "QIAQuick Gel Extraction Kit" (QIAGEN, Hilden) oder das „NucleoTrap ${ }^{\circledR}{ }^{\circledR} \mathrm{Kit}$ (Macherey\&Nagel,Düren) verwendet. Alle benötigten Protokolle und Reagenzien lagen dem Kit bei. 


\subsubsection{Präparative Agarose-Gelelektrophorese mit Low Melting Point (LMP)- Agarose}

Zur Isolierung von hochmolekularer DNA aus Agarosegelen eignet sich eine präparative Agarosegel-Elektrophorese der DNA mit LMP-Agarosegelen. Hierfür wurde die DNA auf ein einprozentiges LMP-Agarosegel (Merck, Darmstadt) aufgetragen. Die Elektrophorese erfolgte bei $35 \mathrm{~V}$ über Nacht in TAE-Puffer. Anschließend wurde die gewünschte DNA-Fragmentgröße aus dem Gel herausgeschnitten (s. II.5.5.3) und die DNA mittels Gelase (Epicentre, Madison, WI, USA) aus den Gelstücken isoliert. Der Vorteil dieser Methode basiert auf dem Verzicht von der Verwendung von Säulen für die Aufreinigung der DNA. Somit wird die Gefahr einer Scherung der DNA reduziert. Die Durchführung erfolgte laut Angaben des Herstellers.

\subsection{Polymerasekettenreaktion (PCR)}

\subsubsection{Amplifikation von DNA-Fragmenten mit der Taq- oder Pfu-DNA- Polymerase}

Die Polymerase-Kettenreaktion (PCR) wurde zur Herstellung spezifischer DNAFragmente für Klonierungen oder Sequenzierungen verwendet. Als Enzyme wurden die Taq-DNA-Polymerase und die Pfu-DNA-Polymerase (Fa. MBI Fermentas, St. Leon-Rot) eingesetzt. Die Reaktionen wurden entsprechend den Herstellerempfehlungen in einem Volumen von 20 bzw. $50 \mu$ durchgeführt und enthielten folgende Bestandteile:

DNA

Oligonukleotide

dNTP-Gemisch

DNA Polymerase

Reaktionspuffer (10x)

$\mathrm{MgCl} 2$ oder $\mathrm{MgSO} 4$

$\mathrm{H}_{2} \mathrm{O}_{\text {bidest. }}$
$0,5-1 \mu \mathrm{g}$

je 100 pmol

$200 \mu \mathrm{M}$

$1 \mathrm{U}$

$10 \mu \mathrm{l}$

1,5 mM

ad 20/50 $\mathrm{ul}$ 
Die Temperaturzyklen wurden den jeweiligen Anforderungen in Bezug auf die Hybridisierungstemperatur $(\mathrm{x})$ und die Dauer der Kettenverlängerung (y) angepasst.

Sie wurden nach folgendem Schema durchgeführt:

$\begin{array}{lrr}\text { Denaturierung } & 95^{\circ} \mathrm{C} & 2 \mathrm{~min} \\ \text { Denaturierung } & 95^{\circ} \mathrm{C} & 1 \mathrm{~min} \\ \text { Hybridisierung } & \mathrm{x}^{\circ} \mathrm{C} & 1 \mathrm{~min} \\ \text { Elongation } & 72{ }^{\circ} \mathrm{C} & \mathrm{y} \text { min } \\ \text { Elongation } & 72{ }^{\circ} \mathrm{C} & 10 \mathrm{~min}\end{array}$

Die Zyklenanzahl betrug für Standard-Ansätze 30 bis 35 Zyklen. Im Falle der Amplifizierung von $16 \mathrm{~S}$ rRNA-Gen spezifische PCRs wurde eine maximale Zyklenanzahl von 25 gewählt, um die Bildung von Chimären möglichst zu vermeiden.

Für die Einstellung der Parameter waren die zu erwartende Fragmentlänge und die Schmelztemperatur $T_{m}$ der verwendeten Oligonukleotide entscheidend. Für die Elongation wurde entsprechend der zu erwartenden Fragmentlänge eine Zeit von ca. $1 \mathrm{~min} / 1000$ bp (Pfu-Polymerase $1 \mathrm{~min} / 500$ bp) gewählt. Die optimale Hybridisierungstemperatur wurde nach der Schmelztemperatur $\mathrm{T}_{\mathrm{m}}$ der Oligonukleotide festgelegt, die über folgende Formel errechnet wurde:

$\mathrm{Tm}=69,3+0,41$ (\% GC-Gehalt) $-650 / \mathrm{L}$

$\mathrm{L}=$ Länge des Oligonukleotids; \% GC-Gehalt = prozentualer GC-Gehalt des Oligonukleotids

Durch Verkürzung der Hybridisierungsdauer, Verringerung der Oligonukleotidkonzentration und Variation der $\mathrm{MgCl}_{2}$-Konzentration konnte die Spezifität der PCR optimiert werden.

Die Temperaturzyklen wurden mit dem "Thermocycler Primus" (Fa. MWG Biotech, Ebersberg) durchgeführt. Die PCR-Produkte wurden durch AgaroseGelelektrophorese (II.5.5.1.) analysiert. 


\subsubsection{Amplifikation von DNA-Fragmenten mit der KOD Hifi DNA Polymerase}

Diese Polymerase (Novagen, Darmstadt) hat eine „Proofreading“-Aktivität und extrem kurze Hybridisierungs- und Verlängerungszeiten. Dadurch wichen das Pipettierschema und die Temperaturzyklen von den der anderen verwendeten Polymerasen ab.

$\begin{array}{ll}\text { DNA }_{\text {max }} & 0,5 \mu \mathrm{g} \\ \text { Oligonukleotide } & 0,4 \mu \mathrm{M} \\ \text { dNTP-Gemisch } & 200 \mu \mathrm{M} \\ \text { DNA Polymerase } & 1 \mathrm{U} \\ \text { Reaktionspuffer (10x) } & 5 \mu \mathrm{l} \\ \mathrm{MgCl}_{2} & 1 \mathrm{mM} \\ \mathrm{H}_{2} \mathrm{O}_{\text {bidest }} & \text { ad } 50 \mu \mathrm{l}\end{array}$

Fragmentgröße 1-2 kb

Denaturierung $\quad 98^{\circ} \mathrm{C} \quad 5 \mathrm{~min}$

Denaturierung $\quad 98^{\circ} \mathrm{C} \quad 15 \mathrm{~s}$

Annealing $\quad \mathrm{T}_{\mathrm{m}}-5^{\circ} \mathrm{C} \quad 2 \mathrm{~s}$

Elongation $\quad 72^{\circ} \mathrm{C} \quad 20 \mathrm{~s}$

Zyklenanzahl 25-30

Fragmentgröße 3-4 kb

Denaturierung $\quad 98^{\circ} \mathrm{C} \quad 5 \mathrm{~min}$

Denaturierung $\quad 98^{\circ} \mathrm{C} \quad 15 \mathrm{~s}$

Annealing $\quad \mathrm{T}_{\mathrm{m}}-5^{\circ} \mathrm{C} \quad 5 \mathrm{~s}$

Elongation $\quad 72^{\circ} \mathrm{C} \quad 40 \mathrm{~s}$

Zyklenanzahl 25-30

\subsubsection{Kolonie-PCR zur Klonüberprüfung}

Als schnelle Alternative zur herkömmlichen PCR, bei der als Matrize isolierte DNA eingesetzt wurde, erfolgte die PCR-Überprüfung großer Zahlen rekombinanter E. coli Klone durch Kolonie-PCR. Dabei wurden PCR-Ansätze im $20 \mu \mathrm{l}$ - Maßstab 
vorbereitet. Zunächst wurden jeweils $10 \mu \mathrm{l}$ steriles bidestilliertes Wasser in PCRGefäße vorgelegt, jeweils eine Kolonie von einer Agarplatte mittels sterilem Zahnstochern abgenommen und in das PCR-Gefäß überführt.

Anschließend wurden jeweils $10 \mu$ l eines vorbereiteten Mastermix hinzugefügt.

Mastermix für 30 Reaktionen

\begin{tabular}{|c|c|}
\hline Taq-Puffer (10x) & $64 \mu \mathrm{l}$ \\
\hline Primer A (100 pmol/ $/ \mu \mathrm{l})$ & $4 \mu \mathrm{l}$ \\
\hline Primer B (100 pmol/ $/ \mu \mathrm{l})$ & $4 \mu \mathrm{l}$ \\
\hline dNTP-Mix (je 10 mM) & $64 \mu \mathrm{l}$ \\
\hline Taq-Polymerase & $8 \mu \mathrm{l}$ \\
\hline DMSO & $32 \mu \mathrm{l}$ \\
\hline $\mathrm{H}_{2} \mathrm{O}_{\text {bidest. }}$ & $144 \mu \mathrm{l}$ \\
\hline
\end{tabular}

\subsubsection{Aufreinigungen von PCR-Produkten und anderen linearen DNA- Fragmenten}

Spezifische DNA Fragmente wurden direkt aus dem Reaktionsansatz mittels Qiaquick PCR Purification Kit (Qiagen, Hilden) aufgereinigt. Bei einem starken unspezifischen Hintergrund wurden die DNA auf einem Agarosegel aufgetrennt und die gewünschten Fragmente mit dem QIAquick Gel Extraction Kit gereinigt. Die aufgereinigten DNA-Fragmente wurden entweder zunächst in Klonierungsvektoren oder direkt in Expressionsvektoren kloniert. 


\subsection{Mechanische Modifikation von DNA}

\subsubsection{DNA-Scherung mittels Nebulizer}

Die Scherung mittels "Nebulizers" (Fa. Invitrogen Corporation, Carlsbad USA) wurde zur Fragmentierung von Fosmid-DNA verwendet, um später eine Subklonierung der erhaltenen Fosmid-Fragmente durchzuführen. Dazu wurden $50 \mu \mathrm{l}$ Fosmid-DNA in $750 \mu \mathrm{l}$ Shearing-Puffer aufgenommen und bei 0,4 bar für 1030s im „Nebulizer" geschert. Mittels analytischer Agarosegelelektrophorese wurde überprüft, ob die gewünschte Fragmentierung erzielt wurde.

Anschließend wurde die DNA-Lösung mittels Vakkumzentrifuge (Speed Vac® Plus SC110A, Savant) einkonzentriert und einer präparativen AgaroseGelelektrophorese unterzogen, wobei Fragmente zwischen 2 und $5 \mathrm{~kb}$ isoliert wurden.

\section{Shearing-Puffer}

$\begin{array}{ll}\text { Tris } & 10 \mathrm{mM} \\ \text { EDTA } & 1 \mathrm{mM} \\ \text { Glycerin } & 10 \% \\ \mathrm{pH} 8,0 & \end{array}$

\subsubsection{DNA-Scherung durch Ultraschall}

Chromosomale -und Fosmid DNA wurde mittels Ultraschall auf unspezifische Fragmentgrößen geschert, indem sie für 4-10 s mit einer Ulraschall-Sonde (Ultraschallprozessor UP 200S, 24 kHz, 200 W, Fa. Dr. Hielscher GmbH, Teltow; Sonotrode S2, $2 \mathrm{~mm}$ ) in einem Eisbad beschallt wurde (20\%ige Amplitude, Cycle $0,5)$. Die DNA Fragmente mit gewünschter Größe wurden anschließend mittels präparativer Agarose-Gelelektrophores isoliert (s. II.5.5.3.). 


\subsection{Enzymatische Modifikation von DNA}

\subsubsection{Restriktionsverdau}

Diese Methode des Schneidens von DNA beruht auf der hohen Spezifität der aus Prokaryoten isolierten Restriktionsendonukleasen (Typ II) gegenüber ihrer meist palindromischen Erkennungssequenz im DNA-Doppelstrang. Die Enzyme hydrolysieren an definierten Stellen die Phosphodiester-Bindungen zwischen zwei Basen in beiden Strängen, woraus überhängende oder glatte Enden resultieren können.

Der Restriktionsverdau wurde in dieser Arbeit für die analytische und die präparative Restriktion genutzt.

\subsubsection{Analytische Restriktion}

Der analytische Restriktionsverdau diente der Überprüfung verschiedener DNAKonstrukte.

\section{Standard-Restriktionsansatz}

DNA-Lösung

$0,5-1,0 \mu g$

10x Restriktionspuffer

$1 \mu \mathrm{l}$

Restriktionsenzym

$\mathrm{H}_{2} \mathrm{O}_{\text {bidest }}$

ad $10 \mu \mathrm{l}$

Der Ansatz wurde bei der vom Hersteller des entsprechenden Enzyms angegeben optimalen Temperatur 1-2 $\mathrm{h}$ inkubiert. Bei einem Doppelverdau mit zwei unterschiedlichen Restriktionsenzymen wurden optimaler Puffer und Konzentration der Enzyme über das Programm DoubleDigest $^{\mathrm{TM}}$ (www.fermentas.com) ermittelt. Das Resultat der Spaltung wurde anschließend mittels Agarosegel-Elektrophorese analysiert. 


\subsubsection{Präparativer Restriktionsverdau}

Wenn ein oder mehrere Fragmente der Restriktionsreaktion für weitere Klonierungsschritte verwendet wurden, erfolgte eine präparative Restriktion.

Restriktionsansatz

DNA-Lösung

10x Restriktionspuffer

Restriktionsenzym

$\mathrm{H}_{2} \mathrm{O}_{\text {bidest }}$
$10 \mu g(\max$.

$5 \mu \mathrm{l}$

$10-25 \mathrm{U}$

ad $50 \mu \mathrm{l}$

Hierbei ist es wichtig, zu gewährleisten, dass der Verdau vollständig erfolgt. Dazu wurde der Verdau entweder ü. N. bei der entsprechenden Temperatur inkubiert oder es wurden nach $2 \mathrm{~h}$ Inkubation weitere $5 \mathrm{U}$ des Enzyms hinzugegeben und der Restriktionansatz für weitere $2 \mathrm{~h}$ inkubiert.

Nach der Restriktion wurden die Fragmente entweder mittels präparativer Gelelektrophorese oder direkt mit dem QIAquick PCR Purification Kit (QIAGEN, Hilden) aufgereinigt.

\subsubsection{Auffüllen von $5^{`}$ Überhängen doppelsträngiger DNA mittels T4-DNA-Polymerase}

Durch eine Restriktion oder Scherung entstandene 5'-Überhänge doppelsträngiger DNA können mit Hilfe der T4-DNA-Polymerase (MBI Fermentas, St. Leon-Rot) aufgefüllt werden.

\section{Reaktionsansatz}

$\begin{array}{ll}\text { DNA } & 50 \mu \mathrm{l} \\ \text { dNTP-Mix (je 10 mM) } & 1 \mu \mathrm{l} \\ \text { T4-Polymerase (5U) } & 1 \mathrm{U} \\ \text { Reaktionspuffer (5x) } & 14 \mu \mathrm{l} \\ \mathrm{H}_{2} \mathrm{O}_{\text {bidest: }} & \text { ad } 70 \mu \mathrm{l}\end{array}$




\subsubsection{Anhängen von dATP an „,blunt-end“-DNA}

Mit Hilfe der Taq-DNA-Polymerase wurde ein Desoxyadenosin an „blunt-endDNA“ angehängt.

Ansatz:

„blunt-end”-DNA $50 \mu \mathrm{l}$

dATP $2 \mathrm{mM}$

Taq-DNA-Polymerase $2 \mathrm{U}$

$\mathrm{MgCl} 2 \quad 6 \mu \mathrm{l}$

Reaktionspuffer $\quad 7 \mu \mathrm{l}$

$\mathrm{H}_{2} \mathrm{O}_{\text {bidest. }} \quad 7 \mu \mathrm{l}$

Es erfolgte eine Inkubation von 20 min bei $72^{\circ} \mathrm{C}$ mit anschließender Reinigung mittels „QIAquick PCR Purification“-Kit (s. II.5.5.3).

\subsubsection{Dephosphorylierung linearer DNA mit „Antarctic Phophatase“}

Zur Vermeidung von Selbstligationen von DNA Fragmenten konnten gegebenenfalls die 5'-Phosphatgruppen enzymatisch mit alkalischer antarctic Phosphatase (NEB, Frankfurt) abgespalten werden. Hierfür wurde dem Ansatz 1x Antarctic Phosphatasepuffer und 5 U Antarctic Phosphatase hinzugefügt. Es folgte eine Inkubation bei $37^{\circ} \mathrm{C}$ für 20 Minuten. Anschließend erfolgte eine Hitzeinaktivierung des Enzyms bei $65^{\circ} \mathrm{C}$ für 5 Minuten.

\subsubsection{Ligation von DNA Fragmenten in Plasmidvektoren}

Für die Ligation von DNA-Fragmenten und Plasmid-Vektor-DNA wurde eine rekombinante DNA-Ligase des T4-Phagen angewendet.

Die T4-Ligase katalysiert unter ATP-Verbrauch die Bildung von Phosphodiesterbindungen zwischen 5'-Phosphat- und 3'-Hydroxyl-Enden von DNA. In dieser Arbeit wurde das Quick Ligation ${ }^{\text {TM }}$ Kit (New England Biolabs $\mathrm{GmbH}$, Frankfurt/Main) verwendet. Besonders wichtig ist hierbei das molare 
Verhältnis zwischen Insert- und Vektor-DNA im Ligationsansatz, welches 3:1 betragen sollte.

Quick Ligation ${ }^{\mathrm{TM}}$ Reaktionsansatz

Vektor-DNA $\quad 50 \mathrm{ng}$

Insert-DNA $\quad x \mathrm{ng}$ (3x molarer Überschuss)

$\mathrm{H}_{2} \mathrm{O}_{\text {bidest }} \quad$ ad $10 \mu \mathrm{l}$

2x Quick Ligation Puffer $10 \mu \mathrm{l}$

Quick T4 DNA Ligase $\quad 0,5 \mu \mathrm{l}$

Der Reaktionsansatz wurde $10 \mathrm{~min}$ bei Raumtemperatur inkubiert. Eine Hitzeinaktivierung war nicht nötig. Der Ansatz wurde entweder sofort für eine Transformation eingesetzt oder für spätere Transformationen bei $-20{ }^{\circ} \mathrm{C}$ eingefroren.

5.8.6. Topoisomerase-Klonierung (TOPO TA Cloning $\AA^{\circledR}$, TOPO® XL PCR Cloning Kit Invitrogen, Carlsbad, CA, USA)

Die TOPO-Klonierung basiert auf der Fähigkeit der Topoisomerase I des VacciniaVirus, 3'T-Überhänge zu produzieren, nachdem sie nach der Sequenz CCCTT doppelsträngige DNA gespalten hat. Dabei bleibt das Enzym kovalent mit dem 5`Ende der geschnittenen DNA verbunden. Ein PCR-Produkt mit 3'Aüberhängenden Enden führt zur Befreiung des Enzyms und zur kovalenten Bindung des PCR-Produkts mit dem Klonierungsvektor.

Für die Klonierung mit dem TOPO TA Cloning® Kit müssen zunächst PCRProdukten oder linearen DNA-Fragmenten gegebenenfalls 3`A-Überhänge angefügt werden, wie unter II.5.8.3. beschrieben.

Die Ligation erfolgte laut Anweisungen des Herstellers. Anschließend wurden $3 \mu \mathrm{l}$ der TOPO ${ }^{\circ}$ Klonierungsreaktion für die Transformation chemisch kompetenter E. coli Top10-Zellen (Invitrogen, Carlsbad, CA, USA) verwendet. Positive Klone konnten durch Blau/Weiß-Selektion identifiziert werden. 


\subsubsection{Klonierung von PCR-Produkten zur heterologen Expression in E. coli mit dem pET Directional TOPO ${ }^{\circledR}$ Expression"-Kit}

Der „pET Directional TOPO ${ }^{\circledR}$ Expression“-Kit (Invitrogen, Karlsruhe) nutzt die Klonierungsstrategie des "TOPO-Cloning“ (s. II.5.8.6.), um blunt-end-PCRProdukte gerichtet in einen Expressionsvektor zu ligieren. Zudem besteht die Möglichkeit, das zu exprimierende Genprodukt N- oder C-terminal mit einem $\mathrm{His}_{6}$ Tag zu versehen, der die Reinigung des gebildeten Proteins ermöglicht. Die gerichtete TOPO-Klonierung wird durch das Anhängen einer spezifischen Sequenz (5'-CACC) an das durch PCR amplifizierte Zielgen erreicht, die komplementär (3'-GTGG) als Einzelstrang-Überhang auf dem Vektor vorhanden ist. Dieser Überhang inseriert das 5'-Ende des PCR-Produkts und führt so zur korrekten Orientierung des inserierten Gens. Das pET-Expressionssystem machte sich die hohe Aktivität und Spezifität der T7-RNA-Polymerase zu Nutze. Dies ermöglichte ausgehend vom T7-Promotor eine regulierte Expression von heterologen Genen in E. coli . Die Durchführung der Ligationsreaktion, der anschließenden Transformation von E. coli und die Expression der Zielgene erfolgte laut Herstellerangaben.

\subsection{Transformation von E. coli-Zellen}

\subsubsection{Transformation durch Elektroporation}

Setzt man biologische Membranen einem starken elektrischen Feld aus, werden sie porös. DNA, die sich außerhalb der Zellmembran befindet, kann während eines elektrischen Impulses durch die entstehenden Poren in die Zellen eindringen. Entscheidend für die Effizienz der Transformation sind die Dauer des elektrischen Pulses, die Stärke des elektrischen Feldes und die Konzentration der eingesetzten DNA. Die Elektroporation ist empfindlich gegenüber Salz-lonen. Falls eine DNA-Lösung aus einem Ligationsansatz direkt für die Elektroporation eingesetzt wird, muss diese vorher in einer Mikrodialyse nach Marusyk und Seargent (1980) mit Hilfe von auf $\mathrm{H}_{2} \mathrm{O}_{\text {bidest }}$ schwimmenden Membranfiltern $(0,025$

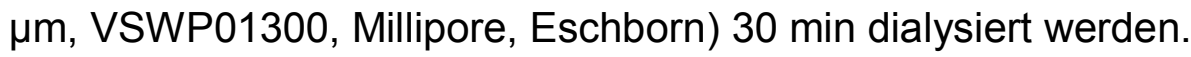


Die elektrokompetenten bei $-70^{\circ} \mathrm{C}$ eingefrorenen Zellen wurden schonend auf Eis aufgetaut. Nach Zugabe von 0,1-1 $\mu \mathrm{g}$ dialysierter DNA-Lösung (2-5 $\mu \mathrm{l})$ wurde der Ansatz in vorgekühlte, sterile Elektroporationsküvetten pipettiert und für 30 min auf Eis inkubiert. Die Zellen wurden dann in einem Elektroporationsgerät (GenePulser ${ }^{\circledR}$ II, Bio-Rad $\mathrm{GmbH}$, München) unter den folgenden Bedingungen elektroporiert:

Kapazität: $25 \mu \mathrm{Fd}$

Spannung: $2,5 \mathrm{kV}$

Widerstand: $200 \Omega$

Die sich ergebenden Entladungszeiten sollten zwischen 4 und $5 \mathrm{~ms}$ liegen. Sofort nach erfolgter Elektroporation wurden $800 \mu \mathrm{l}$ LB-Medium zugesetzt. Die Zellen wurden für eine Stunde bei $37^{\circ} \mathrm{C}$ zur Expression der Selektionsmarker und zur allgemeinen Regeneration inkubiert. Danach erfolgte das Ausplattieren (10-200 $\mu$ l) auf Selektivnährböden.

\subsubsection{Transformation von E. coli durch Hitzeschock (Inoue et al., 1990)}

Um Plasmid-DNA in E. coli einzubringen wurden hochkompetente Zellen benutzt, die nach der Methode von Hanahan (1983) präpariert vorlagen. Die Transformation erfolgte über den Hitzeschock. Dazu wurden die bei $-70^{\circ} \mathrm{C}$ gelagerten Zellen zunächst auf Eis langsam aufgetaut. Anschließend wurden 2-3 $\mu l$ der DNA-Lösung zu den Zellen gegeben und durch leichtes Antippen am Eppendorf-Cup gemischt. Es erfolgte eine 5-minütige Inkubation des Ansatzes auf Eis. Daraufhin wurde der Hitzeschock für $90 \mathrm{sec}$ bei $42^{\circ} \mathrm{C}$ im Heizblock durchgeführt. Sofort danach wurde der Ansatz auf Eis für 3 Minuten abgekühlt. Zu den gekühlten Zellen wurden dann $800 \mu$ kaltes LB Medium gegeben. Zur Ausbildung von Selektivmarkern und zur Regeneration wurden die Zellen eine Stunde bei $37^{\circ} \mathrm{C}$ inkubiert.

\subsection{X-GAL Test}

Einige der verwendeten Klonierungsvektoren erlaubten die Selektion von positiven Klonen über das Blau/Weiß-Verfahren. Grundlage dieses Testes bildet die Spaltung von X-Gal (5-Brom-4-Chlor-3-indoyl-B-D-galaktopyranosid) durch die 
B-Galaktosidase. Als Reaktionsprodukt entsteht ein blauer Indigofarbstoff (Horowitz et al., 1964). Klonierungsstämme wie E. coli XL1 Blue und Top10 enthalten ein B-Galaktosidase-Gen, welches am aminoterminalen Ende eine Deletion (lacZ_M15) vorweist. Nach Induktion mit IPTG wird eine verkürzte inaktive ß-Galaktosidase gebildet. Die Klonierungsvektoren, die das lacZ' Gen tragen, kodieren für das Alpha-Peptid der B-Galaktosidase, welches mit dem verkürzten Protein aus E. coli aggregieren kann und dieses somit aktiviert. In den Klonierungsvektoren liegt im lacZ' Gen die Multiklonierungsstelle vor, in diese rekombinante Proteine kloniert werden. Wenn das lacZ'Gen durch den Einbau eines anderen Gens unterbrochen wird, kann das Alpha-Peptid nicht mehr gebildet werden, die B-Galaktosidase bleibt inaktiv, X-Gal wird nicht gespalten, es bildet sich kein blauer Farbstoff, die Kolonien bleiben weiß. Klone, deren Plasmide keine Insertion vorweisen, färben sich blau.

\subsection{Konstruktion von Genbanken aus Umwelt-DNA}

\subsubsection{Konstruktion einer Fosmidgenbank}

Der Vorteil einer Fosmidgenbank liegt in der Möglichkeit, große DNA Fragmente bis zu $50 \mathrm{~kb}$ zu klonieren und somit Aussagen über der Sequenzumgebung interessanter ORFs treffen zu können.

Für die Konstruktion einer Fosmidgenbank aus der DNA des Blinddarminhaltes des männlichen Bibers wurde das CopyControl ${ }^{\mathrm{TM}}$ Fosmid Library Production Kit von EPICENTRE ${ }^{\circledR}$ (Madison, WI, USA) verwendet.

Zuerst wurde die gesamte genomische DNA aus dem Inhalt des hinteren Blinddarmabschnittes des männlichen Bibers isoliert (s. II.5.4.1-4). Die DNA wurde nicht zusätzlich geschert, da die DNA während des Präparationsvorganges schon ausreichend geschert wurde. Die DNA wurde entweder einer präparativen Agarosegelelektrophorese mit LMP-Agarose (II.5.5.4.) unterzogen oder die DNA wurde nach der Isolierung aus dem Blinddarminhalt direkt für die Reaktion eingesetzt.

Die Größe wurde anhand eines 0,4\%igem Agarosegels (s. II.5.5.1.) überprüft und die Konzentration mittels Nanodrop (s. II.5.2) bestimmt. Anschließend erfolgte eine 
„End Repair"-Reaktion, um die entstandenen 5'phosphorylierten DNA Enden zu glatten Enden aufzufüllen.

\author{
„End Repair"-Reaktion \\ $\mathrm{x} \mu \mathrm{l} \quad \mathrm{H}_{2} \mathrm{O}_{\text {bidest. }}$ \\ $8 \mu \mathrm{l} \quad 10 \times$ End Repair Puffer \\ $8 \mu \mathrm{l} \quad 2,5 \mathrm{mM}$ dNTP Mix \\ $8 \mu \mathrm{l} \quad 10 \mathrm{mM} \mathrm{ATP}$ \\ Max. $20 \mu \mathrm{g}$ gescherte Insert DNA \\ $4 \mu \mathrm{l} \quad$ End-Repair Enzym-Mix \\ $80 \mu \mathrm{l}$ Volumen $n_{\text {total }}$
}

Die Reaktion wurde für $45-90$ min bei RT inkubiert. Anschließend wurde der Enzym-Mix für 10 min bei $70^{\circ} \mathrm{C}$ inaktiviert.

Die aufgefüllte DNA wurde dann mit einer Sure-Clean-Lösung (s. II.5.3.3.) gefällt und gereinigt. Nachdem die DNA-Konzentration mittels Nanodrop (s. II.5.2.) bestimmt wurde, wurde eine Ligationsreaktion durchgeführt:

\title{
Ligations-Reaktion
}

$x \mu \mathrm{l} \mathrm{H}_{2} \mathrm{O}_{\text {bidest. }}$

$1 \mu \mathrm{l} 10 \times$ Fast-Link Ligations-Puffer

$1 \mu \mathrm{l} 10 \mathrm{mM}$ ATP

$1 \mu \mathrm{l}$ CopyControl pCC1Fos Vektor

$x \mu$ l konzentrierte Insert DNA $(0,25 \mu \mathrm{g})$

$1 \mu \mathrm{l}$ Fast-Link DNA Ligase

$10 \mu \mathrm{l}$ Volumen $n_{\text {total }}$

Die Ligation erfolgte 2-3 $\mathrm{h}$ bei RT. Anschließend wurde die Fast-Link-Ligase bei $70{ }^{\circ} \mathrm{C}$ für 10 min hitzeinaktiviert. Der Ansatz wurde bei $-20^{\circ} \mathrm{C}$ gelagert, oder für die sofortige Weiterverarbeitung auf Eis aufbewahrt.

Nach der Ligation wurden die CopyControl Fosmid Klone mittels MaxPlax Lambda Packaging Extracts in Phagen verpackt. Als Wirtsstamm diente E. coli EPI300$\mathrm{T}^{\circledR}{ }^{\circledR}$. Dieser Stamm wurde als $5 \mathrm{ml}$ Vorkultur ü.N. angezogen. Am Tag der Verpackungsreaktion wurden $50 \mathrm{ml}$ LB - Medium + $10 \mathrm{mM}$ MgSO4 mit dieser 
Vorkultur angeimpft und bis zu einer $\mathrm{OD}_{600}$ von $0,8-1$ bei $37^{\circ} \mathrm{C}$ und 150 upm (Infors HT, Bottmingen, $\mathrm{CH}$ ) inkubiert. Währenddessen wurde 1 Reaktionsansatz des MaxPlax Lambda Packaging Extracts pro $10 \mu$ Ligations-Reaktion auf Eis aufgetaut. Ein halber Phagenansatz $(25 \mu \mathrm{l})$ wurde zur Ligations-Reaktion dazupipettiert, vorsichtig gemischt und der restliche Phagenanssatzt wurde sofort wieder bei $-70^{\circ} \mathrm{C}$ eingefroren. Die Verpackungsreaktion wurde dann $90 \mathrm{~min}$ bei $30{ }^{\circ} \mathrm{C}$ inkubiert. Danach wurden die restlichen $25 \mu \mathrm{l}$ Phagenextrakt dazugeben und die Reaktion erneut für 90 min bei $30{ }^{\circ} \mathrm{C}$ inkubiert. Nach der 3-stündigen Inkubation wurde der Ansatz auf ein Volumen von $1 \mathrm{ml}$ mit Phagen Verdünnungspuffer (Phagen Dilution Buffer) aufgefüllt und $25 \mu \mathrm{l}$ Chloroform dazupipettiert. Nach vorsichtigem Mischen wurde die Reaktion bei $4^{\circ} \mathrm{C}$ aufbewahrt.

Im darauffolgenden Schritt wurde der Phagentiter bestimmt. Dazu wurden folgende Verdünnungen aus der $1 \mathrm{ml}$ Reaktion mit dem Phagen Dilution Buffer (PDB) erstellt:

$\begin{array}{ll}1: 10^{2} & 10 \mu \mathrm{l} \text { aus } 1 \mathrm{ml} \text { Phagenreaktion } 990 \mu \mathrm{l} \\ 1: 10^{4} & 10 \mu \mathrm{l} \text { aus } 1: 10^{2} 990 \mu \mathrm{l} \\ 1: 10^{5} & 100 \mu \mathrm{l} \text { aus } 1: 10^{4} 900 \mu \mathrm{l} \\ 1: 10^{6} & 100 \mu \mathrm{l} \text { aus } 1: 10^{5} 900 \mu \mathrm{l}\end{array}$

Aus den einzelnen Verdünnungen wurden je $10 \mu$ l Reaktionsansatz zu je $100 \mu \mathrm{l}$ vorbereiteten EPI300-T1® Zellen pipettiert und diese 40 min bei $37^{\circ} \mathrm{C}$ inkubiert.

Danach wurden die infizierten Zellen auf $\mathrm{LB} / \mathrm{Cm}(12,5 \mu \mathrm{gg} / \mathrm{ml})$ Platten ausgestrichen und ü.N. bei $37^{\circ} \mathrm{C}$ im Brutschrank (HT TR 225, Infors AG) inkubiert. Anhand der Anzahl der Kolonien wurde nun der Phagentiter bestimmt:

$\frac{\text { (\# Kolonien) (Verdünnungsfaktor) }(1000 \mu \mathrm{l} / \mathrm{ml})}{(\text { Vol. ausplattierter Verdünnungsstufe }[\mu \mathrm{l}])}=\mathrm{cfu} / \mathrm{ml}$

PDB (Phage Dilution Buffer):

$10 \mathrm{mM}$ Tris/HCl, $\mathrm{pH} 8,3$

$100 \mathrm{mM} \mathrm{NaCl}$

$10 \mathrm{mM} \mathrm{MgCl} 2$ 


\subsubsection{Konstruktion einer Plasmidgenbank mit dem TOPO ${ }^{\circledR}$ XL PCR Cloning-Kit (Invitrogen ${ }^{\circledR}$, Carlsbad)}

Im Gegensatz zu Fosmidgenbanken, wird bei Plasmidgenbanken eine maximale Insertgröße von $10 \mathrm{~kb}$ erreicht. Daher lassen sich nur geringfügig Aussagen über die Sequenzumgebung interessanter ORFs treffen. Vorteilhaft ist jedoch, dass sich die Inserts aufgrund ihrer geringen Länge leicht sequenzieren lassen.

Da die isolierte DNA aus dem Blinddarm des männlichen Tieres schon stark geschert war, wurde auf eine weitere mechanische oder enzymatische Fragmentverkleinerung verzichtet.

Zunächst wurden mit Hilfe der T4-Polymerase "blunt ends" an den Enden der fragmentierten DNA generiert (s. 11.5.8.3). Es folgte eine Anfügen von Desoxyadenosin an die glatten Enden (s. II.5.8.3), um eine spätere Ligation in den Vektor $\mathrm{pCR} \AA-\mathrm{XL}-\mathrm{TOPO} \AA^{\mathrm{z}}$ zu ermöglichen. Bevor die DNA-Fragmente in den Vektor ligiert wurden, erfolgte eine Dephosphorylierung (s. II.5.8.4) mittels Antarctic Phosphatase (NEB, Frankfurt) und die Isolierung der gewünschten Fragmentgrößen aus einem präparativen Agarosegel (s. II.5.5.3.).

Es folgte eine Ligation in den Vektor $\mathrm{pCR}^{{ }^{\circledR}-\mathrm{XL}-\mathrm{TOPO}}{ }^{\circledR}$, wie in II.5.8.6. beschrieben und eine anschließende Transformation von E. coli Top10 (s. II.5.9.1.).

\subsection{DNA-Sequenzierungen}

\subsubsection{Shotgun-Sequenzierung von Fosmid-DNA}

Um die DNA-Sequenz von der Fosmide aktiver E. coli Fosmid-Klonen mit (hemi-) cellulolytischer Aktivität zu ermitteln, wurde die Fosmid DNA einer shot gunSequenzierung unterzogen. Hierfür wurde die Fosmid DNA mittels QiaPrep ${ }^{\circledR}$ Miniprep (Qiagen, Hilden, II.5.3.6.) isoliert und mit dem Nebulizer geschert. (s. II.5.7.1.) es folgte eine Isolierung von DNA Fragmentgrößen zwischen ein- und 2,5 kb aus einem präparativen Agarosegel (s. II.5.5.3). Anschließend wurden mittels T4-Polymerase glatte Enden und mittels Taq-DNA Polymerase A-Überhänge generiert (s. II.5.8.2.). Nach einer Dephosphorylierungsreaktion (s. II.5.8.4.) wurden die lineare DNA Fragmente in den Vektor pCR2.1 ligiert (s. 
II.5.8.6.). Es folgte eine Transformation von E. coli Top10 Zellen (s. II.5.9.2.). Von den erhaltenen E. coli Klonen wurden 50-200 Klone gepickt und in 1,5 ml LB/Amp (100 $\mu \mathrm{g} / \mathrm{ml}) 96$ well Blöcken angezogen (s. II.3.1.).

Die abzentrifugierten E. coli Zellepellets wurden an das $\mathrm{G}_{2} \mathrm{~L}$ (Göttingen) übergeben, wo nach der automatisierten Isolierung der entsprechenden Plasmide Sequenzierungsreaktionen mit Abi.for und Abi.rev Oligonukleotiden durchgeführt wurde. Die erhaltenen Sequenzdaten wurden mittels Gap4 anschließend assembliert und bearbeitet.

\subsubsection{4-Sequenzierung von $16 S$ rRNA-Gensequenzen}

Um die bakterielle Diversität in den unterschiedlichen Darmabschnitten des Bibers zu ermitteln, wurde die Methode der 454-Sequenzierung von amplifizierten $16 \mathrm{~S}$ rRNA-Gensequenzen verwendet. Der Vorteil dieser Methode ist, dass nach erfolgreichem Lauf mehrere zehntausend Sequenzen zur Analyse zur Verfügung stehen und die Wahrscheinlichkeit, dass die Diversität in einem Standort abgedeckt wird, sehr hoch ist. In dieser Arbeit wurde das „Genome Sequencer FLX“-System von Roche mit einer read-Länge von durchschnittlich 250 bp verwendet.

Zunächst wurden Teilbereiche der 16S rRNA-Gene mit den spezifischen Primern 454V2.for und 454V3.rev (s. Tabelle 3) amplifiziert. Die Primer wurden so konzipiert, dass sie den PCR-Produkten eine 5' Adaptorsequenz anfügten (in Tabelle 3 rot markiert), die für die folgende Sequenzierungsreaktion nötig war. Die PCR wurde nach folgendem Protokoll durchgeführt :

\section{Reaktionsansatz}

$\begin{array}{ll}\text { Template-DNA } & 1 \mu \mathrm{l} \text { (ca. } 50 \mathrm{ng}) \\ \text { dNTPs (je } 10 \mathrm{mM}) & 1 \mu \mathrm{l} \\ \text { Primer 454V2.for }(10 \mathrm{pmol} / \mu \mathrm{l}) & 2 \mu \mathrm{l} \\ \text { Primer 454V3.rev }(10 \mathrm{pmol} / \mu \mathrm{l}) & 2 \mu \mathrm{l} \\ \text { Pfu-Puffer }(10 \mathrm{x}) & 5 \mu \mathrm{l} \\ \text { Pfu-Polymerase }(2,5 \mathrm{U} / \mu \mathrm{l}) & 0,5 \mu \mathrm{l} \\ \mathrm{H}_{2} \mathrm{O}_{\text {bidest. }} & 38,5 \mu \mathrm{l}\end{array}$




\section{PCR-Programm}

$\left.\begin{array}{ll}94{ }^{\circ} \mathrm{C} & 2 \min \\ 94^{\circ} \mathrm{C} & 1 \mathrm{~min} \\ 65+/-5^{\circ} \mathrm{C} & 1 \mathrm{~min} \\ 72{ }^{\circ} \mathrm{C} & 1 \mathrm{~min} 15 \mathrm{sec} \\ 72{ }^{\circ} \mathrm{C} & 10 \mathrm{~min}\end{array}\right\} 25$ Zyklen

Für jede Probe wurde die PCR dreimal unabhängig voneinander durchgeführt. Die enstandenen PCR-Produkte wurden mittels präparativer Gelelektrophorese (s. Il.5.5.3.) aufgereinigt oder bei einer sehr hohen Spezifität direkt gereinigt (s. II.5.6.4.). Anschließend wurden die Konzentrationen der drei PCR-Reaktionen gemessen und im gleichen Verhältnis zueinander vereinigt.

Die weitere Durchführung erfolgte im "Göttingen Genomic Laboratory“. Für die Vorbereitung der PCR-Produkte wurden die Kits "GS emPCR Kit II" und" GS emPCR Kit III" der Firma Roche (Basel, Schweiz) verwendet, die in Kombination eine Sequenzierung von beiden Seiten des PCR-Produktes ermöglichen.

\section{Proteinbiochemische Methoden}

\subsection{Quantitative Proteinbestimmung (Bradford, 1976)}

Die quantitative Proteinbestimmung dient zur Bestimmung der Proteinkonzentration in einer Lösung. Verbunden mit dem Wert für die Menge der Proteinlösung, lässt sich somit die Gesamtausbeute an Protein berechnen, die aus einer Anzucht von Zellen gewonnen wurde. Für die Proteinbestimmung wurde in dieser Arbeit der Bradford- Test benutzt (Bradford, 1976). Dieser Test beruht auf der Bindung der Proteine an Coomassie brilliant blue G-250 und einer damit verbundenen Verschiebung des Absorptionsmaximums der Farbe (465 nm ohne Protein, $595 \mathrm{~nm}$ mit Protein). Die Zunahme der Absorption bei $595 \mathrm{~nm}$ ist dementsprechend ein Maß für die Proteinkonzentration der Lösung.

Für die Messung der Proteinkonzentration wurde das „Protein-Assay Kit“ (BioRad, München) benutzt. Die gebrauchsfertige Lösung wurde 1:5 mit $\mathrm{H}_{2} \mathrm{O}_{\text {bidest }}$ verdünnt. 
Als Standard diente Rinderserumalbumin (BSA), womit eine Eichkurve von 0-10 $\mu$ g Protein/Ansatz hergestellt wurde.

Für den quantitativen Nachweis werden 1-10 $\mu$ ler Proteinlösung mit $1 \mathrm{ml}$ der Färbelösung in einer Küvette vermischt und für max. 10 Minuten unter Lichtauschluss inkubiert. Anschließend erfolgt die Messung der Optischen Dichte bei $595 \mathrm{~nm}$ im Photometer. Als Referenzwert wird die Färbelösung ohne Protein benutzt.

Die Berechnung der Proteinkonzentration erfolgt anhand folgender Gleichung:

Protein $[\mu \mathrm{g} / \mathrm{ml}]=$ OD595 $\times \mathrm{m} / \mathrm{V}$

mit $\mathrm{m}$ als Steigung der Eichgeraden und $\mathrm{V}$ dem Volumen der eingesetzten Proteinlösung in $\mu \mathrm{l}$.

\subsection{Polyacrylamid-Gelelektrophorese}

\subsubsection{SDS- Polyacrylamid-Gelelektrophorese (Laemmli, 1970)}

Bei der SDS-Polyacrylamid-Gelelektrophorese (SDS-PAGE) zerstört das Detergenz SDS (Natrium -Dodecylsulfat) zum einen die Quartiärstruktur der Proteine, zum anderen bindet es an die hydrophoben Proteinbereiche. Durch die negativen Ladungen der angelagerten Dodecylsulfatreste spielt die proteineigene Ladung keine Rolle mehr und die Proteine werden alleine durch ihre unterschiedlichen molekularen Massen aufgetrennt. Für die Trennleistung in einem bestimmten Molekularmassenbereich ist der Vernetzungsgrad des Acrylamid/Bisacrylamid-Gels entscheidend. Für die SDS-PAGE wurden Kammern der Firma BioRad (Mini-Protean III cell 10/0.75 cm) benutzt.

Für die Herstellung der Gele wurden zunächst die Glasplatten gründlich mit 70 \%igem (v/v) EtOH gereinigt und in den Gießstand eingespannt. Das Trenngel wurde nach den unten aufgeführten Pipettierschemata ohne APS und TEMED zusammenpipettiert und gründlich durchmischt. Nach Zugabe von APS und TEMED und wiederholtem Mischen wurde der Ansatz bis $2 \mathrm{~cm}$ unter den oberen Rand der Glasplatten gegossen. Um einen luftblasenfreien Abschluss des Trenngels zu erhalten, wurde es bis zum Rand der Glasplatten mit Isopropanol überschichtet. Nach der Polymerisation des Trenngels wurde das Sammelgel ebenfalls nach den unten aufgeführten Pipettierschemata vorbereitet und auf das 
Trenngel gegossen. Danach wurde der Kamm möglichst ohne Luftblasen eingesetzt. Nachdem auch das Sammelgel vollständig polymerisiert war, wurde das Gel in der Elektrophoresekammer fixiert (Biorad, Mini-PROTEAN II Cell 10/0,75 cm). Anschließend wurden sowohl Anoden- als auch Kathodenraum mit 1x Standardelektrophoresepuffer befüllt. Die Geltaschen konnten nach vorsichtigem Herausziehen des Kamms mit bis zu $20 \mu \mathrm{l}(10 \mu \mathrm{g})$ Probe beladen werden. Die Proben wurden zuvor mit 4x Probenpuffer versetzt und 5-10 min bei $95^{\circ} \mathrm{C}$ gekocht. Die Elektrophorese wurde dann zunächst $15 \mathrm{~min}$ bei $15 \mathrm{~mA}$ pro Gel gestartet, um den Einlauf der Proben in das Sammelgel zu gewährleisten. Anschließend wurde die Spannung auf $30 \mathrm{~mA} / \mathrm{Gel}$ erhöht. Sobald die blaue Lauffront des Probenpuffers das Ende des Gels erreicht hatte, wurde die Elektrophorese gestoppt.

Tabelle 5. Pipettierschema für ein $10 \%$ SDS-Polyacrylamidgel

\section{Trenngel (10 \%) Sammelgel (4\%)}

Trenngelpuffer

Sammelgelpuffer

(37,5:1)Acrylamid/Bisacrylamid

$\mathrm{H}_{2} \mathrm{O}_{\text {bidest }}$

APS

TEMED
$1 \mathrm{ml}$

$0,48 \mathrm{ml}$

$1 \mathrm{ml}$

$0,2 \mathrm{ml}$

$2 \mathrm{ml}$

$1,32 \mathrm{ml}$

$30 \mu \mathrm{l}$

$15 \mu \mathrm{l}$

$3 \mu \mathrm{l}$

$2 \mu \mathrm{l}$

\section{Acrylamid-Stammlösung (AA):}

$40 \%$ (w/v), ( Fa. Feinchemikalien GmbH Biomol, Mannheim)

\section{Trenngel-Stammlösung (TG):}

Tris $\quad 18,2 \mathrm{~g}$

SDS $\quad 0,4 \mathrm{~g}$

$\mathrm{H}_{2} \mathrm{O}_{\text {bidest }}$ ad $100 \mathrm{ml}$

$\mathrm{pH} 8,8$ mit $\mathrm{HCl}$ einstellen 
Sammelgel-Stammlösung (SG):

Tris

$6,1 \mathrm{~g}$

SDS

$0,4 \mathrm{~g}$

$\mathrm{H}_{2} \mathrm{O}_{\text {bidest }}$ ad $100 \mathrm{ml}$

pH 6,8 mit $\mathrm{HCl}$ einstellen

\section{$10 \times$ Standardelektrophorese-Puffer}

Tris

$30,3 \mathrm{~g}$

Glycin $144,1 \mathrm{~g}$

SDS $10,0 \mathrm{~g}$

$\mathrm{H}_{2} \mathrm{O}_{\text {bidest }}$ ad $1000 \mathrm{ml}$

Ammoniumpersulfat (APS): $10 \%$ APS (w/v) in $\mathrm{H}_{2} \mathrm{O}_{\text {bidest }}$

\section{4 x Probenpuffer:}

$\begin{array}{ll}\text { Glycerin } & 7,5 \mathrm{ml} \\ \beta \text {-Mercaptoethanol } & 2,5 \mathrm{ml} \\ \text { SDS } & 1,2 \mathrm{~g} \\ \text { Bromphenolblau (2\%) } & 0,5 \mathrm{ml} \\ \text { Tris- } \mathrm{HCl} & 0,4 \mathrm{~g} \\ \mathrm{H}_{2} \mathrm{O}_{\text {bidest }} & \text { ad } 50 \mathrm{ml}\end{array}$

\subsubsection{Nativ-Polyacrylamidgelelektrophorese (Nativ-PAGE)}

Bei der Nativ-Polyacrylamidgelelektrophorese wird die authentische Struktur eines Proteins, im Gegensatz zur SDS-PAGE nicht zerstört. Eine zuverlässige Bestimmung der molekularen Masse der Proteine ist hier nicht möglich, da die Eigenladung der Proteine nicht durch die Dodecylsulfatreste des SDS überlagert wird.

Die nativen Proteingele wurden auf dieselbe Weise wie die SDS-Gele (II.5.1.2) angefertigt und bestehen ebenfalls aus einem Trenn- und einem Sammelgel. Anstelle von SDS-haltigen Lösungen wurden die unter III.2.1 aufgeführten Lösungen ohne SDS eingesetzt. 
Durchführung:

Die Proteinproben wurden 4:1 mit Probenpuffer versetzt und ohne vorherige Denaturierung in die Geltaschen gefüllt. Nach einem Vorlauf von 15 min bei $50 \mathrm{~V}$ erfolgte die elektrophoretische Auftrennung der Proteine bei $100 \mathrm{~V}$.

\section{4 x Probenpuffer für native Gele:}

Glycerin $[87 \%(\mathrm{v} / \mathrm{v})] \quad 7,5 \mathrm{ml}$

Bromphenolblau [2\%(w/v)] $0,5 \mathrm{ml}$

Tris- $\mathrm{HCl} \quad 0,4 \mathrm{~g}$

$\mathrm{H}_{2} \mathrm{O}_{\text {bidest. }} \quad$ ad $25 \mathrm{ml}$

$\mathrm{pH} 6,8$

\subsubsection{Coomassie-Färbung von Proteinen in Polyacrylamid-Gelen}

Die SDS-Gele wurden nach Beendigung der Elektrophorese kurz mit $\mathrm{H}_{2} \mathrm{O}$ gespült und dann für $30 \mathrm{~min}$ in der Färbelösung unter Schwenken gefärbt. Nach Spülen mit Wasser wurde das Gel in Entfärbelösung, welche mehrmals erneuert wurde, geschwenkt, bis der Hintergrund des Gels farblos war.

\section{Lösungen:}

\section{Coomassie-Färbelösung:}

Coomassie-Brilliant-Blue R $250 \quad 0,5 \mathrm{~g}$

Essigsäure $100 \mathrm{ml}$

Isopropanol $250 \mathrm{ml}$

$\mathrm{H}_{2} \mathrm{O}_{\text {bidest. }} \quad$ ad $1000 \mathrm{ml}$

mehrfach verwendbar

\section{Entfärbelösung:}

Essigsäure (10\%) 


\subsection{Umpufferung durch Dialyse}

Entsalzung und Umpufferung von Proteinlösungen wurden durch Dialyse in Dialyseschläuchen durchgeführt (VISKING ${ }^{\circledR}$ Dialysis Tubing, Serva, Heidelberg). Zunächst wurde ein angemessen großes Schlauchstück abgeschnitten, wobei $1 \mathrm{~cm}$ Dialyseschlauch ca. 2,5 ml Flüssigkeit aufnehmen kann. Der Schlauch wurde in $\mathrm{H}_{2} \mathrm{O}_{\text {bidest. }}$ für 15 min ausgekocht, anschließend mit der Proteinlösung befüllt und an beiden Enden mit Dialyseklammern abgedichtet. Die Dialyse erfolgte über Nacht unter leichtem Rühren gegen 2-5 I Puffer bei $4{ }^{\circ} \mathrm{C}$ im Kühlraum.

\subsection{Einkonzentrierung und/oder Umpufferung von Proteinlösungen mittels Mikrokonzentratoren}

Um Proteinlösungen einzuengen, wurden Mikrokonzentratoren (Vivaspin 15 Sartorius Stedim Biotech $\mathrm{GmbH}$, Göttingen) mit einem Ausschlussgröße von 10 kDa verwendet. Dabei konnten Proteinlösungen von $15 \mathrm{ml}$ auf $200 \mu$ leingeengt werden. Die Mikrokonzentratoren eignen sich zudem zur Umpufferung von Proteinlösungen kleinerer Volumina. Die Zentrifugation erfolgte in einer Kühlzentrifuge (Zentrifuge 5804, Eppendorf, Hamburg) bei 3000 Upm.

\subsection{Aufreinigung von Proteinen}

\subsubsection{Abtrennung thermolabiler Proteine durch Hitzedenaturierung}

Zur ersten Aufreinigung eines thermophilen Enzyms aus dem Rohextrakt eines mesophilen Wirtes eignet sich besonders die Denaturierung der thermolabilen Wirtsproteine durch einen Hitzeschritt. Dazu wurde der aus dem Zellaufschluss gewonnene klare Rohextrakt in einem SS34-Röhrchen im Wasserbad für 20 min bei einer für das rekombinante Protein angemessener Temperatur inkubiert. Die durch die Hitze denaturierten und präzipitierten Wirtsproteine wurden abzentrifugiert (13000 Upm, $15 \mathrm{~min}, 4^{\circ} \mathrm{C}$ ). Anschließend wurde der Überstand mit dem rekombinanten Protein abgenommen. 


\subsubsection{Proteinaufreinigung mittels FPLC}

Bei einer säulenchromatographischen Proteinreinigung mittels FPLC (Fast Protein Liquid Chromatography) wird das zu trennende Substanzgemisch in Lösung (mobile Phase) über eine Säule aus einer festen, porösen Matrix (stationäre Phase) geschickt. Die Wechselwirkungen der gelösten Bestandteile mit der stationären Phase verzögern die Wanderungsgeschwindigkeit durch die Matrix in substanzspezifischer Weise. Auf diesem Wege wird im Idealfall z.B. der hitzegefällte Rohextrakt in separate Fraktionen reiner Proteine aufgetrennt.

Für die Proteinaufreinigung mittels FPLC wurden alle Puffer und Proben vor dem Auftragen filtriert, um eine Verunreinigung des Säulenmaterials mit Staubpartikeln zu vermeiden. Die Filtration der Proben erfolgte durch Einweg-Sterilfilter (Minisart $0,2 \mu \mathrm{m}$, Sartorius). Die Puffer wurden mit $\mathrm{H}_{2} \mathrm{O}_{\text {bidest. }}$ hergestellt und anschließend mit einer Vakuumpumpe (Savant) durch Cellulosenitrat-Filter $(0,45 \mu \mathrm{m}$, Schleicher \& Schuell, Dassel) filtriert. Um das Eindringen von Luftblasen in das Säulenmaterial zu verhindern, wurden alle Anschlüsse „drop to drop“ verbunden. Die Säulen werden in 20 \%igem (v/v) Ethanol gelagert. Direkte Umpufferung der Säulen von Ethanol zu einem salzhaltigen Puffer oder umgekehrt sollte durch Spülen mit MilliQ-Wasser vermieden werden.

Die verwendete ÄKTA-FPLC-Anlage besteht aus folgenden Komponenten (alle GE Healthcare Europe, Freiburg):

Geräte: Monitor UPC-900

Pumpe P-920

In-line Mixer M-925

Motor Valve INV-907

Fraction Collector Frac-900

$10 \mathrm{ml}$ und $50 \mathrm{ml}$ Superloop, $1 \mathrm{ml}$ und $250 \mu \mathrm{l}$ Probenschleife

\section{lonenaustausch-Chromatographie (IEC)}

Das Trennprinzip der Ionenaustausch-Chromatographie beruht auf elektrostatischen Wechselwirkungen zwischen den Proteinen und den funktionellen Gruppen des Gelmaterials. Dabei treten geladene Gruppen auf der Oberfläche der Proteine mit entgegengesetzt geladenen Gruppen auf der Austauschermatrix in Interaktion und führen so zu einer Bindung an die Säule, 
wobei die Stärke dieser Bindung von den individuellen Ladungseigenschaften der einzelnen Polypeptide abhängt. Entscheidende Parameter sind die lonenstärke (Salzkonzentration) und der pH-Wert. Die Elution erfolgt durch eine Erhöhung der lonenstärke, wodurch die elektrostatische Wechselwirkung zwischen Protein und Gelmaterial geschwächt wird.

In dieser Arbeit wurde der starke Kationenaustauscher SOURCE15S in einer vorgepackten Tricorn-Säule (4.6/100 PE ) mit einem Gelbettvolumen von 1,7 ml verwendet. Das Material besteht aus monodispersen Polystyren/DivinylbenzenPartikeln mit $15 \mu \mathrm{m}$ Durchmesser und einer kontrollierten Porenstruktur, die hohe Stabilität und geringen Rückdruck gewährleisten. Die funktionelle Gruppe der SOURCE $15 S$ ist ein quartäres Amin, das über einen hydrophilen Spacer an die Säulenmatrix gebunden ist. Die Proteinbindungskapazität beträgt bis zu $40 \mathrm{mg}$ Protein pro $\mathrm{ml}$ Gelbett. Die empfohlene Flußrate wird mit 0,5 2,5 ml/min bei einem maximalen Rückdruck von $4 \mathrm{MPa}$ angegeben.

Durchführung:

Die Säule wurde zur Vorbereitung zunächst mit 1 Säulenvolumen (SV) Puffer A (= Niedrigsalzpuffer) und anschließend mit drei Säulenvolumina Puffer B (= Hochsalzpuffer) gespült, um die funktionellen Gruppen mit Gegenionen abzusättigen. Dann wurde das Medium mit mindestens 8 SV Auftragungspuffer A auf die Startbedingungen äquilibriert. Die Probe (in Puffer A) wurde unter Niedrigsalzbedingungen auf die Säule aufgetragen und in einem ansteigenden Salzgradienten eluiert.

Puffer A : $50 \mathrm{mM}$ Phosphatpuffer $\mathrm{pH} 7$

Puffer B : $50 \mathrm{mM}$ Phosphatpuffer $\mathrm{pH} 7+1 \mathrm{M} \mathrm{NaCl}$

\subsubsection{Reinigung löslicher Proteine mit Protino ${ }^{\circledR} \mathrm{Ni}-\mathrm{TED}-\mathrm{Säulen}$}

Die Verwendung von Protino ${ }^{\circledR}$-Ni-TED Säulen (Fa. Macherey-Nagel, Düren) ermöglicht eine schnelle und zuverlässige Aufreinigung von rekombinanten Proteinen mit Polyhistidin-tags. Die Bindung des aufzureinigende Proteine basiert auf der Interaktion zwischen immobilisierten $\mathrm{Ni}^{2+}$ Ionen des Säulenmaterials und dem Polyhistidin-Tag des rekombinanten Proteins. Die Elution des Proteins erfolgt durch das im Elutionspuffer enthaltene Imidazol, welches ebenfalls an zweiwertige 
Nickelionen bindet und dabei das rekombinante Protein verdrängt. In dieser Arbeit wurde diese Methode verwendet, um das rekombinante Enzym Xyn1015 aufzureinigen. Zur Aufreinigung wurde Hitze-gefällter Rohextrakt eingesetzt.

Die Durchführung erfolgte laut Herstellerangaben

\section{Nachweis von Enzymaktivitäten}

\subsection{DNSA-Test zur Bestimmung der Menge reduzierender Zucker}

Mit diesem kolorimetrischen Test können die bei der Hydrolyse polymerer Kohlenhydrate entstehenden freien, reduzierenden Zuckerenden quantitativ bestimmt werden. Die freien Halbacetalgruppen reduzieren in Gegenwart von Phenol, Natriumsulfit und Hitze DNSA zu 3-Amino-5-nitrosalicylsäure. Diese Reaktion verursacht bei $96^{\circ} \mathrm{C}$ einen Farbumschlag von gelb nach braun. Die Farbintensität ist dabei der Anzahl der vorhandenen reduzierenden Enden proportional. Die Quantifizierung erfolgt photometrisch bei $575 \mathrm{~nm}$.

Der Ansatz wurde zunächst 10 min bei der gewünschten Temperatur vorinkubiert, bevor der Test durch Zugabe der Enzymlösung gestartet wurde. Die Testdauer bei variierte je nach eingesetztem Substrat und Enzymmenge. Der Test wurde durch Zugabe von $750 \mu$ I DNSA-Reagenz abgestoppt. Anschließend wurde der Ansatz 15 min bei $96{ }^{\circ} \mathrm{C}$ aufgekocht, kurz auf Eis abgekühlt und 2 min abzentrifugiert (13000 Upm, $4^{\circ} \mathrm{C}$ ). Die $\mathrm{OD}_{575}$ wurde gegen eine entsprechende Nullprobe ohne Enzym (die mit einer Nullprobe ohne Substrat und mit Enzym verglichen wurde) gemessen.

Für die Quantifizierung der hydrolytischen Aktivität wurde für B-Glucoside eine Eichgerade mit Glucose, für Xylan eine Eichkurve mit Xylose, im Bereich von 0,3 bis 1,5 $\mu \mathrm{mol}$ reduzierender Enden erstellt. Eine Enzym-Unit (U) wird als die Enzymaktivität definiert, die zur Freisetzung von $1 \mu \mathrm{mol}$ reduzierender Enden pro Minute führt. 


\section{Standardansatz}

$\begin{array}{ll}\text { Substratlösung }(1 \%(\mathrm{w} / \mathrm{v})) & 250 \mu \mathrm{l} \\ \text { Mcllvaine-Puffer } & 100 \mu \mathrm{l} \\ \mathrm{H}_{2} \mathrm{O}_{\text {bidest. }} & 150-\mathrm{x} \mu \mathrm{l} \\ \text { Enzymlösung } & \mathrm{x} \mu \mathrm{l}\end{array}$

\section{DNSA- Reagenz}

$\begin{array}{ll}\text { Dinitrosalicylsäure } & 10 \mathrm{~g} \\ \text { Phenol } & 2 \mathrm{ml} \\ \mathrm{Na}_{2} \mathrm{SO}_{3} & 0,5 \mathrm{~g} \\ \mathrm{~K}-\mathrm{Na}-\mathrm{Ta} \text { artrat } & 200 \mathrm{~g} \\ \mathrm{NaOH} & 10 \mathrm{~g} \\ \mathrm{H}_{2} \mathrm{O}_{\text {bidest. }} & \text { ad } 1000 \mathrm{ml}\end{array}$

Vor Licht schützen und bei $4^{\circ} \mathrm{C}$ lagern.

\section{Substratstammlösungen}

Carboxymethylcellulose (low viscosity, Sigma, Taufkirchen) Hydroxyethylcellulose (Fluka, Buchs, Schweiz)

B-Glucan (Gerste, low viscosity, Megazyme, Wicklow, Irland) $\underline{\text { Xylan }}$

(Birkenholz/Buchenholz/Haferspelzen, Sigma, Taufkirchen) Pachyman ( Poria cocos, Megazyme, Wicklow, Taufkirchen) Zymosan (Saccharomyces cerevisae, Sigma, Taufkirchen) Curdlan (Alcaligenes faecalis, Sigma, Taufkirchen) Auxoferm (Saccharomyces cerevisae, DHW, Nürnberg) Laminarin (Laminaria digitata, Sigma, Taufkirchen) Lichenan ( Cetraria islandica, Megazyme, Wicklow, Irland) Mikrokristalline Cellulose (Serva, Heidelberg)
$1 \%(w / v)$

$1 \%(w / v)$ $1 \%(w / v)$ $1 \%(w / v)$ $1 \%(w / v)$ $1 \%(w / v)$ $1 \%(w / v)$ $1 \%(w / v)$ $1 \%(w / v)$ $1 \%(w / v)$ $40 \mathrm{mg} / \mathrm{ml}$

Die Substrate wurden aufgekocht und autoklaviert. Die mikrokristalline Cellulose wurde aufgekocht und gewaschen. Alle Substrate wurden in $\mathrm{H}_{2} \mathrm{O}_{\text {bidest. }}$ gelöst bzw. suspendiert. 


\subsection{Nachweis der Hydrolyse von Polysacchariden durch Enzyme nach SDS-PAGE}

Zum Nachweis von Proteinen, die B-verknüpfte Polymere hydrolytisch spalten, wurde eine Aktivitäts-PAGE, angewendet. Lösliche Substrate wurden in einer Endkonzentration von $0,15 \%(\mathrm{v} / \mathrm{v})$ in ein $10 \%$ SDS-Gel eingegossen (es wurde entsprechend weniger $\mathrm{H}_{2} \mathrm{O}$ eingesetzt).

Um einen Vergleich zwischen Aktivitäts- und Proteinbanden zu ermöglichen, enthielt auch das zur Proteinfärbung immer mitgeführte Gel das entsprechende Substrat in 0,15 \%iger Endkonzentration (v/v). Zum Nachweis von Xylanaseaktivität wurde das Substrat nicht einpolymerisiert, sondern das zu färbende Gel im Anschluss an die Elektrophorese in xylanhaltigem Puffer inkubiert. Die im SDS-Gel denaturiert vorliegenden Proteine wurden nach Ende der Elektrophorese durch kurzes Spülen des Gels mit Wasser, 5-minütigem Waschen in Mcllvaine-Puffer $+25 \%(\mathrm{v} / \mathrm{v})$ Isopropanol und durch 30-minütiges Schwenken in Mcllvaine-Puffer renaturiert. Das Aktivitätsgel wurde in frischen Mcllvaine-Puffer, bei Nachweisen von Xylanaseaktivität in Mcllvaine-Puffer $+1 \%$ $(\mathrm{w} / \mathrm{v})$ Xylan, überführt und für $30 \mathrm{~min}$ bis $12 \mathrm{~h}$ bei $65^{\circ} \mathrm{C}$ inkubiert. Im Anschluss erfolgte ein nochmaliges Spülen des Gels mit $\mathrm{H}_{2} \mathrm{O}$ und 20-minütige Färbung mit $0,1 \%$ Kongorotlösung. Die Entfärbung erfolgte mit $\mathrm{NaCl}$-Entfärbelösung (1M), bis helle hydrolytisch aktive Höfe sichtbar waren.

\section{Mcllvaine-Puffer}

Lösung A:

Citrat $0,1 \mathrm{~mol} / \mathrm{l}$

Lösung B:

$$
\mathrm{Na}_{2} \mathrm{HPO}_{4} 0,2 \mathrm{~mol} / \mathrm{l} \text { in } \mathrm{H}_{2} \mathrm{O}_{\text {bidest. }}
$$

Lösung $\mathrm{B}$ mit Lösung $\mathrm{A}$ auf den gewünschten $\mathrm{pH}$ einstellen

$$
\begin{aligned}
& \text { Mcllvaine-Puffer }+25 \% \text { 2-Propanol NaCl-Entfärbelösung } \\
& \text { Mc-Illvaine-Puffer }+25 \%(\mathrm{v} / \mathrm{v}) \text { 2-Propanol }
\end{aligned}
$$

\section{Mcllvaine-Puffer mit Xylan}

Buchenholzxylan $1 \%(\mathrm{w} / \mathrm{v})$

Mcllvaine-Puffer wie oben 


\subsection{Produktanalyse durch Dünnschichtchromatographie (TLC)}

Die Dünnschichtchromatographie (TLC) ist eine Form der Verteilungschromatographie zwischen einer hydrophilen (stationären) und einer hydrophoben (mobilen) Phase. Mit dieser Methode lassen sich z.B. Mono- und Oligosaccharide, wie sie bei hydrolytischer Spaltung auftreten, auftrennen, wobei die Wanderungsgeschwindigkeit der zu trennenden Substanzen in Abhängigkeit ihrer relativen Löslichkeit in der stationären und mobilen Phase, d.h. ihrer Polarität, erfolgt. Anhand eines mitgeführten Standards lassen sich die Mono- und Oligosaccharide bestimmen und detektieren.

Der Testansatz erfolgte entsprechend des DNSA-Ansatzes zur Bestimmung reduzierender Zucker (II.7.1.) wobei nach Ende der Inkubationszeit kein DNSAReagenz zugegeben und der Ansatz nicht aufgekocht wurde. Die Proben wurden stattdessen zur Entfernung von unlöslichen Substraten und präzipitierten Proteinen abzentrifugiert (13000 Upm, $4{ }^{\circ} \mathrm{C}, 2 \mathrm{~min}$ ). Aliquote der Proben $(2-15 \mu \mathrm{l})$ wurden entlang einer $1,5 \mathrm{~cm}$ vom unteren Rand entfernten Auftragslinie im Abstand von $1 \mathrm{~cm}$ auf Chromatographieplatten aufgetragen. Der Abstand zum Seitenrand musste mindestens $1,5 \mathrm{~cm}$ betragen. Wurden Probenvolumina von mehr als $2 \mu \mathrm{l}$ aufgetragen, musste die Platte bei RT oder mit Heißluft zwischen den Auftragsschritten getrocknet werden. Die vorbereitete Chromatographieplatte wurde in eine mit Filterpapier (Whatman) ausgekleidete und mit $100 \mathrm{ml}$ Laufmittel befüllte Laufkammer gestellt. Hatte die mobile Phase den oberen Plattenrand bis auf $2 \mathrm{~cm}$ erreicht, wurde diese getrocknet und der Chromatographielauf wiederholt. Die Platte wurde erneut getrocknet und es folgte die Entwicklung der Chromatographieplatte durch gleichmäßiges Besprühen mit frisch angesetztem Entwicklungsreagenz und 10 bis 15-minütiger Inkubation in Alufolie auf einer Heizplatte bei $140{ }^{\circ} \mathrm{C}$. Zur Aufbewahrung wurden die Platten in Schlauchfolie eingeschweißt. Eine Lagerung der Chromatographieplatten zwischen den einzelnen Arbeitsschritten bei $-20^{\circ} \mathrm{C}$ war möglich.

\section{Stationäre Phase}

Mit Kieselgel beschichtete Aluminiumfolien (Kieselgel $60 \mathrm{~F}_{254}$, Fa. Merck, Darmstadt) 


\section{Mobile Phase}

1-Propanol $60 \%(\mathrm{v} / \mathrm{v})$

Ethylacetat $10 \%(\mathrm{v} / \mathrm{v})$

$\mathrm{H}_{2} \mathrm{O}_{\text {bidest. }} 30 \%(\mathrm{v} / \mathrm{v})$

\section{Entwicklungsreagenz}

Schwefelsäure : Ethanol (1:9)

\section{Nachweis (hemi-)cellulolytischer Aktivität von E. coli-Klonen}

Zur Identifizierung von (hemi-) cellulolytischen E. coli Klonen wurden verschieden Methoden verwendet. Grundsätzlich wurden die E. coli Klone zunächst über Nacht auf Fest- oder Flüssigmedium bei $37^{\circ} \mathrm{C}$ angezogen und im nächsten Schritt einer Temperatur von $60^{\circ} \mathrm{C}$ im Inkubator ausgesetzt, um potentielle (hemi-) cellulolytische Aktivitäten thermophiler Enzyme zu ermöglichen. Als Substrate dienten Carboxymethylcellulose (low viscosity; Fluka, Buchs), Hydroxyethylcellulose (medium viscosity; Fluka, Buchs), Birkenholz- Xylan (Fluka, Buchs), Haferspelzen-Xylan (Roth, Karlsruhe), Mikrokristalline Cellulose (Serva, Heidelberg) und 4-Methylumbelliferyl $\beta$-D-cellobiosid (Sigma-Aldrich, Steinheim) Die verschiedenen Verfahren werden im Folgenden vorgestellt:

\subsection{Screening mit Substrat-Agarplatten}

Bei dieser Methode wurden durchzumusternde E. coli Klone auf LB-Agarplatten mit $0,3 \%(w / v)$ des entsprechenden Substrats überstempelt und über Nacht bei $37^{\circ} \mathrm{C}$ im Brutschrank (Brutschrank HT TR 225, Infors AG) angezogen. Anschließend wurden die Agarplatten abgedichtet und $16-20 \mathrm{~h}$ bei $60^{\circ} \mathrm{C}$ inkubiert. Nachdem die Kolonien entfernt wurden, wurden die Agarplatten mit Kongorotlösung $(0,5 \%(w / v)$ für 20 Minuten überschichtet. Abschließend wurde nicht gebundenes Kongorot durch Schwenken mit einer NaCl-Lösung (1 M) ausgewaschen. Polysaccharid-abbauende E. coli Klone zeigten einen klaren Hof vor rotem Hintergrund. 


\section{LB-Substratagar}

Trypton

Hefeextrakt

$\mathrm{NaCl}$

Bacto-Agar

Substrat

$\mathrm{H}_{2} \mathrm{O}_{\text {bidest. }}$.
$10 \mathrm{~g}$

$5 \mathrm{~g}$

$10 \mathrm{~g}$

$15 \mathrm{~g}$

$3 \mathrm{~g}$

ad 11

Im Fall von E. coli Fosmid-Klonen wurde steril filtrierte L-Arabinose (Fluka, Buchs) in der Endkonzentration von $0,001 \%(w / v)$ hinzugefügt, um die FosmidKopienzahl zu erhöhen

\subsection{Screening mit selbst angefärbten Substraten}

(Lee, S.-T. und Lee, 1997, Ten et al., 2005)

Dieses Verfahren ermöglicht die Identifizierung von (hemi-)-cellulolytisch aktiven E. coli Klonen sowohl in LB-Flüssigmedium, als auch auf LB-Agarplatten. Der besondere Vorteil dieser Methode ist, dass verschieden abgefärbte Substrate gleichzeitig getestet werden können und das ein Ergebnis ohne ein nachträgliches Anfärben von Agarplatten mit z.B. Kongorotlösung mit der Bildung von Höfen um die Kolonien sichtbar wird.

Prinzipiell wird ein zunächst semilösliches Substrat mit Hilfe von 1,4-Butandioldiglycidylether mit Cibacron-Farbstoffen quervernetzt und somit in eine unlösliche Form überführt. Der Farbstoff wird nur bei der enzymatischen Degradierung des entsprechenden Substrates wieder freigesetzt, was auf Agarplatten eine Bildung von Höfen verursacht und bei der Anwendung in Flüssigmedium eine Verfärbung des Mediums zur Folge hat.

\section{Herstellung des Substrates :}

In dieser Arbeit wurden die Substrate Birkenholz-Xylan (Sigma, Taufkirchen), Haferspelzenxylan (Sigma, Taufkirchen), Mikrokristalline Cellulose (Serva, Heidelberg) und Hydroxyethylcellulose (Fluka, Buchs, Schweiz) mittels der Methode nach Lee et al. (1997) angefärbt. 
Zunächst wurden $2 \mathrm{~g}$ des entsprechenden Substrates mit $30 \mathrm{ml} \mathrm{H}_{2} \mathrm{O}_{\text {bidest. }}$ vermischt und anschließend unter Rühren mit $10 \mathrm{ml} \mathrm{NaOH}$ (2M) versetzt. Es folgte die Zugabe von 1,5 g der Farbstoffe Cibacron Brilliant Red 3BA oder Cibacron Blue 3GA (Sigma, Taufkirchen). Nach der Zugabe von 1,4 ml 1,4Butandioldiglycidylether wurde die Mixtur weitere 5 Minuten gerührt und anschließend für 48 Stunden bei Raumtemperatur stehen gelassen, bis sich eine feste Gel-Struktur ausgebildet hatte. Das Gel wurde mit $100 \mathrm{ml} \mathrm{H}_{2} \mathrm{O}_{\text {bidest }}$ versetzt und mit einem handelsüblichen Pürierstab püriert, bis die gewünschte Partikelgröße erreicht wurde. Überschüssiger Farbstoff wurde entfernt, indem die Partikel mit kochenden $\mathrm{H}_{2} \mathrm{O}_{\text {bidest. }}$ gewaschen und filtriert wurden (Cellulose Rundfilter, Schleicher\&Schuell $\mathrm{GmbH}$, Dassel), bis das Filtrat farblos wurde. Es folgten Waschschritte mit steigenden Ethanol-Konzentrationen ( $25 \%, 50 \%, 75 \%$ und $100 \%$ ) und ein abschließender Waschritt mit Azeton. Die Partikel wurden bei Raumtemperatur getrocknet, in $200 \mathrm{ml} \mathrm{H}_{2} \mathrm{O}_{\text {bidest. }}$ aufgenommen und 20 Minuten bei $121^{\circ} \mathrm{C}$ autoklaviert. Häufig zeigte sich nach dem Autoklavieren eine erneute Freisetzung des Farbstoffes, so dass die Waschschritte wiederholt werden mussten. Die Lagerung der Substratpartikel erfolgte bei $4^{\circ} \mathrm{C}$.

Die gefärbten Partikel wurden den Festmedien vor dem Autoklavieren, Flüssigmedien nach dem Autoklavieren hinzugefügt.

Da keine allgemeine Aussage für die einzusetzende Partikelmenge getroffen werden konnte, wurde den Medien sukzessiv Substrat beigemengt, bis eine zufriedenstellende Partikel-Konzentration erreicht wurde.

Im Falle von Substrat-LB-Agarplatten wurden die entsprechenden E. coli Klone zunächst ÜN bei $37{ }^{\circ} \mathrm{C}$ unter Selektionsdruck angezogen. Im Falle von FosmidE. coli-Klonen enthielt das Medium 0,001 \% (w/v) L-Arabinose, um die FosmidKopienzahl innerhalb der Zellen zu erhöhen. Anschließend wurden die Platten versiegelt und 1-3 Tage bei $60{ }^{\circ} \mathrm{C}$ inkubiert, um die hydrolytische Aktivität thermophiler Enzyme zu ermöglichen. Positive E. coli Klone wurden durch einen farbigen Hof erkennbar.

Im Fall von Flüssigmedium wurden die Substratpartikel direkt vor dem Beimpfen beigemengt. Nach Wachstum ÜN bei $37^{\circ} \mathrm{C}$ im Brutschrank unter Selektionsdruck, wurden die Kulturen für 1-3 Tage einer Temperatur von $60^{\circ} \mathrm{C}$ ausgesetzt, bis eine Verfärbung des Mediums sichtbar wurde. Diese Methode eignet sich besonders für das Screening im $200 \mu \mathrm{l} 96$ well Mikrotestplatten-Format. 


\subsection{Screening mit 4-Methylumbelliferyl- $\beta$-D-cellobiosid (Chernoglazov et al., 1989)}

(4-MUC)

Diese Methode wurde verwendet, um E. coli Fosmid Klone mit endo-GlucanaseAktivität zu identifizieren. Durch die Spaltung des Substrats wird 4-Methyllumbelliferon freigesetzt, welches bei unter UV Licht bei einer Wellenlänge von $340 \mathrm{~nm}$ fluoresziert.

$\mathrm{Zu}$ analysierende E. coli Klone wurden zunächst in $200 \mu \mathrm{l}$ LB-Medium in 96 well Mikrotestplatten ÜN bei $37^{\circ} \mathrm{C}$ unter Selektionsdruck angezogen. Anschließend wurde L-Arabinose in einer Endkonzentration von 0,001 \% (w/v) hinzugefügt, um die Fosmidanzahl in den Zellen zu erhöhen. Es folgte ein weiterer Inkubationschritt bei $37^{\circ} \mathrm{C}$ für $4 \mathrm{~h}$. Nach der Zugabe des Substrates in einer Endkonzentration von 0,1 mM wurden die Mikrotestplatten für 1-3 Tage bei $50^{\circ} \mathrm{C}-60^{\circ} \mathrm{C}$ inkubiert. Positive E. coli Klone zeigten Fluoreszens bei einer Wellenlänge von 340 nM.

\section{Die Prozessierung von DNA-Rohsequenzen}

\subsection{Die Prozessierung von DNA-Sequenzen mit Hilfe des STADEN- Software-Pakets}

Das STADEN-Software-Paket beinhaltet verschiedene Programme zum Selektieren, Aufbereiten, Assemblieren und Editieren von DNA-Sequenzen (Staden et al., 2000). Es würde den Rahmen dieser Arbeit sprengen, auf die Struktur und Funktionsweise der einzelnen Programme einzugehen. Eine ausführliche Dokumentation kann unter http://www.mrcImb.cam.ac.uk/pubseq/staden home.html abgerufen werden. Im Wesentlichen wurden zur Prozessierung der DNA-Sequenzen die Programme „Pregap4“ und „Gap4" genutzt.

\section{Pregap4}

Bevor DNA-Sequenzen in das Genomassemblierungsprogramm "Gap4“ eingespeist werden können, müssen diese durch diverse Prozesse geleitet werden, welche das Programm „Pregap4“ leistet (Bonfield and Staden, 1996): 
a. Screening auf Vektor-Kontaminationen: Sequenzen, die den Vektor Sequenzen ( $p C R \circledast-X L-T O P O \circledast$ bzw. pCR2.1-TOPO) entsprechen, fallen aus der Datenbank heraus.

b. Screening auf Kontamination mit E. coli DNA: Bei der Herstellung der Genbank kann es zu Kontaminationen mit der DNA des Wirtsstammes (E. coli Top10) kommen. Diese Daten müssen ebenfalls entfernt werden.

c. Qualitätskontrolle: Sequenzen mit einer geringen Qualität fallen aus der Datenbank heraus.

d. „Vektor-Clipping“: Es werden die Basen einer Sequenz maskiert, die im Übergang zum Insert der Vektor-Sequenz entsprechen.

e. Umformatierung in ein neues Dateiformat: Zur Assemblierung benötigt "Gap4“ ein anderes Dateiformat (experimental files).

Zur Erleichterung der Prozessierung der Rohdaten wurden im Göttinger Genomanalyselabor Computerskripte entwickelt, die hier nicht näher erläutert werden. Prinzipiell bewerkstelligen solche Skripte das Umbenennen von Dateinamen, das Einleiten der Rohsequenzen in „Pregap4“ und das Sortieren der Ausgabe von „Pregap4“ in mehrere Listen („Failed, Passed, ScreenVector“, etc.).

\section{Gap4}

Gap4 ist ein Genomassemblierungsprogramm, das auch für kleinere DNAAbschnitte wie Fosmide oder große Plasmide verwendet werden kann (Bonfield et al., 1995) . Neben der Assemblierung kann das Programm auch zur Editierung der Sequenzen benutzt werden. Eine weitere Nutzung von Gap4 liegt in dem sogenannten Finishing, dem Schließen von Sequenzlücken in einem Sequenzierungsprojekt.

Assemblierung:

Mit Hilfe von Algorithmen („PHRAP“,) werden Sequenzüberlappungen ausfindig gemacht http://bozeman.mbt.washington.edu/phrap.docs/phrap.html

Sequenzläufe (readings), die solche Sequenzüberlappungen aufweisen,werden dann passend zueinander ausgerichtet (Alignment) und zu zusammenhängenden DNA-Abschnitten, den sogenannten Contigs, zusammengefasst. Aus den alignten Sequenzen innerhalb eines Contigs bildet das Programm dann eine ConsensusSequenz. 
Editierung: Ziel ist es hierbei, die Qualität der Consensus-Sequenz eines Contigs zu verbessern und Fehler in der Assemblierung zu detektieren und aufzulösen. Dabei wurden entsprechende Einzelsequenzen markiert, aus dem Contig extrahiert und dann manuell in den Datensatz zu passenden Contigs zurücktransferiert. Die Fehlerrate sollte nicht höher als 1 in 10000 Basen betragen. Dabei lässt sich die Qualität jeder einzelnen Base in der Consensus-Sequenz über deren Base Confidence-Wert überprüfen.

Finishing: In "Gap4" können zwei (oder mehrere) Contigs anhand der Lage und Orientierung der enthaltenden readings zueinander geordnet werden, was eine Hilfe zur Überwindung von Sequenzlücken zwischen Contigs ist. Gegebenenfalls können Contigs dann semi-manuell mit Hilfe der Funktion Join Contigs miteinander verbundenwerden.

\subsection{ARB}

Mit Hilfe des Programmes ARB können phylogenetische Beziehungen von 16S rRNA-Gene erstellt werden. Zunächst kann in einem Editierungs-Feld ein Alignment aller 16S rRNA Gensequenzen einer Datenbank erstellt werden. Anschließend können die Daten in phylogenetische Stammbäume über verschiedene Methoden integriert werden. Eine ausführliche Beschreibung des Programmes ARB kann unter www.arb-home.de abgerufen werden.

\subsection{DOTUR}

Mit Hilfe des Programmes DOTUR (Schloss und Handelsman, 2005) lassen sich 16S rRNA Gensequenzen eines Habitats in sogenannte OTUs umrechnen. Ein OTU entspricht dabei allen 16S rRNA Gensequenzen, welche sich untereinander nicht mehr als 3\% unterscheiden. Eine ausführliche Beschreibung kann unter www.plantpath.wisc.edu/fac/joh/dotur.html abgerufen werden.

\subsection{Untersuchung von 16S rRNA-Gensequenzen auf die Existenz chimärer Sequenzen}

Die Sequenzen der 16S rRNA-Gene wurden mit den Programmen "CHIMERA_CHECK Version 2.7“ des „Ribosomal Database Project“ (RDP; 
(Larsen et al., 1993) unter der Internetadresse http://rdp.cme.msu.edu/cgis/chimera.cgi und dem Programm „Bellerophon chimera detectionprogramm“ unter der Internetadresse http://foo.math.uq.au/ huber/bellerophon.pl auf das Vorhandensein von Chimeren überprüft. Das Programm „CHIMERA_CHECK version 2.7“ überprüft, ob es einen möglichen Schnittpunkt in der zu untersuchenden Sequenz gibt, der die Sequenz in zwei Teile teilt, die jeweils zu einer anderen Sequenz aus der RDP-Datenbank die größte Übereinstimmung haben. Dabei macht das Programm „CHIMERA_CHECK version 2.7“ keine definitive Aussage darüber, ob eine Sequenz ein Chimer ist, so dass bei jeder Sequenz im Einzelnen auf das Vorhandensein von Artefakten entschieden werden muss. Das Programm „Bellerophon chimera detection programm“ berechnet dagegen zwei mögliche Stammbäume mit dem Anfang und dem Ende aller Sequenzen. Ergeben sich dabei unterschiedliche Verzweigungen, ist dies ein Anzeichen dafür, dass es sich bei den entsprechenden Sequenzen um Chimere handelt. 


\section{Experimente und Ergebnisse}

1. Teil 1: Identifizierung und Charakterisierung von neuen (hemi-) cellulolytischen Enzymen aus einer metagenomischen Fosmid-DNAGenbank aus Umweltproben des Avachinky Kraters

Die metagenomische "large insert" Fosmid DNA Genbank aus einer Umweltprobe des Avachinsky Kraters (Kamchatka, Sibirien) wurde von Jörg Schuldes (Institut für Mikrobiologie und Genetik, Abteilung für Angewandte und Genomische Mikrobiologie, Universität Göttingen) nach der Methode II.5.11.1 generiert und für das Screening nach Cellulasen und Hemicellulasen zur Verfügung gestellt. Die Ausgangsprobe wurde aus dem Boden der Umgebung des Avachinsky Kraters (pH 9-9,3) entnommen, hatte eine schlammige Konsistenz und war natürlich auf $67^{\circ} \mathrm{C}$ erhitzt.

Die Genbank enthielt 5200 E. coli Fosmid-Klone mit einer durchschnittlichen Insertgröße von $35 \mathrm{kbp}$. Die Gesamtinsertgröße betrug $182 \mathrm{Mbp}$.

Die metagenomischen E. coli Fosmid-Genbankklone wurden mittels den in II.8.1-3. vorgestellten Methoden mit den Substraten Mikrokristalline Cellulose, Haferspelzen-Xylan, Carboxymethylcellulose und 4-Methylumbelliferyl- $\beta$-Dcellobiosid auf (hemi-) cellulolytische Aktivität durchgemustert.

Die E. coli Fosmid Klone wurden auf LB-Substratagarplatten und in 96 well Mikrotiterplatten mit $200 \mu \mathrm{l}$ LB-Medium überstempelt und über Nacht bei $37^{\circ} \mathrm{C}$ angezogen. Im Falle der Substratagarplatten erfolgte eine direkte anschließende Inkubation bei $60^{\circ}$ für 12-36 Stunden. Den E. coli Klonen in flüssigem LB-Medium in Mikrotiterplatten wurde zur Identifizierung von Endo-Glucanase-Aktivität 4-Methylumbelliferyl- $\beta$-D-cellobiosid (4-MUC) in einer Endkonzentration von $0,1 \mathrm{mM}$ hinzugegeben. Anschließend erfolgte ebenfalls eine Inkubation bei $60{ }^{\circ} \mathrm{C}$ für 12-48 Stunden.

Die Detektion von (hemi-)cellulolytischen Aktivitäten erfolgte durch anschließendes Anfärben mit Kongorot oder durch Fluoreszenzmessungen. Bei den Substratagarplatten mit angefärbtem Substrat aus eigener Herstellung konnten aktive $E$. coli Klone direkt durch eine Hofbildung in der Agarplatte identifiziert werden. Beispiele für cellulolytisch bzw. hemicellulolytisch aktive E. coli Klone sind in Abbildung 3 dargestellt. 


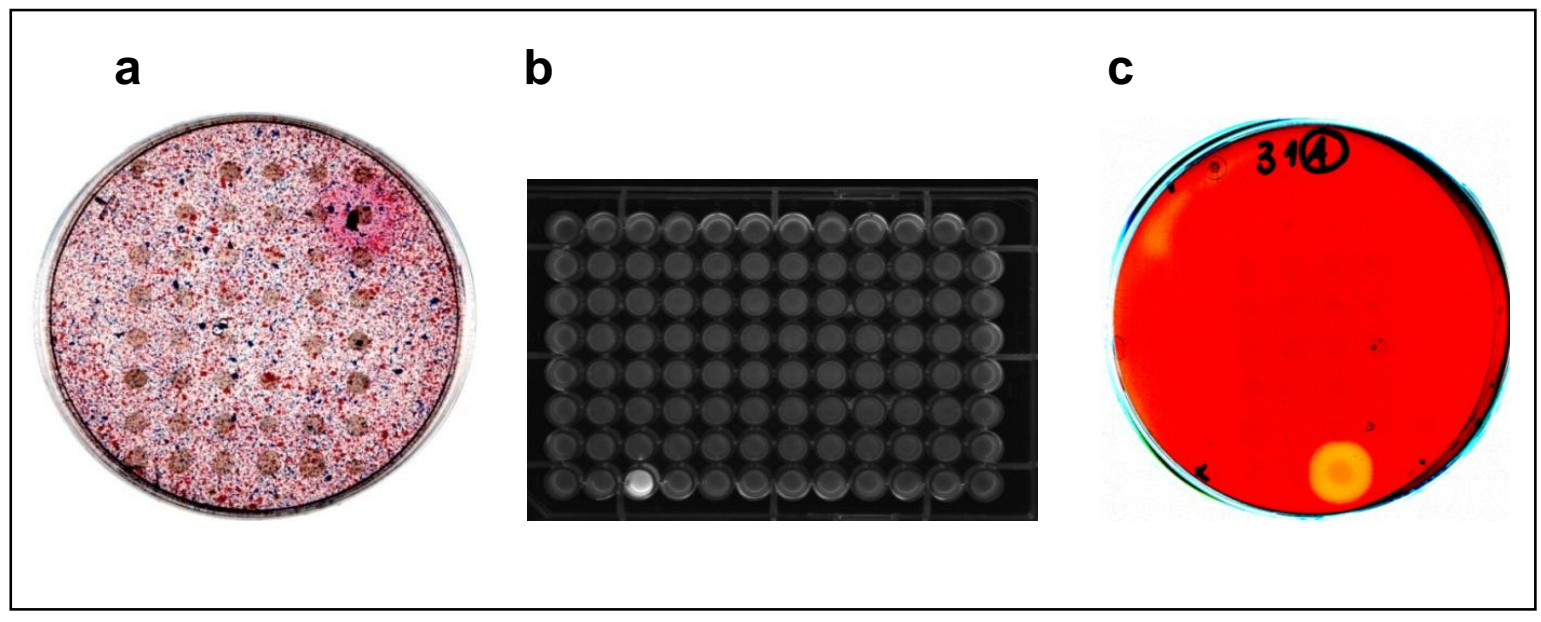

Abbildung 3: Beispiele für die Detektion von (hemi-)cellulolytisch aktiven E. coli-Klonen der Fosmid Genbank a Screening mit den selbst angefärbten Substraten Xylan-Rot und Mikrokristalline Cellulose-Blau (am Beispiel des Fosmid-Klons FosK10B6). Die rote Hofbildung weist auf den Abbau von Xylan hin b Screening in Mikrotiterplatten in flüssigen LB Medium mit dem Substrat 4-MUC am Beispiel des Fosmid Klons FosK48H3 c Screening mit LB-Agarplatten mit eingegossenem Substrat Carboxymethylcellulose $(0,15 \%)$ und anschließender Visualisierung mit Kongorot am Beispiel des E. coli Klons FosK31A4.

\subsection{Ergebnis des Screenings und Sequenzierung der Fosmid-DNA}

Durch die vorgestellten Screeningmethoden konnten elf $E$. coli Klone detektiert werden, die hemicellulolytische beziehungsweise cellulolytische Aktivität zeigten. Die Fosmidbezeichnungen und die entsprechenden Aktivitäten bezüglich der verschiedenen Substrate sind in Tabelle 6 aufgelistet.

Die Fosmide der aktiven Klone wurden aus E. coli isoliert (s. II.5.3.6.) und mittels Restriktionskontrolle bezüglich ihrer Insertgröße analysiert (s. II.5.5.1.). Es zeigte sich, dass sich die resultierenden DNA-Fragmentmuster der Restriktionsreaktionen unterschieden. Einzige Ausnahme stellten die Fosmide FosK23G5 und FosK10B6 dar, bei denen sich das gleiche Muster ergab.

Um die DNA-Sequenz der entsprechenden Fosmide zu ermitteln, wurden diese subkloniert. Hierfür wurden die Fosmide mittels Nebulizer oder Ultraschall geschert (s. II.5.7.). Anschließend wurden durch präparative Agarosegelelektrophorese (s. II.5.5.3.) DNA Fragmente mit den Größen zwischen $1,5 \mathrm{~kb}$ und 2,5 kb isoliert und einer TOPO TA-Klonierung unterzogen (s. II.5.8.6.). 
Nach Transformation der ligierten Plasmide in Escherichia coli TOP10 (s. II.5.9.2.) wurden je subklonierten Fosmid 50 - 200 Klone gepickt, in 96 well Blöcken angezogen (s. II.3.1.). Die Zellpellets wurden zur Plasmidisolierung und Sequenzierung mit Abi.for und Abi.rev Primern (s. Il.1, Tabelle 2) dem Sequenzierungslabor $G_{2} L$ übergeben. Die erhaltenen Sequenzrohdaten wurden anschließend mittels Gap4 assembliert. Wenn nötig wurde ein „Primerwalking“ durchgeführt, um Contigenden verbinden zu können.

Ein weiterer Ansatz zur Ermittlung der für die (hemi-)cellulolytischen Aktivitäten verantwortlichen ORFs auf den Fosmiden war es, die Fosmide subzuklonieren und anschließend die E. coli Plasmidklone auf die entsprechende hydrolytischen Aktivitäten durchzumustern. Hierzu wurden die Fosmide wie im vorigen Textabschnitt subkloniert, jedoch mit der Ausnahme, dass die Größe der fragmentierte Fosmid DNA 4-6 kb betrug. Somit wurde die Wahrscheinlichkeit erhöht, komplette ORFs zu klonieren und somit aktive hydrolytische Enzyme detektieren zu können. Anschließend wurden 200-400 E. coli Subklone bezüglich (hemi-)cellulolytischer Aktivität mittels der in II.8. vorgestellten Methoden durchgemustert. Die Plasmide der als aktiv ermittelten E. coli-Klone wurden isoliert (s. II.5.3.6.) und mittels Abi.for und Abi.rev Primern (s. II.1, Tabelle 2) sequenziert. Um Sequenzabschnitte mit ORFs für Cellulasen oder Hemicellulasen zu detektieren, wurden BLAST Analysen (BLAST P 2.2.1, Altschul et al., 1997, http://www.ncbi.nlm.nih.gov/BLAST/) mit den assemblierten Contigs (s. II.9.1.) durchgeführt.

Die Ergebnisse der Fosmidsequenzierungen und der detektierten möglichen (Hemi-) Cellulase ORFs sind in Tabelle 6 dargestellt.

Mittels Sequenzanalyse der Fosmid-DNA konnte gezeigt werden, dass einige ORFs mehrfach vorhanden waren, obwohl sich die Insert-DNA der Fosmide in der Restriktionsanalyse bis auf eine Ausnahme unterschied. So konnten in den sequenzierten Fosmiden ingesamt sechs unterschiedliche ORFs detektiert werden, dessen Genprodukte mit hoher Wahrscheinlichkeit für die (hemi-) cellulolytische Aktivität der E. coli - Fosmidgenbankklone verantwortlich waren. 
Tabelle 6: Übersicht über detektierte E. coli Fosmidgenbankklone und den auf den entsprechenden Fosmiden identifizierten Glycosidhydrolase-ORFs

\begin{tabular}{|c|c|c|c|}
\hline $\begin{array}{l}\text { E. coli- } \\
\text { Fosmid } \\
\text { Klon }\end{array}$ & $\begin{array}{l}\text { Aktivität } \\
\text { bezüglich } \\
\text { (Substrat) }\end{array}$ & $\begin{array}{c}\text { Sequenzierte } \\
\text { Fosmid-DNA } \\
\text { (kb) }\end{array}$ & $\begin{array}{l}\text { Putativer } \\
\text { (Hemi-)Cellulase ORF } \\
\text { (nächstes Homolog nach } \\
\text { BLAST) }\end{array}$ \\
\hline FosK2H3 & 4-MUC & 44 & $\begin{array}{l}\text { Beta-Glucosidase, } \\
\text { (Clostridium thermocellum) }\end{array}$ \\
\hline FosK31A4 & CMC, 4-MUC & 35,2 & $\begin{array}{l}\text { Glycosyltransferase } \\
\text { Familie } 39 \\
\text { (Roseiflexus sp.) }\end{array}$ \\
\hline FosK48H3 & CMC, 4-MUC & 93,7 & $\begin{array}{l}\text { Glycosidhydrolase } \\
\text { (Thermotoga petrophila) }\end{array}$ \\
\hline FosK40G11 & $\mathrm{CMC}$ & 36,4 & $\begin{array}{l}\text { Cellulase } \\
\text { (Caldicellulosiruptor sp. ) }\end{array}$ \\
\hline $\begin{array}{l}\text { FosK40D12 } \\
\text { FosK29E6 } \\
\text { FosK5F8 }\end{array}$ & $\mathrm{CMC}$ & $\begin{array}{l}59,7 \\
68,3 \\
36,8\end{array}$ & $\begin{array}{l}\text { Cellulase } \\
\text { (Thermus caldophilus) }\end{array}$ \\
\hline $\begin{array}{l}\text { FosK15F7 } \\
\text { FosK23G5 } \\
\text { FosK38H3 } \\
\text { FosK10B6 }\end{array}$ & Xylan (CMC ) & $\begin{array}{l}31,2 \\
56,7 \\
\text { n.d. } \\
32,6\end{array}$ & $\begin{array}{l}\text { Xylanase, GHF10 } \\
\text { (Caldicellulosiruptor } \\
\text { saccharolyticus }\end{array}$ \\
\hline
\end{tabular}

2. Analyse und heterologe Expression von zwei ausgewählten ORFs und Charakterisierung der Genprodukte

\subsection{Analyse des ORFs xyn1015}

Auf den Fosmiden der Genbankklone Fosk15F7, Fosk23G5, Fosk10B6 und FosK38H3 konnte ein ORF identifiziert werden, dessen Genprodukt laut BLAST Analysen 40 \% Identität zu einer Xylanase der Glycosidhydrolasefamilie 10 aus Caldicellulosiruptor saccharolyticus zeigte (Accessionnr. ABP65852). Das Genprodukt wird im Folgenden Xyn1015 benannt. Der ORF xyn1015 konnte am 
Ende eines über $40 \mathrm{kbp}$ großen contigs identifiziert werden. Abbildung 4 zeigt die Sequenzumgebung vor dem ORF xyn1015.

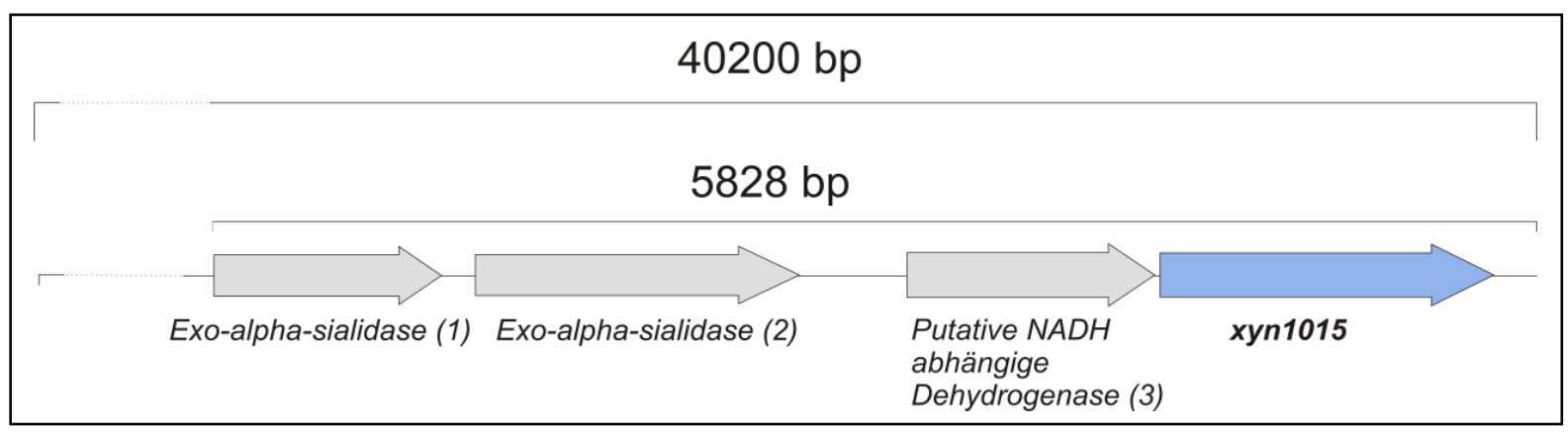

\section{Abbildung 4: Sequenzumgebung des ORFs xyn1015.}

Die Abbildung zeigt einen contig mit einer Länge von 40,2 kb. In der direkten Umgebung des ORFs xyn1015 befinden sich upstream zwei Exo-alpha-Sialidase codierende ORFS und ein ORF für eine putative NADH abhängige Dehydrogenase. ORF 1 zeigt eine 34 \%ige Ähnlichkeit zu einem Exo-alpha-Sialidase Gen von Parabacteroides distasonis ATCC 8503 (Accessionnr. YP_001305150. Das nächste Homolog zu ORF 2 ist ein Exoalpha-Sialidase ORF aus Tannerella forsynthesis mit $38 \%$ er Identität (Accessionnr. AAC50186.1). Der dritte identifizierte ORF zeigt eine 40 \%ige Identität zu einem putativen Dehydrogenase-ORF von Planctomyces maris DSM 8797 (Accessionnr. ZP_01854380)

Die 1332 Basenpaare des ORFs xyn1015 kodieren für ein 444 Aminosäure großes Protein mit einem Molekulargewicht von 51,15 kDA. Der berechnete isoelektrische Punkt liegt bei 8,72. Mittels des Servers SignalP 3.0 konnte mit $97.8 \%$ iger Warscheinlichkeit ein Signalpeptid identifiziert werden. Die Schnittstelle liegt zwischen Aminosäure 20 und 21. Der Abgleich der Aminosäuresequenz mit der Conserved Domain Database (CDD, (Marchler-Bauer et al., 2002) (http://www.ncbi.nlm.nih.gov/Structure/cdd/wrpsb.cgi) ergab für große Teile der Sequenz eine signifikante Ähnlichkeit (e-value $\leq 1 e^{-30}$ ) zur GlycosidhydrolaseFamilie (GHF) 10. 


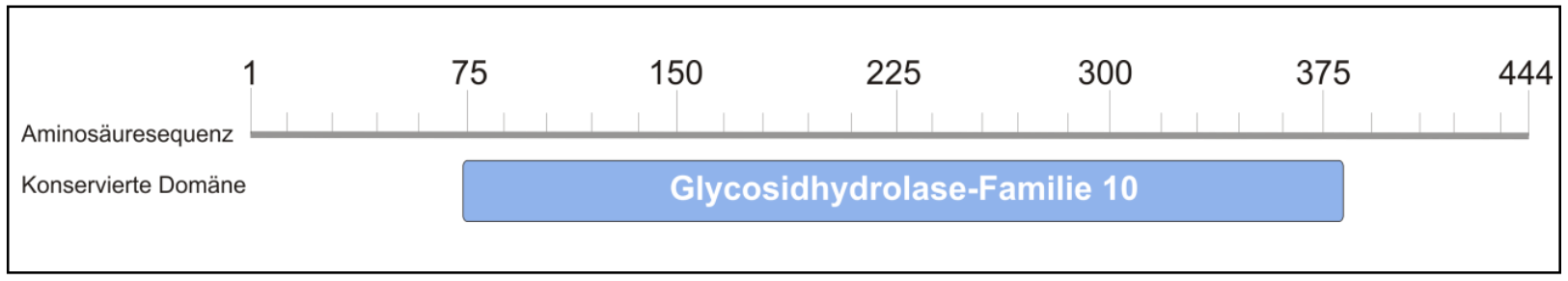

Abb. 5: Alignment der Aminosäuresequenz von Xyn1015 zu konservierten Domänen mit dem Blast conserved domain Suchalgorithmus. Die GHF 10 Domäne ist 316 Aminosäuren lang und wird mit einem e-value von $1 e^{-30}$ der Superfamilie der Glycosidhydrolasefamilie 10 zugeordnet.

\subsubsection{Amplifikation des ORFs xyn1015 und Ligation in den Vektor pET101}

Zur heterologen Expression des ORFs xyn1015 wurde dieser zunächst mittels KOD-Polymerase amplifiziert (s. II.5.6.2.). Für die Amplifikation wurden zwei verschiedene Primerpaare gewählt, die den ORF sowohl mit, als auch ohne die Sequenz für das natürliche Signalpeptid amplifizierten (Abbildung 6). Die entstandenen Amplifikate wurden aufgereinigt (s. II.5.6.4.) und in den Expressionsvektor pET101/D-TOPO kloniert (s. II.5.8.7.). Nach der Transformation von E. coli Top10 Zellen mit den zuvor erstellten Konstrukten, wurden die Zellen auf selektive LB -Agarplatten ausplattiert und über Nacht bei $37^{\circ} \mathrm{C}$ inkubiert. Die richtige Orientierung des DNA-Fragments in dem Vektor wurde mittels Restriktionsverdau überprüft (s. II.5.8.1.). Nach erfolgreicher Klonierung und heterologer Expression sollte das Genprodukt mit einem C-terminalen His6-Tag und einem V5-Epitop versehen sein. Anschließend wurden die erfolgreich erstellten Konstrukte in E. coli BL21 (DE3) transformiert. 


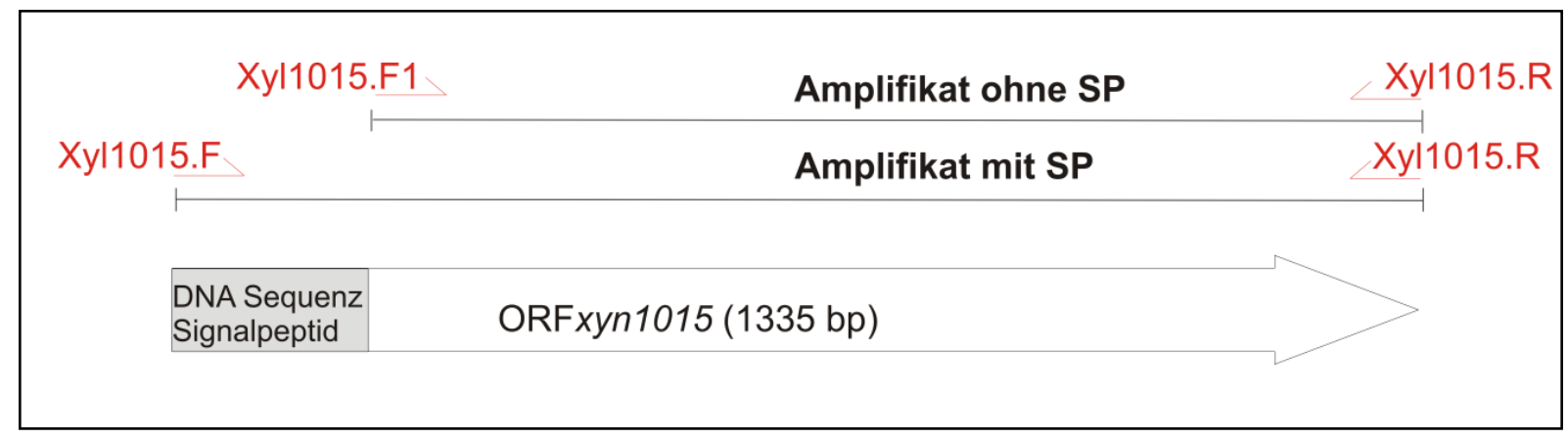

Abbildung 6:Schematische Darstellung der Amplifikation des ORFs xyn1015 mit und ohne DNA-Sequenz für das Signalpeptid (SP). Für die Ligation in den Vektor pET101/D-TOPO wurden mittels den forward-Primern am 5'-Ende die Sequenz „CACC“ angefügt.

\subsubsection{Heterologe Expression des ORFs xyn1015 in E. coli BL21(DE3) und Aufreinigung von Xyn1015}

Zur Expression des rekombinanten Enzyms wurde eine Flüssigkultur mit einem Volumen von $500 \mathrm{ml}$ aus einer Vorkultur von $E$. coli BL21 (DE3)/pET101::Xyn1015+/-SP 2 \%ig beimpft und, wie unter II.3.1. beschrieben, kultiviert. Bei einer $\mathrm{OD}_{600}$ von $\sim 0,6$ wurde die Kultur mit $1 \mathrm{mM}$ IPTG induziert und die Inkubation 6-12 h fortgesetzt. Nach der Resuspension in $30 \mathrm{ml}$ LEW Puffer wurden die Zellen mit der French Pressure Cell aufgeschlossen (s. II.4.3.). Durch eine 20 minütige Hitzefällung bei $90^{\circ} \mathrm{C}$ konnte ein Großteil der mesophilen E. coliProteine entfernt werden. Der hitzedenaturierte Rohextrakt wurde über Nacht gegen LEW Puffer dialysiert. Anschließend erfolgte eine weitere Aufreinigung mittels Nickel-TED-Affinitätschromatographie (s. Il.6.5.3.) über eine Protino ${ }^{\circledR} 2000$ Säule. Die Reinigungsschritte von Xyn1015 ohne Signalpeptidsequenz wurden durch eine SDS-PAGE dokumentiert (s. II.6.2.1.) (Abbildung 7).

Die Abbildung 7 zeigt deutlich die zunehmende Reinheit des Proteins der gesuchten Größe. Um zu bestätigen, dass es sich bei dem aufgereinigten Protein tatsächlich um Xyn1015 handelte, wurde eine Aktivitäts-SDS-PAGE mit den einzelnen Fraktionen der Aufreinigungsschritte mit Birkenholz-Xylan als Substrat durchgeführt (s. II.7.2.). Wie in Abbildung 8 zu erkennen ist zeigt sich ein klarer 
Hof bei etwa 50 kDA. Dieses zeigt, dass es sich bei dem aufgereinigten Protein um Xyn1015 handelte.

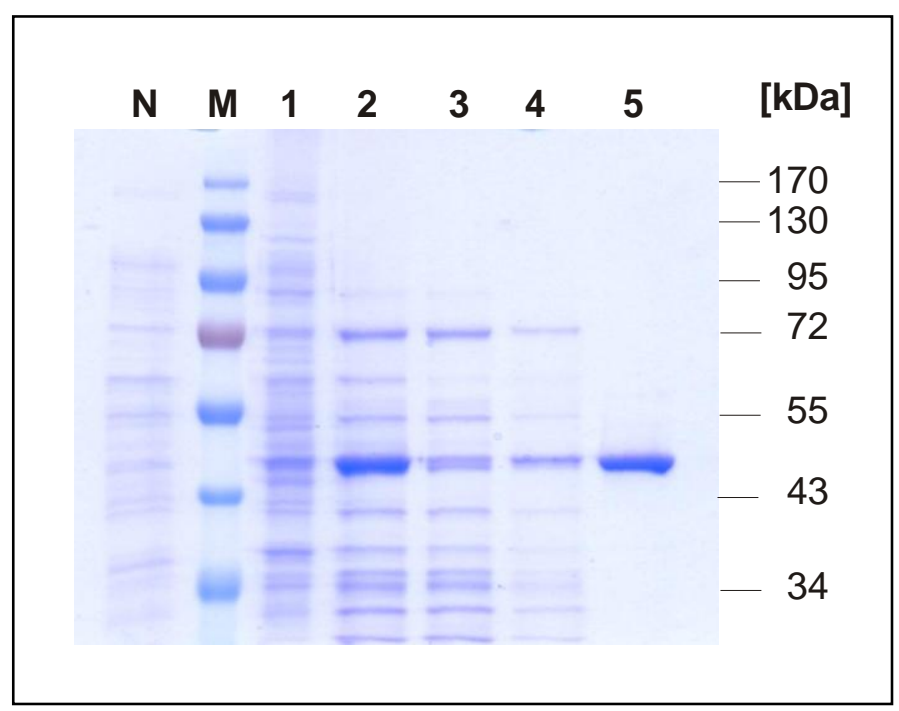

Abbildung 7: SDS-PAGE-Gel der Reinigungsschritte von Xyn1015.

N, Negativkontrolle E. coli BL21(DE3) Rohextrakt (10 $\mu \mathrm{g}$ ), M, Molekularmassenstandard; 1, Rohextrakt von E. coli BL21(DE3)/pET101::Xyn1015 (10 $\mu \mathrm{g})$; 2, Hitzedenaturierter

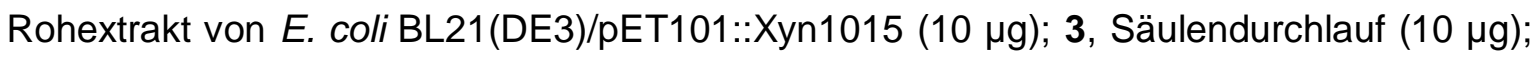
4, Waschschritt (10 $\mu \mathrm{g}) ; \mathbf{5}$, Elutionsfraktion $(5 \mu \mathrm{g})$

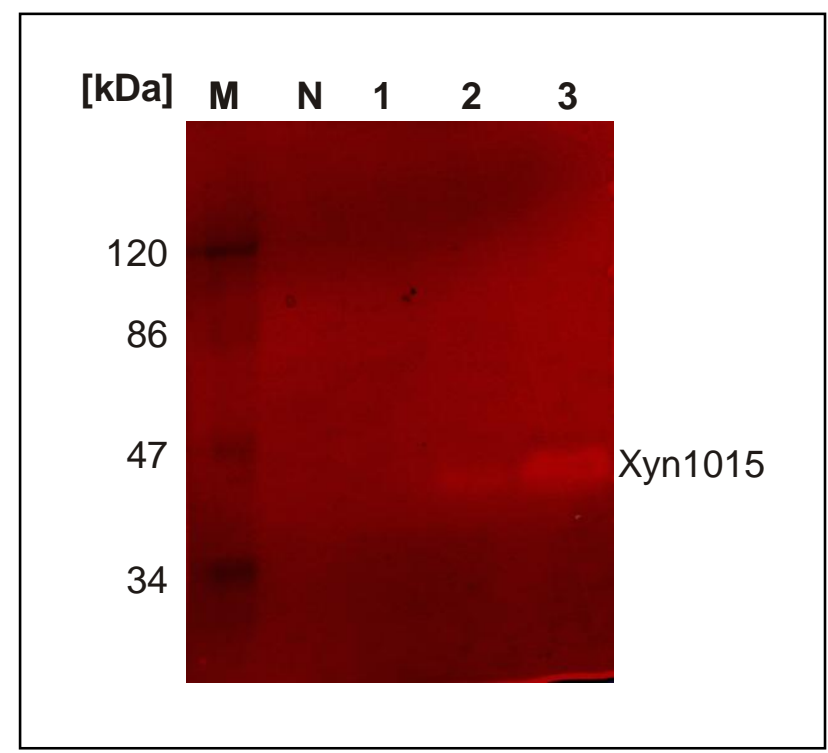

\section{Abbildung 8: Aktivitäts-SDS-PAGE der Aufreinigungsschritte von Xyn1015}

M, Molekularmassenstandard; N, Negativkontrolle $(10 \mu \mathrm{g}$, Hitzegefällter Rohextrakt E. coli BL21(DE3); 1, Rohextrakt E. coli BL21(DE3)/pET101::Xyn1015 (10 $\mu$ g); 2, Hitzegefällter Rohextrakt E. coli BL21(DE3)/pET101::Xyn1015 (10 $\mu \mathrm{g})$; 3, Elutionsfraktion $(5 \mu \mathrm{g})$ 
In Tabelle 7 wird die Bilanz der Aufreinigung dargestellt. Es konnte eine 28 -fache Aufreinigung des rekombinanten Proteins erreicht werden. Die Ausbeute betrug über $85 \%$.

Tabelle 7: Bilanz der Aufreinigung des rekombinanten Xyn1015-Proteins aus E. coli BL21 (DE3)/pET101::Xyn1015. Die Bestimmung der Aktivität erfolgte mittels DNSA-Test mit Haferspelzen-Xylan als Substrat

\begin{tabular}{lccccc}
\hline Fraktion & $\begin{array}{c}\text { Volumen } \\
{[\mathrm{ml}]}\end{array}$ & $\begin{array}{c}\text { Protein } \\
{[\mathrm{mg} / \mathrm{ml}]}\end{array}$ & $\begin{array}{c}\text { Spez. } \\
\text { Aktivität } \\
{[\mathbf{U} / \mathbf{m g}]}\end{array}$ & $\begin{array}{c}\text { Aufreinigung } \\
\text { (Faktor) }\end{array}$ & $\begin{array}{c}\text { Ausbeute } \\
{[\%]}\end{array}$ \\
\hline $\begin{array}{l}\text { Rohextrakt } \\
\text { Hitzegefällter }\end{array}$ & 30 & 6,5 & 1,7 & 1 & 100 \\
$\begin{array}{l}\text { Rohextrakt } \\
\text { Elution }\end{array}$ & 28 & 1,2 & 10,03 & 6 & 97,8 \\
Ni-TED Säule & 18 & 0,3 & 46,8 & 28 & 85,5 \\
\hline
\end{tabular}

\subsection{Biochemische Charakterisierung von Xyn1015}

\subsubsection{Bestimmung des Temperaturspektrums}

Zur Ermittlung der hydrolytischen Aktivität von Xyn1015 in Abhängigkeit von der Temperatur wurde der DNSA-Standardtest (s. II.7.1.) mit Mcllvaine-Puffer (pH8) und aufgereinigtem Enzym $(0,09 \mathrm{mg} / \mathrm{ml})$ mit Haferspelzen-Xylan als Substrat bei Inkubationstemperaturen von $30^{\circ} \mathrm{C}$ bis $115{ }^{\circ} \mathrm{C}$ durchgeführt. Dem Testansatz wurde $\mathrm{NaCl}$ in einer Endkonzentration von $1 \mathrm{M}$ zugeführt, da sich in später beschriebenen Studien zeigte, dass Xyn1015 eine starke Abhängigkeit von $\mathrm{NaCl}$ im Testansatz aufwies. Ab Temperaturen von $90{ }^{\circ} \mathrm{C}$ wurden die Messungen in einem Ölbad durchgeführt, um der Verdunstung im Reaktionsgefäß entgegenzuwirken. 
Die maximale Aktivität wurde bei $95^{\circ} \mathrm{C}$ gemessen. Zwischen $70{ }^{\circ} \mathrm{C}$ und $100{ }^{\circ} \mathrm{C}$ wurden mehr als $50 \%$ der maximalen Aktivität erreicht. Bei einer Erhöhung der Temperatur auf $105{ }^{\circ} \mathrm{C}$ wurde die Aktivität auf $33 \%$ der maximal ermittelten Aktivität gesenkt. Bei Temperaturen zwischen $30{ }^{\circ} \mathrm{C}$ und $60{ }^{\circ} \mathrm{C}$ wurde maximal $30 \%$ der möglichen hydrolytischen Aktivität erreicht.

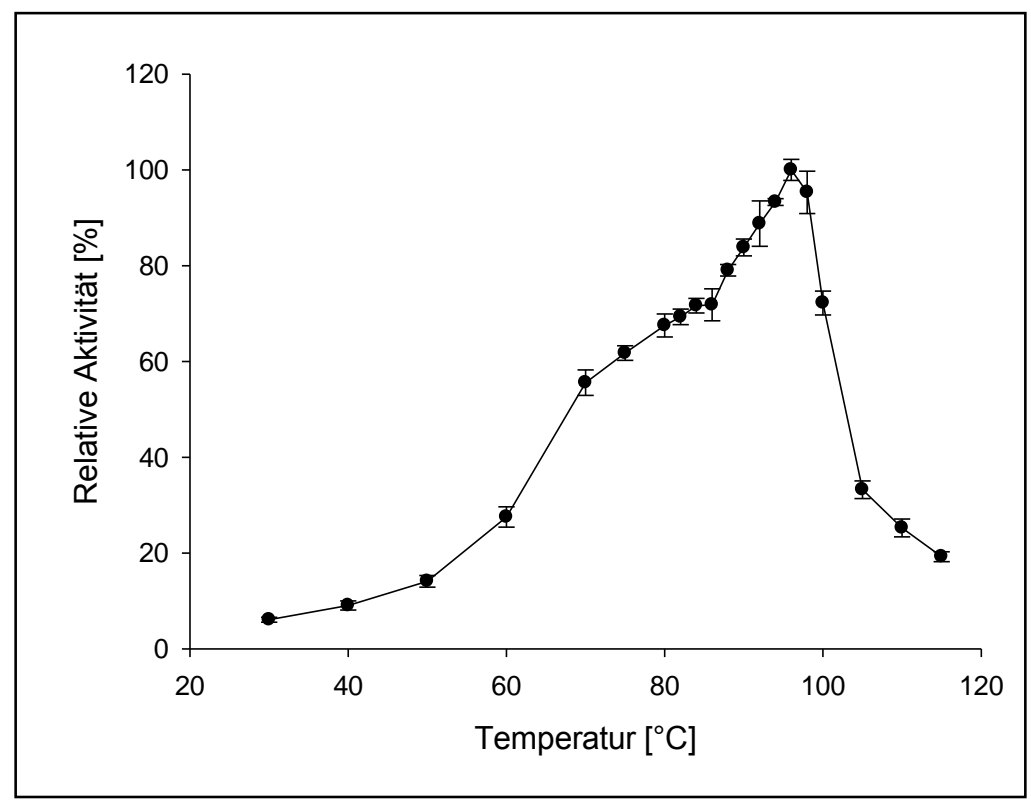

Abbildung 9: Grafische Darstellung der Abhängigkeit der Enzymaktivität von der Temperatur. Die Auftragung erfolgte als relative Aktivität, wobei der höchste Messwert gleich $100 \%$ gesetzt wurde. Jede Bestimmung erfolgte dreifach mit aufgereinigtem Enzym (0,09 mg/ml) und Mcllvaine-Puffer ( $\mathrm{pH} 8)$. Die Inkubationsdauer betrug $15 \mathrm{~min}$.

\subsubsection{Bestimmung der Thermostabilität}

Die thermische Inaktivierung von Xyn1015 ist bei Temperaturen zwischen $65{ }^{\circ} \mathrm{C}$ und $105^{\circ} \mathrm{C}$ im Verlaufe der Zeit ermittelt worden. Das Enzym wurde zunächst in Mcllvaine-Puffer $(\mathrm{pH} \mathrm{7)}$ bei den entsprechenden Temperaturen präinkubiert. Im Laufe der Zeit wurden Aliquots entnommen und bis zum DNSA-Test (II.7.1) bei $4{ }^{\circ} \mathrm{C}$ gelagert. Als Ausgangsprobe diente aufgereinigtes Protein $(0,4 \mathrm{mg} / \mathrm{ml})$.

Wie aus Abbildung 10 hervorgeht wurde die Aktivität von Xyn1015 bei $65^{\circ} \mathrm{C}$ nur sehr gering beeinträchtigt. Selbst nach 50 Stunden Präinkubation wurden noch über $80 \%$ der Ausgangsaktivität erreicht. Bei $75^{\circ} \mathrm{C}$ verblieben nach 50 Stunden 
Inkubation noch über $65 \%$ Restaktivität. Nach einer Vorinkubation von 30 Stunden bei $85{ }^{\circ} \mathrm{C}$ zeigte Xyn1016 noch über $50 \%$ Aktivität, die jedoch noch 48 Stunden auf $17 \%$ der Ausgangsaktivität abfiel. Bei $95{ }^{\circ} \mathrm{C}$ wurde die Aktivität von Xyn1015 nach 24 Stunden um etwa die Hälfte reduziert, nach 48 Stunden war das Enzym komplett inaktiviert. Bei $105^{\circ} \mathrm{C}$ wurde Xyn 1015 nach 5 Minuten inaktiviert.

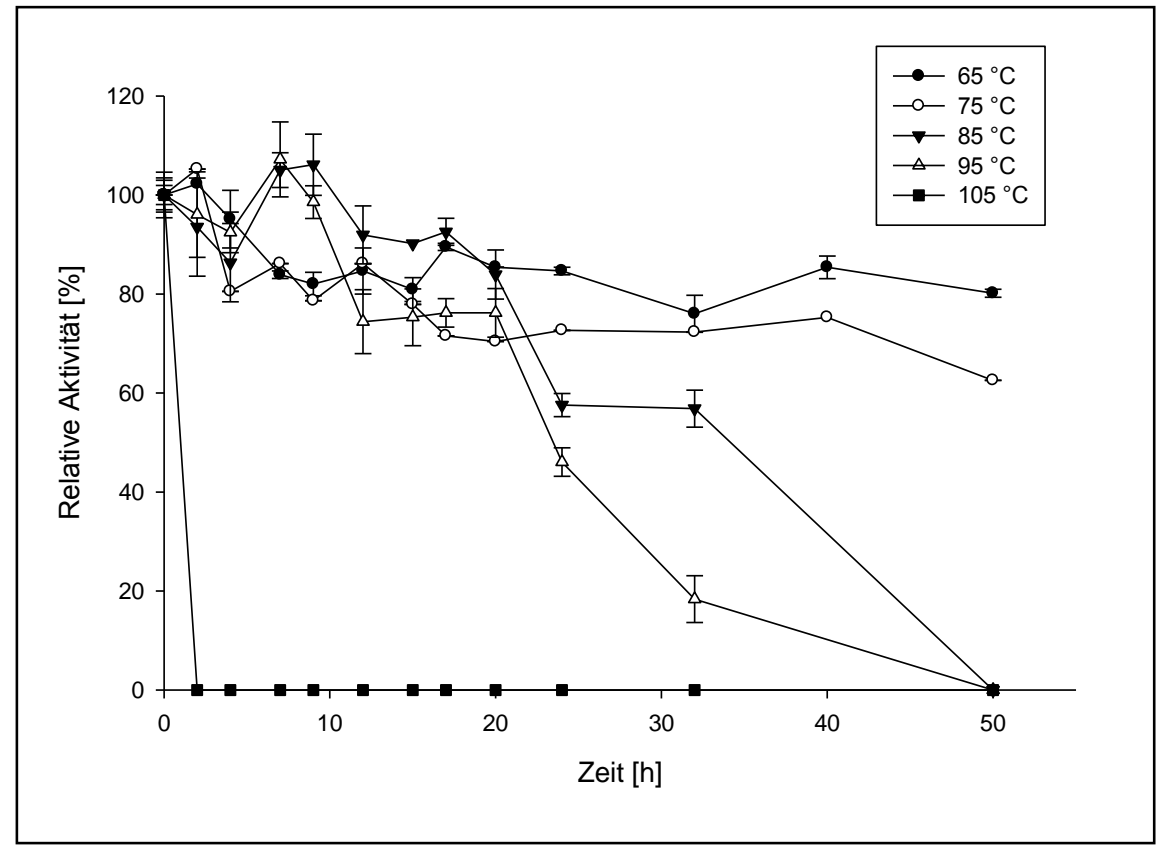

Abbildung 10: Kinetik der Inaktivierung von Xyn1015 bei verschiedenen Temperaturen. Dargestellt ist die relative Aktivität in Bezug auf den jeweils ersten gemessen Wert. Der DNSA-Test erfolgte bei $70{ }^{\circ} \mathrm{C}$ in dreifacher Ausführung mit Birkenholz-Xylan als Substrat mit Mcllvaine-Puffer ( $\mathrm{pH} 7$ ). Die Inkubationsdauer betrug 30 min bei einer Temperatur von $70^{\circ} \mathrm{C}$.

\subsubsection{Bestimmung des $\mathrm{pH}-$ Optimums}

Die Bestimmung der Abhängigkeit der enzymatischen Aktivität von Xyn1015 vom pH-Wert wurde mittels DNSA-Test (s. II.7.1.) mit Haferspelzen-Xylan als Substrat durchgeführt. Hierbei enthielten die Reaktionsansätze im Bereich von pH 4-6 MES-Puffer, im Bereich von 7-8 HEPES-Puffer, für pH 9 CHES-Puffer und für pH 10 wurde CAPS-Puffer eingesetzt. Die Endkonzentrationen der Puffer im Reaktionsansatz betrug jeweils $50 \mathrm{mM}$. Als Enzymprobe wurde aufgereinigtes 
Xyn1015 verwendet $(0,14 \mathrm{mg} / \mathrm{ml})$. Den Ansätzen wurde $\mathrm{NaCl}$ in einer Endkonzentration von $1 \mathrm{M}$ zugesetzt.

Xyn1015 zeigte bei pH 7 die höchste gemessene hydrolytische Aktivität. Bei pH 6 wurde $88 \%$ der maximalen Aktivität erreicht. In den pH-Bereichen zwischen $\mathrm{pH} 4$ und pH 5 bzw. pH 8 und pH 10 konnten höchstens $28 \%$ der maximalen Aktivität gemessen werden (Abbildung 11).

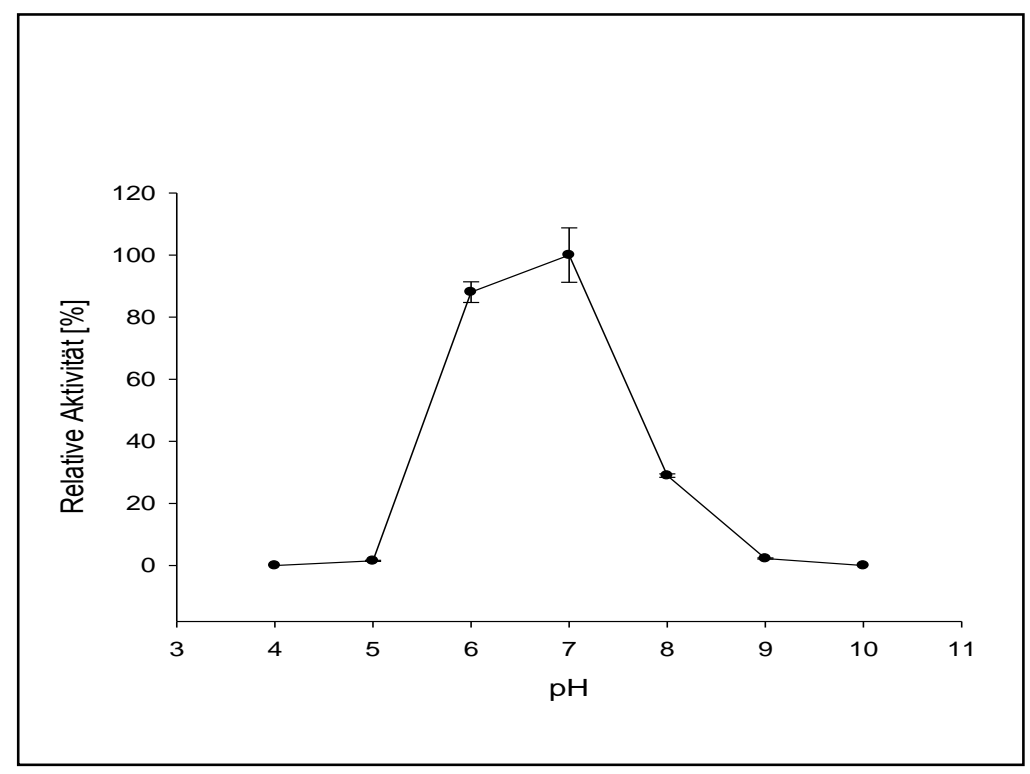

Abbildung 11: Abhängigkeit der Enzymaktivität von Xyn1015 von dem pH - Wert Dargestellt ist die relative Aktivität bezogen auf den maximal erreichten Wert. Die Messung erfolgte in Dreifachbestimmung bei $96{ }^{\circ} \mathrm{C}$ mit aufgereinigtem Enzym $(0,14 \mathrm{mg} / \mathrm{ml})$ und Haferspelzen-Xylan als Substrat. Die Inkubationsdauer betrug $30 \mathrm{~min}$. Die $\mathrm{pH}$-Werte der jeweiligen Puffer wurden bei dieser Temperatur eingestellt.

\subsubsection{Einfluss verschiedener Additive auf die Aktivität}

Der Einfluss ein - oder mehrwertiger Metallionen und anderer Zusätze wie EDTA, SDS und B-Mercaptoethanol auf die Aktivität von Xyn1015 wurden mittels DNSA-Test (s. II.7.1.) mit Birkenholz-Xylan als Substrat bei $80^{\circ} \mathrm{C}$ und McllvainePuffer $(\mathrm{pH} 7)$ getestet. Die Endkonzentrationen der Zusätze betrugen jeweils $1 \mathrm{mM}$ oder $10 \mathrm{mM}$. Für die Bestimmung wurde aufgereinigtes Xyn1015 verwendet $(0,33 \mathrm{mg} / \mathrm{ml})$. Wie in Abbildung $12 \mathrm{zu}$ erkennen ist, wird die Enzymaktivität von Xyn1015 durch einige Zusätze negativ beeinflusst. Bei Zugabe der Metallionen $\mathrm{Cu}^{2+}, \mathrm{Ni}^{+}$, und $\mathrm{Ag}^{+}$wird die hydrolytische Aktivität von Xyn1015 sowohl bei einer 
Konzentration von $1 \mathrm{mM}$ als auch $10 \mathrm{mM}$ fast komplett gehemmt. Auch $\mathrm{Ca}^{2+}$-lonen reduzieren sowohl in einer Konzentration von $1 \mathrm{mM}$ und $10 \mathrm{mM}$ die Aktivität um etwa 70 \%. Bei der Zugabe von Kobalt-Ionen in einer Konzentration von $1 \mathrm{mM}$ verblieb eine Restaktivität von etwa $3 \%$. Bei $10 \mathrm{mM} \mathrm{CoCl}$ im Ansatz konnte hingegen kaum eine Veränderung festgestellt werden. Der Zusatz $\mathrm{FeSO}_{4}$ vermindert die Aktivität in einer Konzentration von $10 \mathrm{mM}$ um etwa $60 \%$ und in einer Konzentration von $1 \mathrm{mM}$ um $30 \%$. Auch zweiwertige Magnesium-lonen hemmen die Aktivität um ca. $25 \%$ in einer Konzentration von 10 mM. Bei einer Konzentration von $1 \mathrm{mM}$ wurde jedoch keine Reduktion der Aktivität verzeichnet. Während Kalium-Ionen keinen Einfluss auf die Aktivität hatten, zeigte sich bei der Zugabe von $\mathrm{NaCl}$ und $\mathrm{LiCl}$ eine leichte Steigerung der Aktivität. Bei einer Konzentration von 10 mM konnte die Aktivität um $15 \%$ beziehungsweise $10 \%$ gesteigert werden.

EDTA verminderte die die Aktivität nur geringfügig (10-16 \%). War jedoch SDS im Reaktionsansatz, wurde das Enzym schon bei der Konzentration von $1 \mathrm{mM}$ komplett inaktiviert. Bei der Zugabe von B-Mercaptoethanol war bei einer Zugabe von $10 \mathrm{mM}$ eine Reduktion um $40 \%$ zu verzeichnen. 


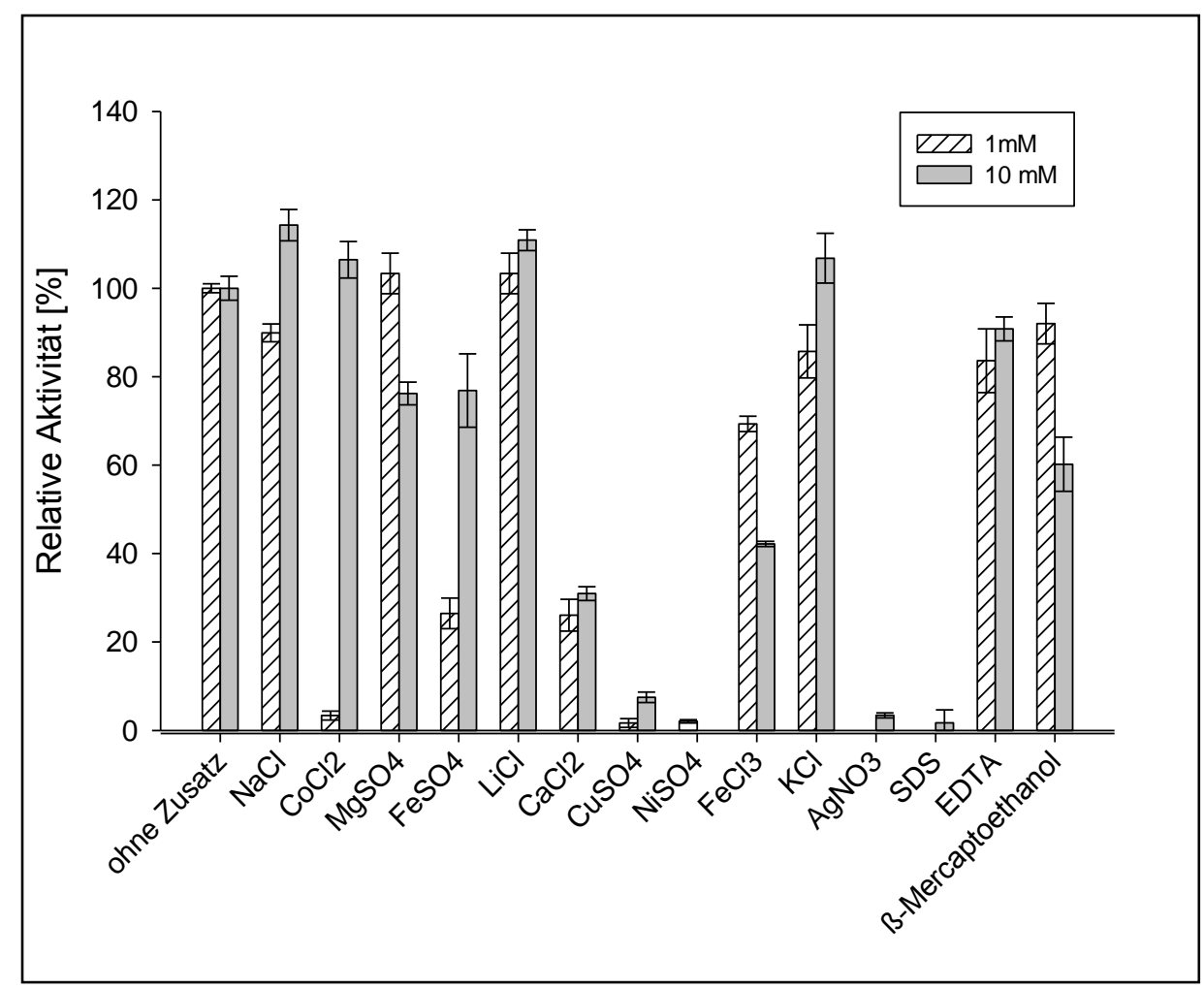

Abbildung 12: Auswirkungen von verschiedenen ein- und zweiwertigen Metallionen, SDS, EDTA und B-Mercaptoethanol auf die Aktivität von Xyn1015. Dargestellt ist die relative Aktivität im Bezug auf den Testansatz ohne Zusatz. Die Messung der Aktivität erfolgte dreifach im Standard-DNSA-Test bei $80^{\circ} \mathrm{C}$ für $35 \mathrm{~min}$ in Mcllvaine-Puffer $(\mathrm{pH} 7)$ mit aufgereinigtem Enzym $(0,33 \mathrm{mg} / \mathrm{ml})$ und Birkenholzxylan als Substrat.

\subsubsection{Einfluss von $\mathrm{NaCl}$ auf die Aktivität}

Da sich bei der Untersuchung des Einflusses verschiedener Zusätze auf Xyn1015 (siehe III.2.2.4.) herausstellte, dass $\mathrm{NaCl}$ die hydrolytische Aktivität des Enzyms steigerte, wurde ein erneuter Versuch mit unterschiedlichen $\mathrm{NaCl}$-Konzentrationen im Testansatz durchgeführt. Zur Bestimmung wurde ein Standard-DNSA-Test mit aufgereinigtem Enzym $(0,08 \mathrm{mg} / \mathrm{ml})$ und mit Mcllvaine-Puffer pH 8 durchgeführt. Die Reaktionsansätze enthielten hier $0 \mathrm{M}$ bis $2 \mathrm{M} \mathrm{NaCl}$, als Substrat diente Haferspelzen-Xylan.

Es zeigte sich, dass Xyn1015 eine starke Abhängigkeit von $\mathrm{NaCl}$ zeigt. So konnte bei einer Konzentration von $1 \mathrm{M} \mathrm{NaCl}$ die höchste hydrolytische Aktivität von Xyn1015 erreicht werden. Es zeigte sich eine fast 26-fache Steigerung der Aktivität im Vergleich zu den Testansätzen ohne $\mathrm{NaCl}$. Ab einer Konzentration von 
$1,25 \mathrm{M} \mathrm{NaCl}$ sank die Aktivität wieder, verblieb jedoch bis zu einer Konzentration von $2 \mathrm{M}$ bei mindestens bei einer 21-fachen Steigerung der Aktivität im Vergleich zur Probe ohne $\mathrm{NaCl}$-Zugabe.

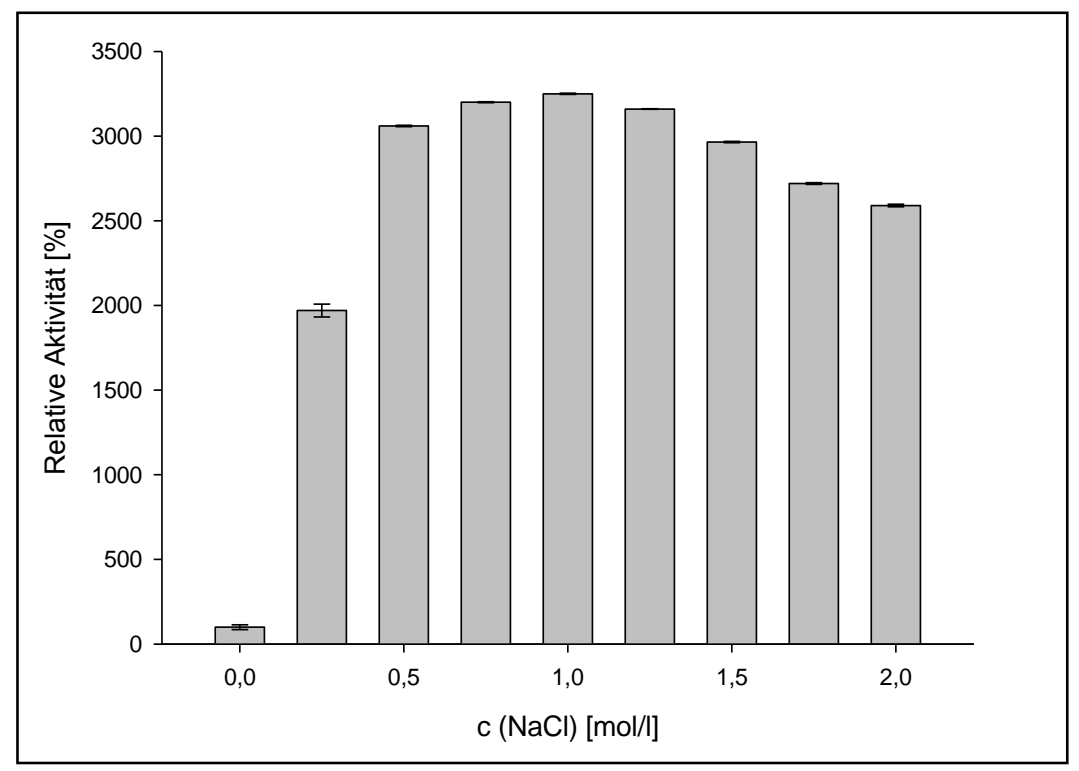

Abbildung 13: Abhängigkeit der Aktivität von Xyn1015 von der NaCl- Konzentration. Dargestellt ist die gemessene Aktivität in Relation zu der Messung des Testansatzes ohne Zugabe von $\mathrm{NaCl}$. Für den dreifachen Standard-DNSA-Test wurde aufgereinigtes Enzym $(0,08 \mathrm{mg} / \mathrm{ml})$ in Mcllvaine-Puffer $(\mathrm{pH} 8)$ und Haferspelzen-Xylan verwendet. Die Testdauer betrug $30 \mathrm{~min}$.

\subsubsection{Substratspektrum}

Zur Untersuchung des Substratspektrums von Xyn1015 wurden sowohl B-1,4 verknüpfte Glucane, als auch B-1,4 verknüpfte Xylane verwendet. Die Durchführung erfolgte mittels Standard-DNSA Test (s. Il.7.1.) mit aufgereinigtem Xyn1015 (0,33 mg/ml) mit Mcllvaine-Puffer ( $\mathrm{pH} 7)$ und den entsprechenden unterschiedlichen Substraten.

Wie in Abbildung 14 zu erkennen ist, zeigt sich vorwiegend Aktivität im Bezug auf Polysaccharide, die ein B-1,4 verknüpftes Xylose-Rückgrat besitzen. B-1,4 verknüpfte Glucane wurden nicht oder nur sehr geringfügig abgebaut. Die höchste messbare Aktivität zeigte Xyn1015 mit Buchenholz-Xylan als Substrat. Als gut zugängliche Substrate erwiesen sich ebenfalls Birkenholz-Xylan und Lärchenholz- 
Xylan, während Haferspelzen-Xylan sich im Rahmen dieser Untersuchung als das am wenigsten zugängliche Xylan-Substrat herausstellte.

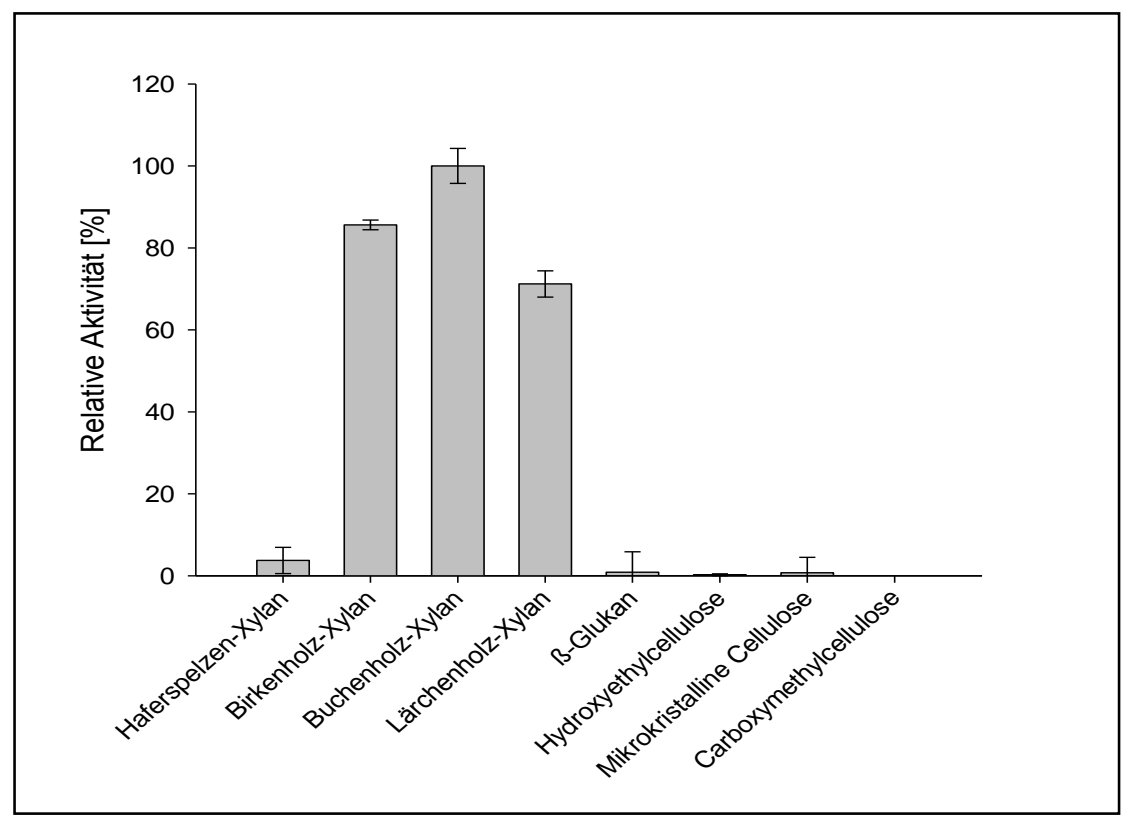

Abbildung 14: Substratspektrums von Xyn1015. Hierbei wurden alle Werte in Relation zu dem maximal erreichten Wert gesetzt. Für den Standard-DNSA-Test wurde aufgereinigtes Enzym verwendet $(0,33 \mathrm{mg} / \mathrm{ml})$. Der Standard-DNSA-Test erfolgte dreifach bei $95^{\circ} \mathrm{C}$ für 10 min mit Mcllvaine-Puffer $(\mathrm{pH} 7)$.

\subsubsection{Qualitative Untersuchung der Produktbildung und des Spaltungsmechanismus von Xyn1015 beim Abbau von Buchenholz- Xylan}

Eine Untersuchung der Spaltungsprodukte mittels Dünnschichtchromatographie sollte klären, ob es sich bei Xyn1015 um eine Endo- oder Exo-Xylanase handelt. Endoxylanasen schneiden nach dem Zufallsprinzip innerhalb der Xylosekette und setzen so Oligosaccharide unterschiedlicher Länge frei. Die Exoxylanasen hingegen wirken an den Enden der Cellulosekette und spalten Xylose oder Xylobiose ab.

Zur Untersuchung der Produktbildung des enzymatischen Abbaus von Buchenholz-Xylan durch Xyn1015 im zeitlichen Verlauf wurde das Substrat mit Xyn1015 $(0,33 \mathrm{mg} / \mathrm{ml})$ bei $95{ }^{\circ} \mathrm{C}$ inkubiert. Der Testansatz entsprach dem 
Testansatz für DNSA-Tests (s. II.7.1.) mit Mcllvaine-Puffer (pH 7). Nach unterschiedlichen Zeitabständen wurden Proben entnommen und mittels Dünnschichtchromatographie aufgetrennt (s. II.7.3).

Der zeitliche Abbau von Buchenholz-Xylan (Abbildung 15) zeigte, dass in der Anfangsphase nur Produkte mit höheren Polymerisationsgraden entstanden. Dieses weist auf einen Endo-Mechanismus des Enzyms hin. Nach etwa 20 Minuten Inkubation wurden erstmals Produkte mit niedrigerem Polymerisationsgrad sichtbar. Nach 24 Stunden Inkubation konnte das Produkt Xylose detektiert werden, während die zuvor entstandenen Produkte mit hohem Polymerisierungsgrad komplett hydrolysiert wurden. Als Hauptprodukte des 24stündigen Abbaus von Buchenholz-Xylan durch Xyn1015 entstanden Produkte mit dem Polymerisationsgrad 2 und 6 , es konnten insgesamt jedoch alle Polymerisationsgrade von 1 bis 7 detektiert werden.

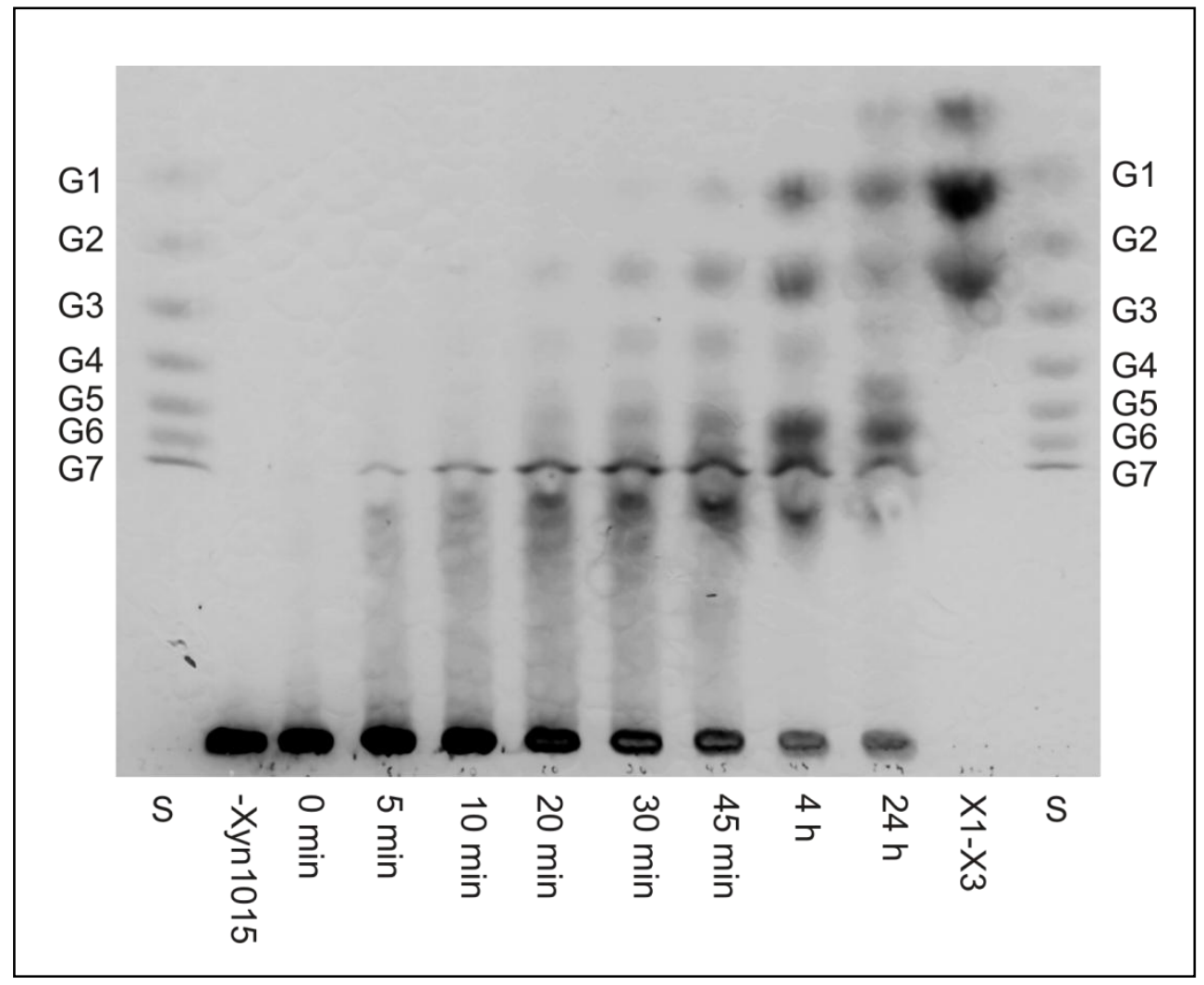

Abbildung 15: Dünnschichtchromatographische Analyse des zeitlichen Abbaus von Buchenholz-Xylan durch Xyn1015. Unter den Spuren ist der Zeitpunkt der Probenentnahme vermerkt. S, Maltooligosaccharid-Standard (G1-G7); -Xyn1015: Testansatz ohne Enzym (Inkubation 24 h); X1-X3, Xylose-Standard (Xylose-Xylotriose). 


\subsubsection{Enzymkinetik}

Für die Feststellung der kinetischen Daten $\mathrm{V}_{\max }$ und $\mathrm{K}_{\mathrm{m}}$ wurden Aktivitätstests im DNSA-Standardtest mit Substratkonzentrationen zwischen $0,05 \mathrm{mg} / \mathrm{ml}$ und 0,8 $\mathrm{mg} / \mathrm{ml}$ gemessen.

Die Messungen erfolgten unter den zuvor ermittelten optimalen Bedingungen für die Aktivität von Xyn1015. Die Testansätze enthielten $1 \mathrm{M} \mathrm{NaCl}$ und wurden bei einer Temperatur von $95{ }^{\circ} \mathrm{C}$ und einem pH-Wert von $\mathrm{pH} 7$ durchgeführt. Als Substrat wurde Buchenholz-Xylan gewählt, da es zuvor als bestes zugängliches Substrat ermittelt wurde. Aus der Steigung der Geraden in der doppeltreziproken Auftragung nach Lineweaver-Burk ließen sich für Xyn1015 ein $\mathrm{K}_{\mathrm{m}}$-Wert von 2 $\mathrm{mg} / \mathrm{ml}$ und ein $V_{\max }-W e r t$ von $400 \mathrm{U} / \mathrm{mg}$ berechnen.

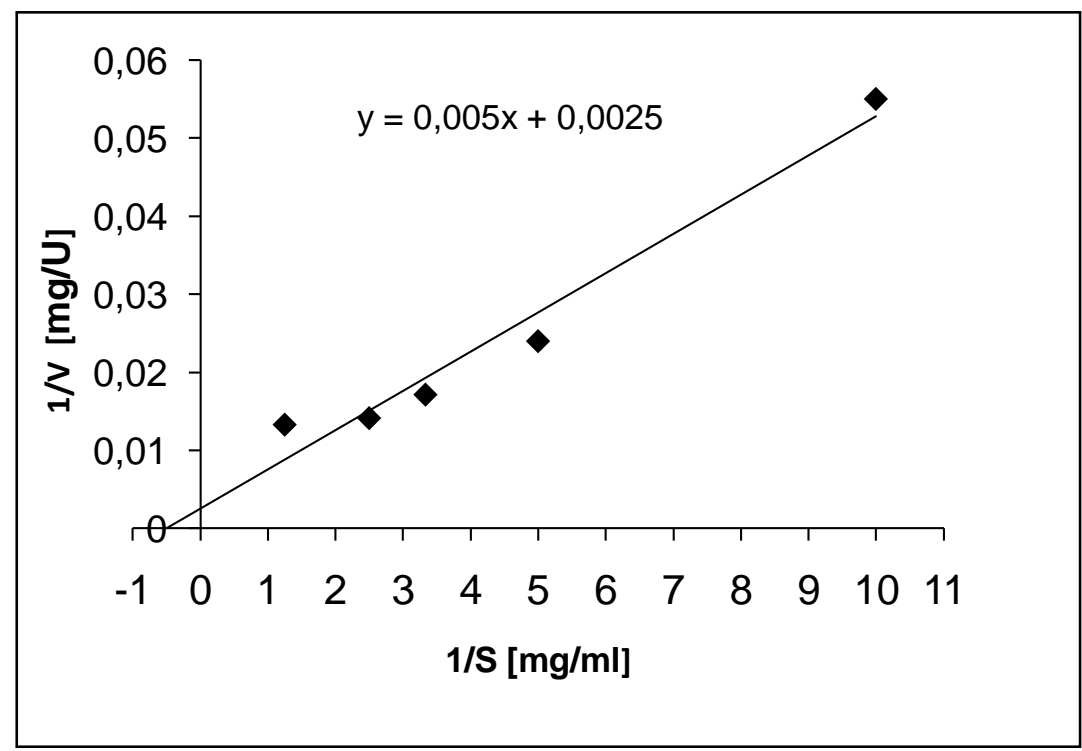

Abbildung 16: Auftragung der Aktivität von Xyn1015 nach Lineweaver-Burk

\subsection{Analyse des ORFs bga48}

Auf dem Fosmid des Genbankklons FosK48H3 konnte ein ORF identifiziert werden, dessen Genprodukt laut BLAST Ergebnis 38 \% Ähnlichkeit zu einer nicht näher charakterisierten Glycosidhydrolase aus Thermotoga petrophila RKU-1 zeigte (Acession no. YP_001244493). Das Genprodukt wird im Folgenden als Bga48, der entsprechende ORF als bga48 bezeichnet. Der ORF bga48 konnte auf einem $33 \mathrm{kbp}$ großen contig identifiziert werden. Die Sequenzumgebung des 
ORFs bga48 auf dem sequenzierten Fosmid-Insert zeigte vor allem Gene, die für putative Transposasen codieren. In Abbildung 17 ist die Sequenzumgebung von bga48 schematisch dargestellt.

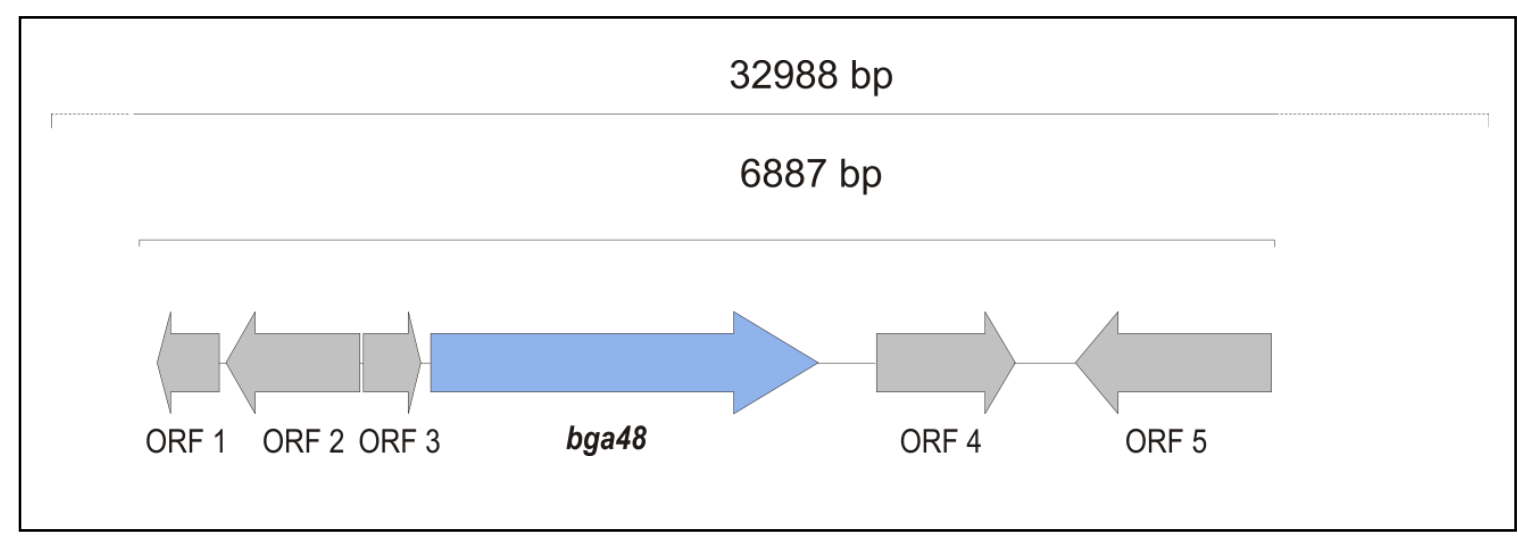

\section{Abbildung 17: Schematische Darstellung der Sequenzumgebung von bga48.}

In der Sequenzumgebung konnten vor allem ORFs, die für putative Transposaseelemente kodieren detektiert werden. In Tabelle 8 werden die Annotationen der einzelnen ORFs dargestellt

Tabelle 8: Annotation der identifizierten ORFs in der Sequenzumgebung von bga38

\begin{tabular}{|c|c|c|c|c|c|}
\hline ORF & $\begin{array}{l}\text { Größe des } \\
\text { Proteins } \\
\text { (AS) }\end{array}$ & $\begin{array}{l}\text { Funktion, nächster Treffer } \\
\text { (laut NCBI BLAST) }\end{array}$ & $\begin{array}{l}\text { Accession- } \\
\text { nummer }\end{array}$ & $\begin{array}{c}\text { Identität } \\
(\%)\end{array}$ & $\begin{array}{c}e- \\
\text { Value }\end{array}$ \\
\hline 1 & 139 & $\begin{array}{l}\text { Transposase, Familie IS4 } \\
\text { (Chloroflexus aurantiacus) }\end{array}$ & YP_001635541 & 56 & $6 e^{-35}$ \\
\hline 2 & 315 & $\begin{array}{l}\text { Transposase, Familie IS4 } \\
\text { (Acaryochloris marina } \\
\text { MBIC11017) }\end{array}$ & YP_001514717 & 36 & $2 e^{-33}$ \\
\hline 3 & 135 & $\begin{array}{l}\text { SSU ribosomales Protein } \\
\text { S20P (Veillonella parvula } \\
\text { DSM 2008) }\end{array}$ & ZP_03854875 & 39 & $4 e^{-10}$ \\
\hline 4 & 322 & $\begin{array}{l}\text { Transposase (Nostoc sp. } \\
\text { PCC } 7120 \text { ) }\end{array}$ & NP_484293 & 46 & $7 e^{-75}$ \\
\hline 5 & 457 & $\begin{array}{l}\text { Konserviertes Protein (TPR } \\
\text { repeat enthaltend;Funktion } \\
\text { unbekannt) } \\
\text { (Candidatus Solibacter } \\
\text { usitatus) }\end{array}$ & YP_822927 & 36 & $1 e^{-76}$ \\
\hline
\end{tabular}


Der ORF bga48 umfasst 2712 Basenpaare. Das entsprechende Genprodukt enthält 903 Aminosäuren mit einer kalkulierten molekularen Masse von 102,7 kDA und einem isolelektrischen Punkt von pH 8.8. Mittels SignalP (http://www.cbs.dtu.dk/services/SignalP/) konnte mit 99,8\%iger Wahrscheinlichkeit ein Signalpeptid ermittelt werden. Die Spaltung wurde zwischen Aminosäure 20 und 21 vorausgesagt. Ein Datenbankabgleich der Aminosäuresequenz mit der Conserved Domain Database (CDD, (Marchler-Bauer et al., 2002) (http://www.ncbi.nlm.nih.gov/Structure/cdd/wrpsb.cgi) ergab für zwei Bereiche geringe Ähnlichkeiten $\mathrm{zu}$ einer konservierten Domäne der Glycosidhydrolase-Familie 42 und zu einer Bindedomäne für Kohlenhydrate (Carbohydrate binding module, CBM) (Abbildung 18). In die GlycosidhydrolaseFamilie 42 werden vorwiegend B-Galaktosidasen eingegliedert (EC 3.2.1.23), die endständige B-D-Galaktosereste in B-D-Galaktosiden hydrolysieren. Der C-terminale Teil der Aminosäuresequenz weist einen großen Bereich ohne Ähnlichkeiten zu konservierten Domänen auf.

\begin{tabular}{|c|c|c|c|c|c|c|c|}
\hline 1 & 125 & 250 & 375 & 500 & 625 & 750 & 875903 \\
\hline \multicolumn{8}{|l|}{ Aminosäuresequenz } \\
\hline Konservierte Domäne & & & CBM4_9 & & & & \\
\hline
\end{tabular}

Abbildung 18: Alignment der Aminosäuresequenz von Bga48 zu konservierten Domänen mit dem Blast conserved domain Suchalgorithmus. Die GHF 42 Domäne ist 188 Aminosäuren lang und stimmt mit einem e-value von $4 e^{-6}$ zu 49,9 \% mit Bga48 überein. Die CBM-Domäne (148 AS) stimmt mit einem e-value von $1 \mathrm{e}^{-12} \mathrm{zu} 70,9 \%$ überein.

\subsubsection{Klonierungen des ORFs bga48 und heterologe Expression in E. coli BL21(DE3)}

Die Analyse der Aminosäuresequenz von Bga48 ergab, dass das Protein geringe Sequenzähnlichkeiten zu verschiedenen konservierte Domäne enthielt, aber auch über einen großen Teil im C-terminalen Bereich keine Ähnlichkeiten zu konservierten Domänen aufwies. Um zu überprüfen, welche möglichen Funktionen diese Bereiche von Bga48 erfüllen, wurde nicht nur der komplette ORF bga48 mit Hilfe der Pfu-Polymerase amplifiziert (s. II.5.6.1.), sondern es erfolgte auch eine 
Amplifikation von Teilabschnitten. In Abbildung 19 wird die Klonierung der einzelnen Bereiche des ORFs schematisch dargestellt. Insgesamt wurden sechs unterschiedliche Konstrukte erstellt, die sowohl den kompletten ORF mit und ohne Sequenz für das Signalpeptid abdecken, als auch die Domänen einzeln oder in Kombination repräsentieren. Die benötigten Oligonukleotide wurden so erstellt, dass sie, wenn nötig, ein neues Start-Codon generierten. Zudem wurde am 34Ende des Amplifikats grundsätzlich ein Stopcodon eingefügt. Die Ligation der entsprechenden PCR-Produkte erfolgte anschließend in den Vektor pET101/DTOPO (s. II.5.8.7.). Die erstellten Vektor-Konstrukte wurden anschließend in $E$. coli Top10 transformiert (s. II.5.9.2.) und auf LB-Ampicillin-Agarplatten ausplattiert. Die richtige Orientierung der DNA-Fragmente in dem Vektor wurde mittels Restriktionsverdau (s. II.5.8.1.2.) überprüft. Zusätzlich erfolgte eine Ansequenzierung des Inserts durch das „Göttingen Genomic Laboratory“. Für die Expression wurden die Vektoren in den E. coli -Stamm BL21(DE3) transformiert und als Stämme E. coli BL21/pET101::48H1 bis 48H6 bezeichnet.

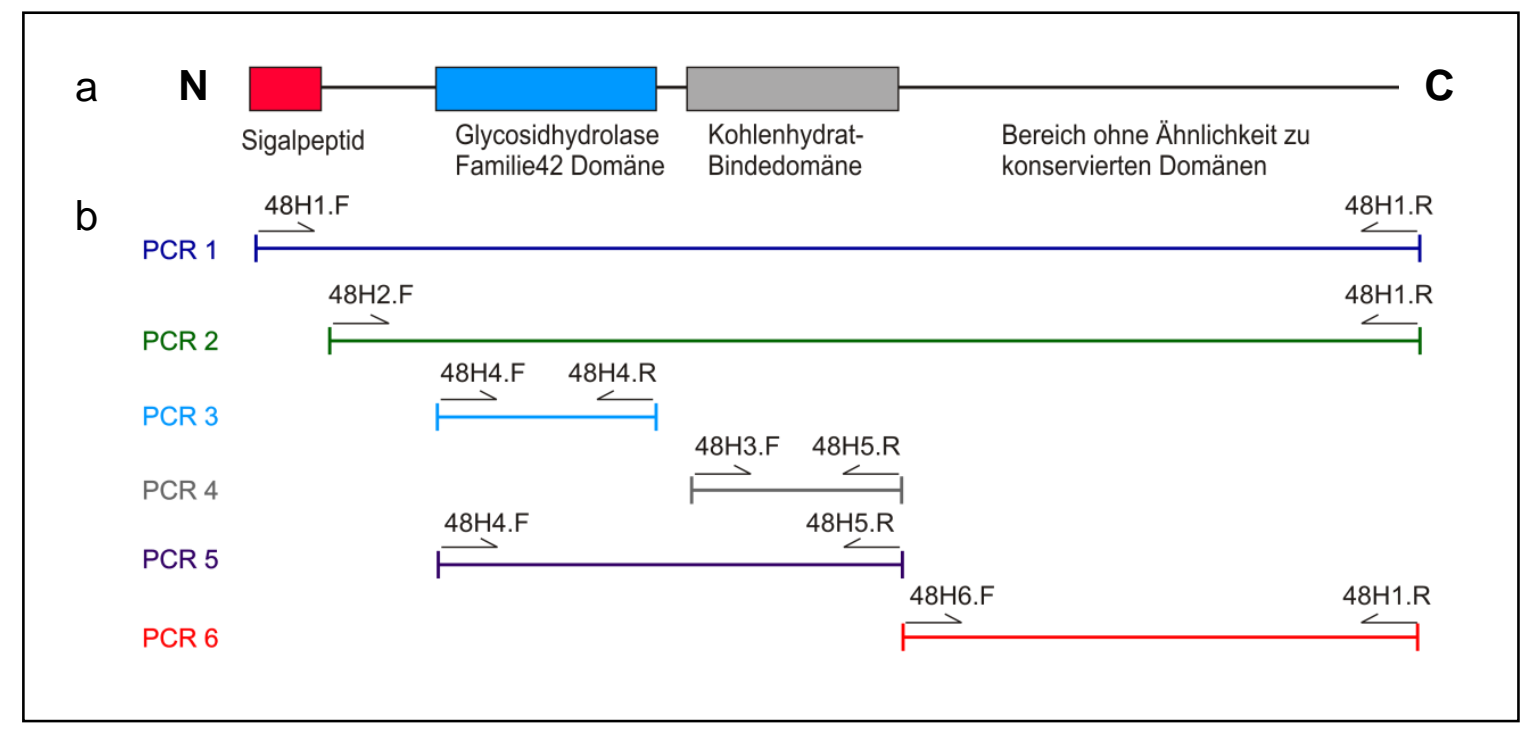

Abbildung 19: Amplifikationen der unterschiedlichen Regionen des ORFs bga48

a, Schematische Darstellung von Bga48 mit den unterschiedlichen Domänen/Bereichen b, PCR Produkte, welche unterschiedliche Bereiche von Bga48 repräsentieren, PCR 1, kompletter ORF mit Sequenz für das Signalpeptid; PCR 2, ORF ohne Sequenz für das Signalpeptid; PCR 3, Amplifikation der Sequenz für die Domäne der GHF42; PCR 4, Amplifikation der Sequenz für die Kohlenhydrat-Bindedomäne, PCR 5, Amplifikation der Domäne GHF42 und der Kohlenhydrat-Bindedomäne in Kombination; PCR 6 , Amplifikation der Sequenz für den C-terminalen, unklassifizierten Bereich. Die Pfeile signalisieren die verschiedenen verwendeten PCR-Primer (s. II.1. Tabelle 2) 
Zur Expression der rekombinanten Proteine wurden Flüssigkulturen mit einem Volumen von $30 \mathrm{ml}$ aus einer Vorkultur von E. coli BL21 (DE3)/pET10148::H1-H6 $2 \%$ ig beimpft und, wie unter II.3.1. beschrieben, kultiviert. Bei einer OD600 von $\sim 0,6$ wurde die Kultur mit 1 mM IPTG induziert und die Inkubation sechs Stunden fortgesetzt. Anschließend wurden die Zellen abzentrifugiert und zweimal mit TrisPuffer $(50 \mathrm{mM}, \mathrm{pH} 8)$ gewaschen. Die Zellen wurden in $1 \mathrm{ml}$ Tris-Puffer $(50 \mathrm{mM}$, $\mathrm{pH}$ 8) aufgenommen und mittels Ultraschall aufgeschlossen (s. II.4.2.). Zelltrümmer wurden durch einen erneuten Zentrifugationsschritt entfernt. Vom entstandenen Zellinhalt der unterschiedlichen E. coli Stämme wurde ein Aliquot entnommen und bei $65^{\circ} \mathrm{C}$ für 20 Minuten hitzegefällt. Anschließend wurde eine SDS-PAGE von den Rohextrakten und den hitzefällten Rohextrakten erstellt. Es konnte auf diesen keine Überexpression der unterschiedlichen Genprodukte mittels SDS-PAGE festgestellt werden. Um eventuelle hydrolytische Aktivitäten der verschiedenen rekombinanten Proteine zu ermitteln, wurde mit den hergestellten Rohextrakten ein DNSA-Test (s. II.7.1.) mit Carboxymethylcellulose und B-Glucan (Gerste) als Substrat durchgeführt. Mit Carboxymethylcellulose als Substrat konnten nur leichte Aktivitäten der Rohextrakte der Stämme E. coli BL21::pET10148H1 (0,9 U/mg) und E. coli BL21::pET10148H2 $(1,1 \mathrm{U} / \mathrm{mg})$ detektiert werden. Bei Verwendung des Substrates B-Glucan konnte ebenfalls nur bei den Stämmen E. coli BL21::pET10148H1 (10,3 U/mg) und E. coli BL21::pET10148H2 $(12,7 \mathrm{U} / \mathrm{mg})$ eine hydrolytische Aktivität festgestellt werden. Die Expressionsprodukte der beiden aktiven E. coli-Stämme repräsentieren das komplette Protein bzw. das komplette Protein ohne Signalpeptid. Daher konnte davon ausgegangen werden, dass die hydrolytische Aktivität von Bga48 nur ermöglicht wurde, wenn alle Bereiche der Aminosäuresequenz, inklusive des unklassifizierten C-terminalen Bereiches, vorhanden waren. Die vollständige Charakterisierung der unterschiedlichen rekombinanten Genprodukte steht noch aus.

\subsubsection{Heterologe Expression und Aufreinigung von Bga48}

Für die biochemische Charakterisierung von Bga48 wurde das Protein ohne Signalpeptid gewählt. Das Protein sollte hier im Cytosol der Zellen verbleiben 
Zur Expression des rekombinanten Enzyms wurde eine Flüssigkultur mit einem Volumen von $500 \mathrm{ml}$ aus einer Vorkultur von E. coli BL21 pET101::48H2 2 \%ig beimpft und, wie unter II.3.1. beschrieben, kultiviert. Bei einer $O_{600}$ von $\sim 0,6$ wurde die Kultur mit $1 \mathrm{mM}$ IPTG induziert und die Inkubation 6-12 h fortgesetzt. Die Zellen wurden mittels Zentrifugation geerntet, zweimal mit $50 \mathrm{mM}$ Phosphatpuffer (pH7) gewaschen und in $30 \mathrm{ml} 50 \mathrm{mM}$ Phosphatpuffer $(\mathrm{pH} 7)$ aufgenommen. Nun wurden die Zellen mit einer French press aufgeschlossen (II.4.3.) und die Zelltrümmer für 20 Minuten bei 13000 Upm abzentrifugiert. Es folgte eine Denaturierung hitzelabiler E. coli Proteine bei $85^{\circ} \mathrm{C}$ für 20 Minuten und ein anschließendes Entfernen der denaturierten Proteine durch einen Zentrifugationsschritt (20 min,13000 rpm). Der so erstellte hitzegefällte Rohextrakt wurde über Nacht gegen $50 \mathrm{mM}$ Phosphatpuffer dialysiert (s. II.6.3.). Die weitere Aufreinigung erfolgte mittels Kationenaustausch-Chromatographie unter der Verwendung einer SOURCE15S-Säule (s. II.6.5.2.).

Die Fraktionen wurden auf ihren Proteingehalt und ihre hydrolytische Aktivität mit B-Glucan als Substrat (DNSA-Test, II.7.1.) überprüft. Nach gelelektrophoretischer Kontrolle der Reinheit des Proteins wurden die Fraktionen 12-14 vereinigt.

Abbildung 20 zeigt das Chromatogramm des Säulenlaufs, die Parameter des Säulenlaufs sind in Tabelle 9 aufgeführt.

Tabelle 9: Parameter des FPLC-Laufs zur Aufreinigung von Bga48

\begin{tabular}{ll}
\hline Parameter & \\
\hline Medium & Source15S \\
Säule & Tricorn-Säule (4.6/100 PE ) \\
Säulenvolumen & $1,7 \mathrm{ml}$ \\
Probe & $\sim 16 \mathrm{mg}$ \\
Puffer A & $50 \mathrm{mM}$ Phosphatpuffer $(\mathrm{pH} 7)$ \\
Puffer B & $50 \mathrm{mM}$ Phosphatpuffer $(\mathrm{pH} 7)+1 \mathrm{M} \mathrm{NaCl}$ \\
Flußrate & $2 \mathrm{ml} / \mathrm{min}$ \\
Fraktionsgröße & $1 \mathrm{ml}$ \\
Equilibrierung & $3 \mathrm{SV}$ Puffer B/ 10 SV Puffer A \\
Gradient & $0-100 \%$ Puffer B (20 SV) \\
\hline
\end{tabular}




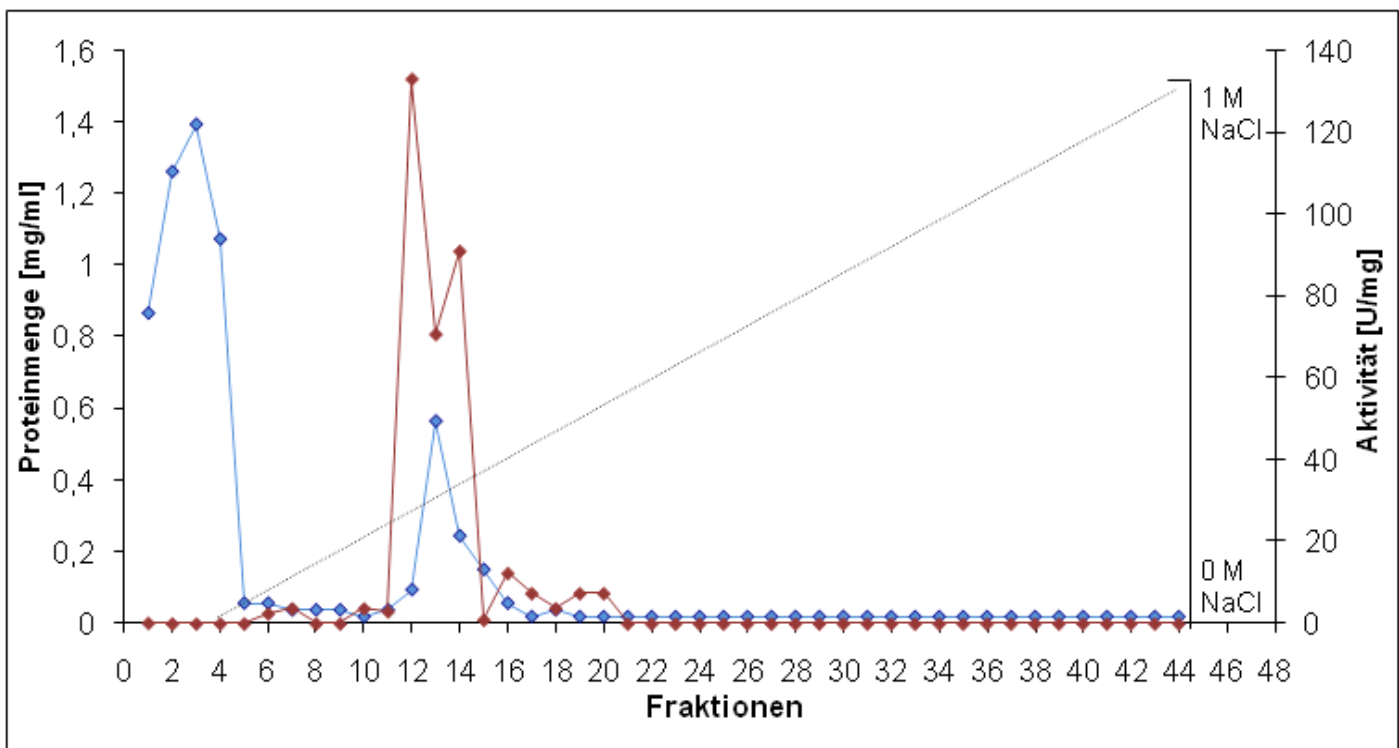

Abbildung 20: Chromatogramm des Source 15S-Säulenlaufs zur Aufreinigung des rekombinanten Bga48 - Proteins. Die blaue Linie stellt die Proteinkonzentration in den Fraktionen dar, die rote Linie die Aktivität und die gepunktete Linie die $\mathrm{NaCl}$-Konzentration des Gradienten. Es wurden die Fraktionen 12-14 vereinigt. Die hydrolytische Aktivität in den einzelnen Fraktionen wurde mit dem Substrat B-Glucan (Gerste) im Standard-DNSATest bestimmt $\left(80^{\circ} \mathrm{C}, 10 \mathrm{~min}\right)$.

In Abbildung 21 sind die einzelnen Schritte der Aufreinigung von Bga48 in einer SDS-PAGE dargestellt. Wie auf dem Gelbild zu erkennen ist, war die Aufreinigung erfolgreich. Es ist nur noch eine Bande bei etwa $100 \mathrm{kDa}$ zu erkennen, was der berechneten molekularen Masse von Bga48 entspricht. Um zu überprüfen, ob es sich bei dem aufgereinigten Protein tatsächlich um Bga48 handelt, wurde eine Aktivitäts-SDS-PAGE erstellt (Abbildung 22). Das Substrat B-Glucan wurde hier $0,15 \%$ ig in das Gel mit eingegossen (s. 11.7.2.). Da sich aufgrund des eingegossenen Substrates das Laufverhalten von Bga48 verändern könnte, wurde ein weiteres SDS-Gel als Referenz angefertigt, welches ebenfalls eingegossenes Substrat enthielt, aber keiner weiteren Aktivitätsfärbung unterzogen wurde. Wie bei Abbildung $22 \mathrm{zu}$ erkennen ist, zeigte sich eine Aufklärung im Kongorotgefärbten SDS-Gel an der gleichen Stelle, an der bei dem nicht angefärbten Gel das aufgereinigte Protein Bga48 zu erkennen ist. Daher konnte davon ausgegangen werden, dass es sich bei dem aufgereinigten Protein tatsächlich um Bga48 handelte. 


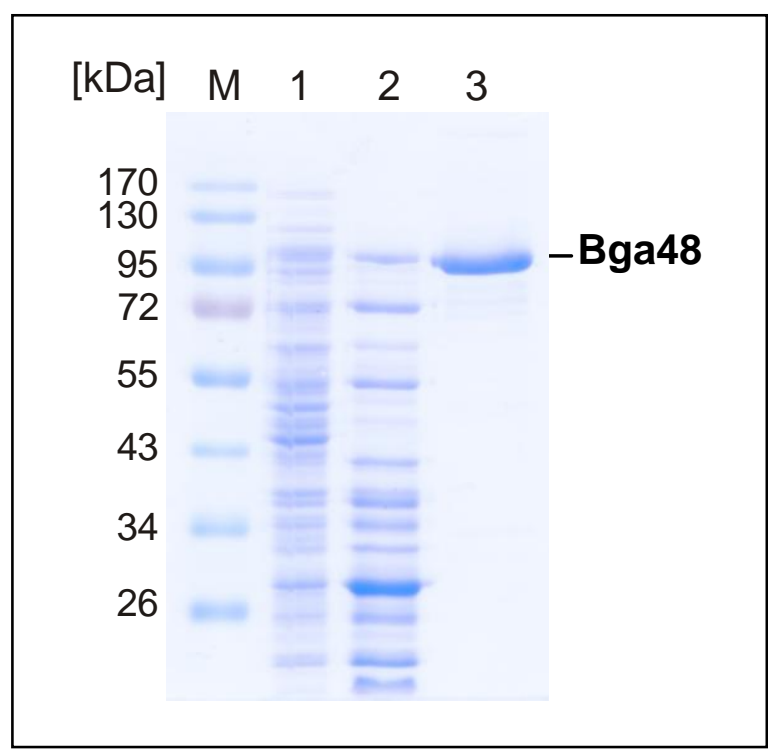

Abbildung 21: 10 \%iges SDS-PAGE-Gel der Aufreinigungsschritte von Bga48

M, Molekularmassenstandard; Spur 1, Rohextrakt von E. coli BL21/pET101::48H2 $(10 \mu \mathrm{g})$; Spur 2, hitzedenaturierter Rohextrakt von E. coli Bl21/pET101::48H2 (10 $\mu \mathrm{g})$; Spur 3, Pool Source15S (5 $\mu \mathrm{g})$.

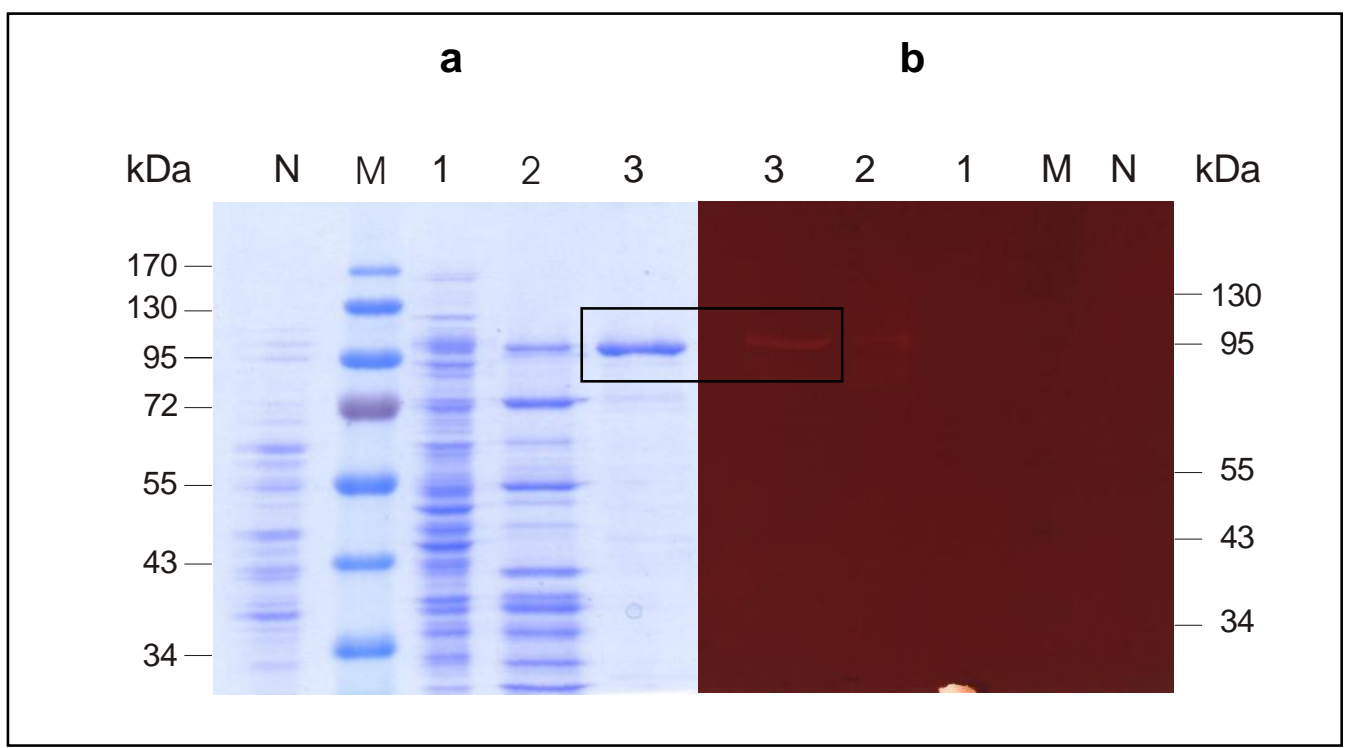

\section{Abbildung 22: 10\% SDS-PAGE Gele mit eingegossenem B-Glucan (0,15\%)}

a: ohne Aktivitätsfärbung $\mathbf{b}$ : mit Aktivitätsfärbung

N, Negativkontrolle (Rohextrakt E. coli BL21 DE3, $10 \mu \mathrm{g}$ ); M, Molekularmassen-Standard; Spur 1, Rohextrakt von E. coli BL21/pET101::48H2 (10 $\mu \mathrm{g})$; Spur 2, hitzedenaturierter

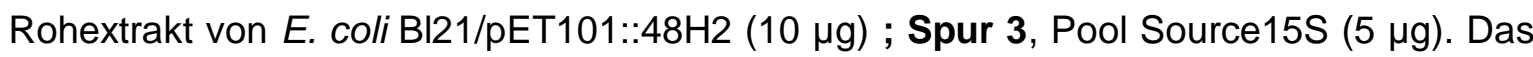
aufreinigte Protein Bga48 und die entsprechende Aufklärung im Kongorot-gefärbten Gel sind mit einem Kasten umrandet. 
In Tabelle 10 ist die Bilanz der Aufreinigung tabellarisch dargestellt. Es konnte eine 68 fache Aufreinigung des Enzyms erreicht werden. Die Ausbeute fiel mit $19,8 \%$ gering aus.

Tabelle 10: Bilanz der Aufreinigung des rekombinanten Bga48-Proteins aus E. coli BL21 (DE3)/pET101::48H2. Die Bestimmung der Aktivität erfolgte mittels DNSA-Test mit B-Glucan als Substrat.

\begin{tabular}{lccccc}
\hline Fraktion & $\begin{array}{l}\text { Volumen } \\
{[\mathrm{ml}]}\end{array}$ & $\begin{array}{l}\text { Protein } \\
{[\mathrm{mg} / \mathrm{ml}]}\end{array}$ & $\begin{array}{l}\text { Spez. } \\
\text { Aktivität } \\
{[\mathrm{U} / \mathrm{mg}]}\end{array}$ & $\begin{array}{l}\text { Aufreinigung } \\
\text { Faktor }\end{array}$ & $\begin{array}{l}\text { Ausbeute } \\
{[\%]}\end{array}$ \\
\hline Rohextrakt & 25 & 8,5 & 2 & 1 & 100 \\
$\begin{array}{l}\text { Hitzegefällter } \\
\begin{array}{l}\text { Rohextrakt } \\
\text { Elution }\end{array}\end{array}$ & 22 & 0,9 & 8,3 & 4,2 & 41 \\
\begin{tabular}{l} 
Source 15S \\
\hline
\end{tabular} & 3 & 0,2 & 132,9 & 67,5 & 19,8 \\
\hline
\end{tabular}

\subsection{Biochemische Charakterisierung von Bga48}

\subsubsection{Bestimmung des Temperaturspektrums}

Zur Ermittlung der hydrolytischen Aktivität von Bga48 in Abhängigkeit von der Temperatur wurde der DNSA-Standardtest (s. II.7.1.) mit B-Glucan (Gerste) als Substrat bei Inkubationstemperaturen von $40^{\circ} \mathrm{C}$ bis $105{ }^{\circ} \mathrm{C}$ durchgeführt. $\mathrm{Ab}$ Temperaturen von $90^{\circ} \mathrm{C}$ wurden die Messungen in einem Ölbad durchgeführt, um der Verdunstung im Reaktionsgefäß entgegenzuwirken. Wie in Abbildung $23 \mathrm{zu}$ erkennen ist, zeigte Bga48 die höchste hydrolytische Aktivität bei $90^{\circ} \mathrm{C}$, zwischen $60{ }^{\circ} \mathrm{C}$ und $100{ }^{\circ} \mathrm{C}$ wurde mindestens $60 \%$ der maximalen Aktivität erreicht. Über 
einer Temperatur von $100{ }^{\circ} \mathrm{C}$ sank die Aktivität von Bga48 stark, so konnte bei $105^{\circ} \mathrm{C}$ nur noch $26 \%$ der maximalen Aktivität gemessen werden.

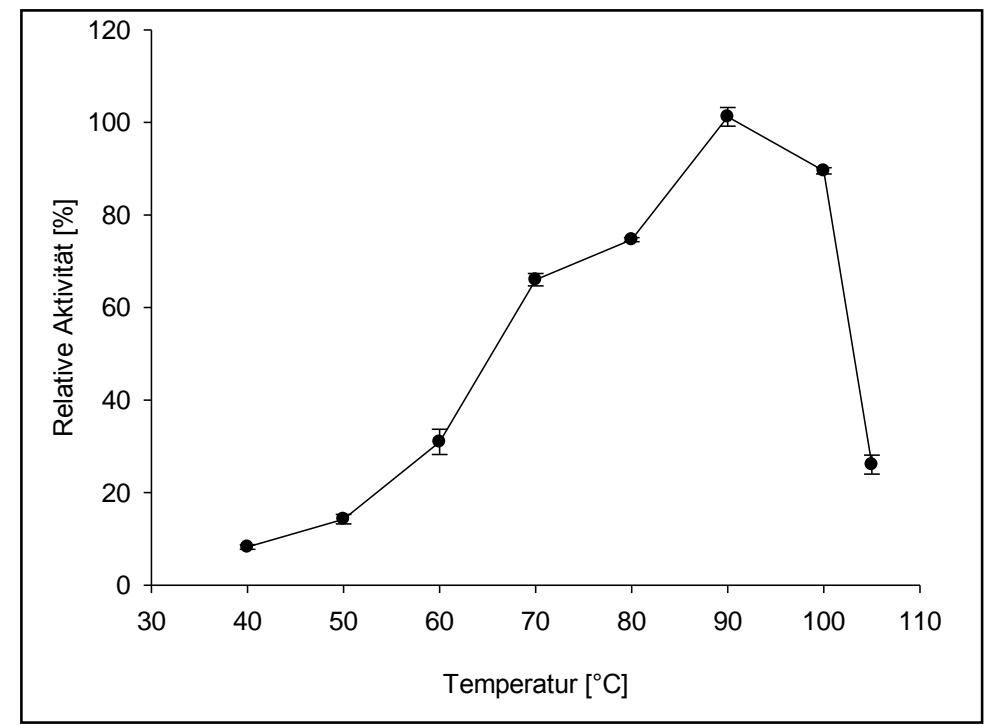

Abbildung 23: Grafische Darstellung der Abhängigkeit der Enzymaktivität von Bga48 von der Temperatur. Die Auftragung erfolgte als relative Aktivität, wobei der höchste Messwert gleich $100 \%$ gesetzt wurde. Jede Bestimmung erfolgte dreifach. Für den Standard-DNSA-Test wurde aufgereinigtes Enzym $(0,06 \mathrm{mg} / \mathrm{ml})$ und Mcllvaine-Puffer (pH 6) verwendet. Die Inkubationsdauer betrug 25 Minuten.

\subsubsection{Bestimmung des $\mathrm{pH}-$ Optimums}

Die Abhängigkeit der enzymatischen Aktivität von Bga48 vom pH-Wert wurde mittels DNSA-Test (s. II.7.1.) mit B-Glucan (Gerste) als Substrat durchgeführt. Hierbei enthielten die Reaktionsansätze im Bereich von pH 4-6 Mcllvaine-Puffer, im Bereich von 6 - 8 Phosphatpuffer und für den pH-Bereich 8-9 wurde Tris-Puffer eingesetzt. Der Test erfolgte bei $80^{\circ} \mathrm{C}$, die $\mathrm{pH}$-Werte aller Puffer wurden bei dieser Temperatur eingestellt. Die Endkonzentration der Puffer im Reaktionsansatz betrug jeweils $50 \mathrm{mM}$. Als Enzymprobe wurde aufgereinigtes Bga48 Protein verwendet $(0,06 \mathrm{mg} / \mathrm{ml})$.

Bga48 zeigte die höchste Aktivität bei pH 6 in Mcllvaine Puffer (Abbildung 24). In Phosphatpuffer des gleichen $\mathrm{pH}$-Wertes konnte nur eine geringfügig verminderte Aktivität festgestellt werden (91\%). Bei den pH-Werten 5 und 7 konnten noch $71 \%$ bzw. $78 \%$ der maximalen Aktivität detektiert werden. Während die Aktivität in Phosphatpuffer bei pH 8 auf $33 \%$ reduziert wurde, zeigte sich in Tris-Puffer bei 
dem gleichen pH-Wert noch eine Restaktivität von über $60 \%$. Bei dem pH-Wert 4 zeigte Bga48 keinerlei Aktivität.

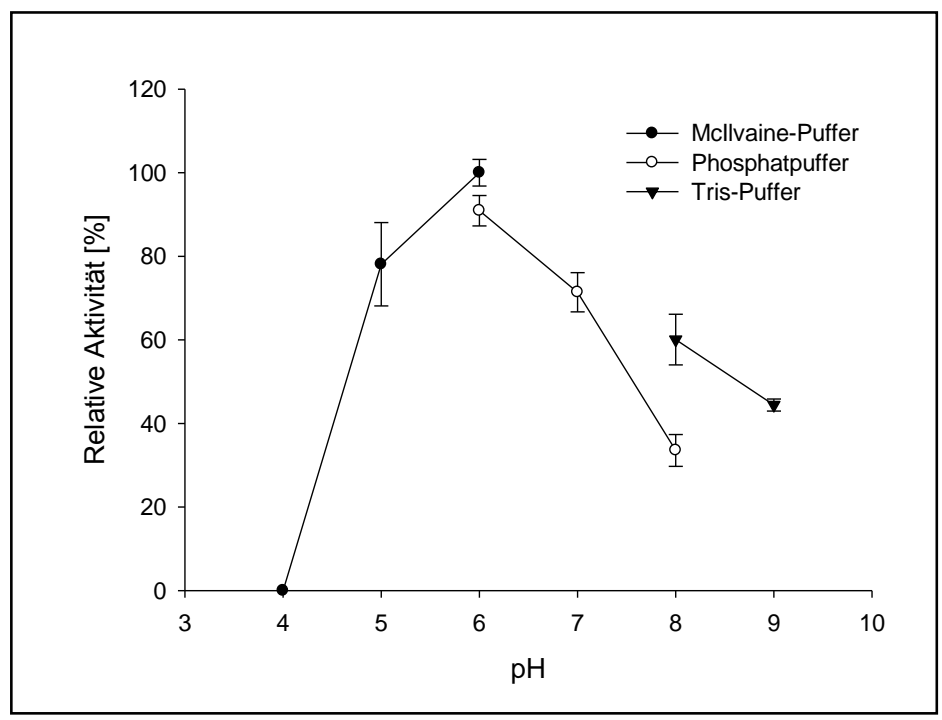

Abbildung 24: Grafische Darstellung der Abhängigkeit der Enzymaktivität von Bga48 vom pH-Wert. Die Auftragung erfolgte als relative Aktivität, wobei der höchste Messwert gleich $100 \%$ gesetzt wurde. Jede Bestimmung erfolgte dreifach im DNSAStandard-Test mit 0,06 mg/ml aufgereinigtem Enzym. Die Testdauer betrug $45 \mathrm{~min}$.

\subsubsection{Bestimmung der Thermostabilität}

Die thermische Inaktivierung von Bga48 wurde bei Temperaturen zwischen $65{ }^{\circ} \mathrm{C}$ und $95^{\circ} \mathrm{C}$ im Verlaufe der Zeit ermittelt. Das Enzym wurde zunächst in McllvainePuffer ( $\mathrm{pH}$ 6) bei den entsprechenden Temperaturen präinkubiert. Im Laufe der Zeit wurden Aliquots entnommen und bis zum DNSA-Test (s. II.7.1.) bei $4{ }^{\circ} \mathrm{C}$ gelagert. Als Ausgangsprobe diente mittels FPLC aufgereinigtes Protein $(0,2 \mathrm{mg} / \mathrm{ml})$.

Wie in Abbildung 25 zu erkennen ist, zeigte das Enzym bei einer Präinkubation bei $65^{\circ} \mathrm{C}$ für 6 Stunden nur einen geringen Aktivitätsverlust von etwa $33 \%$. Bei der Inkubation bei $75{ }^{\circ} \mathrm{C}$ wurde die Enzymaktivität nach 6 Stunden auf $44,4 \%$ herabgesetzt. Bei den Temperaturen $85{ }^{\circ} \mathrm{C}$ und $95{ }^{\circ} \mathrm{C}$ konnte nach 5 Stunden Inkubation keine Aktivität mehr festgestellt werden. Nach einer Stunde war bei diesen Temperaturen nur noch $51,3 \%$ bzw. 43,1 \% der Ausgangsaktivität vorhanden. 


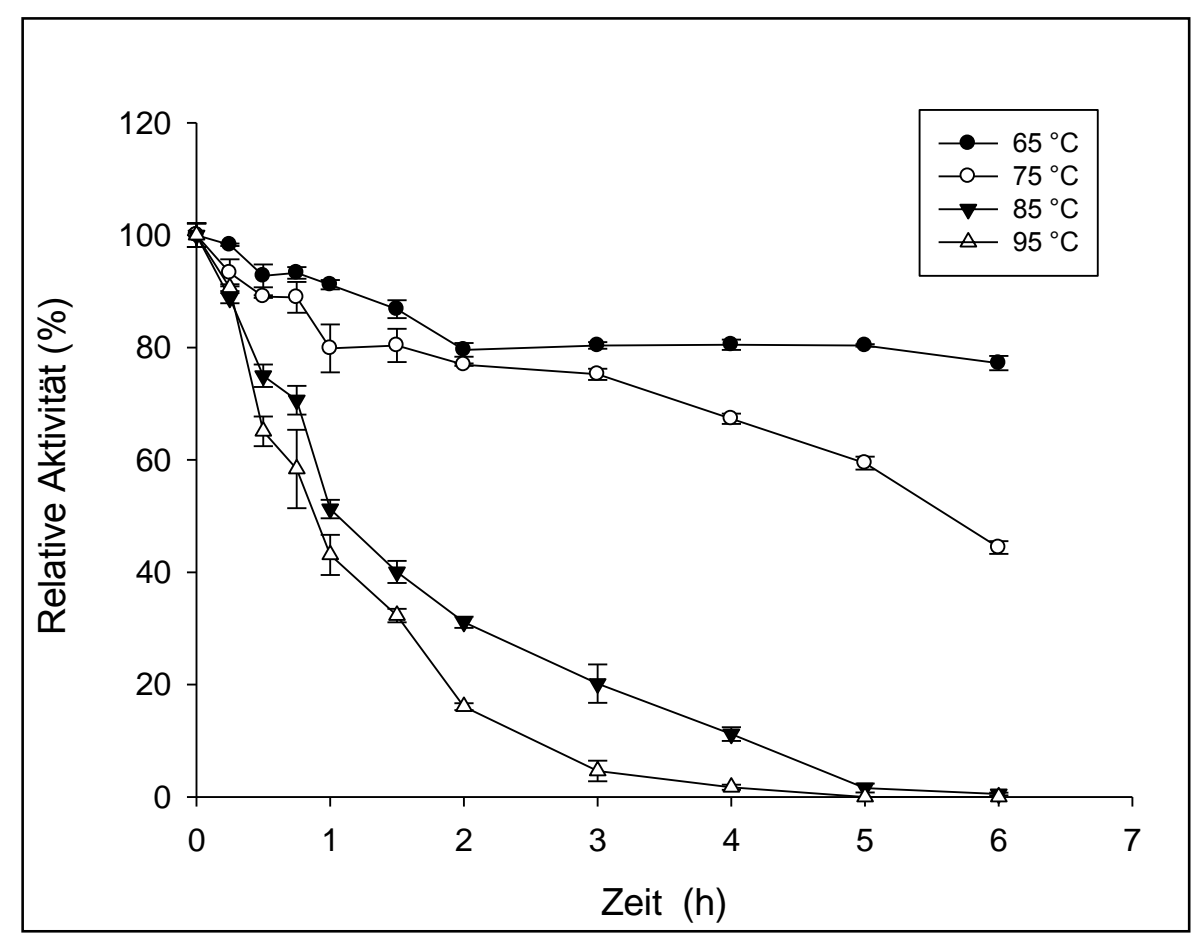

Abbildung 25: Kinetik des Einflusses unterschiedlicher Temperaturen auf Bga48 über einen Zeitraum von 6 Stunden. Dargestellt ist die relative Aktivität in Bezug auf den jeweils ersten gemessen Wert. Der DNSA-Test erfolgte bei $80^{\circ} \mathrm{C}$ in dreifacher Ausführung mit B-Glucan (Gerste) als Substrat in Mcllvaine-Puffer (pH6). Die Testdauer betrug $20 \mathrm{~min}$.

\subsubsection{Einfluss verschiedener Additive auf die Aktivität}

Zur Untersuchung, ob verschiedene ein- und zweiwertige Metallionen, SDS, EDTA und B-Mercaptoetanol Einfluss auf die Aktivität von Bga48 zeigen, wurde ein Standard-DNSA-Test (s. II.7.1.) mit den entsprechenden Additiven in den Endkonzentrationen von $1 \mathrm{mM}$ und $10 \mathrm{mM}$ durchgeführt. Der Test erfolgte mit aufgereinigtem Enzym $(0,6 \mathrm{mg} / \mathrm{ml})$ bei $90^{\circ} \mathrm{C}$ mit B-Glucan (Gerste) als Substrat in Dreifachbestimmung. Wie in Abbildung 26 zu erkennen ist, steigerte insbesondere $\mathrm{CoCl}_{2}$ in einer Konzentration von $1 \mathrm{mM}$ die Aktivität signifikant. In Relation zu dem Testansatz ohne Additive konnte eine 3,5 fache Steigerung der Aktivität erzielt werden. Bei einer Konzentration von $10 \mathrm{mM}$ zeigte sich jedoch eine Aktivitätsverminderung um etwa $4 \%$. Desweiteren konnte bei den Additiven $\mathrm{FeSO}_{4}$ (relative Aktivität von $165 \%$ ), $\mathrm{FeCl}_{3}(184 \%), \mathrm{NaCl}(134 \%), \mathrm{CuSO}_{4}$ $(136 \%), \mathrm{NiSO}_{4}(127 \%)$ in $1 \mathrm{mM}$ Konzentration einer Steigerung der Aktivität beobachtet werden. In Anwesenheit dieser Zusätze in $10 \mathrm{mM}$ Konzentration wurde 
jedoch, mit Ausnahme von $\mathrm{NaCl}$, Bga48 negativ beeinflusst. Es zeigte sich bei einer Konzentration von $10 \mathrm{mM} \mathrm{FeSO}_{4}$ nur noch etwa $33 \%$, bei $\mathrm{FeCl}_{3}$ etwa $72 \%$, $\mathrm{CuSO}_{4} 28 \%$ und bei $\mathrm{NiSO}_{4} 79 \%$ der Aktivität in Relation zu dem Testansatz ohne Additiv. Ebenso hatten die Zusätze $\mathrm{AgNO}_{3}$ und SDS in einer Konzentration von $10 \mathrm{mM}$ einen negativen Einfluss auf die hydrolytische Aktivität von Bga48. Es konnte nur noch wenig oder gar keine Aktivität festgestellt werden. EDTA verringerte die Aktivität in einer Konzentration von $10 \mathrm{mM}$ um etwa $77 \%$ (siehe Abbildung 26).

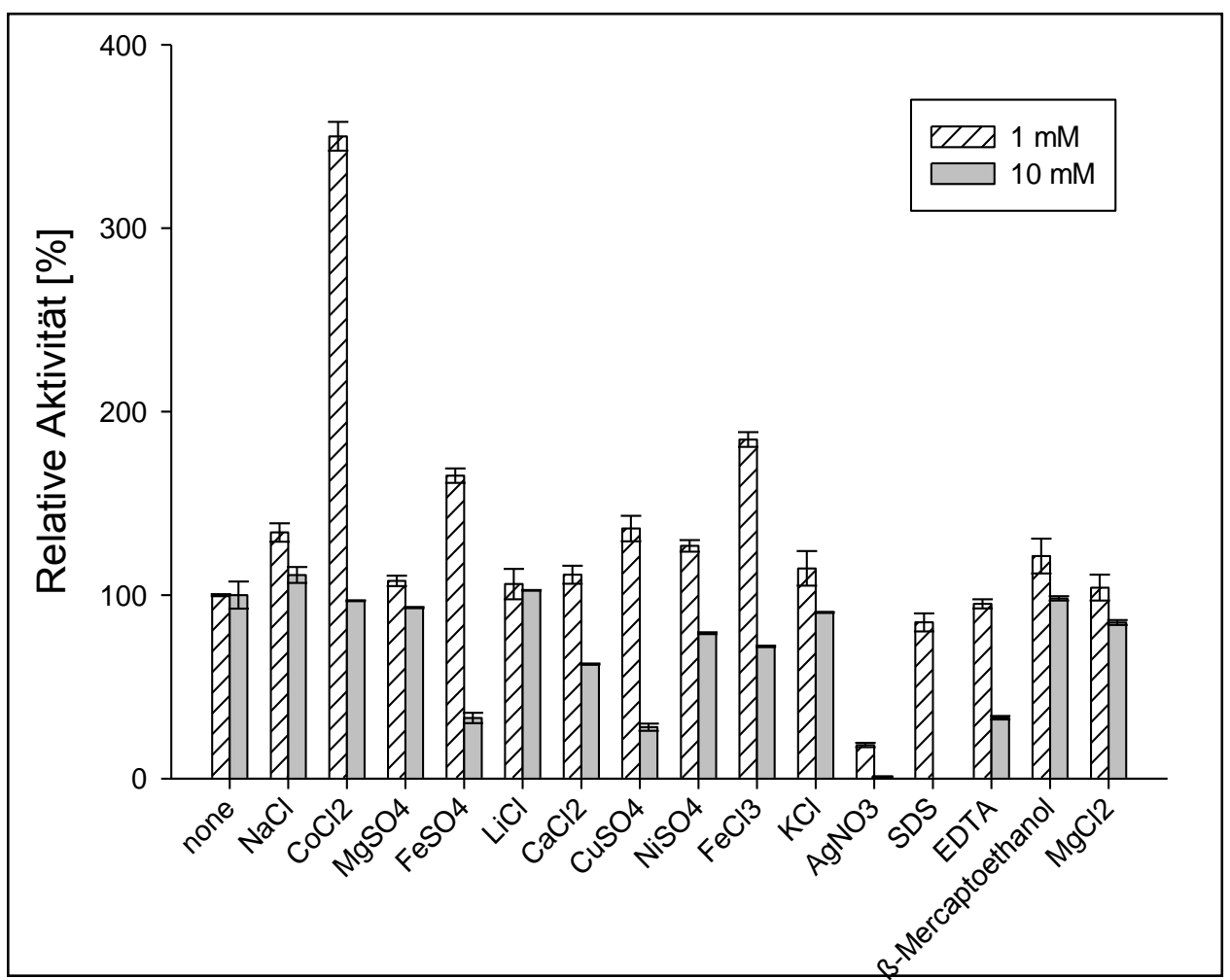

Abbildung 26: Auswirkungen von verschiedenen ein- und zweiwertigen Metallionen, SDS, EDTA und B-Mercaptoethanol auf die Aktivität.

Dargestellt ist die relative Aktivität im Bezug auf den Testansatz ohne Zusatz. Die Ermittlung der Aktivität erfolgte dreifach mit aufgereinigtem Bga48 $(0,6 \mathrm{mg} / \mathrm{ml}) \mathrm{im}$ Standard-DNSA-Test bei $90^{\circ} \mathrm{C}$ für 12 min mit Mcllvaine-Puffer $(\mathrm{pH} 6)$. 


\subsubsection{Untersuchung des Substratspektrum}

Zur Untersuchung des Substratspektrums mittels DNSA-Standardtest (s. II.7.1.) wurden die Substrate B-Glucan, Lichenan, Carboxymethylcellulose, Hydroxyethylcellulose, Pachyman, Zymosan, Curdlan, Auxoferm, Laminarin und mikrokristalline Cellulose verwendet. Der Test erfolgte in Dreifachbestimmung bei $80^{\circ} \mathrm{C}$ mit aufgereinigtem Bga48-Protein $(0,2 \mathrm{mg} / \mathrm{ml})$.

Da die BLAST-Analyse der Aminosäuresequenz von Bga48 ergab, dass ein Bereich Ähnlichkeiten zu einer konservierten Domäne der Glycosidhydrolase Familie 42 zeigte, sollte zudem mittels Dünnschichtchromatographie qualitativ ermittelt werden, ob Bga48 in der Lage ist, Lactose zu spalten. Lactose stellt ein typische Substrat für Vertreter dieser Familie der Glycosidhydrolasen dar. Für die Analyse wurde das Substrat mit Bga48 für 2 Stunden bei $90^{\circ} \mathrm{C}$ in Mcllvaine-Puffer $(\mathrm{pH}$ 6) inkubiert und anschließend mittels Dünnschichtchromatographie aufgetrennt (s. II.7.3.). Der Testansatz entsprach hierbei dem Ansatz für DNSATests (s. II.7.1.). Als Negativkontrollen dienten ein Ansatz ohne Zugabe des Enzyms und ein Ansatz ohne Inkubation bei $90^{\circ} \mathrm{C}$. Als Positivkontrolle dienten Ansätze mit B-Glucan als Substrat.

Zudem wurde qualitativ überprüft, ob Bga48 fähig ist, das Substrat X-Gal (5-Brom-4-Chlor-3-indoyl-B-D-galaktopyranosid) zu spalten. Hierfür wurde der Stamm E. coli BL21::pET10148H2 auf selektive LB-Agarplatten mit X-GAL und IPTG (s. II.2.2.) ausplattiert und über Nacht bei $37^{\circ} \mathrm{C}$ angezogen. Es folgte ein weiterer Inkubationsschritt bei $60^{\circ} \mathrm{C}$ für 3 Tage. Im Falle einer Spaltung des Substrates wäre eine Blaufärbung erkennbar gewesen.

Wie anhand Abbildung 27 ersichtlich ist, zeigt sich die höchste Aktivität mit B-Glucan (Gerste) und Lichenan als Substrate. Die Substrate Carboxymethylcellulose und Hydroxyethylcellulose sind für Bga48 schwerer zugänglich. Es konnten nur 9,1\% bzw. 3,5 \% der maximal erreichten Aktivität detektiert werden. Mit Pachyman, Zymosan, Curdlan, Auxoferm, Laminarin und mikrokristalliner Cellulose konnte keine Aktivität festgestellt werden. Dieses zeigt, das Bga48 offensichtlich nur Substrate hydrolysiert, die B-1,4 glycosidisch verknüpfte Glucoseverbindungen enthalten 


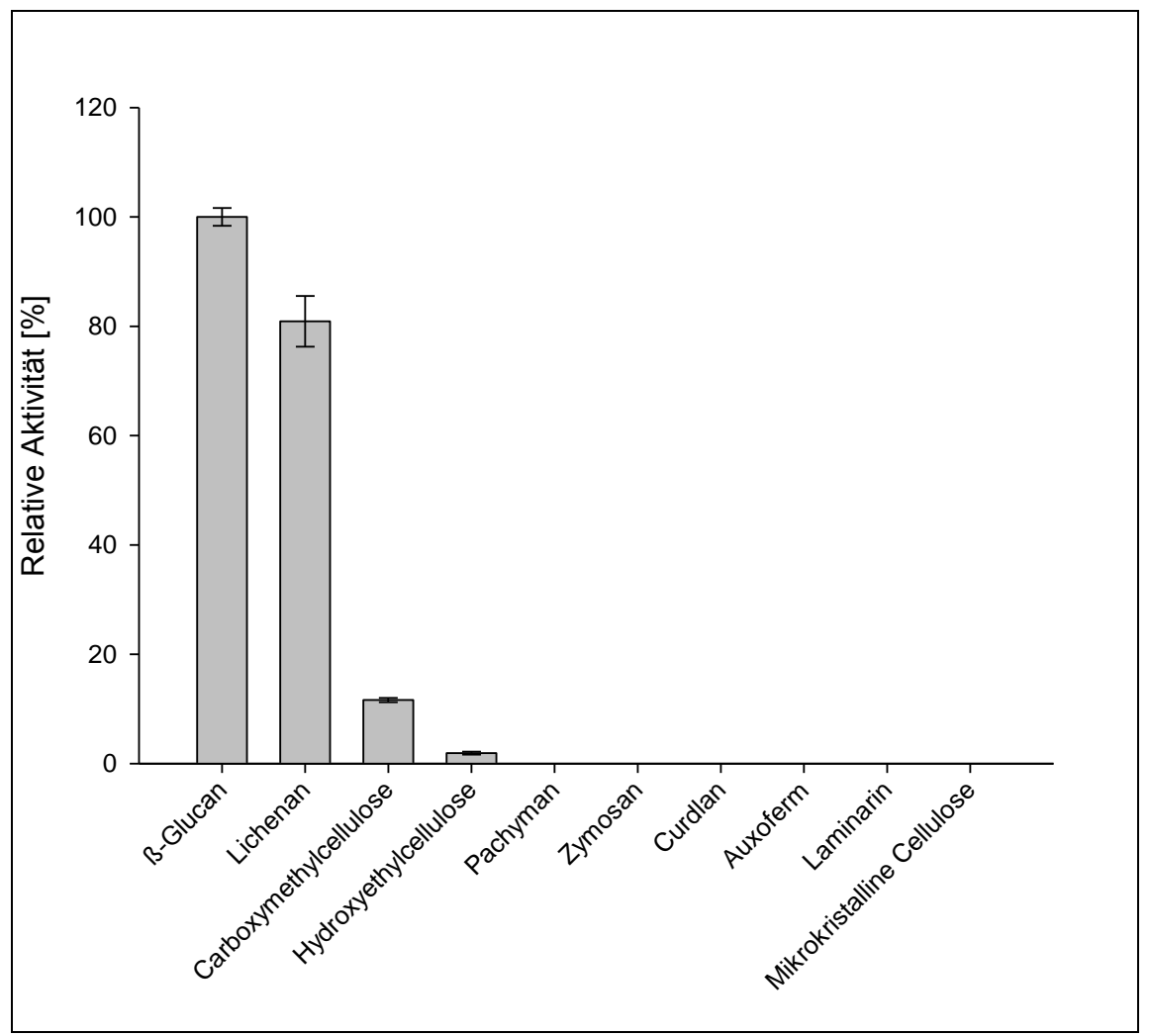

Abbildung 27: Quantitative Untersuchung des Substratspektrum von Bga48.

Die Werte wurden in prozentualer Relation zu dem höchsten gemessen Wert gesetzt. Die Ermittlung der hydrolytischen Aktivität von Bga48 erfolgte im DNSA-Standardtest mit aufgereinigtem Enzym $(0,2 \mathrm{mg} / \mathrm{ml})$ bei $90^{\circ} \mathrm{C}$ für $20 \mathrm{~min}$ mit Mcllvaine-Puffer $(\mathrm{pH} 6)$.

Die qualitativen Untersuchungen der Spaltung der Substrate Lactose und X-Gal zeigten, dass Bga48 nicht in der Lage ist, diese Substrate zu degradieren. Die Dünnschichtchromatographie (Abbildung 28) zeigt nach zwei Stunden Inkubation der Lactose mit Bga48 keine Verringerung des Polymerisationsgrades der Lactose. Das Substrat B-Glucan (Positivkontrolle) wurde hingegen gespalten.

Ebenso konnte auf den Agarplatten mit dem Substrat X-GAL keine Blaufärbung detektiert werden. 


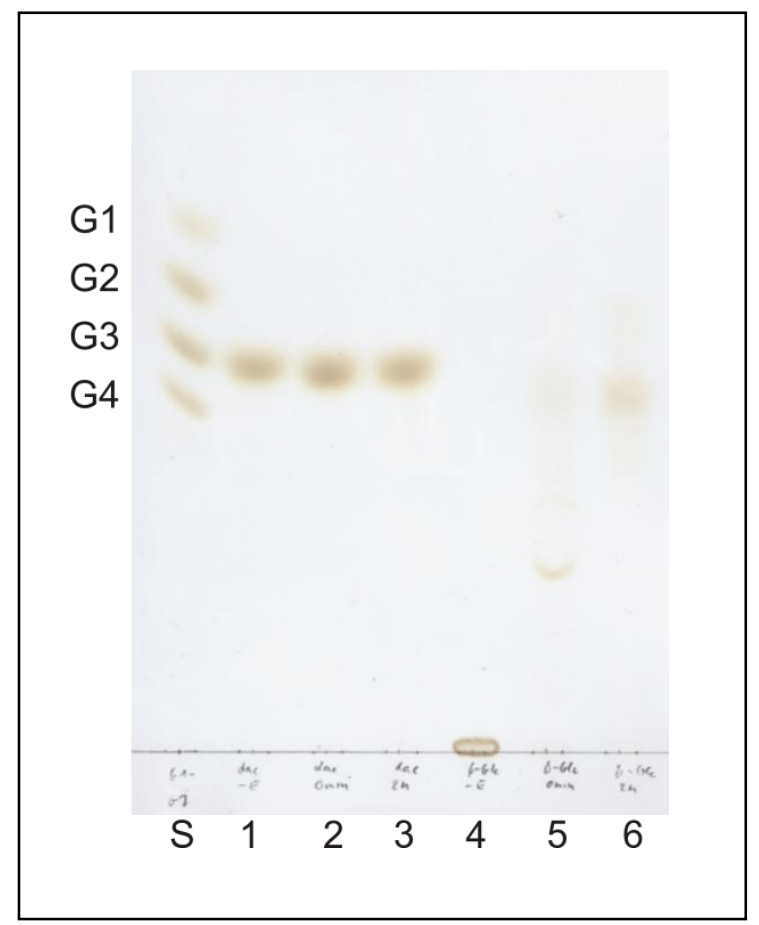

\begin{abstract}
Abbildung 28: Dünnschichtchromatographische Analyse der Spaltung von Lactose durch Bga48

S, Maltooligosaccharid-Standard (G1-G4); 1, Ansatz mit Lactose ohne Bga48; 2, Ansatz mit Lactose und Bga48 ohne Inkubation; 3; Ansatz mit Lactose und Bga48 mit $2 \mathrm{~h}$ Inkubation bei $90^{\circ} \mathrm{C} ; 4$, Ansatz mit B-Glucan ohne Bga48; 5, Ansatz mit B-Glucan und Bga48 ohne Inkubation; 6, Ansatz mit B-Glucan und Bga48 mit $2 \mathrm{~h}$ Inkubation bei $90^{\circ} \mathrm{C}$.
\end{abstract}

\title{
2.4.6. Qualitative Untersuchung der Produktbildung und des Spaltungsmechanismus von Bga48 beim Abbau von B-Glucan
}

Um zu untersuchen, wie Bga48 das Substrat B-Glucan (Gerste) im zeitlichen Verlauf abbaut, wurde eine Dünnschichtchromatographie angefertigt. Diese sollte klären, ob Bga48 innerhalb der B-Glucan-Kette spaltet, oder ob das Enzym exo wirkt und Moleküle an den Enden der Kette abspaltet. Zudem kann durch diese Analyse ermittelt werden, welches Produkt vorwiegend gebildet wird.

Zur Analyse der Produktbildung des enzymatischen Abbaus von B-Glucan durch Bga48 im zeitlichen Verlauf wurde das Substrat mit aufgereinigtem Bga48 $(0,2 \mathrm{mg} / \mathrm{ml})$ bei $90{ }^{\circ} \mathrm{C}$ inkubiert. Der Testansatz entsprach dem Testansatz für DNSA-Tests. (s. II.7.1.). Nach unterschiedlichen Zeitabständen wurden Proben entnommen und mittels Dünnschichtchromatographie aufgetrennt (s. II.7.3.). 


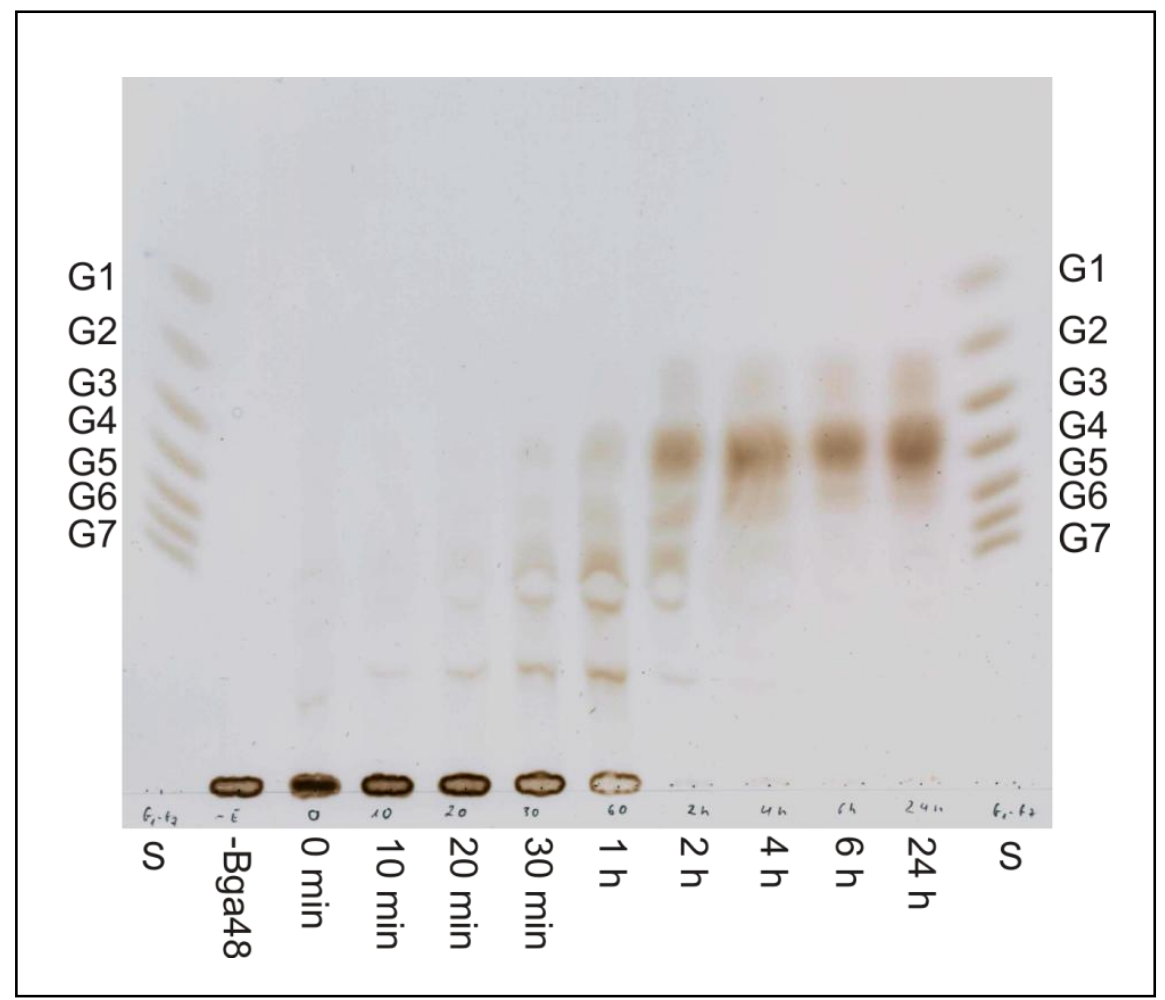

Abbildung 29: Dünnschichtchromatographische Analyse des zeitlichen Abbaus von B-Glucan (Gerste) durch Bga48. Unter den Spuren ist der Zeitpunkt der Probenentnahme vermerkt. S: Maltooligosaccharid-Standard (G1-G7); -Bga48: Testansatz ohne Enzym (Inkubation $24 \mathrm{~h} / 90^{\circ} \mathrm{C}$ )

Wie in Abbildung 29 zu erkennen ist zeigten sich erstmals nach etwa 20 Minuten Produkte mit hohem Polymerisationsgrad. Dieses weist auf einen endoMechanismus des Enzyms hin. Nach etwa einer Stunde Inkubation bei $90^{\circ} \mathrm{C}$ entstanden neben den Produkten mit hohem Polymerisierungsgrad auch Oligosaccharide mit einem kleineren Polymerisationsgrad von 4 bis 7 . Nach 4 Stunden zeigten sich ausschließlich Produkte mit dem Polymerisationsgrad von 3 bis 5, das Ausgangssubstrat und die hochpolymerisierten Zwischenprodukte waren komplett abgebaut. Als Hauptprodukt zeigte sich ein Produkt mit dem Polymerisationsgrad 4.

Nach 24 Stunden Inkubation konnte keine Veränderung der Produktbildung festgestellt werden. 


\subsubsection{Enzymkinetik}

Für die Feststellung der kinetischen Daten $\mathrm{V}_{\max }$ und $\mathrm{K}_{\mathrm{m}}$ wurden Aktivitätstests im DNSA-Standardtest mit Substratkonzentrationen zwischen $0,05 \mathrm{mg} / \mathrm{ml}$ und $0,8 \mathrm{mg} / \mathrm{ml}$ gemessen.

Die Messungen erfolgten im DNSA-Standardtest mit aufgereinigtem Enzym (0,2 $\mathrm{mg} / \mathrm{ml}$ ) unter den zuvor ermittelten optimalen Bedingungen für die Aktivität von Bga48. Der Test erfolgte bei $90^{\circ} \mathrm{C}$ und bei dem pH Wert 6 (Mcllvaine-Puffer) für 10 min. Als Substrat wurde B-Glucan aus Gerste gewählt, da es zuvor als zugänglichstes Substrat ermittelt wurde. Aus der Steigung der Geraden in der doppeltreziproken Auftragung nach Lineweaver-Burk ließen sich für Bga48 ein $K_{\mathrm{m}}$-Wert von 0,24 mg/ml und ein $V_{\max }$-Wert von $200 \mathrm{U} / \mathrm{mg}$ berechnen.

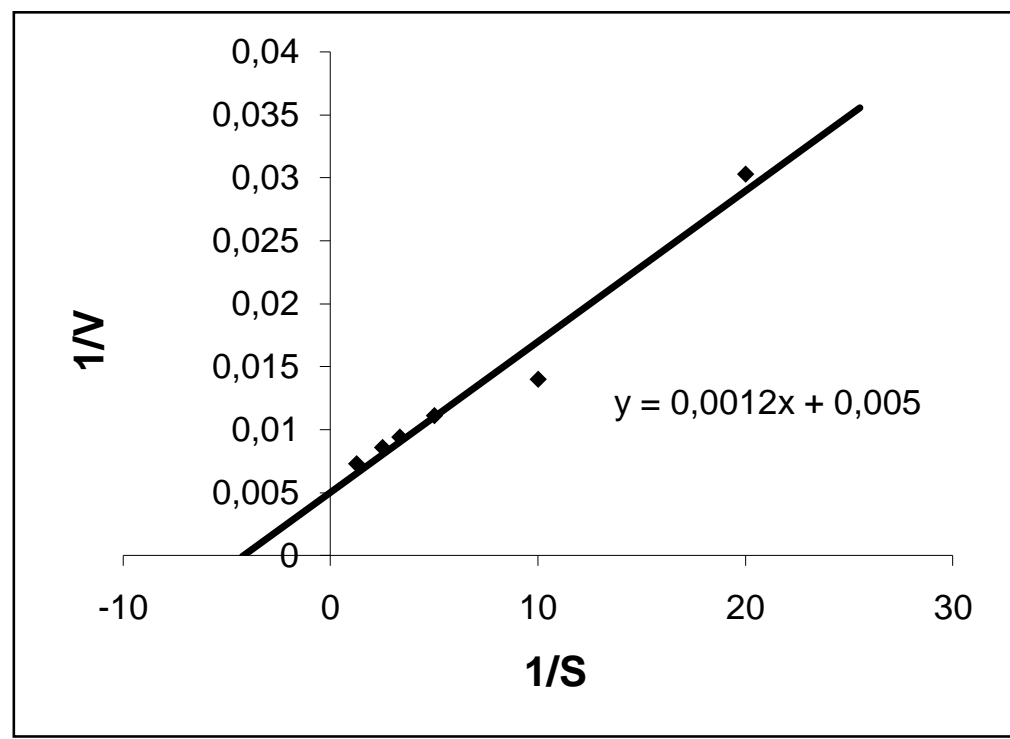

Abbildung 30: Auftragung der Aktivität von Bga48 nach Lineweaver-Burk 
3. Teil 2: Untersuchung der Diversität in unterschiedlichen Teilen des Intestinaltraktes des europäischen Bibers (Castor fiber albicus)

\subsection{Sektion der Biber und Isolierung des Inhalts der unterschiedlichen Darmabschnitte}

Insgesamt wurden zwei europäische Biber (Castor fiber albicus) vom Biosphärenreservat Mittelelbe (Dessau-Roßlau) zur Verfügung gestellt. Es handelte sich hierbei um ein Männchen, das im Oktober 2006 aufgrund einer Kollision mit einem PKW verstarb und ein Weibchen, das im Juli 2007 einer nicht bekannten Krankheit erlag. Beide Tiere wurden nach dem Auffinden bei $-20{ }^{\circ} \mathrm{C}$ eingefroren und im August 2007 in dem Tierärztlichen Institut der Georg-AugustUniversität Göttingen nach dem Auftauen bei $4{ }^{\circ} \mathrm{C}$ durch eine Tierärztin fachgerecht seziert. Während das weibliche Tier keine inneren Verletzungen aufwies, zeigten sich bei dem männlichen Tier die Folgen des Aufpralls mit dem PKW deutlich. Mehrere innere Organe und Teile des Darmtraktes wiesen Risse auf, so dass nur kleinere intakte Teile der unterschiedlichen Darmabschnitte entnommen werden konnten. Der Inhalt der unterschiedlichen Bereiche des Verdauungstrakte wurden anschließend entnommen und bei $-80^{\circ} \mathrm{C}$ eingefroren. Abbildung 31 zeigt ein Foto des Darmtraktes und die Entnahmestellen.

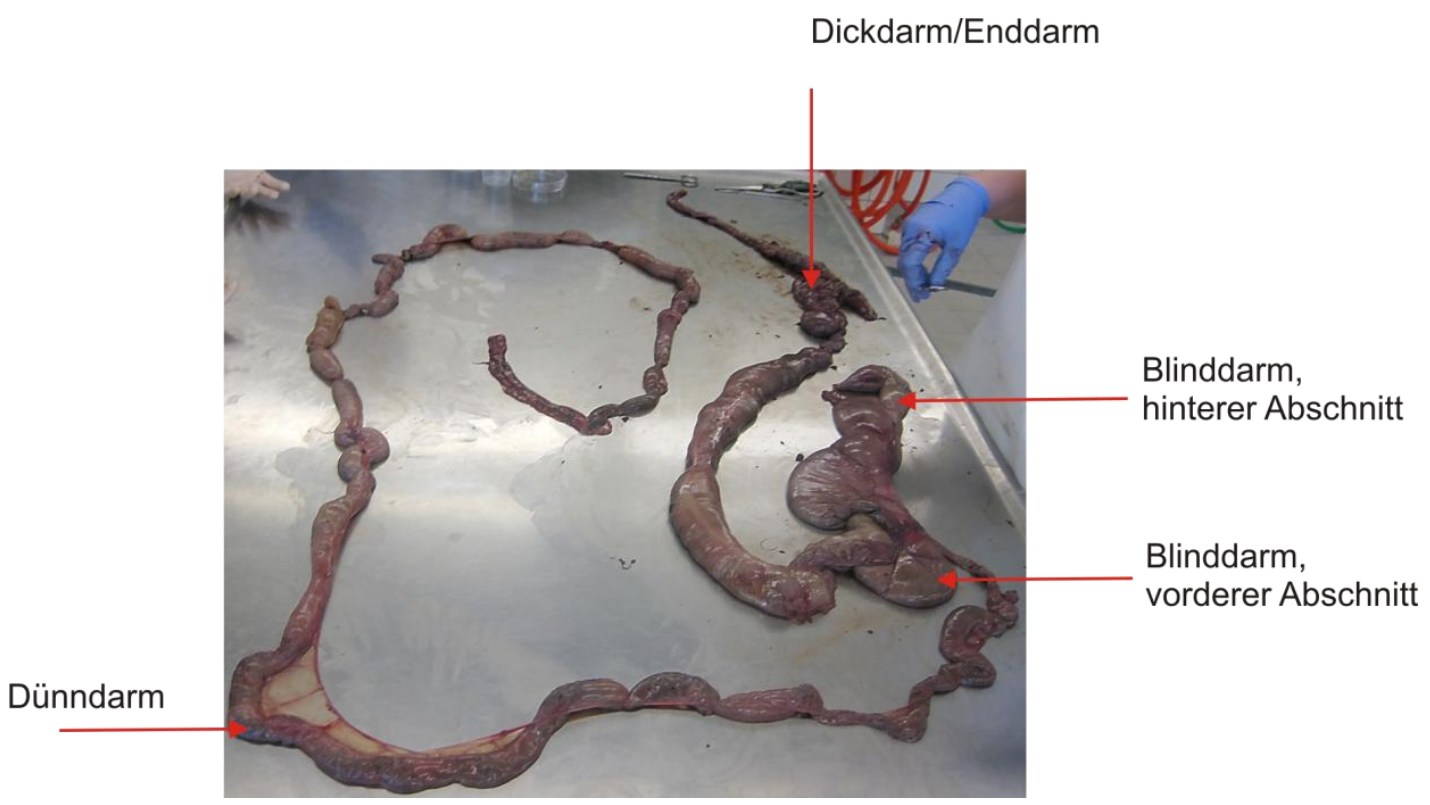

Abbildung 31: Präparierter Darmtrakt des Bibers (Castor fiber albicus) Es fehlt der Magen. Die Probenentnahmestellen sind mit einem roten Pfeil gekennzeichnet. 


\subsection{Methoden zur Untersuchungen der mikrobiellen Diversität in den Darmabschnitten des Bibers mittels 16S rRNA-Genanalysen}

Für die Untersuchung der mikrobiellen Diversität in den verschiedenen Bereichen des Verdauungstraktes wurden zwei verschiedene Methoden angewendet. Nach der Isolierung metagenomischer DNA aus den unterschiedlichen Darmbereichen wurden zum einen klassische 16S rRNA-Genanalysen, zum anderen wurden 16S rRNA-Genanalysen mit Hilfe der neuen Sequenzierungsmethode der 454-Pyrosequenzierung durchgeführt.

Die klassische Methode umfasste die partielle Amplifikation von einem etwa 1100 bp langen Bereich der Gene für die 16S rRNA aus dem Metagenom der verschiedenen Proben mittels PCR, eine anschließende Klonierung der PCRProdukte in einen Klonierungsvektor und die Sequenzierung der inserts mittels der Sanger-Methode. Die Sequenzdaten wurden anschließend für die Konstruktion von Stammbäumen mit dem Programm ARB verwendet (s. II.9.2).

Bei der 16S rRNA-Analyse unter Verwendung der 454 Pyrosequenzierung wurde nur ein etwa 250 bp umfassender Teilbereich der Gene für die 16S rRNA amplifiziert und diese direkt ohne eine vorherige Ligation in einen Klonierungsvektor sequenziert (s. II.5.12.2.). Der Vorteil der 454-Sequenzierung liegt in dem geringen Zeitaufwand und dem hohen Durchsatz. So können pro Lauf bis zu 3 Gbp DNA sequenziert werden. Die Daten der 454-Pyrosequenzierungen dienten zur Erstellung einer Übersicht der Diversität auf Phylumebene mit dem RDP Classifier (http://rdp.cme.msu.edu/classifier/classifier.jsp) mit hoher Abdeckung, während die klassische Methode einen tieferen Einblick bis auf Artenebene gewährte, jedoch die Artenvielfalt nur zum Teil abdeckte.

\subsection{Untersuchung der phylogenetischen Diversität unterschiedlicher Darmabschnitte des Bibers}

Für die Untersuchung der phylogenetischen Diversität von Teilen des Verdauungstraktes wurden vorwiegend Proben des männlichen Bibers verwendet. Dieser verstarb in einer Jahreszeit, in der sich Biber vorwiegend von schwer verdaulichem Pflanzenmaterial wie Baumrinde ernähren. Durch die Veränderung 
des Nahrungsangebotes im Herbst verändert sich auch die Zusammensetzung der mikrobiellen Gemeinschaften in den Darmbereichen. Für die spätere Isolierung von biotechnologisch interessanten Biokatalysatoren ist besonders das Metagenom dieser Mikroorganismen interessant. Zur Untersuchung der mikrobiellen Zusammensetzung in den Intestinalbereichen wurde sowohl die klassische Methode verwendet, als auch eine 16S rRNA-Gensequenzanalyse der durch die 454-Pyrosequenzierung generierten Sequenzdaten durchgeführt.

Um einen groben Vergleich der bakteriellen Diversität des Blinddarminhaltes zwischen des im Herbst und im Sommer verstorbenen Tieres zu erhalten, wurde zusätzlich von der Probe des hinteren Abschnittes des Blinddarmes des weiblichen Tieres eine phylogenetische Analyse der Diversität unter Verwendung der 454-Pyrosequenzierung partiell amplifizierter 16S rRNA-Gensequenzen erstellt. Eine 16S rRNA Gensequenzanalyse mit der klassischen Methode erfolgte nicht.

Zur Analyse der bakteriellen Diversität im Intestinaltrakt des männlichen Tieres wurden Proben aus dem Dünndarm, des vorderen Bereiches des Blinddarmes, des hinteren Bereiches des Blinddarmes und des Bereiches zwischen Dick- und Enddarm verwendet. Aus den Inhalten dieser Darmabschnitte wurde zunächst die DNA isoliert (s. II.5.4.3.). Die DNA-Isolierung aus dem Dünndarminhalt verblieb trotz der Verwendung unterschiedlicher DNA-Isolierungsmethoden erfolglos (II.5.4.).

Die Gesamt-DNA aus den Proben des Dick-/Enddarmes und der beiden Abschnitte des Blinddarmes wurden anschließend für die Amplifikation von 16S-rRNA kodierenden Genen mit spezifischen Primern für Bakterien und Archaen (s. II.1,Tabelle 3) mittels PCR mit der Taq-Polymerase (s. II.5.6.1.) eingesetzt. Die Amplifikation von archaellen 16S rRNA kodierenden Genen blieb bei allen Proben erfolglos.

Es folgte eine Klonierung der Amplifikate in den Vektor pCR.2.1-TOPO (s. II.5.8.6.) Die Sequenzierung der Plasmid-inserts erfolgte durch das „Göttingen Genomics Laboratory" nach der Sanger-Methode.

Die anschließende Bearbeitung der Sequenzrohdaten erfolgte mittels dem „STADEN"-Software-Pakets (s. II.9.1.). Hier wurden forward und reverse-Läufe vereinigt und jede einzelne Sequenz auf Sequenzierungsfehler untersucht und gegebenenfalls editiert. Es folgte eine anschließende Untersuchung der 
Datensätze auf putative Chimere mit den Programmen CHIMERA_CHECK und Bellerophon (s. II.9.4.). Nachdem detektierte Chimere entfernt wurden, wurden mittels NCBI BLAST bakterielle 16S rRNA Gensequenzen mit der höchsten Sequenzidentität $\mathrm{zu}$ den aus den Metagenomen des Interstinaltraktes amplifizierten 16S rRNA-Gensequenzen ermittelt.

Die so vorbereiten $16 \mathrm{~S}$ rRNA-Gensequenzen wurden für die Erstellung phylogenetischer Stammbäume in das Programm ARB (s. II.9.2.) eingeladen. Nachdem Fehler in der automatischen Alignierung manuell behoben wurden, wurden distance matrices erstellt und diese einer DOTUR-Analyse (Schloss und Handelsman, 2005) unterzogen (s. II.9.3.). Hierbei wurden die Sequenzen in sogenannte operational taxonomic units (OTUs) eingeteilt. In einem OTU werden alle 16S rRNA-Gensequenzen vereinigt, die sich untereinander nicht mehr als um einen bestimmten Prozentsatz in ihrer DNA-Sequenz unterscheiden. Für die Erstellung der phylogenetischen Stammbäume wurden OTUs mit einer Ausschlußgrenze von $1 \%$ verwendet. Mit Hilfe der DOTUR-Analyse ließen sich zudem durch den ACE (abundance-based coverage estimator) und dem Chao1Schätzverfahren Aussagen über die potentielle Vielfalt treffen.

Für die Analyse der bakteriellen Diversität mit Hilfe der 454-Pyrosequenzierung wurden die 16S rRNA-Gene zunächst partiell mit den Primern 454V2.for und 454V3.rev (s. Il.1., Tabelle 3) mittels PCR mit der Pfu-Polymerase amplifiziert (s. II.5.12.2.). Je Probe wurden jeweils drei PCRs durchgeführt. Anschließend wurden die PCR-Produkte der drei PCRs im gleichen Verhältnis zueinander vereinigt. Nachdem die DNA-Proben laut II.5.12.2. vorbereitet wurden, erfolgte die 454Pyrosequenzierungsreaktion im $\mathrm{G}_{2} \mathrm{~L}$ Göttingen. 


\subsubsection{Analyse der 16S rRNA Gensequenzen aus der Probe des vorderen Bereiches des Blinddarmes (männlicher Biber)}

Der Inhalt des vorderen Abschnittes des Blinddarmes bestand aus einer kompakten Masse, die vorwiegend unverdaute Rinden-und Holzbestandteile enthielt (Abbildung 32)

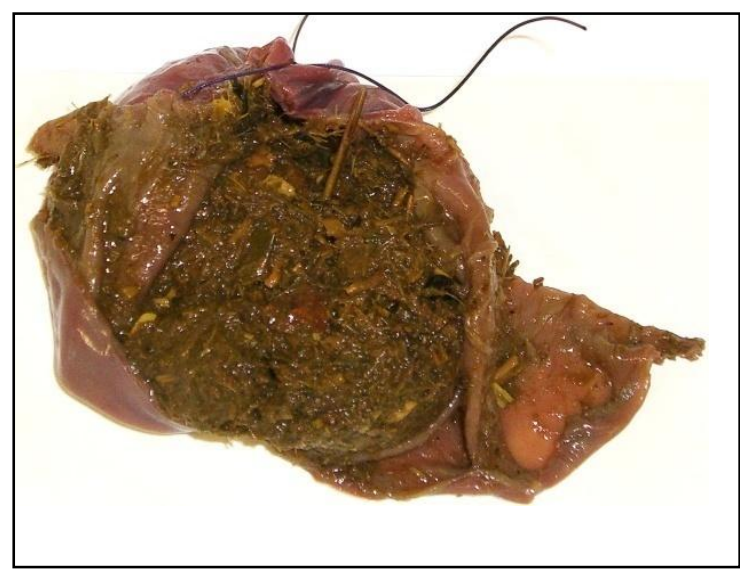

Abbildung 32: Geöffneter Teil des vorderen Bereiches des Blinddarmes des männlichen Bibers.

Zur Untersuchung der phylogenetischen Diversität wurde sowohl eine klassische $16 S$ rRNA-Genanalyse, als auch eine Analyse der mit der 454-Pyrosequenzierung generierten 16S rRNA-Gensequenzdaten durchgeführt.

Im Rahmen der klassischen Analyse wurden insgesamt 257 16S rRNA Gene sequenziert. Die Überprüfung auf chimäre Sequenzen ergab einen Anteil von 19,5\%, so dass letztendlich 207 Sequenzen mit einer Länge zwischen 930 und 1115 bp für phylogenetische Analysen mit dem Programm ARB zur Verfügung standen. In Tabelle 11 wird das Ergebnis der DOTUR-Analyse der Sequenzen dargestellt. Bei einer genetischen Distanz von $<3 \%$ (Artenebene) wurden insgesamt 30 OTUs identifiziert. Nach Berechnungen des ACE (abundance-based coverage estimator) und Chao1 wurden somit $61,2 \%$ bzw. $50 \%$ der OTUs mit einer Sequenzähnlichkeit von >97\% abgedeckt. 
Tabelle 11: Bestimmte und abgeschätzte Diversität der bakteriellen 16S rRNAGensequenzen auf Distanzebenen von $1 \%$, $3 \%$ und $20 \%$.

\begin{tabular}{lccc}
\hline $\begin{array}{c}\text { Genetische } \\
\text { Distanz }\end{array}$ & Detektierte OTUs & ACE & Chao1 \\
\hline 0,01 & 39 & 94 & 108 \\
0,03 & 30 & 49 & 60 \\
0,20 & 5 & 6 & 6 \\
\hline
\end{tabular}

Von den 39 detektierten OTUs bei einer gegentischen Distanz < 1\% enthielten 15 OTUs zwei (doubletons) oder mehr Sequenzen. Vierundzwanzig OTUs enthielten nur eine Sequenz (singletons).

In Abbildung 33 sind die rarefaction-Kurven der Distanzebenen $1 \%, 3 \%$ und $21 \%$ dargestellt. Wie zu erkennen ist, wurde in einer Distanz von $3 \%$ (Artenebene) keine vollständige Abdeckung der OTUs erreicht. Bei einer genetischen Distanz von $20 \%$ (Phylumebene) wurde hingegen eine gute Abdeckung erreicht. Diese Ergebnisse zeigen, dass ein substantieller Teil der Diversität durch die vorliegende Studie abgedeckt wurde.

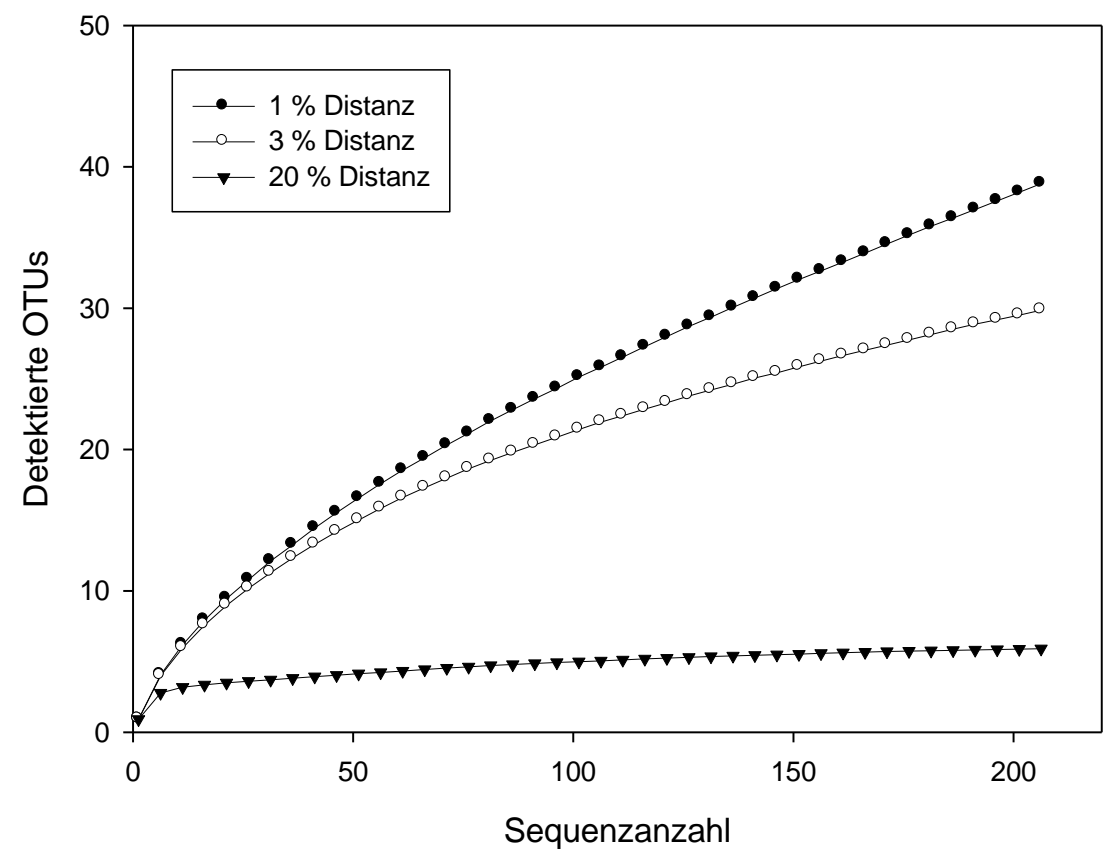

Abbildung 33: Mit DOTUR kalkulierte rarefaction-Kurven der Einteilung der amplifizierten 16S rRNA Gensequenzen in OTUs. Gezeigt sind die Einteilungen in OTUs auf genetischen Distanzebenen von $1 \%, 3 \%$ und $20 \%$. 
Zum Vergleich wurde zudem die Methode der 454-Pyrosequenzierung angewendet. Insgesamt konnten 14130 partielle 16S rRNA-Gensequenzen mit einer durchschnittlichen Länge von 240 bp sequenziert werden. Aufgrund der geringen Länge der amplifizierten 16S rRNA Gensequenzen konnte eine Einteilung der Sequenzen mittels RDP Classifier nur auf Phylumebene erfolgen. In Abbildung 34 werden die Ergebnisse der Einteilung der erhaltenen Sequenzdaten im Vergleich zu dem Ergebniss der klassischen 16S rRNA-Gensequenzanalyse dargestellt. Um die Ergebnisse vergleichbar zu gestalten, wurden die $20716 \mathrm{~S}$ rRNA-Gensequenzen ebenfalls mit dem RDP Classifier in Phyla eingeteilt.

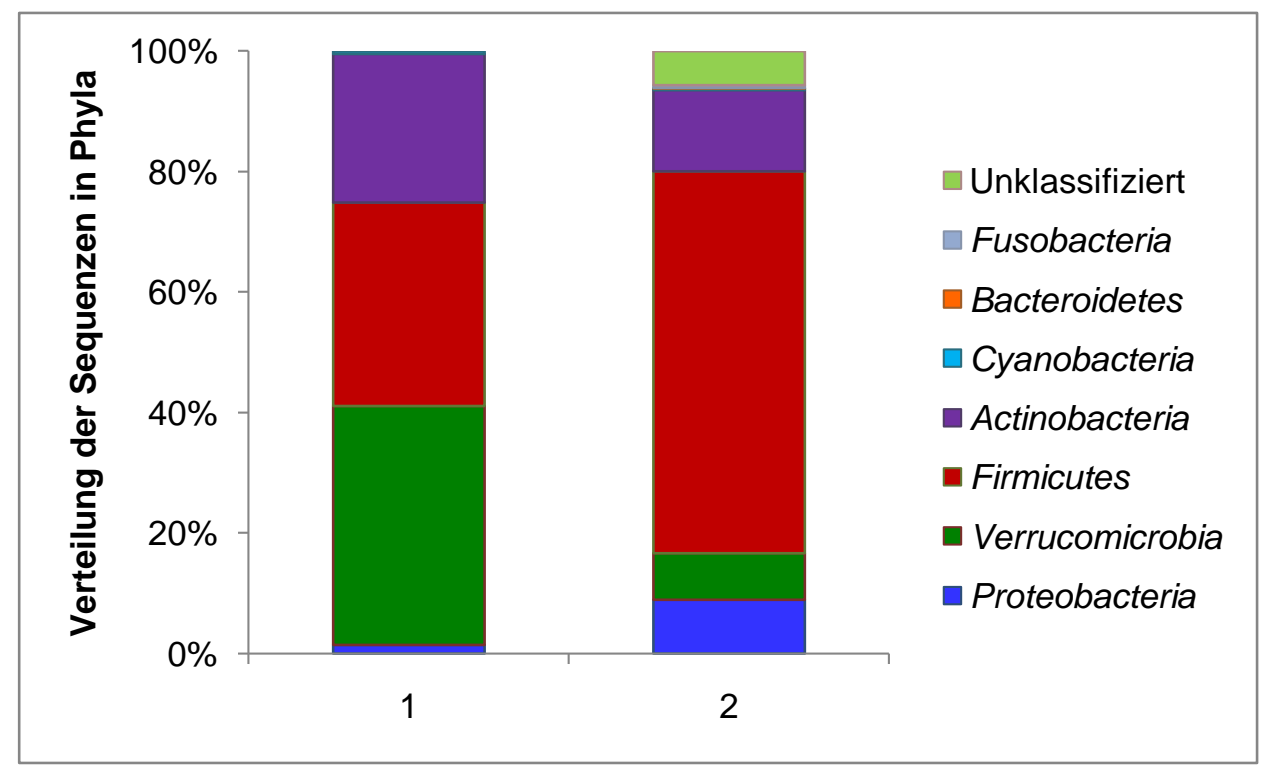

Abbildung 34: Vergleich der Ergebnisse der Einteilung der generierten 16S rRNAGensequenzdaten in Phyla durch die [1] klassische Methode (207 16S rRNAGensequenzen) und die Methode der 454-Pyrosequenzierung (14130 Sequenzen) aus dem Inhalt des vorderen Blinddarmbereiches. Die Einteilung der 16S rRNAGensequenzen in Phyla erfolgte mit dem RDP Classifier-Programm.

Wie in Abbildung 34 zu erkennen ist, zeigen sich erhebliche Unterschiede der Verteilung der erhaltenen Sequenzdaten aus der klassischen 16S rRNA-Analyse und den Sequenzdaten der 454-Sequenzierung in die unterschiedlichen Phyla. Mit der klassischen Analyse konnten insgesamt 5 Phyla identifiziert werden. Die Sequenzen wurden in die Phyla Proteobacteria, Verrucomicrobia, Firmicutes, 
Actinobacteria und Cyanobacteria eingeteilt. Ein Hauptanteil der Sequenzen $(39,6 \%)$ wurde den Verrucomicrobia zugeordnet. Ein Anteil von 33,8 \% Prozent aller Sequenzen wurden in das Phylum Firmicutes eingeteilt. Das Phylum Actinobacteria wurde durch 24,6 \% der Gesamtsequenzdaten vertreten. Die Proteobacteria und Cyanobacteria wurden durch $0,5 \%$ der Sequenzen repräsentiert. Bei der Auswertung der 454-Sequenzdaten ergab die Einteilung der 14130 partiell amplifizierten 16S-rRNA -Gensequenzen ein unterschiedliches Muster. Die Sequenzdaten wurden vorwiegend in die fünf Phyla eingeteilt, die auch die Sequenzdaten der klassischen Analyse zugeordnet wurden. Es zeigte sich jedoch ein großer Unterschied in der prozentualen Verteilung innerhalb der Phyla. So wurde zum Beispiel 63,4\% aller Gensequenzen den Firmicutes zugeordnet. In der klassischen Analyse wurde dieses Phyla nur durch etwa $33 \%$ der Sequenzen abgedeckt. Das Phylum der Verrucomicrobia, das mit etwa $39 \%$ den höchsten Anteil in der klassischen Analyse hatte, wurde durch die 454Pyrosequenzierung erhaltenen Sequenzdaten nur durch einen Anteil von 7,7 \% repräsentiert. Desweiteren konnten durch die Auswertung der Sequenzdaten weitere Phyla identifiziert werden. So wurden $0,1 \%$ der partiellen 16S rRNA Sequenzen den Bacteroidetes und 0,5\% den Fusobacteria zugeordnet. Ein Anteil von $5.6 \%$ der erhaltenden Sequenzdaten konnten keinem Phylum zugeordnet werden.

\subsubsection{Konstruktion phylogenetischer Stammbäume der bakteriellen Diversität im vorderen Abschnittes des Blinddarmes (männlicher Biber)}

Die mit DOTUR detektierten 39 OTUs mit einer Ausschlußgrenze > $99 \%$ wurden in fünf Phyla eingeteilt. Drei OTUs gehörten hierbei dem Phyla der Proteobakterien an, zwei OTUs wurden in das Phylum Verrucomicrobia eingeordnet. In dem Phylum Firmicutes befanden sich 22 OTUs. Desweiteren konnten OTUs in die Phyla Actinobacteria (11 OTUs) und Cyanobacteria (1 OTU) eingeordnet werden. Die phylogenetischen Stammbäume wurden mit dem Programm „ARB“ unter der Verwendung der "Maximum-Parsimony"-Methode und 100-facher bootstrap - Analyse konstruiert. 
In Abbildung 35 wird ein phylogenetischer Stammbaum der Phyla Proteobacteria, Verrucomicrobia und Firmicutes dargestellt.

In dem Phylum Proteobacteria wurden zwei OTUs in die Klasse der Gammaproteobakterien eingeteilt. Beide 16S rRNA-Gensequenzen wurden der Ordnung der Pseudomonadales und der Familie der Moraxellaceae zugeordnet. Die mittels BLAST ermittelten nächsten Nachbarn sind im Falle der Sequenz Blv3_D09 mit 100\%iger Identität die 16S-rRNA-Gensequenz des Bakterium Acinetobacter junii (FJ596644) und für die Sequenz Blv3_B08 mit $99.6 \%$ iger Sequenzidentität ein nicht kultiviertes Bakterium aus dem Präriehundfloh (Gropsylla hirsuta).

Die Klasse der Betaproteobakterien wurde durch ein OTU (16S rRNA Gensequenz Blv3_B06) vertreten, welches zur Ordnung der Burkholderiales und der Familie der Comamonadaceae eingeordnet wurde. Die Sequenz zeigt eine 99,6 \%ige Identität zur 16S rRNA-Gensequenz von Comamonas sp. BF-5 [EU312978]. Dieses Bakterium wurde aus Belebtschlamm einer Kläranlage isoliert. Das Phylum Verrucomicrobia wurde durch zwei OTUs vertreten (Blv3_G07; Blv2_H10), die der Klasse der Verrucomicrobiae und der Ordnung Verrucomicrobiales angehören. Der nächste Nachbar dieser 16S rRNA-Gensequenzen ist mit 94 \%iger bzw. 95 \%iger Identität die 16S rRNA-Sequenz eines unkultivierten Bakteriums aus menschlichen Fäkalien [DQ795617].

Die 22 OTUs des Phylums Firmicutes wurden vorwiegend in die Klasse der Clostridia zugeteilt (21 OTUs). Ein OTU gehörte der Klasse der Erysipelotrichi an. Die 11 OTUs der Klasse der Clostridia wurden alle der Ordnung der Clostridiales zugeordnet. Hierbei waren die Familien der Clostridiaceae (1 OTU), der Lachnospiraceae (5 OTUs), der Ruminococcaceae (12 OTUs) und der Eubacteriaceae (3 OTUs) vertreten. Der nächsten Nachbar der Sequenz Blv1_A05, die der Familie Clostridiacaea zugehört, ist mit $99.6 \%$ \%iger Sequenzidentität ein unkultiviertes Bakterium aus menschlichen Fäkalien [EF401043]. Die Sequenzen, die in die Familie Lachnospiraceae eingestuft wurden, zeigten Sequenzidentitäten zwischen $95,5 \%$ und $98,2 \%$ zu Sequenzdaten von unkultivierten Bakterien aus menschlichen Fäkalien [DQ796689,EU763205], aus dem menschlichen Dickdarm [AY978280,AY979133] und aus Fäkalien des schwarz-weißen Stummelaffen [EU774464]. 
Die Ruminococcaceae, vertreten durch 12 16S rRNA Gensequenzen, wiesen Sequenzähnlichkeiten zwischen $94 \%$ und 99,6 \% zu unkultivierten Bakterien aus Proben von Verdauungstrakten verschiedener Lebewesen auf. Als Beispiele werden hier Proben aus dem Pansen des Rindes [EU842924], Fäkalien des afrikanischen Elefanten [EU771855], des Blinddarmes von Hasen, Maus und Truthahn [EF445201, EU507073,DQ456442] und Fäkalien von Mensch, Schwein, Schaf, Ratte und des Weißkopfsakis [ DQ796799,AF371795, EU465584, DQ777942, EU461926] genannt. Die 16S rRNA Sequenzen, die der Familie der Eubacteriaceae zugeordnet wurden wiesen Sequenzidentitäten von 96,4 \%, 97,2\% und 96,4\% zu unkultivierten Bakterien von Fäkalien des Schweines [EU475093], der Hyäne [EU458353] und des Okapis [EU777315] auf.

Der einzige Vertreter der Klasse Erysipelotrichiales (Blv3_H09) des Phylums Firmicutes konnte der Familie der Erysipelotrichaceae zugeordnet werden. Der nächste ermittelte Verwandte auf Sequenzebene ist mit 90,5 \%iger Identität ein unkultiviertes Bakterium aus Proben des Blinddarmes der Maus [EU509084].

In Abbildung 36 wird der phylogenetische Stammbaum der Actinobacteria und Cyanobacteria dargestellt.

Insgesamt waren elf OTUs in dem Phylum Actinobacteria vertreten. In dem Phylum Cyanobacteria konnte ein OTU detektiert werden.

Die Sequenzen die den Actinobacteria zugeordnet wurden, konnten alle in die Ordnung der Coriobacteriales und Familie der Coriobacteriaceae eingeteilt werden. Die 16S rRNA Gensequenz Blv2_B11 zeigte eine 91,6 \%ige Identität zu dem 16S rRNA Gen des Bakteriums Adlercreutzia equolifaciens [AB306662]. Diese Bakterium wurde aus menschlichen Fäkalien isoliert. Die restlichen zehn Sequenzen (Blv4_C09, Blv1_F11, Blv2_D12, Blv4_E03, Blv3_E06, Blv4_A01, Blv4_B09, Blv3_C05, Blv2_A02 und Blv1_D10) zeigten nur Sequenzidentitäten zu 16S rRNA-Gensequenzen von unkultivierten Organismen. Es zeigten sich zwischen 90\% und 98,9 \%ige Sequenzidentitäten zu Bakterien aus verschiedenen Fäkalien, wie zum Beispiel Fäkalien des Menschen [DQ794611], des Gorillas [EU474337], der Gazelle [EU469019] oder des Schafes [EU773141].

Für das Phylum der Cyanobakterien wurde ein OTU detektiert. Es wurde in die Ordnung der Chroococcales eingeteilt. Die 16S rRNA Sequenz zeigt eine 99,1\%ige Identität zu einem unkultivierten Bakterium, dass mit einem humanen kolorektalen Darmkrebsgeschwür assoziiert war [EU530305 


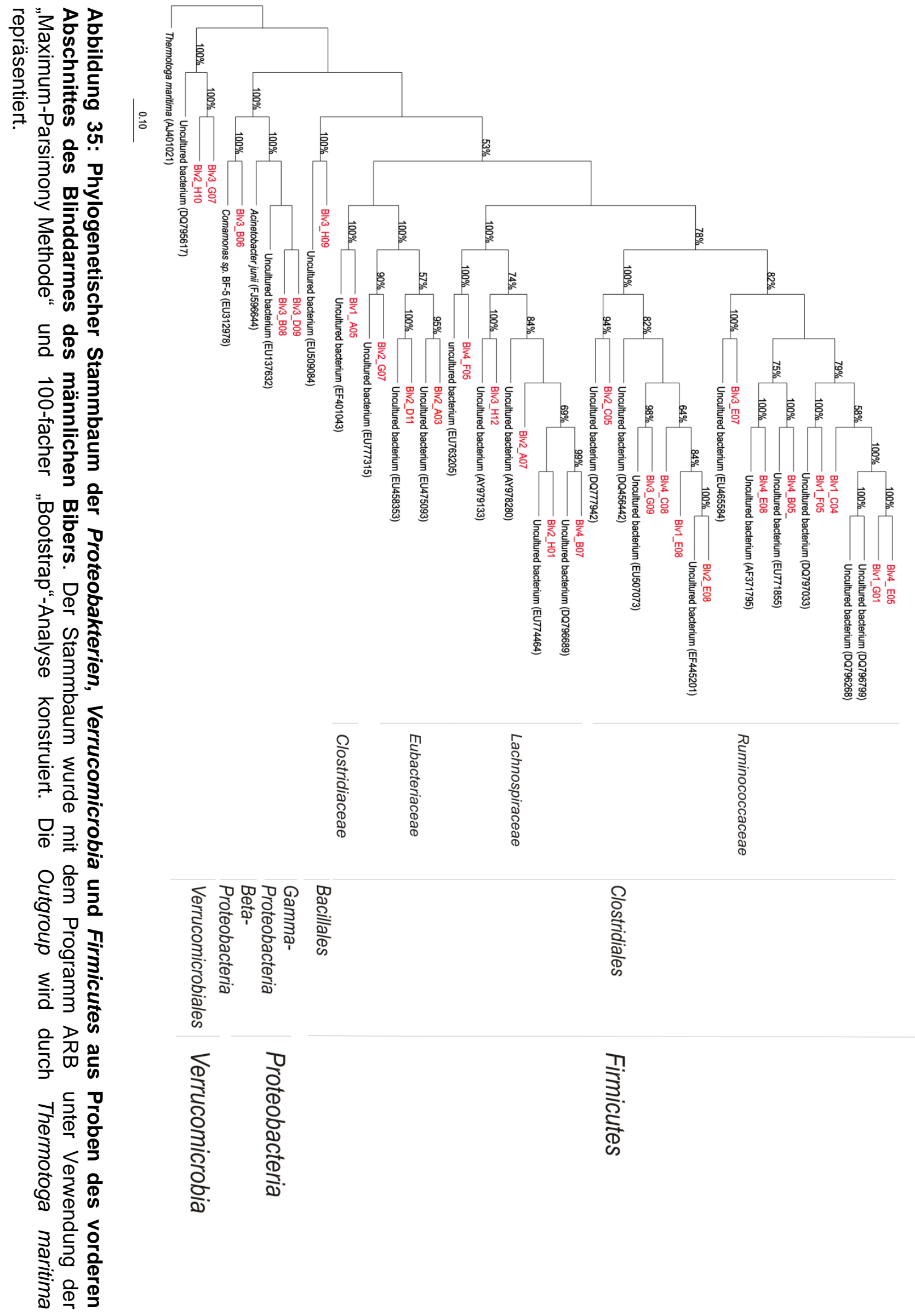




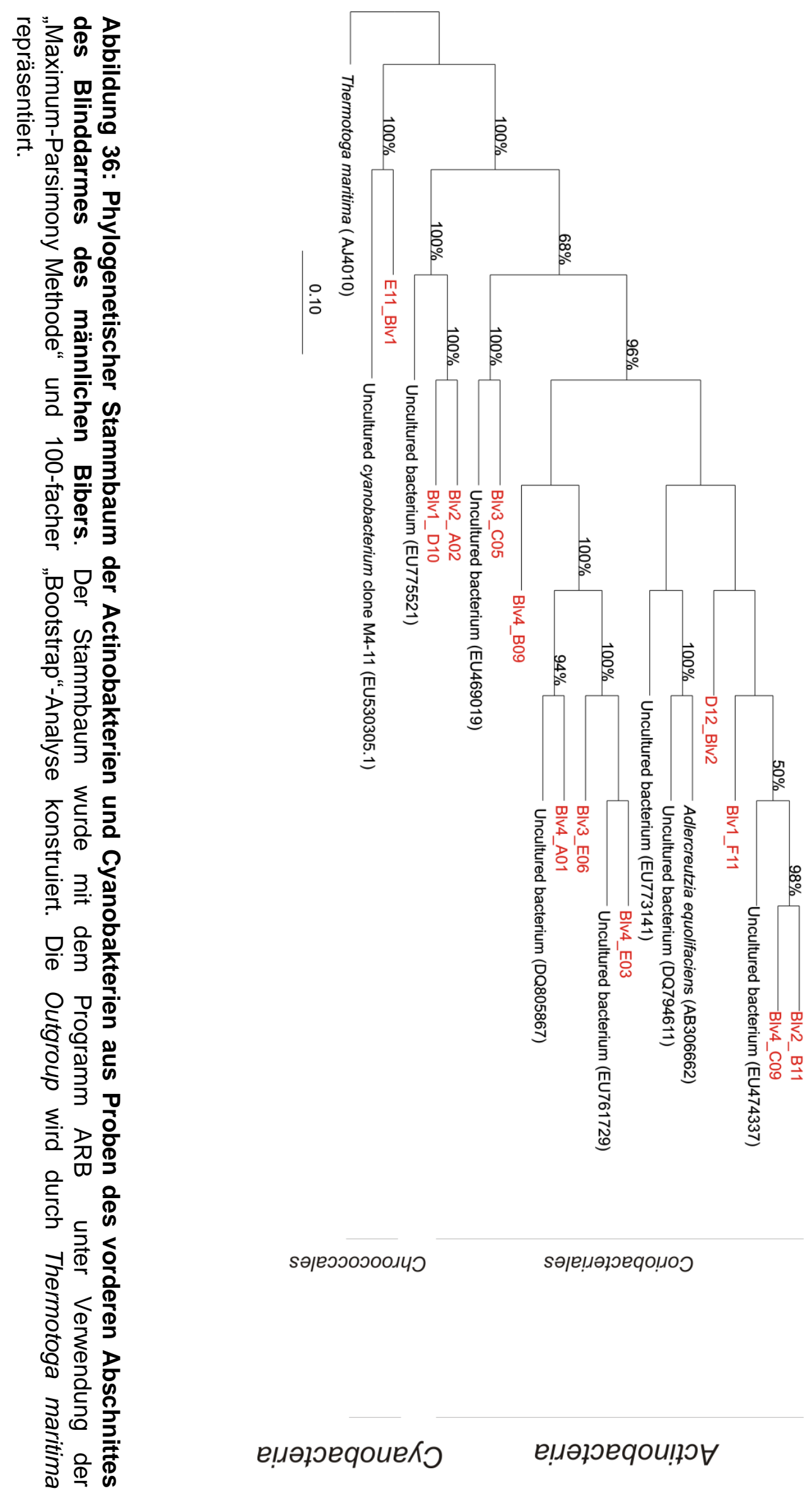




\subsubsection{Analyse der 16S rRNA Gensequenzen aus der Probe des hinteren Bereiches des Blinddarmes des männlichen Bibers}

Der Inhalt des hinteren Bereichs des Blinddarmes des Bibers zeigte im Vergleich zu dem vorderen Bereich eine flüssigere Konsistenz. Es konnten vereinzelt hölzerne Bestandteile identifiziert werden, die aber im Allgemeinen degradierter als im vorderen Bereich des Blinddarmes erschienen (Abbildung 37).

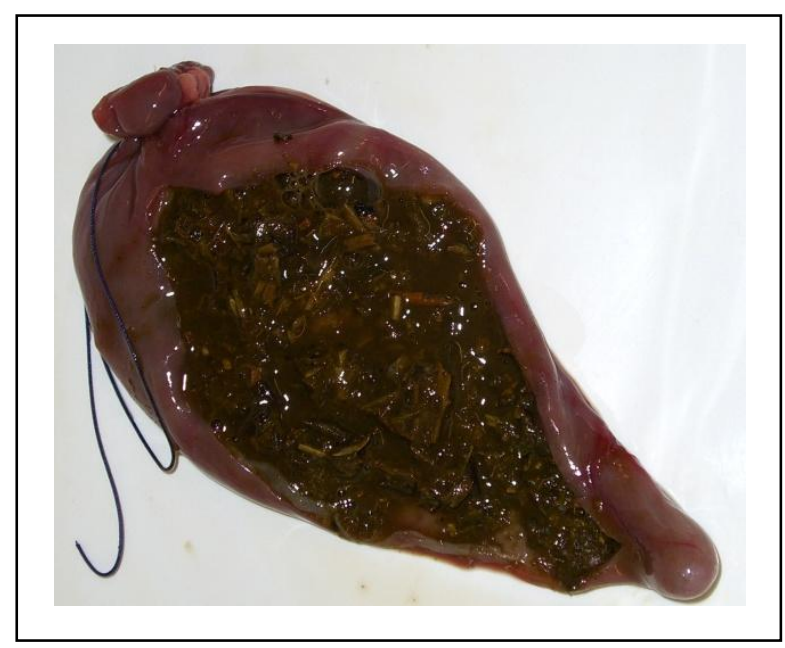

Abbildung 37: Geöffneter hinterer Bereich des Blinddarmes des männlichen Tieres

Zur Untersuchung der phylogenetische Diversität in dem hinteren Bereich des Blinddarmes des männlichen Tieres wurden sowohl klassische 16S rRNAGenanalysen, als auch Analysen unter der Verwendung der Methode der 454-Pyrosequenzierung partiell amplifizierter 16S rRNA Gene durchgeführt.

Für die klassische 16S Analyse wurden insgesamt 344 16S rRNA Gene amplifiziert und sequenziert. Es wurden $24,4 \%$ Chimäre detektiert und entfernt, so dass für die weitere Analysen $26016 \mathrm{~S}$ rRNA Gensequenzen mit Längen zwischen 813 bp und 1104 bp zur Verfügung standen. Nach der Einspeisung der Sequenzen in das Programm ARB wurde eine distance matrix erstellt und diese einer DOTUR Analyse unterworfen (s. II.9.3.) (Tabelle 12). Auf einer Distanzebene von $3 \%$ (Artenebene) konnten 35 OTUs detektiert werden. Laut ACE und Chao1 Abschätzungen waren auf dieser Ebene maximal 75 bzw. 67 OTUs möglich gewesen, so dass $46,7 \%$ bzw. 52,2 \% aller OTUs mit einer Ausschlußgrenze $<97 \%$ Ähnlichkeit abgedeckt wurden. 
Tabelle 12: Bestimmte und abgeschätzte Diversität der bakteriellen 16S rRNA Gensequenzen auf genetischen Distanzebenen von $1 \%, 3 \%$ und $20 \%$.

\begin{tabular}{lccc}
\hline $\begin{array}{c}\text { Genetische } \\
\text { Distanz }\end{array}$ & Detektierte OTUs & ACE & Chao1 \\
\hline 0,01 & 44 & 159 & 143 \\
0,03 & 35 & 75 & 67 \\
0,20 & 5 & 10 & 8 \\
\hline
\end{tabular}

In Abbildung 38 wird die rarefaction-Analyse der Distanzebenen $1 \%$, $3 \%$ und $20 \%$ grafisch dargestellt. Wie zu erkennen ist, wurde auf Phylumebene $(20 \%)$ eine ausreichende Abdeckung erreicht, während die Kurven auf Artenebene (3\%) und einer Distanz von $1 \%$ keine vollständige Abdeckung zeigen. Dies zeigt, dass mit klassischen 16S rRNA-Analysen ein grundsätzlicher Überblick über die Diversität in der Probe des hinteren Bereiches des Biberblinddarmes erstellt werden konnte.

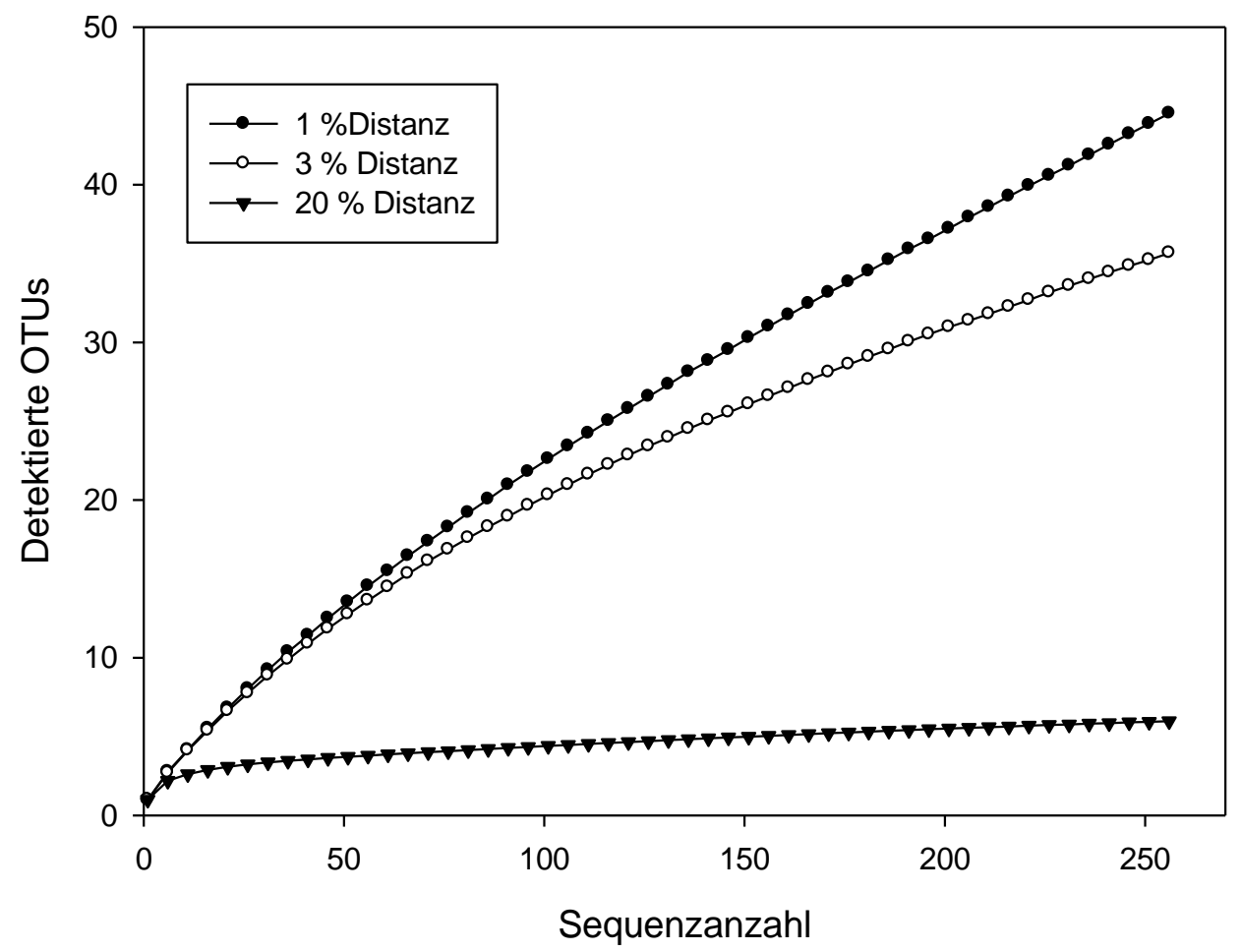

Abbildung 38: Mit DOTUR kalkulierte rarefaction-Kurven der Einteilung der amplifizierten 16S rRNA Gensequenzen in OTUs. Gezeigt sind die Einteilungen in OTUs auf genetischen Distanzebenen von $1 \%, 3 \%$ und $20 \%$. 
Neben der klassischen 16s rRNA Genanalyse wurde als Vergleich zudem die Methode der 454-Sequenzierung von partiell amplifizierten 16S rRNA Genen angewendet. Insgesamt konnten die Daten von partiellen 16S rRNAGensequenzen mit einer durchschnittlichen Länge von 264 bp für die Untersuchung der bakteriellen Diversität auf Phylumebene mit dem RDP Classifier eingesetzt werden. In Abbildung 39 werden die Ergebnisse der Einteilung der erhaltenen Sequenzdaten im Vergleich zu der klassischen 16S rRNA-Analyse dargestellt.

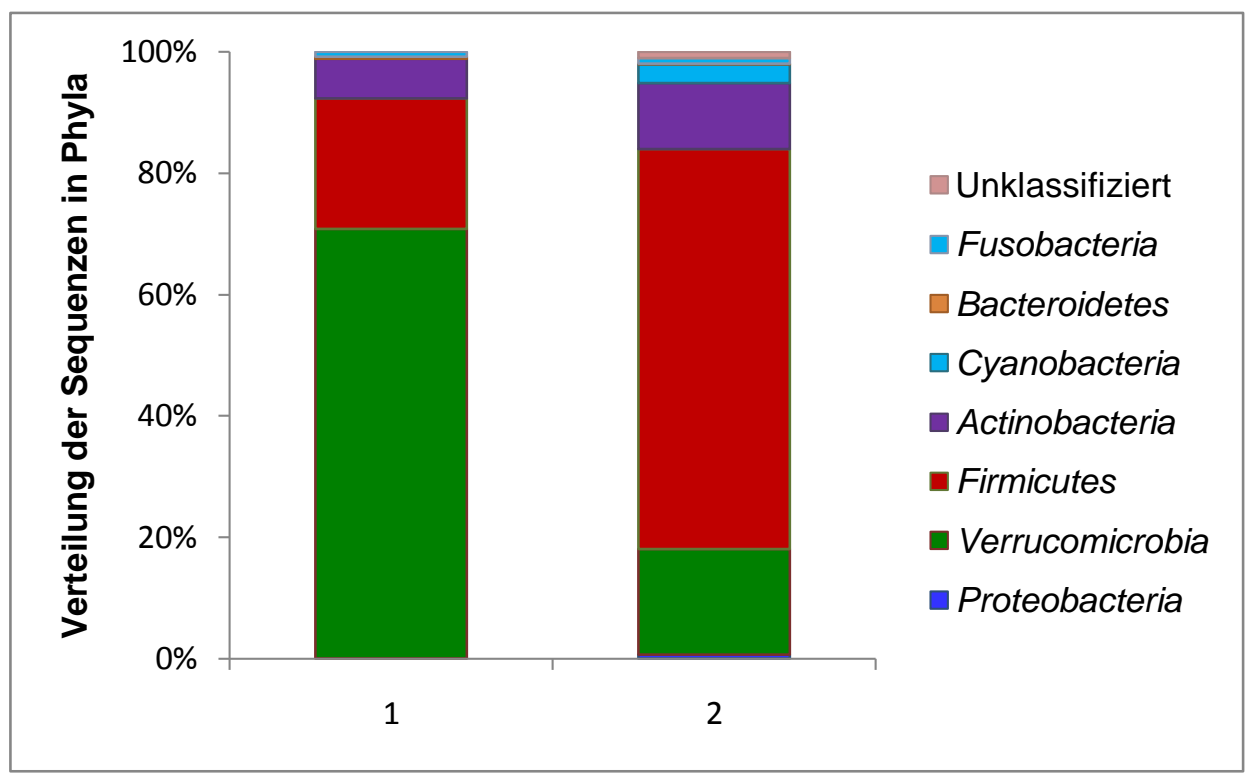

Abbildung 39: Vergleich der Ergebnisse der Einteilung der generierten 16S rRNAGensequenzdaten in Phyla durch die [1] klassische Methode (260 16S rRNAGensequenzen) und die Methode der 454-Pyrosequenzierung (53000 Sequenzen) aus dem Inhalt des hinteren Blinddarmbereiches.

Die Einteilung der 16S rRNA-Gensequenzen in Phyla erfolgte mit dem RDP ClassifierProgramm.

Es zeigen sich bei dem Vergleich der Einteilung der Sequenzdaten aus klassischer 16S rRNA-Analyse und aus der 454-Sequenzierung Unterschiede in der prozentualen Verteilung innerhalb der Phyla. Zudem konnten mittels 454 Sequenzierung zusätzliche Phyla identifiziert werden, die in der klassischen Analyse nicht detektiert werden konnten.

Während die Sequenzdaten der klassischen 16S rRNA-Analyse vorwiegend mit einem Prozentsatz von über $70 \%$ in das Phylum der Verrucomicrobia eingeordnet 
wurde, wurde dieses Phylum nur durch $17 \%$ der Sequenzen der 454-Pyrosequenzierung vertreten. Hingegen zeigte sich bei dem 454pyrosequenzierten Sequenzdatensatz eine vorwiegende Einteilung in das Phylum Firmicutes (66 \%), das im Datensatz der klassischen Analyse nur durch $23 \%$ aller Sequenzen vertreten wurde. Die Actinobacteria wurden in der klassischen Analyse mit $6 \%$ und in der 454-Sequenzierung mit $3 \%$ aller Sequenzen vertreten. Insgesamt wurden durch die 454-Sequenzierung der partiell amplifizieren $16 \mathrm{~S}$ rRNA-Gene alle Phyla gezeigt, die auch in der klassischen Analyse detektiert wurden.

Zudem konnten zwei weitere Phyla durch die Analyse des 454Sequenzdatensatzes identifiziert werden. Ein Anteil von $3 \%$ der partiellen $16 S$ rRNA Gensequenzen wurden den Cyanobacteria und 0,6\% den Proteobacteria zugeordnet. Ein Anteil von $1 \%$ der erhaltenen Sequenzdaten konnten keinem Phylum zugeordnet werden.

\subsubsection{Konstruktion phylogenetischer Stammbäume des hinteren}

\section{Abschnittes des Blinddarmes}

Für die Konstruktion phylogenetischer Stammbäume wurden die mittels DOTUR detektierten 44 OTUs der 16S rRNA-Genbank mit einer Ausschlussgrenze <99\% verwendet. Diese wurden in fünf Phyla eingeteilt. Jeweils ein OTU wurde in die Phyla Fusobacteria und Bacteroidetes eingeordnet. Den Verrucomicrobia wurden zwei OTUs zugeteilt. Die Firmicutes waren mit 33 OTUs, die Actinobacteria mit sieben OTUs vertreten. Die phylogenetischen Stammbäume wurden mit dem Programm „ARB“ unter der Verwendung der "Maximum-Parsimony“-Methode und 100-facher bootstrap - Analyse konstruiert.

In Abbildung 40A werden die Phyla Fusobacteria, Bacteroidetes und Verrucomicrobia in einem phylogenetischen Stammbaum dargestellt. Die Fusobacteria werden im hinteren Blinddarmbereich durch ein OTU vertreten (16S rRNA-Sequenz Cbm7_A05), das nicht weiter klassifiziert wurde. Der ähnlichste Treffer der 16S rRNA-Gensequenz in dem NCBI - Datenbankabgleich war mit 94,4\% Identität die 16S rRNA-Gensequenz eines unkultivierten Bakteriums aus menschlichen Fäkalien [EF401391], das der Ordnung Fusobacteriales und der Familie Fusobacteriaceae angehört. Die Bacteroidetes wurden durch ein OTU mit 
der 16S rRNA Gensequenz Cbm9_F04 vertreten. Diese konnte ebenfalls nicht in eine Ordnung oder Familie eingegliedert werden und zeigt $88 \%$ Sequenzidentität zu einem unkultivierten Bakterium aus dem Blinddarm der Maus [EF099724], In das Phylum der Verrucomicrobia wurden zwei OTUs eingeteilt (16S rRNA Sequenzen Cbm7_F01 und Cbm8_E02). Beide Sequenzen zeigten eine 94 \%ige Identität zu einem nicht kultivierten Bakterium aus menschlichen Fäkalien [DQ795617] und wurden den Verrucomicrobiales zugeordnet.

In Abbildung 40B wird ein Stammbaum der Actinobacteria dargestellt. Alle sieben detektierten OTUs dieses Phylums wurden in die Unterklasse Coriobacteridae und der Familie der Coriobacteriaceae zugeteilt. Die 16 S rRNA Gensequenz Cbm7_C10 zeigte eine 91 \%ige Identität zu dem Bakterium Adlercreutzia equolifaciens [AB306662], das aus menschlichen Fäkalien isoliert wurde. Die nächsten Nachbarn der restlichen sechs aus dem Blinddarminhalt amplifizierten $16 S$ rRNA Gensequenzen waren mit Sequenzidentitäten von $92 \%$ - $96 \% 16 S$ rRNA Gensequenzen unkultivierter Bakterien aus dem Blinddarm der Maus [AY993741] Fäkalien des Schafes [EU773141] oder aus menschlichen Fäkalien [DQ800380,DQ805867, DQ794611].

Das Phylum der Firmicutes wurde durch die meisten OTUs vertreten. 32 OTUs wurden in die Klasse der Clostridia und ein OTU wurde in die Klasse der Erysipelotrichi eingeordnet. Die 32 OTUs der Clostridia wurden innerhalb der Ordnung Clostridiales in drei Familien aufgeteilt, den Lachnospiraceae (8 OTUs), den Ruminococcaceae (18 OTUs) und Eubacteriaceae (6 OTUs). In der Familie der Lachnospiraceae zeigten sich Sequenzidentitäten von $94 \%-98 \%$ zu 16S rRNA-Gensequenzen unkultivierter Bakterien, die aus Proben von Fäkalien des Kängurus [AY776475], des Menschen [DQ824049, AY979133, FJ365126], des westlichen Gorillas [EU775456], des Warzenschweines [EU779326] und des Steppenschafes [EU470226] amplifiziert wurden. Die Familie der Ruminococcaceae wurden durch 16S rRNA Gensequenzen vertreten, die Identitäten von $97 \%$ - $98 \%$ zu 16S rRNA Genen unkultivierter Bakterien aus dem Blinddarms des Truthahns [DQ456423], des Hasen [EF445201] und der Maus zeigten. Desweiteren zeigten sich phylogenetische Beziehungen zu unkultivierten Bakterien aus Fäkalien der Ratte [DQ777942], des Schweines [DQ105657], des Schafes [EU474537] und des Menschen [EF434365,DQ803711,DQ796268, 
EF404072]. Hier wurden Identitäten von $93 \%$ bis $98 \%$ erreicht. Die 16S rRNA Sequenzen zweier OTUs (Cbm9_C02 und Cbm8_C12) zeigten Identitäten von $93 \%$ und $98 \%$ zu den aus den Pansen von Rentier [DQ394604] und des Rindes [EU842924] amplifizierten bakteriellen 16S rRNA-Genen. Die aus der Blinddarmprobe amplifizierten 16S rRNA-Gensequenzen, die der Familie der Eubacteriaceae zugeordnet wurden, zeigten Identitäten von $94 \%-98 \%$ zu $16 \mathrm{~S}$ rRNA Genen von unkultivierten Bakterien aus Proben des Blinddarmes der Maus [AY993741] oder aus Fäkalien aus Mensch [DQ800380,DQ794611, DQ805867] und Schaf [EU773141].

Das einzige OTU, das in die Klasse der Erysipelotrichi in dem Phylum Firmicutes eingeteilt wurde, wird durch die amplifizierte Sequenz Cbm8_A02 vertreten. Sie wurde in die Familie der Erysipelotrichaceae eingeordnet und zeigt eine $91 \%$ Sequenzidentität zu einer 16S rRNA Gensequenz, die aus Proben des Blinddarmes der Maus amplifiziert wurde [EU509712]. 

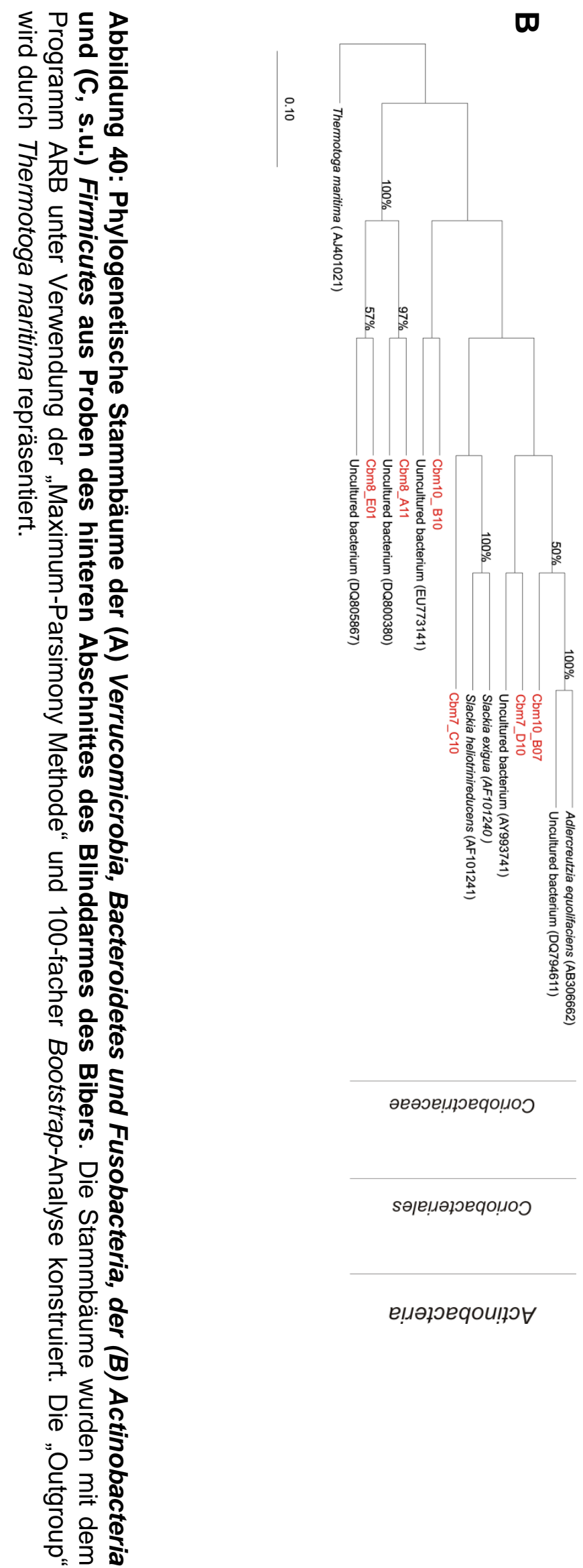

әеәэецџэеqоцоว

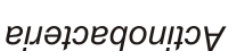

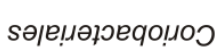
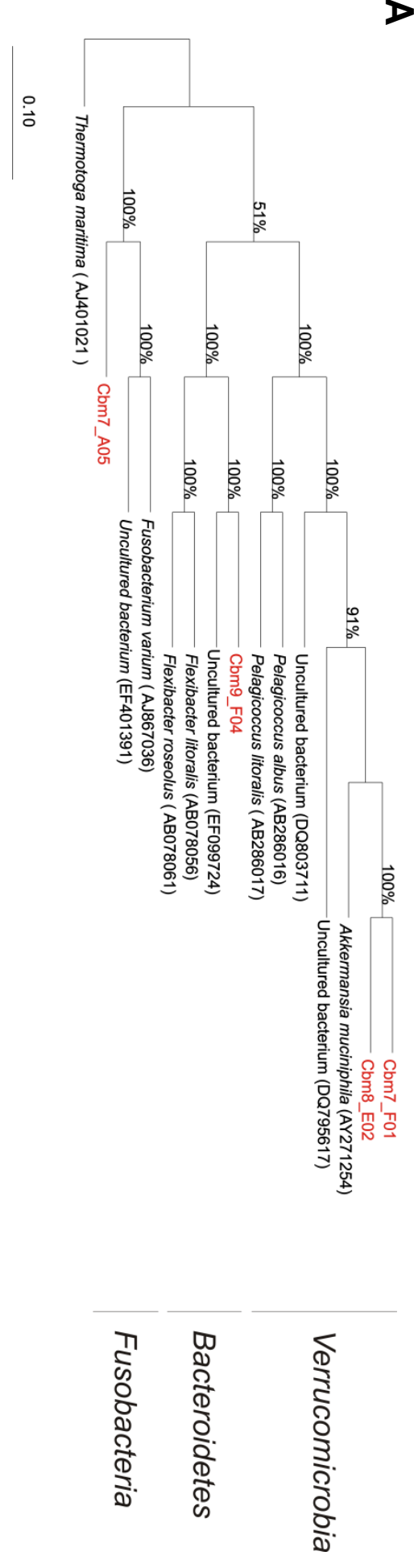
음
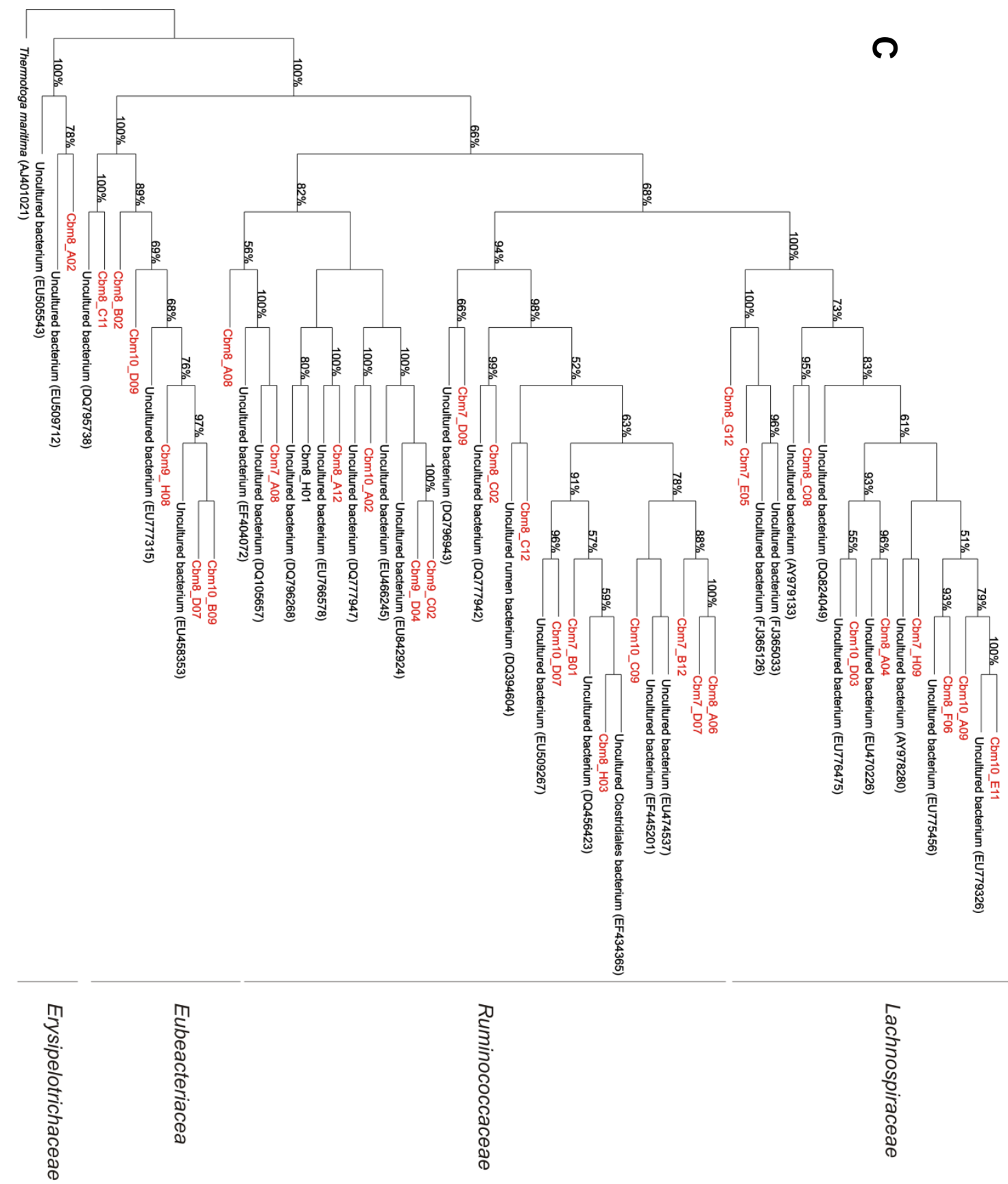


\subsubsection{Analyse der 16S rRNA Gensequenzen aus der Probe des Dickdarms des männlichen Tieres}

Für die phylogenetische Analyse wurden Proben aus dem unteren Bereich des Dickdarmes (Colons) entnommen, der in den Enddarm übergeht. Hier hatten sich schon sichtbare Kotkugeln ausgebildet, die aus Holzfasern und anderen Pflanzenbestandteilen bestanden (Abbildung 41).

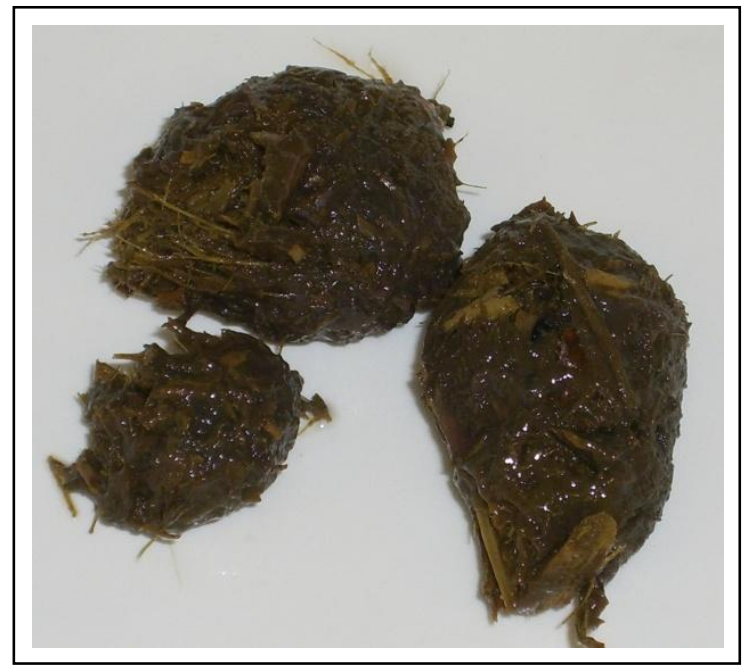

Abbildung 41 : Inhalt des Endbereiches des Dickdarms des männlichen Tieres

Es wurde sowohl eine klassische 16S rRNA Genanalyse unter der Verwendung von Sanger-sequenzierten, als auch eine Analyse mit Hilfe der 454Pyrosequenzierung partiell amplifizierter 16S rRNA Gene durchgeführt.

Für die klassische Analyse wurden insgesamt 257 16S rRNA Gene amplifiziert und sequenziert. Es wurden 10,5\% Chimäre detektiert und entfernt, so dass 229 16S rRNA-Gensequenzen mit einer Länge zwischen 925 bp und 1110 bp für die weitere Sequenzanalyse zur Verfügung standen. Die DOTUR-Analyse der Sequenzdaten (s. II.9.3.) ergab 27 OTUs in einer Ausschlußgrenze < $97 \%$ (Artenebene). Im Vergleich zu der abgeschätzten Artenvielfalt laut ACE und Chao1 wurden somit $35 \%$ bzw. 24, 1\% der potentiellen Arten abgedeckt (Tabelle 13). 
Tabelle 13: Bestimmte und abgeschätzte Diversität der bakteriellen 16S rRNA Gensequenzen auf Distanzebenen von $1 \%$, $3 \%$ und $20 \%$.

\begin{tabular}{cccc}
\hline $\begin{array}{c}\text { Genetische } \\
\text { Distanz }\end{array}$ & Detektierte OTUs & ACE & Chao1 \\
\hline 0,01 & 31 & 107 & 115 \\
0,03 & 27 & 77 & 112 \\
0,20 & 6 & 7 & 7 \\
\hline
\end{tabular}

In Abbildung 42 werden die rarefaction-Analysen auf den Distanzebenen 1\%, $3 \%$ (Arteneben) und $20 \%$ (Phylumebene) in einer Grafik dargestellt. Wie zu erkennen ist, zeigt die Kurve auf Phylumebene eine Absättigung, während auf Artenebene und einer Distanz von 1\% keine ausreichende Absättigung erreicht wurde. Somit konnte in der klassischen 16S rRNA-Genanalyse ein Überblick über die bakterielle Diversität im Dickdarm des Bibers geschaffen werden.

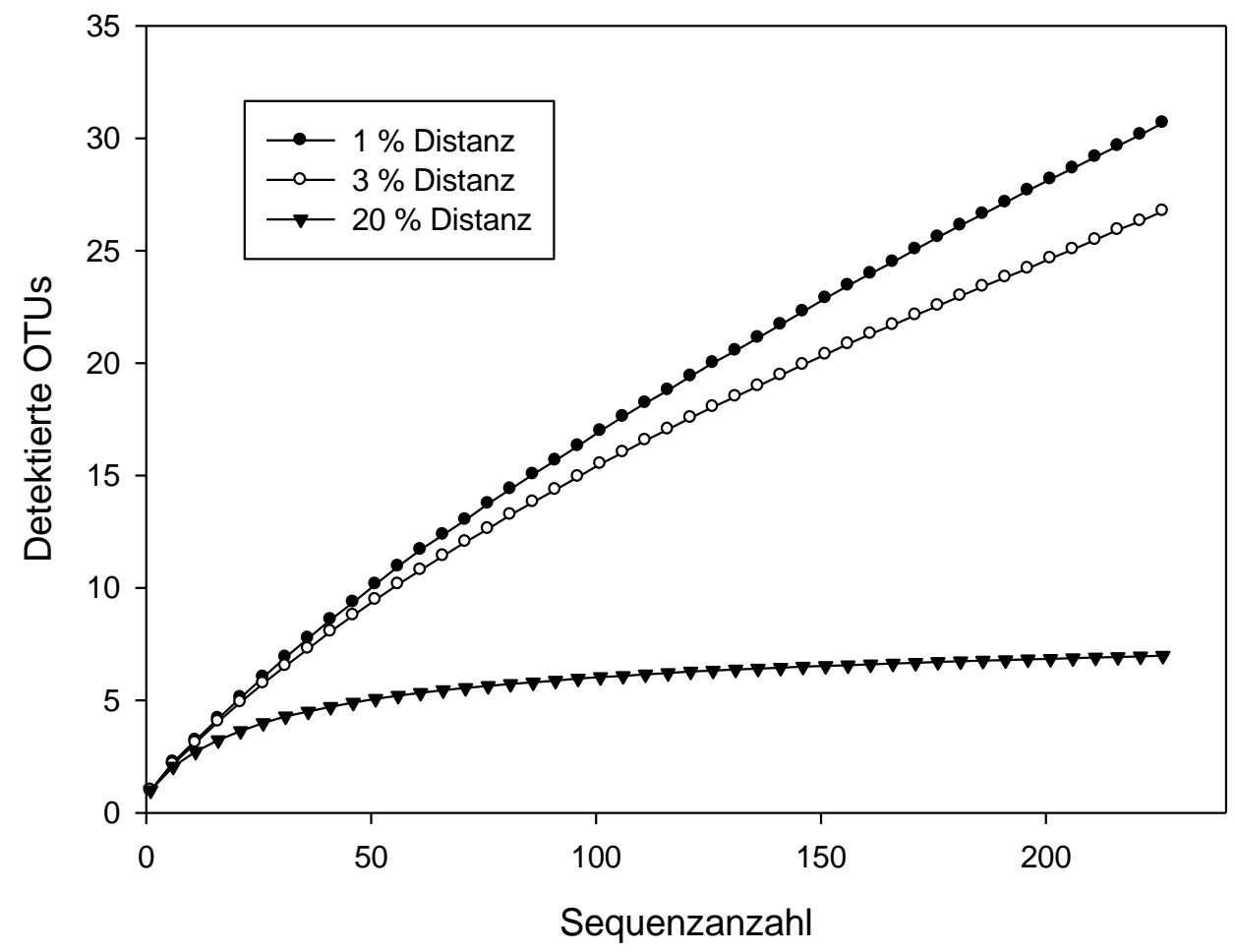

Abbildung 42: Mit DOTUR kalkulierte rarefaction-Kurven der Einteilung der amplifizierten 16S rRNA Gensequenzen in OTUs. Gezeigt sind die Einteilungen in OTUs auf genetischen Distanzebenen von $1 \%, 3 \%$ und $20 \%$. 
Neben der klassischen 16S rRNA Analyse wurde zudem eine 454-Sequenzierung partiell amplifizierter 16S rRNA-Genen durchgeführt. Insgesamt wurden hier 56731 partielle Gensequenzen mit einer durchschnittlichen Länge von 263 bp sequenziert. In Abbildung 43 werden die Ergebnisse der Einteilung der erhaltenen Sequenzdaten in Phyla mittels dem RDP Classifier im Vergleich zu der klassischen 16S rRNA-Analyse dargestellt.

Wie schon bei den Proben der Blinddarmabschnitte zeigt sich auch hier eine grundsätzliche Ähnlichkeit der Komposition der Phylaeinteilungen. Bei allen Ansätzen wurden die 16S rRNA-Gensequenzen in die Phyla Proteobacteria, Verrucomicrobia, Firmicutes, Actinobacteria, Bacteroidetes und Fusobacteria eingeordnet. Es zeigten sich jedoch erneut Unterschiede in der prozentualen Verteilung innerhalb der Phyla. So wurde in der klassischen 16S rRNAGenanalyse das Phylum der Verrucomicrobia mit etwa 79 \% der Sequenzdaten vertreten, während die Sequenzdaten der 454-Pyrosequenzierungsmethode dieses Phylum nur mit 43,5\% repräsentierten. Während die Firmicutes in der klassischen 16S rRNA-Analyse nur mit etwa $13 \%$ vertreten sind, zeigten sich anhand der 454-Pyrosequenzierung ein prozentualer Anteil von etwa $37 \%$. Das Phylum Actinobacteria wurde in beiden Methoden in ähnlichen Anteilen vertreten, in der klassischen Methode waren es 2,9\% und in dem 16S rRNA Sequenzdatensatz der 454-Pyrosequenzierung $3,8 \%$ aller 165 rRNAGensequenzen. Die Fusobacteria zeigten in der 454-Pyrosequenzierung der amplifizierten 16S rRNA-Genabschnitten einen Anteil von 4,5\%, während mittels der klassischen 16S rRNA-Analyse ein Prozentsatz von 0,4 \% erreicht wurde. Die Sequenzdaten der 454-Sequenzierung wurden zu $7 \%$, die der klassischen $16 S$ rRNA-Analyse zu 3,9\% in das Phylum Proteobacteria eingeordnet. 


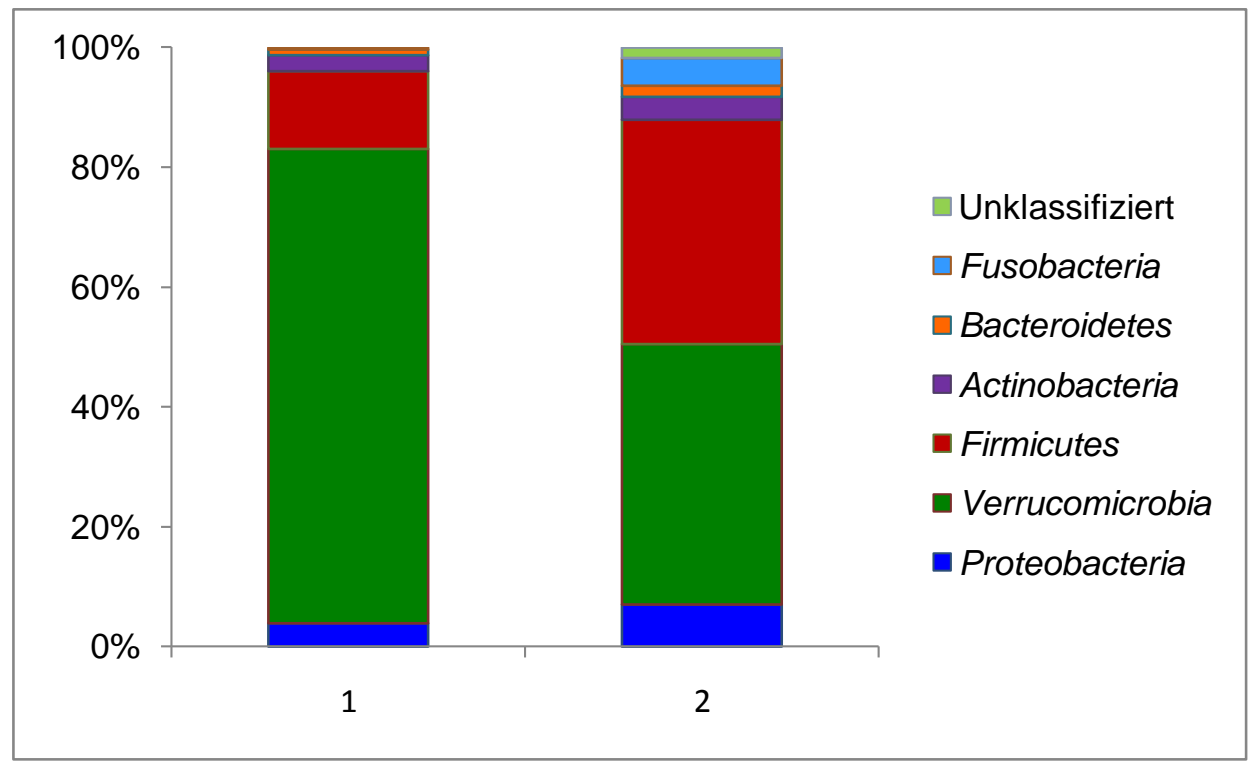

Abbildung 43: Vergleich der Ergebnisse der Einteilung der generierten 16S rRNAGensequenzdaten in Phyla durch die [1] klassische Methode (229 16S rRNAGensequenzen ) und die Methode der 454-Pyrosequenzierung (56731 Sequenzen) aus dem Inhalt des Dickdarms. Die Einteilung der 16S rRNA-Gensequenzen in Phyla erfolgte mit dem RDP Classifier-Programm.

\subsubsection{Konstruktion phylogenetischer Stammbäume des Inhaltes des Endbereiches des Dickdarmes}

Für die Konstruktion phylogenetischer Stammbäume der bakteriellen Diversität im Colon (Dickdarm) des männlichen Bibers wurden OTUs mit einer Ausschlussgrenze unter $99 \%$ genetischer Distanz verwendet. Für die Berechnung der Stammbäume mit dem Programm ARB wurde die "Maximum-Parsimony"Methode in einer 100-fachen bootstrap - Analyse eingesetzt.

Die mittels DOTUR detektierten 31 OTUs wurden in sechs verschiedene Phyla eingeteilt. Insgesamt drei OTUs wurden in das Phylum Proteobacteria eingeordnet. Den Fusobacteria wurde 1 OTU und den Phyla Bacteroidetes und Verrucomicrobia wurden jeweils zwei OTUs zugeordnet. Das Phylum Firmicutes wurde von dem Hauptanteil der OTUs vertreten. 19 OTUS wurden in dieses Phylum eingegliedert. In dem Phylum Actinobacteria wurden 4 OTUs detektiert. In Abbildung 44A wird ein phylogenetischer Stammbaum dargestellt, der die Phyla Proteobacteria, Fusobacteria, Bacteroidetes und Verrucomicrobia repräsentiert. 
Das Phylum der Proteobacteria wurde durch jeweils ein OTU in den Klassen Gamma-, Beta- und Deltaproteobacteria vertreten. Die 16S rRNA-Gensequenz Co2_H12, die in die Ordnung der Enterobacteriales und Familie der Enterobacteriaceae der Klasse der Gammaproteobacteria eingeordnet wurde, zeigt eine 99,6 \%ige Sequenzidentität zu einem unkultivierten Bakterium aus dem Darmtrakt des Schwarzkäfers [AJ487021]. Der Klasse der Betaproteobacteria und in die Ordnung der Burkholderiales wurde die 16S rRNA-Gensequenz Co1_C10 zugeteilt. Die Sequenz stimmt mit einer Sequenzidentität von 94,6 \% mit einer 16S rRNA Gensequenz eines nicht kultivierten Bakteriums aus menschlichen Fäkalien [EF405224] überein. Die 16S rRNA -Sequenz Co2_G11 wurde den Deltaproteobacteria zugeordnet und in die Ordnung Desulfovibrionales und Familie der Desulfovibrionaceae eingeteilt. Der nächste Nachbar ist mit 95,3 \%iger Sequenzidentität eine 16S rRNA-Gensequenz eines unkultivierten Bakterium aus dem Darmtrakt des Eichhörnchens [EU459956].

Das Phylum Fusobacteria wurde durch ein OTU repräsentiert. Eine weitere Klassifizierung in eine Ordnung oder Familie erfolgte nicht. Die 16S rRNAGensequenz zeigte eine 94,9 \%ige Identität zu einem nicht kultivierten Bakterium aus Fäkalien des Buschhundes [EU772848].

Zwei OTUs wurden in das Phylum Bacteroidetes ohne weitere Klassifizierung eingeordnet. Die 16S rRNA Sequenzen wiesen Sequenzidentitäten von 94,2 \% bzw. 93,6 \% zu unkultivierten Bakterien aus den Fäkalien der Maus [EU656107] und des Warzenschweines [EU779316] auf. Ebenfalls zwei OTUs wurde dem Phylum Verrucomicrobia und der Ordnung der Verrucomicrobiales zugeteilt. Die entsprechenden 16S rRNA-Gensequenzen wiesen Identitäten von 94,9\% und 94,2 \% zu Bakterien aus menschlichen Fäkalien [DQ795617] und aus dem Blinddarm der Maus [EU456712] auf.

In Abbildung 44B ist der phylogenetische Stammbaum der Firmicutes und Actinobacteria dargestellt. Insgesamt wurden den Firmicutes 19 OTUs zugeteilt, während dem Phylum der Actinobacteria vier OTUs zugeteilt wurden.

In dem Phylum Firmicutes waren die Klassen Clostridia (16 OTUs) und Erysipelotrichi (3 OTUs) vertreten. Alle OTUs der Klasse der Clostridia wurden in die Ordnung Clostridiales eingeteilt. Hier fand eine weitere Klassifizierung in die Familien der Lachnospiraceae (4 OTUs), Eubacteriaceae (3 OTUs) und Ruminococcaceae (9 OTUs) statt. Die 16S rRNA-Gensequenzen, die der Familie 
der Lachnospiracea zugeteilt wurden, zeigten Identitäten von 96,1\% bis 97,7\% zu 16S rRNA Gensequenzen, die aus Fäkalien des Klammeraffens [EU462142], des Kängurus [EU776475] oder des Menschen [EU762918, EU979133] amplifiziert wurden. Die nächsten Nachbarn der in die Familie der Eubacteriaceae eingeteilten 16S rRNA Sequenzen waren mit $91,5 \%$ bis $97,1 \%$ die $16 \mathrm{~S}$ rRNA Gensequenzen von unkultivierten Bakterien aus Fäkalien der Hyäne [EU458353], des Blinddarmes der Maus [EF097941] und Klärschlamm in einer Kläranlage [EU478748]. Der Datenbankabgleich der 16S rRNA-Gensequenzen der neun OTUs, die in die Familie der Ruminococcaceae eingeordnet wurden, ergab Identitäten von $95,8 \%$ bis $98,9 \%$ zu $16 \mathrm{~S}$ rRNA-Gensequenzen, die aus den Fäkalien des Weisskopfsakis [EU461926], des Springbocks [EU778755] des Gorillas und Schimpansen [EU469921, EU774380] und des Menschen [FJ365778, AY976010], sowie aus dem Blinddarm des Truthahns [DQ455830] und aus dem Rinderrumen [EU842232] amplifiziert wurden. Die 16S rRNA-Gensequenz Co1_B12 zeigte eine Identität von 94,8 \% zu dem 16S rRNA Gen des "Clostridiales Bakterium DJF-B152“ [EU728715]. Dieses Bakterium wurde aus dem Intestinaltrakt des Schweines isoliert.

Die 3 OTUs die der Klasse der Erysipelotrichi zugeordnet wurden, konnten alle in die Familie der Erysipelotrichaceae eingeteilt werden. Hier ergaben sich bei dem Datenbankabgleich der amplifizierten 16S rRNA Sequenzen Identitäten von $92 \%$ bis $92,5 \%$ zu 16S rRNA Genen unkultivierter Bakterien aus dem Blinddarm der Maus [EU507578, EU511408] und Fäkalien der Ratte [ DQ777940].

Das Phylum Actinobacteria wurde durch vier OTUs repräsentiert. Alle OTUs wurden in die Unterklasse der Coriobacteridae und in die Familie der Coriobacteriaceae eingeordnet. Hier ergaben sich bei dem Datenabgleich der amplifizierten 16S rRNA-Gensequenzen Identitäten von $89,3 \%$ bis $92,7 \%$ zu $16 \mathrm{~S}$ rRNA Genen von unkultivierten Bakterien aus Fäkalien des Gorillas [EU474337, EU775521] und des Blinddarmes der Maus [EU511816]. 

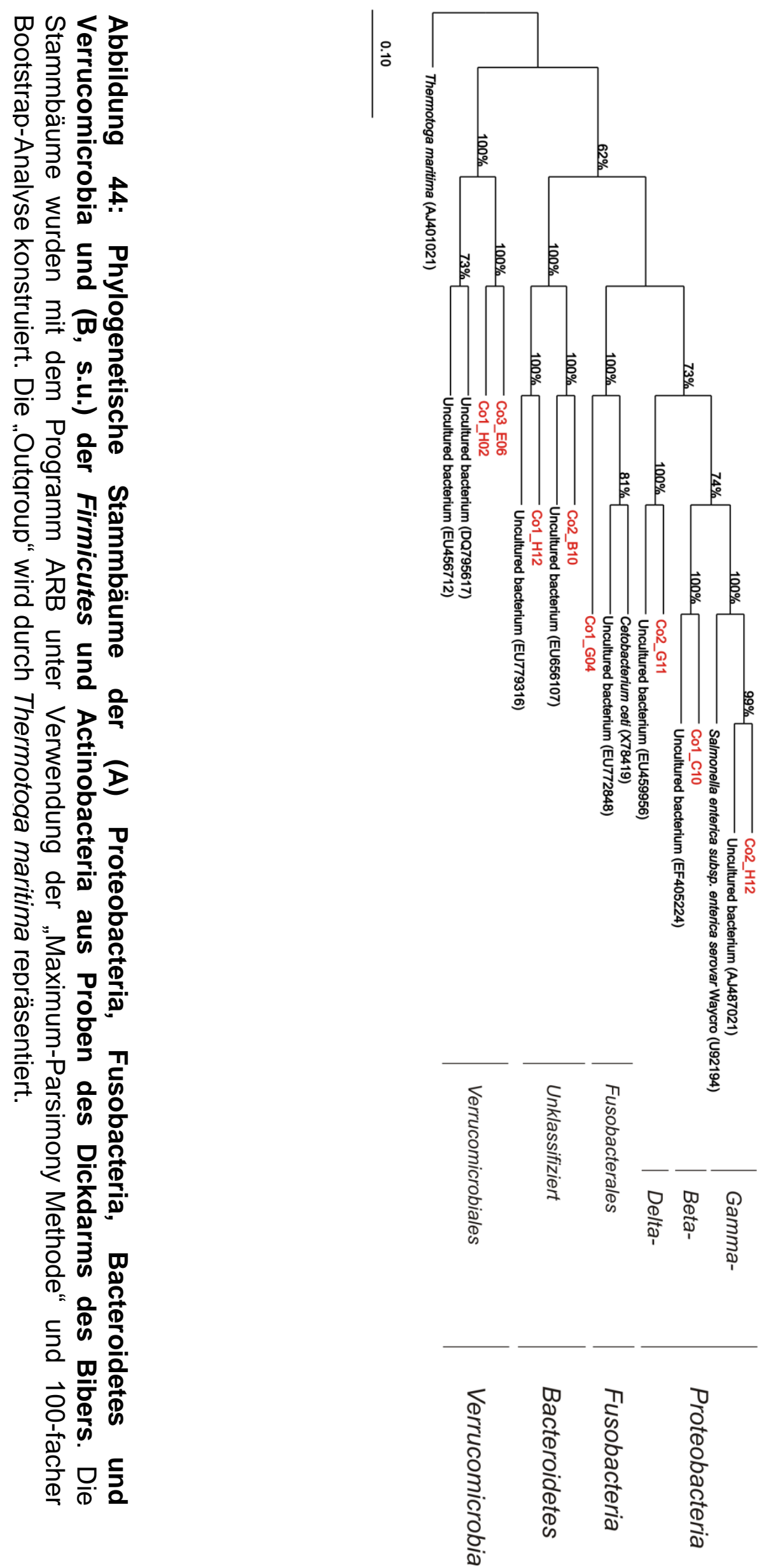

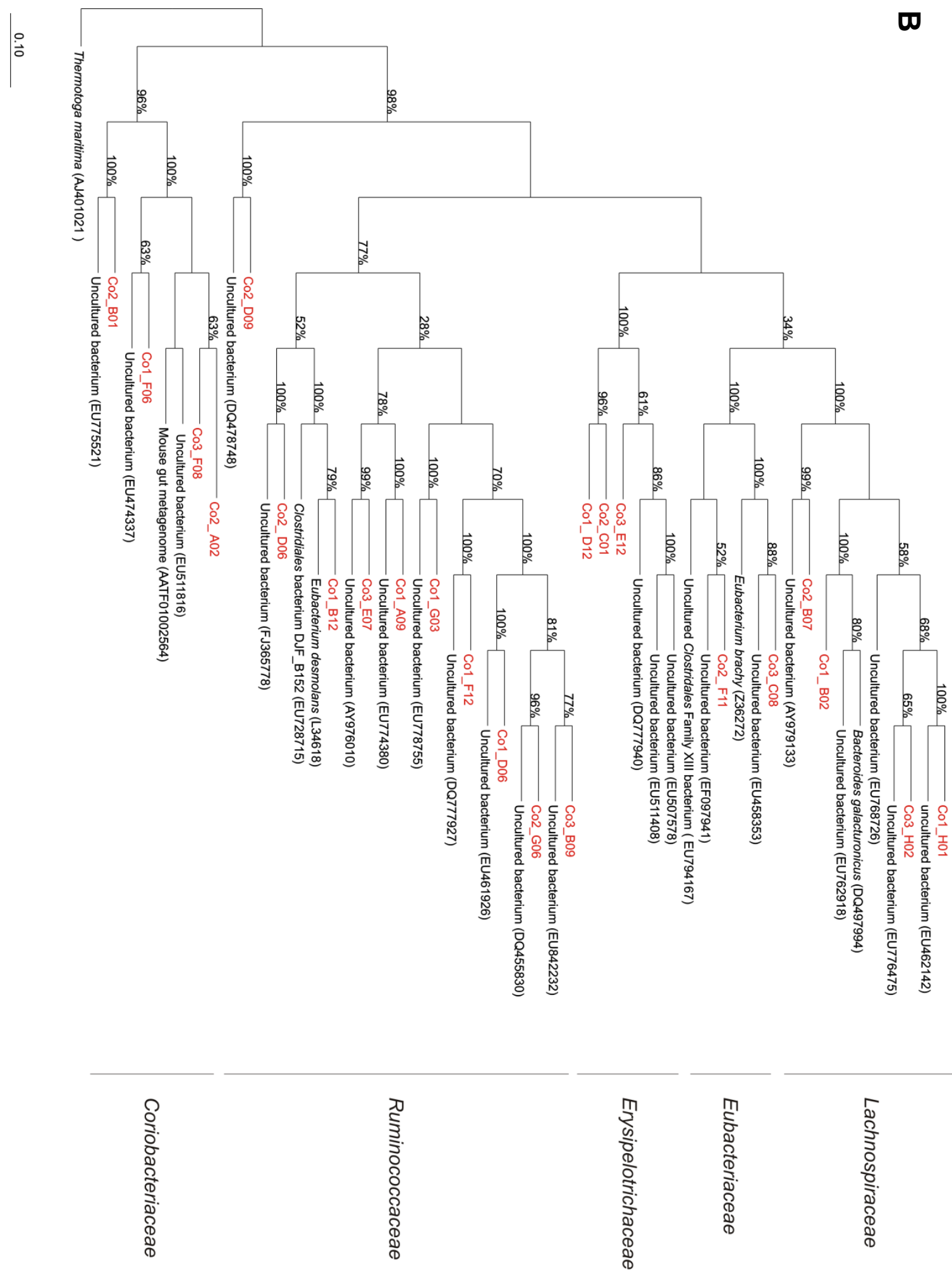


\subsection{Vergleich der bakteriellen Diversität in den hinteren Abschnitten des Blinddarms des weiblichen und männlichen Tieres}

In dieser Analyse wurden die bakterielle Diversitäten in den Blinddärmen zwischen des im Oktober verstorbenen, männlichen Tieres und des im Juli verstorbenen weiblichen Tieres untersucht. $\mathrm{Da}$ in diesen beiden Jahreszeiten ein unterschiedliches Nahrungsangebot für den Biber bereit steht, sollte sich parallel dazu die mikrobielle Zusammensetzung der Blinddarmflora unterscheiden. Während die Nahrung im Sommer vorwiegend aus Gräsern und anderen Pflanzen wie z.B. Seerosen besteht, steht dem Biber im Herbst/Winter nur schwer verdauliche Nahrung wie Rindenholz von Pappel, Weide oder anderen Weichhölzern zur Verfügung.

Die unterschiedliche Ernährungsweisen des im Sommer und des im Herbst verstorbenen Tieres zeigte sich auch in der Konsistenz der entsprechenden Blinddarminhalte. Während im Blinddarm des Weibchens, das im Sommer verstarb, fast ausschließlich Gräser zu finden waren, bestand der Blinddarminhalt des männlichen Bibers vorwiegend aus holzigen Bestandteilen (Abbildung 45).

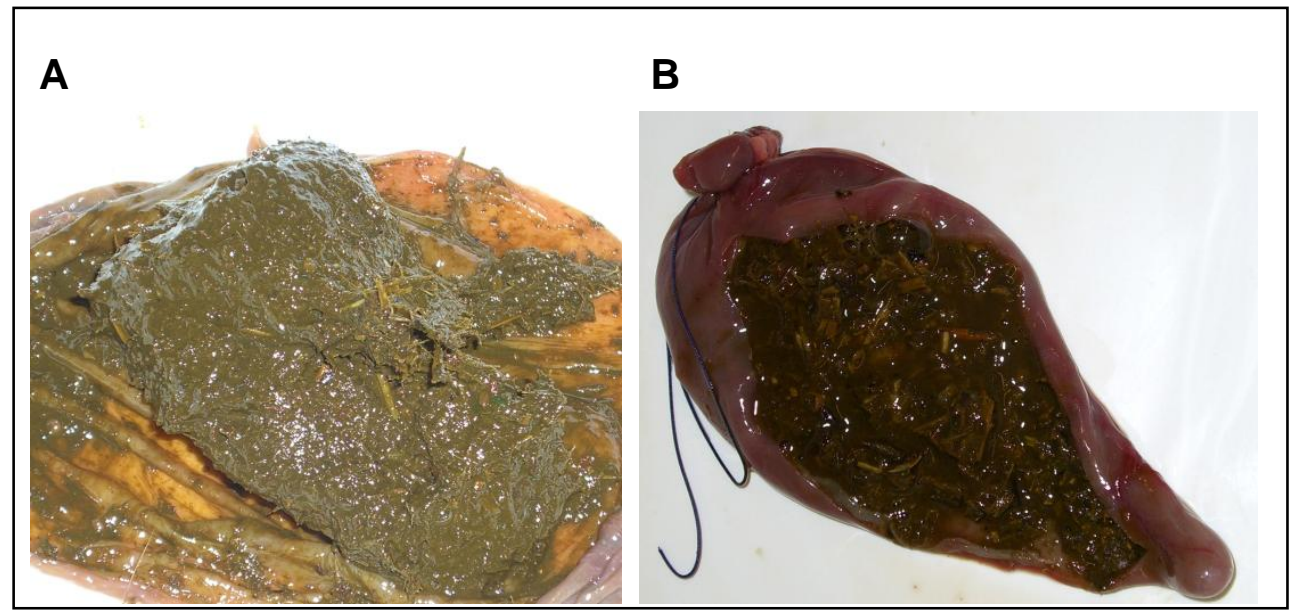

Abbildung 45: Inhalte der hinteren Blinddarmabschnitte des weiblichen (A) und männlichen Bibers (B).

Zur Untersuchung der bakteriellen Diversität in dem Blinddarm der Biber wurde zunächst die enthaltene Gesamt-DNA isoliert (s. II.5.4.3.). Es folgte eine partielle 
Amplifikation von bakteriellen $16 \mathrm{~S}$ rRNA-Genen mit den Primern 454V2.for und 454V3.rev (s. Il.1, Tabelle 3) mit der Pfu-Polymerase mittels PCR (s. II.5.6.1). Für jede Probe wurden jeweils drei voneinander unabhängige PCRs durchgeführt. Anschließend wurden die drei PCR-Produkte jeder Probe im gleichen Verhältnis zueinander vereinigt. Nachdem die PCR-Produkte entsprechend II.5.12.2. vorbereitet wurden, erfolgte die Sequenzierung mit der 454-Pyrosequenzierungsmethode im $\mathrm{G}_{2} \mathrm{~L}$ Göttingen.

Insgesamt konnten für die Probe des Blinddarminhaltes des Männchens 53000 partielle 16S rRNA-Gensequenzen mit einer durchschnittlichen Länge von 264 bp sequenziert werden. Die Probe aus dem weiblichen Tier ergab 43486 16S rRNAGensequenzen mit einer durchschnittlichen Länge von 261 bp.

Die erhaltenen Sequenzdaten wurden anschließend mittels RDP Classifier bakteriellen Phyla zugeteilt. In Abbildung 46 wird die Einteilung der beiden Proben in Phyla grafisch dargestellt.

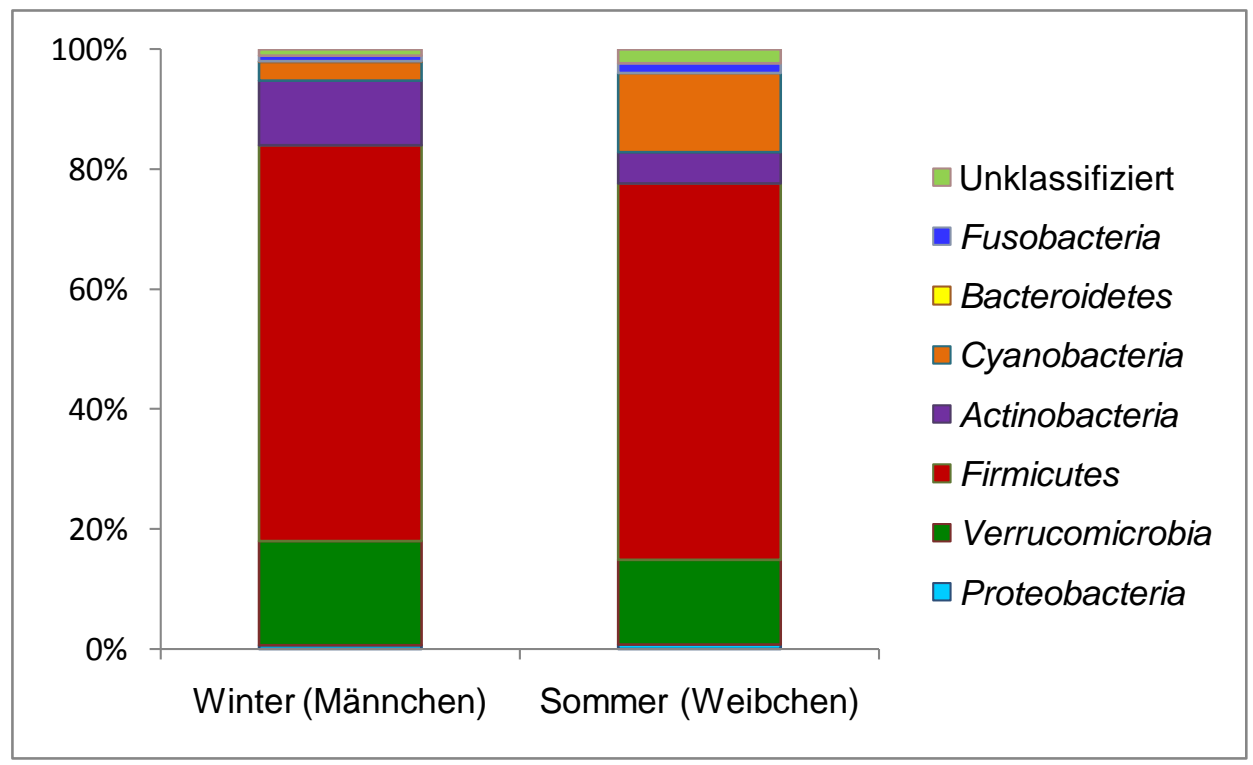

Abbildung 46: Einteilung der Sequenzdaten der partiell amplifizierten bakteriellen 16S rRNA-Gene der mikrobiellen Gemeinschaft aus dem Blinddarminhalt des männlichen und weiblichen Bibers

Wie in Abbildung 46 zu erkennen ist, zeigten sich Unterschiede zwischen den Proben des im Herbst verstorbenen männlichen und im Sommer verstorbenen 
weiblichen Bibers vorwiegend bei der prozentualen Verteilung der 454-Pyrosequenzierungsdaten innerhalb der identifizierten Phyla. Grundsätzlich konnten bei beiden Tieren die gleichen Phyla identifiziert werden, mit der Ausnahme, dass bei dem weiblichen Tier das Phylum der Bacteroidetes nicht vertreten wurde. Die Sequenzdaten beider Tiere wurden in die Phyla Proteobacteria, Verrucomicrobia, Firmicutes, Actinobacteria, Cyanobacteria und Fusobacteria eingeteilt. Bei der Probe des männlichen Bibers konnten 1,1\% und beim weiblichen Tier 2,4\% der Sequenzdaten keinem Phylum zugeordnet werden.

Bei beiden Tieren zeigte sich ein ähnlicher Prozentanteil der Phyla Proteobacteria mit $0,6 \%$ beim Männchen und $0,7 \%$ beim Weibchen. Das Phylum der Verrucomicrobia wurde bei dem männlichen Tier mit $17,4 \%$ der Sequenzdaten vertreten, beim weiblichen Tier wurde ein Prozentsatz von $14 \%$ erreicht. Der höchste Anteil der amplifizierten partiellen 16S rRNA-Gene wurde bei beiden Tieren dem Phylum der Firmicutes zugeordnet (Männchen 65,9 \%, Weibchen $62,5 \%$ ). Das Phylum der Fusobacteria wurde beim Männchen mit 0,9\% und beim Weibchen mit $1,7 \%$ vertreten.

Die größten Unterschiede zwischen den beiden Tieren wurden in der prozentualen Verteilung der 16S rRNA-Gensequenzen in die Phyla Actinobacteria und Cyanobacteria detektiert. Während beim männlichen Tier 10,9\% aller Sequenzen in das Phylum Actinobacteria eingeordnet wurde, ergab die Analyse der Sequenzdaten der Probe des weiblichen Tieres nur einen Anteil von 5,2\%. Bei der Einteilung der 16S rRNA-Gensequenzen in das Phylum der Cyanobacteria zeigte sich ein noch deutlicherer Unterschied. Während beim männlichen Biber nur 3,1\% aller Sequenzdaten in dieses Phylum eingeordnet wurden, betrug der Anteil bei der Probe des weiblichen Tieres einen Prozentsatz von 13,2\%. Desweiteren wurden in der Probe des männlichen Tieres zudem 16S rRNAGensequenzen von Bakterien des Phylums Bacteroidetes mit einem Anteil von $0,15 \%$ identifiziert. 


\subsection{Konstruktion von Genbanken mit metagenomischer DNA aus dem hinteren Caecumbereich}

Im Rahmen dieser Arbeit wurde versucht, mit DNA aus dem hinteren Caecumbereich metagenomische Genbanken zu konstruieren. Es sollten sowohl Plasmid- als auch Fosmidgenbanken erstellt werden. Hierfür wurde DNA aus dem Caecuminhalt mit den in II.5.5.6.1-4 dargestellten Methoden isoliert. Bei allen Isolierungsmethoden wies die DNA eine starke Scherung auf (Beispiel Abbildung 47 mit Methode II.5.4.4.). Wie in Abbildung 47 erkenntlich ist, tritt eine Anhäufung von Nukleinsäuren in dem Bereich zwischen 250- und 1000 bp auf. Da vermutet wurde, dass es sich hierbei um RNA handelt, wurde die Probe einer zusätzlichen RNAse-Behandlung unterzogen. Da dies keinen Einfluss auf die Nukleinsäuren in diesem Bereich hatte, wurde davon ausgegangen, dass es sich nicht um RNA, sondern um stark degradierte DNA handelte.

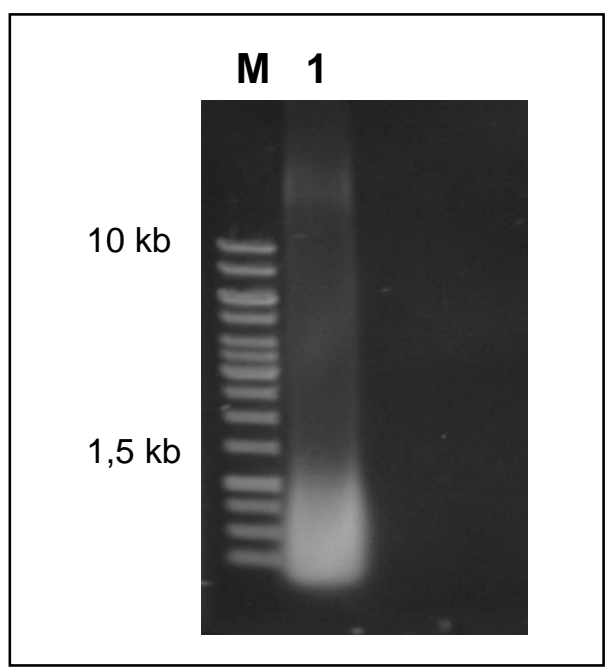

Abbildung 47: Aus dem Inhalt des hinteren Bereiches des Blinddarmes isolierte DNA. 0,8 \%iges analytisches Agarosegel. M, Größenstandard (250 bp - 10 kb, Gene Ruler $^{\mathrm{TM}} 1 \mathrm{kB}$ DNA Ladder, MBI Fermentas, St Leon-Rot); 1, isolierte DNA aus dem Caecuminhalt.

Die DNA wurde verwendet, um laut II.5.11.1 bzw. II.5.11.2. Fosmid- bzw. Plasmidgenbanken zu erstellen. Trotz der Verwendung verschieden isolierter DNA-Ausgangsproben blieb die Konstruktion von metagenomischen Genbanken aus dem Inhalt des hinteren Caecumbereiches erfolglos. 


\section{Diskussion}

Schätzungen gehen davon aus, dass $4-6 \times 10^{30}$ Prokaryoten die Erde besiedeln (Whitman et al., 1998). Als älteste Lebensform haben prokaryotische Mikroorganismen im Laufe der Zeit eine enorme physiologische und funktionelle Diversität entwickelt und stellen daher die Mehrheit der genetischen Diversität auf der Erde. Traditionelle Methoden, um diese genetischen Informationen zu erschließen umfassten die Kultivierung der Mikroorganismen, um anschließend individuelle Vertreter mit dem gewünschten Phänotyp zu identifizieren. Diese Vorgehensweise wird durch die Tatsache limitiert, dass unter Standardlaborbedingungen nur etwa geschätzte $1 \%$ aller Mikroorganismen kultivierbar sind (Torsvik und Øvreås, 2002). Diese Problematik wird durch die Methodik der Metagenomik in heutigen wissenschaftlichen Studien umgangen. Hier kann die gesamte genetische Information aller Mikroorganismen eines Habitats genutzt werden ohne diese zuvor kultivieren zu müssen. Die genetischen Informationen können so verwendet werden, um nicht nur Aussagen über die phylogenetische Diversität eines Standortes zu treffen, sondern auch neuartige Biokatalysatoren und bioaktive Substanzen zu identifizieren.

\section{1: Durchmusterung der metagenomischen Fosmidgenbank aus Umweltbodenproben des Avachinsky Kraters in Kamchatka/Sibirien auf cellulolytische und hemicellulolytische Enzyme}

Für die Durchmusterung metagenomischer Genbanken bieten sich zwei verschiedene methodische Ansätze an. Zum einen können neuartige Biokatalysatoren mittels einer Sequenz-basierten Analyse der enthaltenen Umwelt-DNA detektiert werden, zum anderen kann die Durchmusterung auf funktioneller Ebene erfolgen, indem mittels verschiedener Methoden Enzymaktivtäten der rekombinanten E. coli Genbank-Klone detektiert werden (Streit und Schmitz, 2004). In der Sequenz-basierten Durchmusterung werden Gene mit Oligonukleotiden, die schon von bekannten Genen abgeleitet wurden, direkt aus der genetischen Information der Genbank mittels PCR amplifiziert. Eine weitere Möglichkeit ist die Sequenzierung der gesamten metagenomischen DNA. Hier können anschließend Gene für interessante Enzyme durch die Verwendung 
bioinformatischer Methoden identifiziert werden. Durch die sinkenden Sequenzierungskosten und die Entwicklung neuer schnellerer Sequenzierungsmethoden wie die 454-Sequenzierung wird diese Methodik der Durchmusterung immer häufiger verwendet. Zur Zeit werden 168 Metagenome verschiedenster Habitate sequenziert, von denen 56 Projekte abgeschlossen wurden (Liolios et al., 2008).

Die Durchmusterung der in dieser Arbeit untersuchten metagenomischen Fosmidgenbank erfolgte auf funktioneller Ebene. So wurden insgesamt 5200 E. coli Klone mit einer Gesamtumwelt-DNA von $182 \mathrm{Mbp}$ auf hemicellulolytische und cellulolytische Aktivität durchgemustert. Der Vorteil der Verwendung funktionsbasierter Methoden ist die Möglichkeit, vollkommen neuartige Biokatalysatoren mit der gewünschten Eigenschaft zu detektieren. Die Problematik der funktionsbasierten Methodik ist, dass die Gene aus der Umwelt-DNA heterolog exprimierbar sein müssen, was der zurzeit am häufigsten verwendete Wirt $E$. coli oft nicht ermöglichen kann. Für die Expression und die anschließende Aktivität der entsprechenden Enzyme müssen verschiedene Bedingungen erfüllt werden. So limitieren Unterschiede zwischen dem Ursprungsorganismus und $E$. coli bezüglich z.B. codon usage, Transkriptions- und/oder Translationsinitiierungssignale, posttranslationaler Modifikationen oder Proteinfaltungsmechanismen die erfolgreiche Expression und Aktivität der rekombinanten Enzyme und somit die davon abhängige Detektion in funktionsbasierten Durchmusterungen. Um diese Problematik zu umgehen werden zurzeit neue Wirtssystem entwickelt, in denen alternative Wirtsorganismen wie z. B. Pseudomonas putida, Bacillus subtilis oder Thermus thermophilus zur heterologen Expression von Genen aus Umwelt-DNA verwendet werden (Angelov et al., 2009, Martinez et al., 2004). Mit der funktionsbasierten Durchmusterung der metagenomischen Fosmidgenbank aus Umweltbodenproben des Avachinsky Kraters konnten insgesamt elf verschiedene E. coli Klone detektiert werden, die cellulolytische und/oder hemicellulolytische Aktivität zeigten. Die Sequenzanalyse der unterschiedlichen Fosmid-Inserts offenbarte jedoch nur sechs verschiedene ORFs, die für die (hemi-)cellulolytische Aktivität der rekombinanten E. coli-Klone verantwortlich gewesen sein konnten (s. III.1.1). Dies zeigt, dass in der zur Verfügung stehenden Genbank offenbar die Abdeckung der klonierten Umwelt-DNA ausreichend war, um die in der Umweltprobe enthaltene genetische Information zumindest für die abundant 
vorkommenden und im Wirt E. coli gut detektierbaren (hemi-)cellulolytischen ORFs, auszuschöpfen. Um noch zusätzlich weitere ORFs für Hemicellulasen oder Cellulasen aus dem Metagenom der Bodenprobe des Avachinsky-Kraters zu identifizieren, müssten sequenzbasierte Methoden angewendet werden oder ein alternatives Wirtssystem verwendet werden. Eine weitere Möglichkeit wäre eine Veränderung der Durchmusterungsbedingungen. In dieser Arbeit erfolgte die Durchmusterung der Metagenombank bei $60^{\circ} \mathrm{C}$ und einem neutralen $\mathrm{pH}$-Wert. An dem Standort herrschte eine Temperatur von $67{ }^{\circ} \mathrm{C}$ und leicht alkalische Bedingungen ( $\mathrm{pH}$ 9-9,3). Bei der späteren Charakterisierung der rekombinanten Enzyme Xyn1015 und Bga48 wurden jedoch vollkommen unterschiedliche optimale Bedingungen bezüglich Temperatur $\left(\geq 90^{\circ} \mathrm{C}\right)$ und pH-Wert $(\mathrm{pH} 7 \mathrm{bzw}$. pH 6) für die Enzymaktivität ermittelt (s.III.2.2./4.). Eventuell ließen sich durch die Erhöhung oder Erniedrigung der Temperatur und/oder Veränderung des pH-Wertes im Durchmusterungsverfahren weitere Enzyme detektieren.

In Tabelle 14 werden die Ergebnisse anderer Studien zur Identifizierung von Cellulasen und Hemicellulasen aus Metagenom-Genbanken verschiedener Umweltproben dargestellt. Im Vergleich zu der Anzahl der detektierten (Hemi-)Cellulase ORFs dieser Studien zu der erreichten Anzahl, die durch die Durchmusterung der Metagenombank aus Umweltproben des Avachinsky-Kraters erzielt wurden, zeigt sich eine gute Ausbeute. In den meisten anderen Studien wurden small insert-Genbanken erstellt, in denen nur wenige ORFs detektiert wurden. Es zeigt sich, dass die Verwendung von large insert Genbanken zu besseren Ergebnissen führt, da die Wahrscheinlichkeit, komplette ORFs zu klonieren und somit aktive Klone zu detektieren höher ist, als bei small insert Genbanken. Zumindest in dem hier beschriebenen Fall überwiegt offenbar dieser Vorteil den Nachteil von large insert Genbanken, dass Gene ohne für den Wirt E. coli geeignete Expressionssignale in dem angewandten funktionellen Screening nicht erkannt werden können. 
Tabelle 14: Überblick verschiedener identifizierter (Hemi-)Cellulasen aus Metagenomen

\begin{tabular}{|c|c|c|c|c|c|c|}
\hline Enzym & Quelle des Metagenoms & $\begin{array}{l}\text { Vektor- } \\
\text { system }\end{array}$ & $\begin{array}{c}\text { Insert- } \\
\text { größe } \\
\text { [kb] }\end{array}$ & $\begin{array}{l}\text { Anzahl } \\
\text { Klone }\end{array}$ & $\begin{array}{l}\text { Positive } \\
\text { Klone }\end{array}$ & Referenz \\
\hline $\begin{array}{l}\text { Cellulasen/ } \\
\text { Hemicellulasen }\end{array}$ & $\begin{array}{l}\text { Bodenprobe Avachinsky } \\
\text { Krater }\end{array}$ & Fosmid & $\varnothing 35$ & 5200 & $\begin{array}{l}11 \\
\text { (6 Gene) }\end{array}$ & Diese Arbeit \\
\hline Cellulase & Teichproben Ost-Afrikas & Lambda & $2-10$ & 114.000 & 4 & $\begin{array}{l}\text { (Rees et al., } \\
\text { 2003) }\end{array}$ \\
\hline Cellulase & $\begin{array}{l}\text { Sedimente Natronsalzsee } \\
\text { Wadi Natrun, Ägypten }\end{array}$ & Lambda & $2-5,5$ & 35.000 & 1 & $\begin{array}{l}\text { (Grant et al., } \\
\text { 2004) }\end{array}$ \\
\hline Cellulase & $\begin{array}{l}\text { Anreicherungen mit } \\
\text { Cellulose-Medium aus } \\
\text { Natronsalzseen Wadi } \\
\text { Natruns, Ägypten }\end{array}$ & Lambda & $2-6$ & 37.000 & 1 & $\begin{array}{l}\text { (Grant et al., } \\
\text { 2004) }\end{array}$ \\
\hline Cellulase & Blinddarm des Hasen & Cosmid & $22-47$ & 32.500 & $\begin{array}{l}11 \\
\text { (6 Gene) }\end{array}$ & $\begin{array}{l}\text { (Feng et al., } \\
2007 \text { ) }\end{array}$ \\
\hline Cellulase & $\begin{array}{l}\text { Bodenproben eines } \\
\text { landwirtschaftlich } \\
\text { genutzten Feldes }\end{array}$ & Cosmid & $25-40$ & 1523 & 1 & $\begin{array}{l}\text { (Voget et al., } \\
\text { 2003, Voget } \\
\text { et al., 2006) }\end{array}$ \\
\hline Xylanase & $\begin{array}{l}\text { Insektendärme aus } \\
\text { Termiten und Motten }\end{array}$ & Lambda & $3-6$ & 1.000 .000 & 4 & $\begin{array}{l}\text { (Brennan et } \\
\text { al., 2004) }\end{array}$ \\
\hline Xylanase & $\begin{array}{l}\text { Abwasser eines } \\
\text { Milchbetriebs }\end{array}$ & Lambda & $4-10$ & 5.000 .000 & 1 & $\begin{array}{l}\text { (Lee, C. C. } \\
\text { et al., 2006) }\end{array}$ \\
\hline $\begin{array}{l}\text { Endo-ß-1,4- } \\
\text { Glucanase }\end{array}$ & Pansen des Rindes & Lambda & $\varnothing 5,5$ & 14.000 & 9 & $\begin{array}{l}\text { (Ferrer et al., } \\
\text { 2005) }\end{array}$ \\
\hline
\end{tabular}

\section{Sequenzanalyse, Expression und biochemische Charakterisierung von Xyn1015 und Bga48}

Von den sechs detektierten (Hemi-)Cellulase-ORFs aus der Metagenombank wurden zwei besonders interessant erscheinende ORFs ausgewählt, die dann erfolgreich mittels PCR amplifiziert, in Expressionsvektoren kloniert und heterolog in E. coli exprimiert wurden. Die rekombinanten Proteine konnten aufgereinigt und biochemisch charakterisiert werden (s. III.2). 


\subsection{Sequenzanalyse des ORFs xyn1015}

Der ORF xyn1015 konnte auf den Fosmidinserts vier verschiedener E. coli Genbankklone detektiert werden (FosK15F7, FosK23G5, FosK38H3 und FosK10B6, s. III.1.1.). Für die Sequenzierung des kompletten ORFs wurden die Sequenzdaten der Fosmide von den Klonen FosK15F7 und FosK10B6 assembliert. Der 1332 bp große ORF konnte am Ende eines 40,2 kb großen contigs identifiziert werden. In der direkten Sequenzumgebung zeigten sich stromaufwärts gelegen zwei ORFs, die für putative Sialidasen und ein ORF der für eine putative NADH-abhängige Dehydrogenase kodieren. Sialidasen oder auch Neuraminidasen gehören zu den Glycosidhydrolasen (EC 3.2.1.18) und katalysieren die Hydrolyse von $\alpha-2,3-, \alpha-2,6$ oder $\alpha-2,8$ glycosidisch verknüpften Sialinsäuren an Polysacchariden, Glycoproteinen und Glycolipiden und werden häufig in pathogenen Bakterien gefunden (Roggentin et al., 1993). Diese nutzen das Hydrolyseprodukt Sialinsäure, um ihre Zelloberfläche zu maskieren und sich so vor dem Immunsystem des Wirtsorganismus zu schützen (Severi et al., 2007). Eine bedeutendere Funktion von Sialidasen wird jedoch der Nährstoffversorgung zugesprochen. Durch die Abspaltung der Sialinsäuren von Polysacchariden können diese anschließend als Energiequelle genutzt werden (Corfield, 1992). Es könnte sich im Zusammenhang mit dem Xylanase-ORF eventuell um ein Genkluster handeln, das Gene enthält, die für Enzyme für die Nutzbarmachung von Kohlenhydratquellen kodieren.

Das Genprodukt des ORFs xyn1015 enthält 444 Aminosäuren und wurde als Xyn1015 bezeichnet. Der Abgleich der Aminosäuresequenz von Xyn1015 mit der Conserved Domain Database (CDD, (Marchler-Bauer et al., 2002) ergab mit einem e-value von $1 \mathrm{e}^{-30}$ eine nicht insignifikante Ähnlichkeit zu konservierten Domänen der Glycosidhydrolase-Familie 10 (GHF10) (s. III.2.1.). Die gesamte Aminosäuresequenz ergab eine 40 \%ige Identität zu einem Enzym der GHF10 aus dem Bakterium Caldicellulosiruptor saccharolyticus DSM8902. Die Glycosidhydrolase-Familie 10 umfasst Endo-1,3- $\beta$-Xylanasen (EC 3.2.1.32) und Cellobiohydrolasen (EC 3.2.1.91), der Hauptanteil wird jedoch durch Endo- $\beta-1,4$-Xylanasen (EC 3.2.1.8) repräsentiert (Cantarel et al., 2009, Collins et al., 2005).

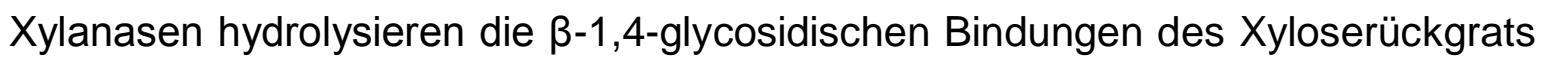
mittels eines double displacement-Mechanismus mit Beibehaltung der 
Konfiguration des anomeren Kohlenstoffatoms (Sinnott, 1990). Bei der generellen Säurekatalyse sind zwei Glutamatreste beteiligt, wobei ein Glutamatrest als Nukleophil und der andere Rest als Protonendonor wirkt (Derewenda et al., 1994, Tull et al., 1991). Zudem konnte nachgewiesen werden, dass vier weitere Aminosäurereste an der Spaltung des Substrats Xylan beteiligt sind. Es konnte gezeigt werden, dass drei Tryptophanreste und ein Tyrosinrest Rollen in der Substratbindung spielen und in Xylanasen hoch konserviert sind (Roberge et al., 1999).

In einem Vergleich der Aminosäuresequenz von Xyn1015 mit anderen charakterisierten Endo- $\beta$-1,4-Xylanase konnten alle die zuvor genannten an der Hydrolyse beteiligten Aminosäurereste detektiert werden (Abbildung 48). Im Sequenzvergleich konnte der Glutamatrest 198 als Protonendonor und der Glutamatrest 305 als Nukleophil identifiziert werden. Die vier Aminosäuren W153, Y246, W353 und W361 sind an der Substratbindung beteiligt. So kann durch den Vergleich der Aminosäuresequenz von Xyn1015 mit den Aminosäuresequenzen bekannter Xylanasen die Vermutung bestätigt werden, dass es sich bei Xyn1015

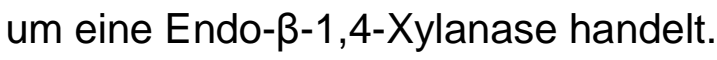

Die Analyse und der Vergleich von Aminosäuresequenzen vieler Cellulasen und Xylanasen zeigten, dass diese Enzyme häufig eine Multidomänen-Struktur aufweisen und verschiedene funktionelle Elemente enthalten. Sie enthalten katalytische Domänen, Kohlenhydratbindedomänen (carbohydrate binding modules, CBMs), linker-Regionen, die die einzelnen Domänen verbinden und Regionen mit charakteristischen Sequenzwiederholungen (Gilkes et al., 1991). Neben der katalytischen Domäne konnten in der Aminosäuresequenz von Xyn1015 keine Bereiche mit Ähnlichkeit zu anderen bekannten funktionellen Modulen detektiert werden. Das Enzym besteht nur aus einer großen katalytischen Domäne und weiteren nicht-konservierten Bereichen (s. III.2.1.) 


\subsection{Biochemische Charakterisierung von Xyn1015}

Die Sequenzanalyse des ORFs xyn1015 und des entsprechenden Genproduktes zeigte, dass es sich bei dem Enzym höchstwahrscheinlich um eine Endo- $\beta-1,4$-Xylanase (EC 3.2.1.8) handelt. Dieses sollte durch die biochemische Charaktersierung bestätigt werden. Das Enzym zeigt eine starke Spezialisierung auf $\beta-1,4$ glycosidisch verknüpfte, Xylose-basierte Polysaccharide. Es war nur geringfügig in der Lage, Cellulosen wie Carboxymethylcellulose, Hydroxyethylcellulose oder mikrokristalline Cellulose zu hydrolysieren (s. III.2.2.6.).

Die Analyse des Spaltungsmechanismus mittels Dünnschichtchromatographie ergab, dass das Enzym endo wirkt und zunächst innerhalb des Xylose-Rückgrates von Buchenholz-Xylan spaltet (s. III.2.7.).

Xyn1015 zeigte in einem 15-min Enzymassay ein hohes Temperaturoptimum von $95{ }^{\circ} \mathrm{C}$ und eine außergewöhnlich hohe Beständigkeit gegen Hitzeinaktivierung (s. III.2.2.1/2). Zu diesem Zeitpunkt sind nur zwei weitere Xylanasen bekannt, die ein höheres Temperaturoptimum für die hydrolytische Aktivität besitzen: XynA aus dem Thermotoga sp.-Stamm FjSS3-B.1 und XynB aus Thermotoga maritima MSB8 mit Temperaturoptima von $105^{\circ} \mathrm{C}$. Diese Enzyme zeigten jedoch eine geringere Stabilität gegen Thermoinaktivierung (Simpson et al., 1991, Winterhalter und Liebl, 1995). Bei einer Inkubation von Xyn1015 bei $95{ }^{\circ} \mathrm{C}$ konnten nach 24 Stunden noch $50 \%$ der Ausgangsaktivität festgestellt werden. Bei einer Inkubation bei $65{ }^{\circ} \mathrm{C}$ wurde die Enzymaktivität nach 50 Stunden nur um $20 \%$ reduziert. Bei vielen thermostabilen Xylanasen wurden Domänen identifiziert, die für die Stabilität der Enzyme bei hoher Temperatur bedeutsam sind (Fontes et al., 1995). Diese „thermostabilisierenden Domänen“ (TSDs) sind normalerweise direkt neben den katalytischen Domänen von thermostabilen Xylanasen lokalisiert und dienen zudem der Substratbindung (Sunna, A. et al., 2000). Die Entfernung der TSDs durch molekularbiologische Methoden führte zu einer Verminderung der Thermostabilität bei den untersuchten Enzymen (Bergquist, 1999, Blanco et al., 1999, Lee, Y. E. et al., 1993). Der Sequenzvergleich der Aminosäuresequenz von Xyn1015 mit den Sequenzen thermostabiler Xylanasen und der Datenbankabgleich mit verschiedenen Proteindatenbanken zeigte jedoch keine Existenz solcher TSDs in Xyn1015. So muss die Thermostabilität auf anderen intrinsischen Faktoren beruhen, wie zum Beispiel einer erhöhten Anzahl von 
Wasserstoff-, Salz- oder Disulfidbrücken, zusätzliche oder verbesserte elektrostatische Interaktionen, eine größere Packungsdichte oder eine erhöhte Dichte geladener Aminosäurereste an der Oberfläche des Enzyms (Hakulinen et al., 2003, Kumar et al., 2000, Xiong et al., 2004). Dass die hohe Thermostabilität nicht alleine von der Existenz von TSDs abhängt, zeigt sich auch bei dem Vergleich zweier Xylanasen aus dem Bakterium Thermotoga maritima. Die Xylanase XynB, die nur aus einer katalytischen Domäne besteht, zeigt eine höhere Resistenz gegen Thermoinaktivierung als die Multidomänen-Xylanase XynA, die im N-terminalen Bereich zwei TSDs besitzt (Winterhalter et al., 1995, Winterhalter und Liebl, 1995).

Die Untersuchung der Xylanase Xyn1015 bezüglich des Einflusses verschiedener Metallionen und Zusätze wie SDS, EDTA und $\beta$-Mercaptoethanol zeigte, dass die Metallionen $\mathrm{Cu}^{2+}, \mathrm{Ni}^{+}$und $\mathrm{Ag}^{+}$sowie SDS in einer Konzentration von $1 \mathrm{mM}$ im Testansatz die Enzymaktivität nahezu oder komplett inhibierten (s. III.2.2.4). Der Zusatz von $\mathrm{Fe}^{2+}, \mathrm{Fe}^{3+} \mathrm{Mg}^{2+}$ und $\mathrm{Ca}^{+}$verminderten die Aktivität zwischen $25 \%$ und $70 \%$. Diese Sensitivität gegenüber ein- und zweiwertigen Metallionen ist bei Xylanasen der GHF 10 nicht ungewöhnlich und konnte bei mehreren charakterisierten Enzymen festgestellt werden (Schomburg et al., 2002). Interessanterweise verminderte die Zugabe von $\mathrm{CoCl}_{2}$ in einer Konzentration von $1 \mathrm{mM}$ die Enzymaktivität um etwa $97 \%$, während eine Konzentration von $10 \mathrm{mM}$ keinen Einfluss auf die Enzymaktivität hatte. Eine Erklärung für dieses Phänomen wäre, dass Kobaltionen in einer geringen Konzentration direkten negativen Einfluss auf das aktive Zentrum des Enzym haben. Bei einer höheren Konzentration der lonen könnten sich eventuelle positive Faktoren für die Enzymaktivität auswirken, wie zum Beispiel eine bessere Substratbindung oder eine Veränderung der Substrateigenschaften, so dass dieses leichter hydrolysiert werden kann. Diese positiven Faktoren könnten den negativen Einfluss der Kobaltionen ausgleichen. Um dieses genauer zu untersuchen, muss in weiteren Studien der Einfluss von höheren und niedrigeren $\mathrm{CoCl}_{2}-\mathrm{K}$ onzentrationen auf die Enzymaktivität von Xyn1015 analysiert werden.

Der Chelatbildner EDTA hatte nur einen geringen Einfluss auf die hydrolytische Aktivität von Xyn1015, so dass davon ausgegangen werden kann, dass zweiwertige Kationen nicht für die Hydrolyse benötigt werden. 
Die Untersuchung der Abhängigkeit von Xyn1015 von NaCl im Testansatz ergab, dass eine starke Abhängigkeit des Enzyms von der Anwesenheit des Salzes besteht (s. III.2.2.5.). So konnte die Enzymaktivität bei der optimalen Konzentration von $1 \mathrm{M}$ um fast das Doppelte gesteigert werden. Die Steigerung der Aktivität durch $\mathrm{NaCl}$ konnte auch bei den thermostabilen Xylanasen XynA und XynB aus Thermotoga maritima (Optima bei $0,5 \mathrm{M} \mathrm{NaCl}$ ) und einer Cellobiohydrolase aus Thermotoga sp. Stamm FjSS3-B.1 mit einer optimalen Salzkonzentration von 0,8 M beobachtet werden (Ruttersmith und Daniel, 1991, Winterhalter und Liebl, 1995). Auf welche Art und Weise $\mathrm{NaCl}$ Einfluss auf den Hydrolysemechanismus hat ist jedoch zurzeit noch unklar.

In Tabelle 15 werden die biochemischen Eigenschaften von Xyn1015 mit anderen Xylanasen aus metagenomischen Genbanken und aus isolierten Organismen verglichen. Bei der Xylanase1015 handelt es sich zu diesem Zeitpunkt um die siebte Xylanase, die durch eine funktionelle Durchmusterung einer Metagenombank identifiziert wurde. Sie ist dabei die einzige thermostabile Xylanase. Bei den anderen aus der Durchsuchung von Metagenombanken identifizierten Xylanasen handelt es sich um mesophile Enzyme. Im Vergleich zu thermophilen Xylanasen isolierter Bakterien (Tabelle 15) zeigt sich, dass durch die Methodik der Durchmusterung einer Metagenombank auf funktioneller Ebene ein neues Enzym mit vorteilhaften Eigenschaften gefunden werden konnte, das sich besonders durch die hohe Thermostabilität auszeichnet. Xyn1015 besitzt ein hohes Temperaturoptimum bei hoher Resistenz gegen eine Thermoinaktivierung.

Zurzeit geht das höchste Interesse an thermostabilen Xylanasen von der Papierindustrie aus. Hier werden Xylanasen in der Zellstoffbleiche eingesetzt, um den Einsatz von aggressiven Chlor-basierten Chemikalien und Natriumhydrogensulfid möglichst zu vermeiden (Beg et al., 2001). Für den Einsatz im Bleichprozess müssen die eingesetzten Xylanasen verschiedene Bedingungen erfüllen. Da der Prozess der Bleichung unter rauen Bedingungen wie z. B. einer Temperatur von bis zu $80{ }^{\circ} \mathrm{C}$ abläuft, müssen die Xylanasen bei hohen Temperaturen und unter basischen pH-Bedingungen aktiv sein und eine hohe Thermostabilität aufweisen. Zudem sollten die Xylanasen keine Cellulase-Aktivität besitzen, um den Zellstoff nicht anzugreifen (Haki und Rakshit, 2003). Bis zum heutigen Zeitpunkt konnte noch keine bakterielle oder eukaryotische Xylanase charakterisiert werden, die all diese Bedingungen erfült. Es wäre vorstellbar, 
Xyn1015 in der Papierbleiche einzusetzen. Das Enzym ist bei hohen Temperaturen aktiv, besitzt nur eine geringe Cellulaseaktivität und ist sehr thermostabil. Das pH-Optimum von Xyn1015 liegt bei pH 7, das Enzym ist jedoch auch im leicht basischen $\mathrm{pH}$-Bereich aktiv. 
Tabelle 15: Übersicht über charakterisierte Xylanasen

\begin{tabular}{|c|c|c|c|c|c|c|c|c|c|c|}
\hline Quelle/Enzym & $\begin{array}{l}\text { Molekular- } \\
\text { gewicht } \\
{[\mathrm{kDa}]}\end{array}$ & $\begin{array}{l}\text { Aufreini- } \\
\text { gung } \\
\text { [Faktor] }\end{array}$ & $\begin{array}{c}\text { Ausbeute } \\
\text { [\%] }\end{array}$ & $\begin{array}{c}\text { pH- } \\
\text { Optimum }\end{array}$ & $\begin{array}{c}\text { Temperatur } \\
\text { Optimum } \\
{\left[{ }^{\circ} \mathrm{C}\right]}\end{array}$ & $\begin{array}{c}\text { Thermostabilität } \\
\text { (Halbwertzeit) } \\
\left.\text { [ }{ }^{\circ} \mathrm{C} / \text { Zeit }\right]\end{array}$ & pl & $\begin{array}{c}\mathrm{K}_{\mathrm{m}} \\
{[\mathrm{mg} / \mathrm{ml}]}\end{array}$ & $\begin{array}{c}V_{\max } \\
{[\mathrm{U} / \mathrm{mg}]}\end{array}$ & Referenz \\
\hline Xyn1015 & 51,2 & 47 & 85 & $6-.7$ & 95 & $95^{\circ} \mathrm{C} / 24 \mathrm{~h}$ & 8,7 & 2 & 400 & Diese Arbeit \\
\hline $\begin{array}{l}\text { XYL6806, XYL6419, } \\
\text { XYL6807, XYL6805 } \\
\text { (Metagenombank aus } \\
\text { Insektendarm) }\end{array}$ & n.b. & n.b. & n.b. & $5-.6$ & 50 & n.b. & n.b. & n.b. & n.b. & (Brennan et al., 2004) \\
\hline $\begin{array}{l}\text { Xyn8 } \\
\text { (Metagenombank aus } \\
\text { Abwasser eines } \\
\text { Milchbetriebes) }\end{array}$ & 45,9 & n.b. & n.b. & $6-7$ & 20 & n.b. & 5 & 5,3 & 768 & (Lee, C. C. et al., 2006) \\
\hline $\begin{array}{l}\text { ManFX10 } \\
\text { (Metagenombank aus } \\
\text { Kuhfladen) }\end{array}$ & 50 & n.b. & n.b. & 7 & 40 & $45^{\circ} \mathrm{C} / 30 \mathrm{~min}$ & n.b. & 2,8 & 49,5 & (Li, R. et al., 2009) \\
\hline $\begin{array}{l}\text { XynA } \\
\text { (Metagenombank, } \\
\text { PCR basierte } \\
\text { Durchmusterung) }\end{array}$ & 42 & n.b. & n.b. & 6 & 100 & $90^{\circ} \mathrm{C} / 10 \mathrm{~h}$ & n.b. & n.b. & n.b. & $\begin{array}{c}\text { (Sunna und Bergquist, } \\
\text { 2003) }\end{array}$ \\
\hline $\begin{array}{l}\text { Bacillus } \\
\text { amyloquefaciens } \\
\text { Xylanase }\end{array}$ & $\sim 19$ & 7,3 & 53,9 & $6,8-.7$ & 80 & $55^{\circ} \mathrm{C} / 15 \mathrm{~min}$ & 10,1 & n.b. & n.b. & (Breccia et al., 1998) \\
\hline
\end{tabular}




\begin{tabular}{|c|c|c|c|c|c|c|c|c|c|c|}
\hline $\begin{array}{l}\text { Fortsetzung Tabelle } 15 \\
\text { Quelle/Enzym }\end{array}$ & $\begin{array}{l}\text { Molekular- } \\
\text { gewicht } \\
\text { [kDa] }\end{array}$ & $\begin{array}{c}\text { Aufreini- } \\
\text { gung } \\
\text { [Faktor] }\end{array}$ & $\begin{array}{c}\text { Ausbeute } \\
\text { [\%] }\end{array}$ & $\begin{array}{c}\text { pH- } \\
\text { Optimum }\end{array}$ & $\begin{array}{l}\text { Temperatur } \\
\text { Optimum } \\
{\left[{ }^{\circ} \mathrm{C}\right]}\end{array}$ & $\begin{array}{c}\text { Thermostabilität } \\
\text { (Halbwertzeit) } \\
{\left[{ }^{\circ} \mathrm{C} / \text { Zeit }\right]}\end{array}$ & pl & $\begin{array}{c}\mathrm{K}_{\mathrm{m}} \\
{[\mathrm{mg} / \mathrm{ml}]}\end{array}$ & $\begin{array}{c}V_{\max } \\
{[\mathrm{U} / \mathrm{mg}]}\end{array}$ & Referenz \\
\hline $\begin{array}{l}\text { Bacillus sp. SPS-.0 } \\
\text { Xylanase }\end{array}$ & 99 & 36 & 25 & 6 & 75 & $70^{\circ} \mathrm{C} / 4 \mathrm{~h}$ & n.b. & 0,7 & 145 & (Bataillon et al., 2000) \\
\hline $\begin{array}{l}\text { Dictyoglomus } \\
\text { Rt46B.1 } \\
\text { XynA }\end{array}$ & 33 & n.b. & n.b. & 6,5 & 85 & $85^{\circ} \mathrm{C} / 24 \mathrm{~h}$ & n.b. & n.b. & n.b. & (Gibbs et al., 1995) \\
\hline $\begin{array}{l}\text { Caldibacillus } \\
\text { cellulovorans } \\
\text { XynA }\end{array}$ & 57 & n.b. & n.b. & 6 & 90 & $70^{\circ} \mathrm{C} / 4 \mathrm{~h}$ & n.b. & 1,8 & 256 & $\begin{array}{c}\text { (Sunna, Anwar et al., } \\
\text { 2000) }\end{array}$ \\
\hline $\begin{array}{l}\text { Geobacillus sp. MT1 } \\
\text { Xylanase }\end{array}$ & 36 & n.b. & n.b. & 7 & 70 & $65^{\circ} \mathrm{C} / 50 \mathrm{~min}$ & n.b. & 1,6 & 289 & (Wu et al., 2006) \\
\hline $\begin{array}{l}\text { Streptomyces sp.S27, } \\
\text { XynBS27 }\end{array}$ & 21 & n.b. & n.b. & 6,5 & 65 & $60^{\circ} \mathrm{C} / 30 \mathrm{~min}$ & n.b. & 6,2 & 9930 & (Li et al., 2008) \\
\hline $\begin{array}{l}\text { Thermotoga maritima } \\
\text { MSB8 } \\
\text { Xyn A }\end{array}$ & 120 & 31 & 4,4 & 6,2 & 92. & $90^{\circ} \mathrm{C} / 45 \mathrm{~min}$ & n.b. & 0,11 & 109 & $\begin{array}{c}\text { (Winterhalter und Liebl, } \\
\text { 1995) }\end{array}$ \\
\hline $\begin{array}{l}\text { Thermotoga maritima } \\
\text { MSB8 } \\
\text { XynB }\end{array}$ & 40 & 288 & 3,5 & 5,4 & 105 & $95^{\circ} \mathrm{C} / 125 \mathrm{~min}$ & 5,6 & n.b. & n.b. & $\begin{array}{l}\text { (Winterhalter und Liebl, } \\
\text { 1995) }\end{array}$ \\
\hline $\begin{array}{l}\text { Thermotoga sp. } \\
\text { FjSS3-B1 } \\
\text { XynA }\end{array}$ & 40,5 & n.b. & n.b. & 6,3 & 100 & $90^{\circ} \mathrm{C} / 22 \mathrm{~h}$ & n.b. & n.b. & n.b. & (Saul et al., 1995) \\
\hline
\end{tabular}




\subsection{ORF bga48}

Der ORF bga48 wurde auf dem Fosmidinsert des E. coli-Genbankklons Fosk48H3 detektiert. Er umfasst 2712 Basenpaare. In der direkten Sequenzumgebung wurden stromauf- und abwärts insgesamt drei ORFs detektiert, die für putative Transposase-Enzyme kodieren( s. III.2.3). Die Transposasen wurden der Klasse I der transponierbaren Elemente, den Insertionssequenzen (IS) der Familie 4 zugeordnet. Insertionssequenzen können bis zu $5 \%$ der genomischen DNA ausmachen und können zur Mobilisierung eines Genabschnittes beitragen, indem sie diesen auf beiden Seiten flankieren. Als zusammengesetztes Transposon kann dann eine Transposition des Genabschnittes erfolgen (Aubert et al., 2006). Es ist möglich, dass der ORF bga48 solch einem Transpositionsereignis unterworfen wurde und aus diesem Grund von Insertionssequenzen umgeben ist.

Der Datenbankabgleich der Aminosäuresequenz des Genproduktes Bga48 mit dem blastp-Algorithmus ergab eine nur $38 \%$ ige Identität zu einem Protein aus dem Bakterium Thermotoga petrophila RKU-1, welches den Glycosidhydrolasen zugeordnet wurde. Ein Abgleich der Aminosäuresequenz der „Conserved Domains Database“ (Marchler-Bauer et al., 2005) ergab für den Bereich zwischen Aminosäure 96 und 284 mit nur einem hohen e-value von $4 e^{-6}$ eine Ähnlichkeit zur katalytischen Domänen der GHF 42 (s. III.2.3.). Die Domäne war jedoch unvollständig. Des Weiteren konnte in dem Bereich zwischen Aminosäure 291 und 441 mit einem e -value von $1 e^{-12}$ eine Kohlenhydrat-Bindedomäne der Familie CBM4_9 identifiziert werden. In die GHF 42 werden vorwiegend B-Galaktosidasen eingeordnet, die endständige Galaktosereste von Polysacchariden abspalten. Ein typisches Substrat für B-Galaktosidasen ist Lactose, bekannt geworden ist dieses Enzym jedoch durch die Anwendung als Reportergen in der Molekularbiologie im sogenannten X-Gal-Test (siehe Material und Methoden II.5.10.).

Kohlenhydratbindedomänen (CBMs) sind nicht-katalytische Module von Glycosidhydrolasen, die Oligo- oder Polysaccharide erkennen und an diese binden können. CBMs werden, ähnlich wie bei den Glycosid-Hydrolasen, aufgrund von Ähnlichkeiten ihrer Aminosäuresequenz, Struktur und Substratspezifitäten in zur Zeit 55 unterschiedliche Familien eingeteilt. Es konnte die Bindung an kristalline Cellulose, Chitin, B-1,3-Glucan und Glucanen mit einer Mixtur aus B-1,3und B-1,4-Bindungen, sowie Xylan, Mannan, Galactan und Stärke nachgewiesen werden (Boraston et al., 2004). Neben der Bindeeigenschaft von CBM-Modulen 
und der damit verbundenen Steigerung der hydrolytischen Aktivität der katalytischen Domäne werden auch andere Funktionen vermutet, wie z. B. eine nicht-katalytische Disruption des Substrats (Shoseyov et al., 2006). Die Kohlenhydrat-Bindedomänen der Familie CBM4_9, die durch den Datenabgleich der Aminosäuresequenz von Bga48 mit einem hohen e-value von $1 e^{-12}$ identifiziert wurde, wird in die Superfamilie der "Galaktose-Binde-Domänen-Ähnlichen“ eingeordnet. Diese CBMs konnten auch in einer Cellulase aus Cellulomonas fimi, einer Laminarase aus Thermotoga maritima und einer Xylanase aus Rhodothermus marinus gefunden werden (Boraston et al., 2004). Die CBMs dieser Enzyme waren in der Lage, Xylan, B-1,3-Glucan, B-1,3/1,4-Glucan, B-1,6Glucan und an amorphen Cellulosebereichen zu binden. Eine Bindung an kristalline Cellulose erfolgt jedoch nicht (Cantarel et al., 2009).

Aufgrund der hohen nicht-signifikanten e-values von $4 \mathrm{e}^{-6}$ bzw. $1 \mathrm{e}^{-12}$ für die Wahrscheinlichkeiten, dass das Protein Bga48 eine katalytische Domäne der Glycosidhydrolase Familie 42 bzw. eine Kohlenhydrat-Bindedomäne der Familie 4 enthält, können diese Ergebnisse nur als Hinweis für die Funktion von Bga48 und den enthaltenen Domänen verwendet werden. Der C-terminalen Hälfte $(>400$ Aminosäuren) der Proteinsequenz von Bga48 konnte auf der Basis von Sequenzvergleichen keine putative Funktion zugeordnet werden.

Um die Funktion der einzelnen Domänen und Proteinbereiche von Bga48 zu untersuchen, wurden in dieser Arbeit die Genbereiche, die für die einzelnen Bereiche kodieren, mittels PCR amplifiziert, in einen Expressionsvektor kloniert und heterolog in E. coli exprimiert (s.III.3.1.). Insgesamt wurden sechs auf dem Vektor pET101/D-TOPO basierende rekombinante Plasmide hergestellt erstellt, deren Inserts für das vollständige Protein, das vollständige Protein ohne Signalpeptidsequenz, die putativen GHF 42- und CBM 4_9-Domänen einzeln und in Kombination und den langen nicht-klassifizierten C-terminalen Bereich von Bga48 kodieren. In keinem der Fälle konnte eine erfolgreiche Überexpression in $E$. coli mittels SDS-PAGE festgestellt werden. Es konnte jedoch eine hydrolytische Aktivität der rekombinanten Proteine, die das vollständige Protein und das Protein ohne Signalpeptid darstellten in den Rohextrakten der entprechenden E. coliStämme festgestellt werden. Es konnte keine Aktivitäten der einzelnen putativen Domänen bzw. der kombinierten Domänen detektiert werden. Dieses kann zum einen an einer erfolglosen Expression der Proteine liegen oder aber daran, dass 
für eine katalytische Funktion des Enzyms alle Domänen inklusive des langen C-terminalen Bereiches notwendig sind. Um eine genauere Aussage über die Funktionen der einzelnen Domänen bzw. Bereiche des Proteins Bga48 treffen zu können, müsste in zukünftigen Arbeiten eine bessere Expression der verschiedenen rekombinanten Proteine erreicht werden, um mit diesen anschließend im aufgereinigten Zustand intensivere Untersuchungen durchzuführen.

\subsection{Biochemische Charakterisierung von Bga48}

Um zu überprüfen, ob es sich bei Bga48 um eine B-Galaktosidase handelt, wurde qualitativ untersucht, ob das rekombinante Enzym in der Lage ist, Lactose und 5-Brom-4-Chlor-3-indoyl-B-D-galaktopyranosid (X-Gal) zu spalten (s. III.4.5.). In beiden Fällen erfolgte keine Hydrolyse des Substrates. Es zeigten sich zwar bei zwei charakterisierten B-Galaktosidasen aus dem Archaeon Haloferax alicantei und dem Bakterium Bifidobacterium adolecentis ebenfalls keine Fähigkeit zur Hydrolyse von Lactose (Holmes et al., 1997, Van Laere et al., 2000), aber zusammen mit den Ergebnissen der Sequenzanalyse kann davon ausgegangen werden, dass es sich bei dem aus der Metagenombank isolierten Gen nicht um ein Gen für eine B-Galaktosidase handelt.

Es wurden weitere mögliche Substrate getestet, und es konnte gezeigt werden, dass Bga48 vorwiegend B-Glucan und Lichenan hydrolysiert. Zudem hydrolysierte Bga48 auch in geringen Maße Carboxymethylcellulose und Hydroxyethylcellulose, während Pachyman, Zymosan, Curdlan, Auxoferm, Laminarin und mikrokristalline Cellulose nicht gespalten wurden. Eine Übersicht über die verschiedenen Substrate und der Fähigkeit von Bga48, diese zu hydrolysieren, ist in Tabelle 16 dargestellt. 
Tabelle 16: Hydrolyse verschiedener Substrate durch Bga48

\begin{tabular}{|c|c|c|}
\hline Substrat & $\begin{array}{l}\text { Glycosidische } \\
\text { Bindungen }\end{array}$ & Aktivität ${ }^{1}$ \\
\hline B-Glucan (Gerste) & ß-1,3; ß-1,4, linear & ++ \\
\hline Lichenan (C. islandica) & ß-1,3; ß-1,4, linear & ++ \\
\hline Carboxymethylcellulose & B-1,4, linear & + \\
\hline Hydroxyethylcellulose & ß-1,4, linear & + \\
\hline Pachyman (P. cocos) & $\begin{array}{l}\text { ß-1,3 mit } ß-1,6 \\
\text { Verzweigungen }\end{array}$ & - \\
\hline Zymosan (S. cerevisae) & ß-1,3, linear; Proteinkomplex & - \\
\hline Curdlan (A. faecalis) & B-1,3, linear & - \\
\hline Auxoferm (S.cerevisae) & B-1,3 & - \\
\hline Laminarin (L. digitata) & B-1,3;ß-1,6, linear & - \\
\hline Mikrokristalline Cellulose & ß-1,4; kristalline Struktur & - \\
\hline
\end{tabular}

(1): ++ = starke Aktivität; +: Aktivität vorhanden, jedoch schwach; - : Keine Aktivität

Die am besten durch Bga48 hydrolysierten Substrate B-Glucan und Lichenan sind lineare Homopolysaccharide aus 400-1200 Glucose-Einheiten, die B-1,4- und ß-1,3-glycosidische Bindungen in einem ungefähren Verhältnis von $2: 1$ aufweisen. Hierbei wird eine Kette von drei bis vier ß-1,4-glycosidisch verknüpften Glucose-Einheiten durch jeweils eine einzige B-1,3 Bindung unterbrochen (Johansson, 2006, Yoo et al., 2007). Die Spaltung von B-Glucan erfolgt in der Natur durch drei verschiedene Enzymgruppen. Cellulasen sind in der Lage die B-1,4-Bindungen zu spalten. Die Gruppe der Laminarinasen hydrolysieren sowohl B-1,3- als auch B-1,4-Verknüpfungen. Die Vertreter der dritten Enzymgruppe, die Lichenasen, agieren spezifischer und sind nur zur Spaltung von B-1,4-Bindungen befähigt, wenn diese auf B-1,3-Bindungen folgen. Das Substratspektrum von Bga48 deutet darauf hin, dass es sich bei dem Enzym um eine Lichenase handelt. Da Bga48 nicht in der Lage ist, rein B-1,3-glycosidisch verknüpfte Substrate (Zymosan, Curdlan und Auxoferm) zu spalten, kann davon ausgegangen werden, dass das Enzym die ß-1,4-glycosidischen Bindungen zwischen den Glucoseresten von B-Glucan und Lichenan spaltet. Bga48 zeigt nur eine geringe Aktivität bezüglich der rein ß-1,4 glycosidisch vernüpften Substrate Carboxymethylcellulose und Hydroxyethylcellulose, was darauf hinweist, dass das Enzym bevorzugt B-1,4-glycosidische Bindungen spaltet, die sich in der Umgebung von 
B-1,3-Verknüpfungen befinden. Dieses zeigt auch das Ergebnis der Produktanalyse der Hydrolyse von B-Glucan durch Bga48 mittels Dünnschichtchromatographie (III.2.4.6.). Beim enzymatischen Abbau des B-Glucans durch Bga48 wurden zunächst Produkte mit einem hohen Polymerisierungsgrad gebildet, während nach etwa 4 Stunden die Produkte höheren Polymerisierungsgrades weiter hydrolysiert wurden und sich das Hauptprodukt Cellotetraose herausgebildet hat. Neben der Cellotetraose wurde ebenfalls zu einem geringeren Anteil Cellotriose erkennbar. Nach 24 Stunden Inkubation konnte keine weitere Hydrolyse der Cellotetraose bzw. Cellotriose beobachtet werden. Wenn eine Unabhängigkeit von B-1,3 glycosidischen Bindungen bestehen würde, wäre als Endprodukt Cellobiose zu erwarten gewesen. Das Ergebnis der Dünnschichtchromatographe zeigt zudem, dass Bga48 endo wirkt und somit innerhalb der Glucosekette spaltet. Somit kann Bga48 als Endo-ß-1,3-ß-1,4-Glucanase bezeichnet werden. Dieses spricht auch für die Existenz einer Kohlenhydratbindedomäne der Familie CBM4_9, die an B-1,3-1,4-Glucansubstraten binden kann.

Lichenasen (B-1,3-B1,4-Glucanasen, (EC 3.2.1.73) mit einer Spezifität für B-1,4

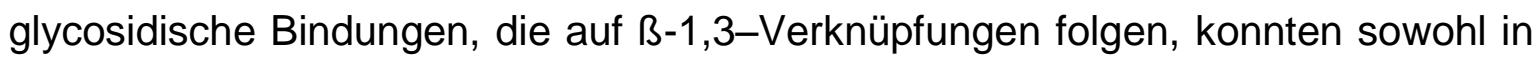
Pflanzen und Pilzen, als auch in Bakterien nachgewiesen werden. Bei der Hydrolyse von B-Glucan aus Gerste entstehen als Hauptprodukte stets Tri -und Tetrasaccharide, wie es auch bei Bga48 der Fall ist (Planas, 2000). In Abbildung 49 wird die enzymatische Depolymerisierung von B-Glucan (Gerste) durch B-1,3-ß1,4-Glucanasen schematisch dargestellt. Aufgrund der verfügbaren Daten kann allerdings nicht unterschieden werden, welche der zur B-1,3-Bindung benachbarten B-1,4-Bindungen gespalten wird, die in Richtung reduzierendes Ende oder die in Richtung nicht-reduzierendes Ende. 


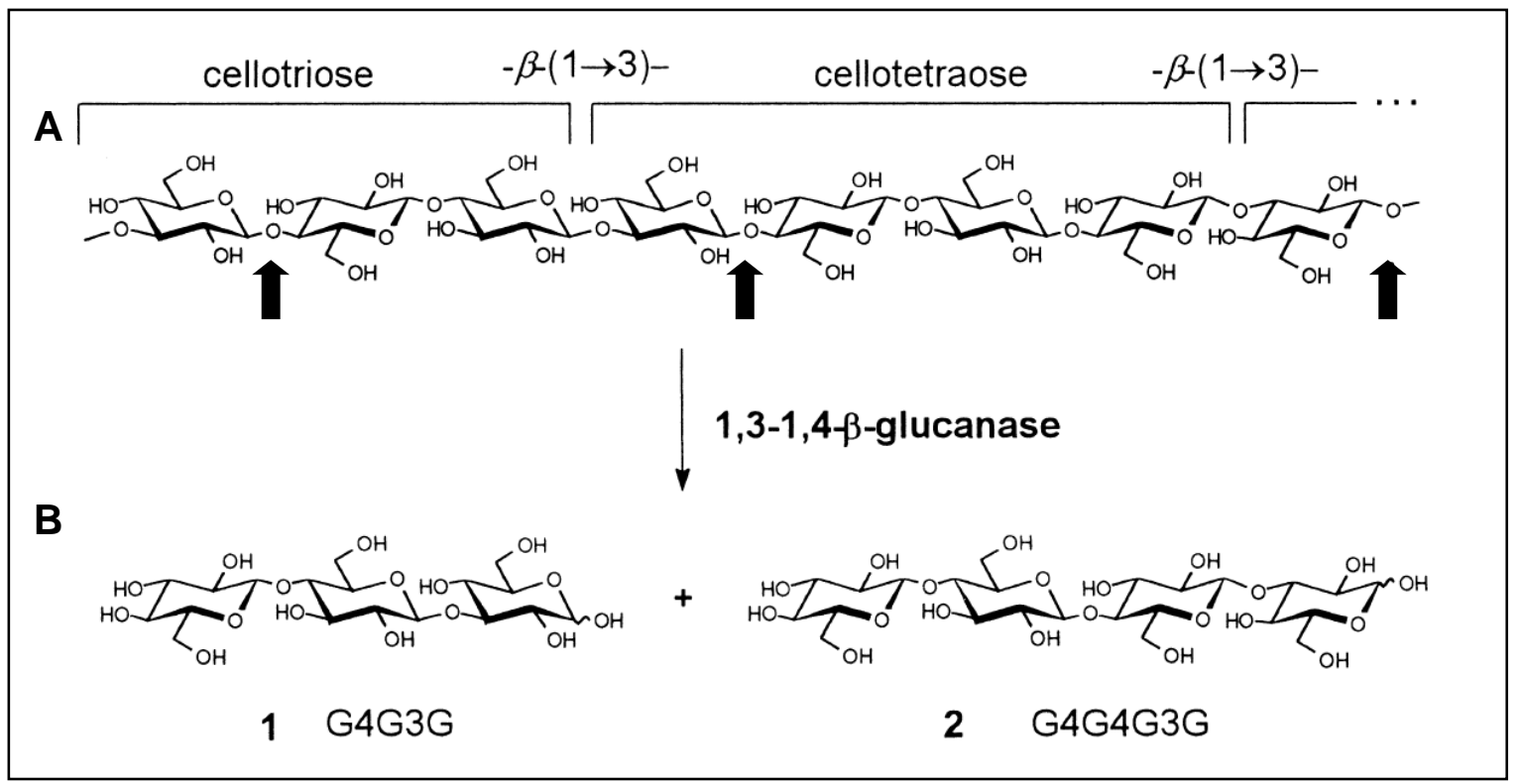

Abbildung 49: Enzymatische Spaltung von B-Glucan (Gerste) durch B-1,3-ß-1,4-Glucanasen (EC 3.2.1.73). Das lineare B-Glucan besteht aus Cellotriosylund Cellotetraosylresten, die durch eine einzelne $B-1,3$ glycosidische Bindung verknüpft werden (A). Beim enzymatischen Abbau durch B-1,3-ß1,4-Glucanasen (B) entstehen Cellotriose (1) und Cellotetraose (2) (nach Planas, 2000; modifiziert).Die Pfeile signalisieren den Spaltungsort.

Endo-ß-1,3-ß-1,4-Glucanasen oder auch Lichenasen (EC 3.2.1.73) werden aufgrund ihrer Aminosäuresequenz in zur Zeit fünf verschiedene Glycosidhydrolase-Familien eingeordnet. Zwischen den Vertretern der einzelnen Familien gibt es keine erkennbaren Ähnlichkeiten in der Aminosäuresequenz oder in der dreidimensionalen Struktur, was auf eine konvergente Proteinevolution bezüglich der Substratspezifität hinweist. So bilden beispielsweise B-1,3-ß-1,4Glucanasen aus Pflanzen eine $(\beta / \alpha)_{8}$-TIM-Barrel-Faltung aus und werden in die Glycosidhydrolasefamilie 17 eingeordnet, während Lichenasen aus Bakterien vorwiegend Mitglieder der Familie 16 sind und eine B-Sandwichstruktur ausbilden (Cantarel et al., 2009).

Da 1. die Analyse der Aminosäuresequenz von Bga48 keine Ähnlichkeiten zu anderen Endo-ß-1,3-ß-1,4-Glucanasen zeigte und 2. unter den zu Bga48 am nächsten verwandten Enzymen (GHF42) es bisher keine mit B-Glucanaseaktivität gibt, ist es in dieser Arbeit gelungen, ein neuartiges Enzym zu identifizieren. 
Damit konnte erfolgreich demonstriert werden, dass die funktionelle Durchmusterung von Metagenombanken im Gegensatz zu sequenzbasierten Methoden zur Identifizierung vollkommen neuer Biokatalysatoren mit interessanten Eigenschaften führen kann.

Bga48 zeichnet sich besonders durch das hohe Temperaturoptimum $\left(90^{\circ} \mathrm{C}\right)$, ein breites pH-Spektrum ( $\mathrm{pH}$ 5-9, Optimum $\mathrm{pH}$ 6) und eine hohe Resistenz gegen Thermoinaktivierung aus (s. III.2.4.1-3) Bei $75^{\circ} \mathrm{C}$ waren nach 5 Stunden Inkubation noch etwa $60 \%$ der Ausgangsaktivität vorhanden. Bei $95{ }^{\circ} \mathrm{C}$ konnten nach 45 Minuten $58 \%$ der ursprünglichen Aktivität festgestellt werden. Wenn es sich bei Bga48 tatsächlich um eine ß-1,3-ß-1,4-Glucanase handelt, ist Bga48 die erste aus einem Metagenom isolierte, klonierte und charakterisierte B-1,3-ß-1,4Glucanase (EC 3.2.1.73).

In Tabelle 17 sind die Eigenschaften von Bga48 im Vergleich $\mathrm{zu}$ anderen charakterisierten thermophilen Enzymen dieser Klasse dargestellt. Das $\mathrm{pH}-$ Optimum von Bga48 ist vergleichbar mit den Optima anderer Lichenasen (pH 5,5-8). Bga48 besitzt das zurzeit zweithöchste berichtete Temperaturoptimum. Nur eine B-13-1,4-Glucanase aus dem Pilz Trichoderma koningii weist ein höheres Temperaturoptimum von $100^{\circ} \mathrm{C}$ auf (Wang, J. L. et al., 2007). Des Weiteren fällt besonders die hohe molekulare Masse (102,7 kDa) von Bga48 auf. Das Enzym mit der bis zum heutigen Zeitpunkt höchsten berichteten molekularen Masse ist eine Lichenase aus Thermomonospora sp. mit einer Masse von 65,5 kDa (Anish und Rao, 2007). Die fehlende signifikante Ähnlichkeit der Aminosäuresequenz von Bga48 mit den Sequenzen anderer Lichenasen und die ungewöhnlich hohe molekulare Masse zeigt erneut, dass in dieser Arbeit durch die funktionelle Durchmusterung einer Metagenombank eine neuartige Lichenase entdeckt wurde, die eventuell in eine neue Glycosidhydrolase-Familie eingeordnet werden müsste.

Thermostabile Lichenasen sind nützliche biotechnologische Helfer in vielen industriellen Prozessen. Der Einsatz von ß-1,3-1,4-Glucanasen kann den negativen Einfluss von Gersten-ß-Glucan im Bierbrauprozess verringern. Hier erhöht das B-Glucan die Viskosität der Maischelösung und kann später zu Filtrationsproblemen führen oder beim Enprodukt gelartige Präzipitate erzeugen (Scott, 1972). Da der Maischeprozess bei Temperaturen bis zu $80{ }^{\circ} \mathrm{C}$ stattfindet und endogene ß-1,3-1,4-Glucanasen hitzeinaktiviert werden, kann der Zusatz von 
exogenen hitzestabilen B-1,3-1,4-Glucanasen zur Spaltung des störenden Gersten-ß-Glucans beitragen (Planas, 2000, Wainwright, 1999). In der Futtermittelherstellung werden thermostabile B-Glucanasen ebenfalls eingesetzt, um B-Glucane abzubauen, da diese eine erhöhte intestinale Viskosität verursachen und somit die Verdauung und Absorbtion von Nährstoffen verschlechtern können (Planas, 2000). Bga48 könnte aufgrund des hohen Temperaturoptimums und seiner Robustheit gegenüber Denaturierung in diesen industriellen Zweigen Verwendung finden. 
Tabelle 17: Übersicht über charakterisierte thermophile Lichenasen (EC 3.2.1.73)

\begin{tabular}{|c|c|c|c|c|c|c|c|c|c|c|}
\hline Quelle/Enzym & $\begin{array}{l}\text { Mol. } \\
\text { Gewicht } \\
\text { [kDa] }\end{array}$ & $\begin{array}{l}\text { Aufreinigungs- } \\
\text { faktor }\end{array}$ & $\begin{array}{c}\text { Ausbeute } \\
{[\%]}\end{array}$ & $\begin{array}{c}\mathrm{pH} \\
\text { Optimum }\end{array}$ & $\begin{array}{c}\text { Temperatur } \\
\text { Optimum } \\
{\left[{ }^{\circ} \mathrm{C}\right]}\end{array}$ & $\begin{array}{c}\text { Thermostabilität } \\
\text { (Halbwertzeit) } \\
\left.\text { [ }{ }^{\circ} \mathrm{C} / \text { Zeit }\right]\end{array}$ & pl & $\begin{array}{c}\mathrm{K}_{\mathrm{m}} \\
{[\mathrm{mg} / \mathrm{ml}]}\end{array}$ & $\begin{array}{c}V_{\max } \\
{[\mathrm{U} / \mathrm{mg}]}\end{array}$ & Referenz \\
\hline Bga48 & 102,7 & 85,4 & 19,8 & 6 & 90 & $75^{\circ} \mathrm{C} / 5,5 \mathrm{~h}$ & 8,8 & 0,24 & 200 & Diese Arbeit \\
\hline $\begin{array}{l}\text { Trichoderma koningii } \\
\text { (Pilz) }\end{array}$ & 26,5 & n.b. & n.b. & 2 & 100 & $100^{\circ} \mathrm{C} />3 \mathrm{~h}$ & n.b. & n.b. & n.b. & $\begin{array}{c}\text { (Wang, J. L. et al., } \\
\text { 2007) }\end{array}$ \\
\hline $\begin{array}{l}\text { Clostridium } \\
\text { thermocellum } \\
\text { (Gen licB) }\end{array}$ & 35 & n.b. & n.b. & 8 & 80 & $75^{\circ} \mathrm{C} />24 \mathrm{~h}$ & n.b. & n.b. & n.b. & $\begin{array}{c}\text { (Schimming et al., } \\
1991 \text { ) }\end{array}$ \\
\hline $\begin{array}{l}\text { Bacillus subtilis } \\
\text { (Synthetisches } \\
\text { Chimer) }\end{array}$ & 25,3 & n.b. & n.b. & 5 & 70 & n.b. & n.b. & n.b. & n.b. & $\begin{array}{l}\text { (Fu et al., 2008, Li, } \\
\text { R. et al., 2009) }\end{array}$ \\
\hline $\begin{array}{l}\text { Paecilomyces } \\
\text { thermophila J18 } \\
\text { (Pilz) }\end{array}$ & 38,6 & 122,5 & 8,9 & 7 & 70 & $60^{\circ} \mathrm{C} / 10 \mathrm{~h}$ & 4,2 & 2,46 & 9980,9 & (Yang et al., 2008) \\
\hline $\begin{array}{l}\text { Thermotoga maritima } \\
\text { MSB8 }\end{array}$ & 40 & n.b. & n.b. & 6,6 & 70 & n.b. & n.b. & 0,78 & n.b. & (Khan et al., 2007) \\
\hline Bacillus brevis & 29 & n.b. & n.b. & 8 & 65 & $75^{\circ} \mathrm{C} />1 \mathrm{~h}$ & n.b. & n.b. & n.b. & (Louw et al., 1993) \\
\hline $\begin{array}{l}\text { Bacteroides } \\
\text { succinogenes }\end{array}$ & 37,2 & n.b. & n.b. & $5,5-6$ & 50 & $60^{\circ} \mathrm{C} / 10 \mathrm{~min}$ & n.b. & 0,35 & n.b. & (Erfle et al., 1988) \\
\hline Thermomonospora sp. & 65,5 & n.b. & n.b. & 7 & 50 & $80^{\circ} \mathrm{C} / 5 \min$ & 4,27 & n.b. & n.b. & $\begin{array}{c}\text { (Anish und Rao, } \\
\text { 2007) }\end{array}$ \\
\hline $\begin{array}{l}\text { Fibrobacter } \\
\text { succinogenes }\end{array}$ & 35 & n.b. & n.b. & 8 & 50 & $90^{\circ} \mathrm{C} / 10 \mathrm{~min}$ & n.b. & 2,5 & n.b. & (Wen et al., 2005) \\
\hline $\begin{array}{l}\text { Bacillus licheniformis } \\
\text { EGW039 }\end{array}$ & 28 & 8,7 & 82,7 & 5,6 & 40 & $70^{\circ} \mathrm{C} / 10 \mathrm{~min}$ & n.b. & n.b. & n.b. & (Teng et al., 2006) \\
\hline
\end{tabular}




\section{Phylogenetische Untersuchung des Intestinaltraktes des Elbebibers (Castor fiber albicus)}

Ein wichtiger Aspekt der Metagenomforschung ist es, die mikrobielle Diversität eines Standortes zu erfassen. Da oft wenig über die natürlichen Interaktionen in mikrobiellen Lebensräumen und die physiologischen Ansprüche der einzelnen mikrobiellen Arten bekannt ist, bleibt eine Kultivierung der meisten Arten in vitro unter Laborbedingungen erfolglos (Amann et al., 1995). Für die Erfassung der mikrobiellen Diversität eines komplexen Habitates sind daher kulturunabhängige Methoden erforderlich. Mit der Entwicklung molekularbiologischer Methoden wie der Polymerasekettenreaktion und der Klonierung und Sequenzierung von Nukleinsäurefragmenten wurde es ermöglicht, eine Charakterisierung der mikrobiellen Gemeinschaft eines Standortes auf molekularer Ebene vorzunehmen und somit auf eine Kultivierung zu verzichten.

Die Vorraussetzung für die phylogenetische Analyse mikrobieller Lebensgemeinschaften ist die Existenz eines ubiquitären Markergens. Carl Woese stellte 1987 den ersten phylogenetischen Stammbaum auf der Basis des Gens für die 16S rRNA vor. Dieses Gen erfüllt alle Voraussetzungen eines Markergens. Es ist ubiquitär in Archaeen und Bakterien vorhanden und besitzt hochkonservierte und variable Regionen. Mit der Amplifikation und Sequenzierung der PCR-Produkte kann eine phylogenetische Einordnung der dazugehörigen Mikroorganismen ohne eine vorherige Kultivierung erfolgen (Riesenfeld et al., 2004, Woese, 1987).

In der vorliegenden Arbeit konnte mit dieser Methodik ein Einblick in die mikrobielle Diversität des Intestinaltraktes des europäischen Bibers (Castor fiber albicus) gewonnen werden. Der Darmtrakt des Bibers zeichnet sich durch einen sehr ausgeprägten Blinddarm aus, in dem (hemi-)cellulolytische Mikroorganismen an der Degradierung der pflanzlichen Nahrung beteiligt sind. Dieses macht den Biber als Untersuchungsobjekt interessant, da die intestinale mikrobielle Flora als Quelle für neue Enzyme des (Hemi-)Celluloseabbaus dienen kann. Bisher gibt es weder kulturabhängige, noch auf 16S rRNA-basierte Studien, die sich mit der Zusammensetzung der mikrobiellen Gemeinschaft im Darm des Bibers auseinandergesetzt hat. 


\subsection{Vergleich zwischen der klassischen 16S rRNA-Genanalyse und der 16S rRNA-Genanalyse von 454-Pyrosequenzdaten partiell amplifizierter 16S rRNA-Gene}

In dieser Arbeit wurden zwei verschiedene methodische Ansätze zur Ermittlung der mikrobiellen Diversität angewendet. Die erste, klassische Methode, umfasste die Amplifikation von bakteriellen 16S rRNA-Genen, einer anschließenden Klonierung der etwa 1100 bp langen Amplifikate in Plasmidvektoren und der Sequenzierung der inserts nach Sanger (Sanger et al., 1977). Durch diesen methodischen Ansatz konnte die mikrobielle Vielfalt in den unterschiedlichen Proben aufgrund der nicht vollständigen Abdeckung aller potentiellen 16S rRNAGensequenzen nur zum Teil erfasst werden. Es konnte jedoch eine Einordnung der Sequenzen bis auf Artenebene erfolgen. Der zweite Ansatz umfasste die Amplifikation eines kurzen Teilbereiches der 16S rRNA-Gene mit einer Länge von etwa 250 bp und der anschließenden Sequenzierung mit der Methode der 454-Pyrosequenzierung. Durch diese Methodik konnten bis zu 56700 Sequenzdaten pro Standort produziert werden. Dieses ermöglichte eine höhere Abdeckung der vorliegenden Diversität. Eine Einordnung der 16S rRNAGensequenzen konnte aufgrund der kurzen Sequenzlängen jedoch nur auf Phylumebene erfolgen.

In Tabelle 18 werden die Ergebnisse der Einteilungen der erhaltenen 16S rRNAGensequenzdaten in bakterielle Phyla durch die klassische Methode und der 454-Pyrosequenzierung vergleichend dargestellt. Durch die Methode der 454-Pyrosequenzierung konnten alle Phyla nachgewiesen werden, die auch durch die klassische Methode ermittelt wurden. Zusätzlich konnten in der Probe des vorderen Caecumbereiches die Bacteroidetes und Fusobacteria und im hinteren Caecumbereich die Phyla Proteo- und Cyanobacteria nachgewiesen werden.

Beim Vergleich der prozentualen Verteilung der 16S rRNA-Gensequenzen innerhalb der unterschiedlichen Phyla wiesen die Ergebnisse der beiden Methoden jedoch gravierende Unterschiede auf.

Inbesondere bei den Phyla Verrucomicrobia und Firmicutes, aber auch bei allen anderen detektierten Phyla, zeigten sich bei den untersuchten Intestinalproben stark unterschiedliche prozentuale Anteile. Bei Verwendung der Methode der 454-Pyrosequenzierung hat eine prozentuale Verschiebung von dem Phylum Verrucomicrobia zu Gunsten des Phylums Firmicutes stattgefunden. So ist bei 
allen analysierten Habitaten die prozentuelle Einteilung in das Phylum Verrucomicrobia gesunken und in etwa gleichen Maßen der Anteil der erhaltenen Sequenzdaten des Phylums Firmicutes gestiegen.

Tabelle 18: Vergleich der Ergebnisse der Phylaeinteilungen der 16S rRNASequenzdaten durch Sanger-Sequenzierung und 454-Pyrosequenzierung

\begin{tabular}{|c|c|c|c|c|c|c|}
\hline \multirow[b]{3}{*}{ Phylum } & \multicolumn{6}{|c|}{ Einordnung der $16 \mathrm{~S}$ rRNA-Gensequenzdaten in Phyla [\%] } \\
\hline & \multicolumn{2}{|c|}{ Caecum (vorne) } & \multicolumn{2}{|c|}{ Caecum (hinten) } & \multicolumn{2}{|c|}{ Colon } \\
\hline & Klassisch $^{1}$ & $454^{2}$ & Klassisch ${ }^{1}$ & $454^{2}$ & Klassisch $^{1}$ & $454^{2}$ \\
\hline Proteobacteria & 1,4 & 8,9 & 0 & 0,7 & 3,9 & 7 \\
\hline Verrucomicrobia & 39,6 & 7,7 & 70,8 & 17,4 & 79,1 & 43,5 \\
\hline Firmicutes & 33,8 & 63,4 & 21,5 & 65,9 & 13,0 & 37,4 \\
\hline Actinobacteria & 24,6 & 13,6 & 6,5 & 10,9 & 2,6 & 3,8 \\
\hline Cyanobacteria & 0,5 & 0,2 & 0 & 3,1 & 0 & 0 \\
\hline Bacteroidetes & 0 & 0,1 & 0,4 & 0,1 & 0,9 & 1,9 \\
\hline Fusobacteria & 0 & 0,5 & 0,8 & 0,9 & 0,4 & 4,6 \\
\hline Unklassifiziert & 0 & 5,6 & 0 & 1,1 & 0 & 1,8 \\
\hline
\end{tabular}

Aufgrund der hohen Anzahl der analysierten 16S rRNA-Gensequenzen unter der Verwendung der 454-Pyrosequenzierung ist eine gute Abdeckung der mikrobiellen Diversität in den verschiedenen Darmabschnitten sehr wahrscheinlich. So standen zum Beispiel für den Standort „hinterer Caecum“ für die klassische Analyse 260 $16 S$ rRNA-Gensequenzen zur Verfügung, die in fünf verschiedene Phyla eingeordnet werden konnten. Im Gegenzug dazu wurden durch die Methode der 454-Sequenzierung über 53000 16S-rRNA-Gensequenzdaten generiert, die insgesamt sieben verschiedene Phyla zugeteilt wurden (s. III.3.3.1.).

Bei der Verwendung der klassischen Methode wurden mit Hilfe des Programmes "DOTUR" (Schloss und Handelsman, 2005) Kalkulationen der Distanzmatrizen der eingesetzten $16 \mathrm{~S}$ rRNA-Gensequenzdaten durchgeführt. Hier wurden sowohl die vorhandene, als auch die zu erwartende Diversität nach Chao1 und ACE berechnet. Mit Hilfe der klassischen Methode konnte in keiner der untersuchten Proben - weder auf Artenebene (24,1\% - 61,2 \% Abdeckung) noch auf 
Phylumebene (55,5 \% - 83,3 \% Abdeckung) - die kalkulierte mögliche bakterielle Diversität abgedeckt werden (s. III.3.3.1-3). Wenn jedoch die Anzahl der Phyla, die durch die Analyse unter Verwendung der 454-Sequenzierung mit der zu erwarteten Anzahl der Phyla nach Chao1 und ACE in der klassischen Analyse verglichen wird, zeigt sich, dass bei allen untersuchten Proben eine vollkommene Abdeckung der Diversität auf Phylumebene erreicht wurde. Daher kann davon ausgegangen werden, dass das Ergebnis der 16S rRNA-Analyse mit Hilfe der 454-Sequenzierung die natürliche bakterielle Diversität auf Phylumebene in den unterschiedlichen Bereichen des Intestinaltraktes des Bibers nahezu vollständig darstellt. Die klassische 16S rRNA - Gensequenzanalyse kann hingegen nur einen Einblick in die bakterielle Diversität der untersuchten Proben gewährleisten, sie ermöglicht jedoch andererseits die Erstellung von phylogenetischen Stammbäumen mit dem Programm ARB oder ähnlichen Programmen.

\subsection{Die mikrobielle Diversität im Darm des Bibers}

In dieser Arbeit wurde die mikrobielle Vielfalt in dem vorderen und hinteren Abschnitt des Blinddarmes (Caecum) und des Endbereiches des Dickdarmes (Colon) eines Tieres untersucht, das im Herbst starb. Aufgrund der Wetterlage veränderte sich das Nahrungsangebot. Während Biber im Frühling und im Sommer Gräser und andere unverholzte Nahrung zu sich nehmen, werden sie im Herbst und Winter dazu gezwungen, sich von schwer verdaulicher und nährstoffarmer Nahrung wie Rinden von Weichhölzern zu ernähren (Jenkins, 1979). In dieser Zeit besteht eine große Abhängigkeit des Bibers von Mikroorganismen im Intestinaltrakt, die die schlecht zugänglichen (ligno-)celluloseund hemicellulosehaltigen Substrate spalten können. Die Degradierung der Nahrung durch Mikroorganismen erfolgt vorwiegend im gut ausgebildeten Caecum der Tiere. Biber sind caecotrophe Lebewesen, $d$. h. sie scheiden den Blinddarminhalt separat vom normalen Kot aus, fressen und verdauen diesen erneut und profitieren somit von den von Mikroorganismen produzierten Vitaminen, Proteinen und Kohlenhydraten (Hirakawa, 2001). Zum heutigen Zeitpunkt ist nur wenig über die mikrobielle Vielfalt im Caecum caecotropher Tiere bekannt. Caecotrophie kommt bei allen Lagomorpha (Hasenartige) und vielen Rodentia (Nagetiere) vor. Bislang gibt es nur zwei Studien, in denen 
kulturunabhängige 16S rRNA-Gensequenzanalysen der mikrobiellen Flora des Blinddarmes des Hasen durchgeführt wurden (Abecia et al., 2005, Monteils et al., 2008) Frühere Studien der caecalen mikrobiellen Zusammensetzung des caecotrophen mongolischen Gerbils und des Chinchillas beruhten auf einer Kultivierung und anschließender phylogenetischer Einordnung der isolierten Mikroorganismen (Worthington und Fulghum, 1988). In dieser Arbeit wurde zum ersten Mal die mikrobielle Flora des Intestinaltraktes des Elbebibers (Castor fiber albicus) untersucht.

Insgesamt wurden im Rahmen dieser Arbeit 696 bakterielle 16S rRNA Gensequenzen für die Konstruktion phylogenetischer Stammbäume verwendet. Zudem standen durch die Methode der 454-Pyrosequenzierung über 121600 Sequenzdaten für die Einteilung in die unterschiedlichen Phyla zur Verfügung. Es konnten mittels 454-Pyroequenzierung aus den Metagenomen der verschiedenen Verdauungstrakte des Elbebibers bakterielle Vertreter der Phyla Proteobacteria, Verrucomicrobia, Firmicutes, Bacteroidetes, Fusobacteria, Cyanobacteria und Actinobacteria nachgewiesen werden s. (III.3.3.). Dieses Ergebnis korreliert mit anderen Studien über die Zusammensetzung der bakteriellen Flora anderer herbivorer Säugetiere wie der Maus (Salzman et al., 2002), des Pferdes (Daly et al., 2001), der Kuh (Koike et al., 2003) oder des Hasen (Valérie et al., 2008).

Die Amplifikation archaeeller 16S rRNA-Gene blieb trotz Modifikation der Primerzusammensetzungen und PCR-Bedingungen erfolglos. In Studien über die mikrobielle Zusammensetzung im Intestinaltrakt des caecotrophen Hasen wird von einem prozentualen Anteil von Archaeen von bis zu $22 \%$ berichtet (Bennegadi et al., 2003). Da ungewiss ist, ob der Fehler in der PCR-Reaktion liegt oder eventuell keine Archaeen im Intestinaltrakt des Bibers vorkommen, kann in dieser Arbeit keine Aussage über die Existenz von Archaeen getroffen werden.

In der klassischen 16S rRNA-Gensequenzanalyse zeigten über $58 \%$ aller OTUs (Ausschlussgrenze <99\%) beim Abgleich mit der NCBI-Datenbank eine Identität zu anderen 16S rRNA-Gensequenzen unter $97 \%$. Diese zeigt, dass in der vorliegenden Studie zahlreiche neue Bakterienarten entdeckt werden konnten. Die nächsten anhand des Abgleichs der $16 \mathrm{~S}$ rRNA-Gensequenzen mit der NCBIDatenbank ermittelten Verwandten waren bis auf wenige Ausnahmen unkultivierte Bakterien, die in diversen Studien zur Untersuchung der mikrobiellen Flora in Intestinaltrakten oder fäkalen Proben von herbivoren, carnivoren oder omnivoren 
Säugetieren beschrieben wurden (siehe Tabellen 20-22, Anhang). Das einzige Bakterium, dass in dieser Studie mit 100 \%iger Identität identifiziert werden konnte, ist das Bakterium Acinetobacter junii [FJ596644] im vorderen Bereich des Blinddarmes des Bibers. Ebenfalls im vorderen Bereich des Blinddarmes konnten 16S rRNA Gensequenzen mit Identitäten von 99,5\% bzw. 91,6 \% zu den Bakterien Comamonas sp. BF-5 [EU312978] und Adlercreutzia equolifaciens [AB306662] detektiert werden (s. III.3.3.3.1.). Acinetobacter junii ist ein Gramnegatives obligat aerobes Bakterium der Klasse der $y$-Proteobacteria und wurde aus menschlichen klinischen Proben isoliert (Bouvet und Grimont, 1986). Die natürlichen Habitate dieses strikt aeroben Bakteriums sind u. a. Boden, Gewässer oder der Belebtschlamm von Kläranlagen (Towner et al., 1991). Im Darmtrakt von Säugetieren konnte $A$. junii bislang nicht nachgewiesen werden. Es ist möglich, dass es sich hier nicht um einen Bewohner der caecalen Flora handelt, sondern dass der Biber diese Bakterien mit der Nahrung oder passiv bzw. aktiv durch die Lebensweise im Wasser aufgenommen hat. Die Gattung Comamonas (Klasse B-Proteobacteria) enthält ebenfalls strikt aerobe Gram-negative nichtfermentative chemoorganotrophe Arten. Die Vertreter dieser Arten konnten aus Schlamm, Wasser, Boden und Belebtschlamm von Kläranlagen isoliert werden (Willems et al., 1992). Des Weiteren wurde die Art Comamonas odontotermites aus dem Verdauungstrakt der Termite (Odontotermes formosanus) isoliert (Chou et al., 2007). Termiten sind in der Lage, mit Hilfe von Mikroorganismen im Darmtrakt lignocellulosehaltige Nahrung zu degradieren (Shinzato et al., 2007). Eventuell spielt der in dieser Studie entdeckte nahe Verwandte der Gattung Comamonas ebenfalls eine Rolle in der Spaltung von Nahrung mit holzigen Bestandteilen. Adlercreutzia equolifaciens wurde aus Fäkalien des Menschen isoliert und wird den Actinobacteria zugeordnet. Es ist ein asaccharolytisches obligat anaerobes nicht-sporenbildendes Gram-positives Bakterium (Maruo et al., 2008). Da A. equolifaciens nicht in der Lage ist, Kohlenhydrate zu fermentieren, scheint dieses Bakterium nicht an der Degradierung von (ligno-)celluloser Nahrung im Darm von Säugetieren beteiligt zu sein. Da die 16S rRNA-Gensequenz des im vorderen Abschnitt des Biberblinddarms identifizierten Bakteriums jedoch nur eine geringe Identität von $91,6 \%$ zu $A$. equolifaciens aufweist, kann die Lebensweise des charakterisierten Bakteriums nur einen Anhaltspunkt auf die physiologischen Eigenschaften des im Biberblinddarm vorkommenden Bakteriums geben. 


\subsection{Vergleich der bakteriellen Diversität in verschiedenen Bereichen des Darmtraktes des Bibers.}

Im folgenden Abschnitt werden die Unterschiede der bakteriellen Diversität auf Phylumebene in den verschiedenen Darmbereichen diskutiert und mit den Ergebnissen der klassischen 16S rRNA Analyse vertieft. Da eine Degradierung der schwer verdaulichen pflanzlichen (ligno-)cellulosehaltigen Nahrung vorwiegend im Caecum erfolgt, soll hier auf die Existenz von cellulolytischen Mikroorganismen im Vergleich zu der bakteriellen Flora im Colon eingegangen werden.

Abbildung 50 zeigt die Einteilung der aus den Metagenomen der unterschiedlichen Bereiche des Verdauungstraktes amplifizierten 16S rRNA-Gensequenzen auf Phylumebene. Hierfür wurden die mit der Methode der 454-Pyrosequenzierung generierten Sequenzdaten verwendet, da aufgrund der hohen Sequenzanzahl eine Abdeckung auf Phylumebene gewährleistet wird. Somit kann ein Überblick über die prozentuale Verteilung der Bakterienarten in der mikrobiellen Gemeinschaft in den unterschiedlichen Abschnitten des Intestinaltraktes geschaffen werden.

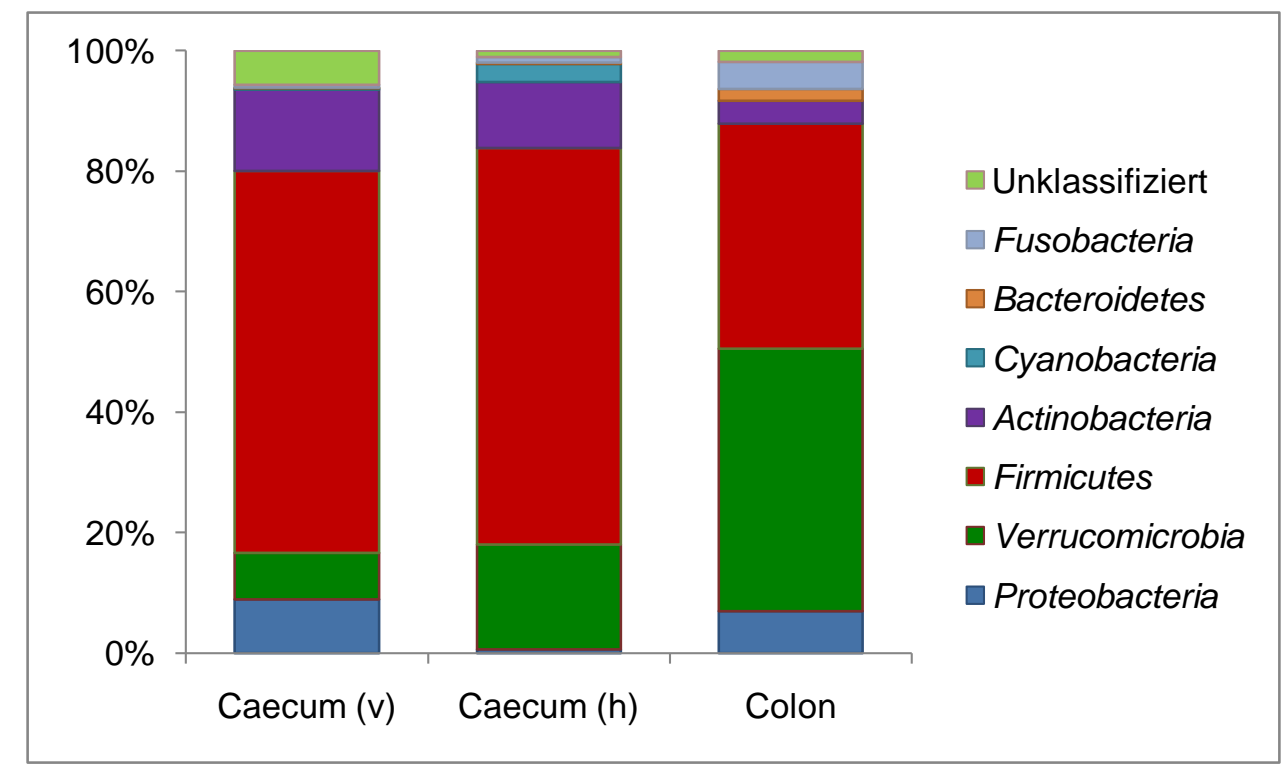

Abbildung 50: Vergleich der bakteriellen Diversität auf Phylumebene im vorderen Bereich des Caecums [Caecum (v)], hinteren Bereich des Caecums [Caecum (h)] und des Colons. 
Beim Vergleich der unterschiedlichen Bereiche des Intestinaltraktes auf Phylumebene fällt besonders der Unterschied zwischen den untersuchten Proben der Blinddarmbereiche zu der Probe des Colons auf. Während in den untersuchten Bereichen des Caecums das Phylum Firmicutes dominiert (63,4\% im vorderen Bereich; 65,9\% im hinteren Bereich), ist das Phylum Firmicutes im Colon nur durch 37,4\% aller Sequenzen vertreten (siehe Abbildung 50). In Studien über die bakterielle Zusammensetzung der Darmflora des Pferdes konnte gezeigt werden, dass das Phylum Firmicutes den Hauptanteil an cellulolytischen und hemicellulolytischen Organismen beeinhaltet (Daly et al., 2001). Auch in phylogenetischen Analysen über die mikrobielle Flora im Blinddarm caecotropher Hasen wurden $94 \%$ aller OTUs in das Phylum Firmicutes eingeordnet (Valérie et al., 2008). Da im Blinddarm im Vergleich zum Colon die Firmicutes signifikant stärker vertreten sind, kann davon ausgegangen werden, dass im Blinddarm des Bibers ebenfalls vorwiegend Bakterien dieses Phylums für die Degradierung (ligno-)cellulosehaltiger Nahrung verantwortlich sind. In der klassischen phylogenetischen Analyse der bakteriellen Diversität im vorderen und hinteren Bereich des Caecums wurden die durch die Sanger-Sequenzierung erhaltenen 16S rRNA-Gensequenzen (s. III.3.3.1/2) des Phylums Firmicutes vorwiegend in die Ordnung Clostridiales eingeteilt. Es erfolgte eine weitere Einteilung der anaeroben Bakterien hauptsächlich in die Familien Lachnospiraceae und Ruminococcaceae. In der Familie der Ruminococcaceae sind zahlreiche Arten vertreten, die in der Lage sind, cellulose- bzw. hemicellulosehaltige Substrate zu hydrolysieren. Als Beispiele werden hier Ruminococcus albus und $R$. flavefaciens genannt, die als die wichtigsten (Hemi-)Celluloseabbauer im Pansen von Wiederkäuern angesehen werden (Chen und Weimer, 2001). Die Lachnospiracea werden ebenfalls durch viele Arten vertreten, die in der Lage sind, (hemi-)cellulosehaltige Pflanzenfasern zu degradieren. So sind besonders Arten der Gattung Butyrivibrio (z. B. B. fibrisolvens) (hemi-)cellulolytisch (Cotta und Forster, 2006).

Ein ebenfalls signifikanter Unterschied der bakteriellen Diversität in den beiden Blinddarmbereichen und des Colons zeigt sich in der Einteilung der 16S rRNAGensequenzen in das Phylum Actinobacteria. Während dieses Phylum im Caecum zu 13,6 \% bzw. 10,9 \% vertreten wird, wurden im Colon nur 3,8 \% aller Sequenzen den Actinobacteria zugeordnet. In der klassischen 16S rRNA-Analyse 
wurden alle 16S rRNA-Gensequenzen den Coriobacteriales zugeordnet. Den Coriobacteriales werden einige anaerobe Gattungen zugeordnet, die u. a. im Verdauungstrakt des Rindes nachgewiesen werden konnten (Anderson et al., 2000). Des Weiteren konnten Vertreter der Actinobacteria in der lignocelluloseverwertenden Termite Nasutitermes corniger identifiziert werden (Lefebvre et al., 2009).

Im Vergleich zwischen den beiden Abschnitten innerhalb des Caecums zeigt sich, dass im vorderen Bereich des Blinddarmes 8,9\% aller 16S rRNA-Gensequenzen den Proteobacteria zugeordnet wurden, während diese nur durch $0,7 \%$ aller Sequenzen im hinteren Bereich repräsentiert wurden. Des Weiteren enthält der vordere Abschnitt nur 7,7\% bakterielle Arten der Verrucomicrobia, während im hinteren Bereich des Blinddarmes dieses Phylum durch 17,4\% vertreten wird. In der klassischen 16S rRNA-Analyse wurden die 16S rRNA-Gensequenzen, die dem Phylum Proteobacteria zugeordnet wurden, im vorderen Bereich des Caecums in die Klasse der $y$-Proteobakterien und der B-Proteobakterien eingeordnet. Es handelt sich hierbei u.a. um das im vorherigen Abschnitt beschriebene zu 100\% identifizierte Bakterium Acinetobacter junii und um einen nahen Verwandten von Comamonas sp. BF5. Bei beiden Organismen handelt es sich um strikt aerobe Bakterien. Es ist möglich, dass im vorderen Bereich des Blinddarms eine geringe Menge Restsauerstoff vorhanden ist, die eventuell assoziert mit der Nahrung in diesen Teil des Caecums gelangt ist und somit diesen Bakterien zur Verfügung steht, während im hinteren Bereich des Blinddarmes anaerobe Verhältnisse herrschen und somit das Überleben dieser aeroben Arten unmöglich wird.

Dem Phylum Verrucomicrobia, das in dem hinteren Bereich des Caecums stärker vertreten ist als im vorderen Bereich, konnten in der klassischen 16S rRNA-Gensequenzanalyse der bakteriellen Diversität in beiden Proben jeweils zwei OTUs zugewiesen werden. Alle OTUs wurden in die Familie der Verrucomicrobiaceae eingeordnet und wiesen mit 94,2 \% - 94,7\% Identität als nächsten Nachbarn eine 16S rRNA-Gensequenz eines unkultivierten Bakteriums auf, die aus dem Metagenom menschlicher Fäkalien amplifiziert wurde [DQ795617]. Das Phylum der Verrucomicrobia stellt physiologisch eine sehr heterogene Gruppe dar. Die gramnegativen Bakterien können sowohl strikt aerob, fakultativ aerob als auch strikt anaerob sein. Als Kohlenstoff- und Energiequelle 
dienen vorwiegend Kohlenhydrate aus Zuckern oder Polysacchariden (Schlesner et al., 2006). Ein Vertreter dieses Phylums, Opitutus terrae, ist beispielsweise zur Degradierung und Verwertung von Cellulose und Xylan im Darm von Termiten befähigt (Stevenson et al., 2004). In Studien über die bakterielle Diversität in fäkalen Proben des Gorillas wurden 17,2 \% aller 16S rRNA-Gensequenzen in das Phylum Verrucomicrobia eingruppiert (Frey et al., 2006). Zudem konnten Vertreter dieses Phylums im Dünndarm des Pferdes (Daly et al., 2001), im Caecum des Hasen (Monteils et al., 2008) und im Dünndarm der Maus (Salzman et al., 2002) identifiziert werden.

Ein weiterer signifikanter Unterschied zwischen beiden Bereichen des Caecums ist eine erhöhte Anzahl der Cyanobacteria (3,1\%) im hinteren Bereich des Caecums. Im vorderen Bereich wurden nur 0,2 \% aller 16S rRNA-Gensequenzen diesem Phylum zugeteilt. Cyanobakterien konnten auch im Intestinaltrakt der Ratte, des Menschen, des Pferdes im Pansen der Kuh und auch in caecalen Proben der Maus identifiziert werden (Ley et al., 2005). Hierbei handelt es sich, abgesehen vom Menschen, um Säugetiere, die mit Hilfe von Mikroorganismen im Verdauungstrakt in geringen Maße Cellulose verwerten können. In der klassischen 16S rRNA Analyse konnte nur im vorderen Caecumbereich eine 16S rRNA Gensequenz (Blv1_E11) identifiziert werden, die in das Phylum Cyanobacteria und der Familie der Chroococcales eingeordnet wurde (s. III.3.3.3.1.) Der nächste Verwandte in der NCBI-Datenbank ist mit 99,1\% ein unkultiviertes Bakterium, das mit einem colorectalen Darmgeschwür assoziert war [EU530305]. Eine Studie über den Vergleich der bakteriellen Diversität zwischen Proben aus dem Verdauungstrakt von 59 Säugetieren (u.a. auch Nagetieren) zeigte, dass 0,1\% der Gesamtheit aller 16S rRNA-Gensequenzen den Cyanobacteria zugeordnet werden konnten. Bei den identifizierten Cyanobakterien handelte es sich um einen tiefverwurzelten Zweig der Cyanobacteria (Ley et al., 2008). Nicht alle Cyanobakterien sind auf die ausschließlich phototrophe Lebensweise angewiesen. So wurden Arten entdeckt, die unter anaeroben Verhältnissen unter Lichtausschluss wachsen können (z. B. O. terebriformis, O. limosa und Microcoleus chthonoplastes). Diese Arten sind in der Lage, Substrate wie Glykogen zu degradieren und verschiedene Zucker zu fermentieren (Cohen und Gurevitz, 2006). Um zu klären, welche physiologischen Eigenschaften die Cyanobakterien im hinteren Blinddarmbereich des Bibers besitzen und ob es sich 
um Darmbewohner oder nur um Darmpassanten handelt, die mit der Nahrung (z.B. Flechten am Rindenmaterial) aufgenommen wurden, müssen weitere Studien durchgeführt werden, die eine Kultivierung und Isolierung dieser Bakterien beinhaltet.

\subsection{Vergleich der bakteriellen Diversität im Caecum von zwei Individuen mit unterschiedlicher Nahrungsaufnahme}

In dieser Arbeit wurde die bakterielle Diversität der mikrobiellen Flora der Blinddärme von zwei verschiedenen Biberindividuen untersucht, die zu unterschiedlichen Jahreszeiten starben und sich somit bezüglich der zu sich genommenen Nahrung unterschieden. Das im Herbst/Winter gestorbene, männliche Tier ernährte sich vorwiegend von Weichholzrinden, während das weibliche, im Sommer gestorbene Tier vorwiegend Gräser und andere unverholzte pflanzliche Nahrung zu sich nahm. Hier sollte untersucht werden, ob sich die bakterielle Diversität im Caecum aufgrund des unterschiedlichen Nahrungsangebots verändert. Die 16S rRNA Analyse der bakteriellen Gemeinschaften erfolgte mit Hilfe der 454-Pyrosequenzierung der aus den Metagenomen amplifizierten 16S rRNA-Gensequenzen (s. III.3.4.). Eine Einteilung der erhaltenen Sequenzdaten erfolgte mit Hilfe des „RDP Classifiers“(Larsen et al., 1993).

In Abbildung 51 wird die Einteilung der 16S rRNA-Gensequenzen in Phyla dargestellt. Da es sich bei den untersuchten Proben um Proben aus zwei unterschiedlichen Individuen handelt, können die Ergebnisse nur einen Hinweis auf die Anpassung der mikrobiellen Flora im Caecum auf eine Nahrungsumstellung geben. Um genauere Aussagen treffen zu können, müsste die ceacale mikrobielle Flora im Verlauf der Jahreszeiten nur eines Individuums untersucht werden. Da dieses jedoch aus naturschutzrechtlichen und ethischen Gründen nicht möglich war, wurden zwei verschiedene schon gestorbene Tiere untersucht.

Wie in Abbildung 51 zu erkennen ist, treten signifikante Unterschiede vorwiegend in den Phyla Cyanobacteria und Actinobacteria auf. Während beim männlichen Tier 10,9\% aller Sequenzen in das Phylum Actinobacteria eingeordnet wurden, ergab die Analyse der Sequenzdaten der Probe des weiblichen Tieres nur einen 
Anteil von 5,2\%. Bei der Einteilung der 16S rRNA-Gensequenzen in das Phylum der Cyanobacteria zeigte sich ein noch deutlicherer Unterschied. Während beim männlichen Biber nur 3,1\% aller Sequenzdaten in dieses Phylum eingeordnet wurden, betrug der Anteil bei der Probe des weiblichen Tieres einen Prozentsatz von 13,2 \%. Vermutlich spielen Actinobacteria eine Rolle im Abbau von verholzten, lignocellulosehaltigen Pflanzenfasern, da dieses Phylum besonders im Winter vertreten war. Im Sommer, in dem die pflanzliche Nahrung leichter zu verwerten ist, treten scheinbar Cyanobacteria in den Vordergrund. Dieses läßt sich dadurch erklären, dass Biber im Sommer verschiedene (Wasser-)Pflanzen, die mit Vertretern der Cyanobacteria assoziert sein könnten, zu sich nehmen und diese somit in das Caecum gelangen. Des Weiteren ist die Verbreitung von Cyanobakteria im Sommer in Seen, Teichen und Bächen, den natürlichen Habitaten des Bibers, besonders hoch. Daher kann der hohe Anteil an Cyanobakterien zudem durch die Trinkwasseraufnahme begründet werden.

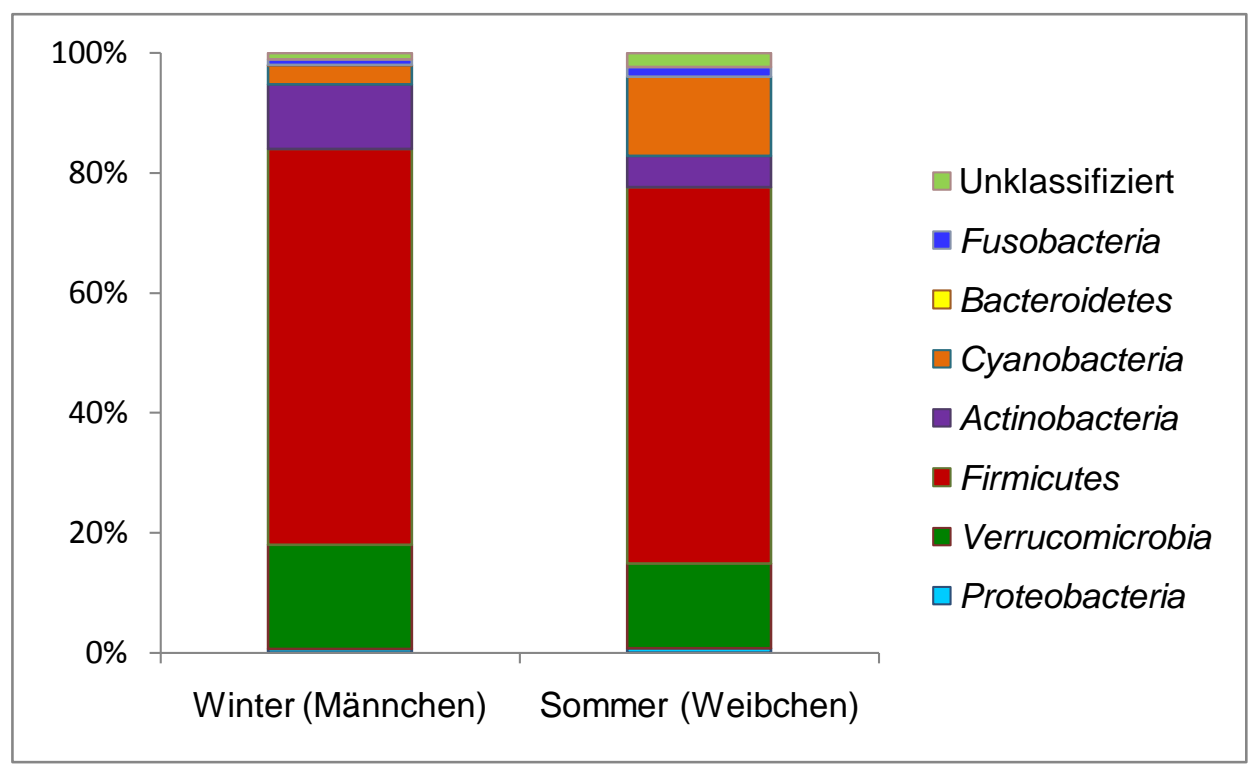

Abbildung 51: Einteilung der Sequenzdaten der partiell amplifizierten bakteriellen $16 \mathrm{~S}$ rRNA-Gene der mikrobiellen Gemeinschaft aus dem Blinddarminhalt des im Winter verstorbenen, männlichen und des im Sommer verstorbenen, weiblichen Bibers 


\section{5: Konstruktion von metagenomischen Genbanken aus Proben des hinteren Caecumbereiches}

Die Konstruktion von Metagenombanken blieb in dieser Arbeit erfolglos. Dieses beruht höchstwahrscheinlich auf der schlechten Qualität der isolierten DNA. Für die Isolierung der DNA wurden sowohl kommerzielle DNA-Isolierungs-Kits u.a für fäkalen Ausgangsproben, als auch klassische Methoden angewendet. Bei allen Isolierungen wies die DNA eine starke Scherung auf (s. Abbildung 47, III.3.3.3.1.), so dass die DNA für die Konstruktion von large insert- Fosmidgenbanken weniger geeignet war. Eine weitere Problematik bei der DNA-Isolierung aus fäkalen Proben, insbesondere bei herbivoren Säugetieren, ist die Koextraktion von Inhibitoren für enzymatische Reaktionen. Dabei kann es sich um diverse Verbindungen handeln wie zum Beispiel Humin- oder Fulvinsäuren, Bilirubin oder Hämoglobin (Wilson, I. G., 1997). Des Weiteren wurde von einer inhibierenden Wirkung von Polysacchariden in PCR-Reaktionen berichtet (Monteiro et al., 1997). $\mathrm{Da}$ besonders in herbivoren Tieren wie dem Biber, eine große Menge an Polysacchariden im Darmtrakt vorkommt, ist es möglich, dass diese die folgenden enzymatischen Modifikationen der DNA für die Konstruktion der Genbanken ebenfalls störten. Daher ist es notwendig, für folgende Versuche der Erstellung von Genbanken aus metagenomischer DNA des Blinddarminhalts besonders auf die Entfernung von Enzyminhibitoren einzugehen.

\subsection{Ausblick}

Die Analyse der bakteriellen Diversität im Intestinaltrakt des Elbebibers weist darauf hin, dass dieses Metagenom ein großes Potential besitzt für die Isolierung von Genen für neue cellulolytische und hemicellulolytische Enzyme. Wenngleich in dieser Arbeit weder die (hemi)cellulolytischen Mikroorganismen kultiviert, noch die beteiligten Enzymaktivitäten charakterisiert werden konnten, kann angenommen werden, dass sich besonders im vorderen und hinteren Teil des Blinddarmes eine Vielzahl von (hemi-)cellulolytischen Bakterien aufhalten. Somit kann dieses Habitat als wertvolle Ressource für die Gewinnung von neuen Biokatalysatoren dienen, deren Gene durch die Konstruktion von Metagenombanken und anschließendem Enzymscreening identifiziert werden können. Da sich die Konstruktion von Metagenombanken mit der aus dem Caecum isolierten DNA als 
schwierig erwies, sollten in zukünftigen Versuchen ein besonderes Augenmerk auf die Isolierungsmethode der DNA gelegt werden, um möglichst eine Scherung und eine Verunreinigung mit Inhibitoren zu vermeiden. 


\section{Zusammenfassung}

In der vorliegenden Dissertation wurden Metagenomanalysen von zwei sehr unterschiedlichen Habitaten mit (hemi)celluloseabbauenden Mikroorganismen, einer Bodenprobe des Avachinsky-Kraters (Kamchatka/Sibirien) und des Intestinaltrakts des Elbebibers (Castor fiber albicus), durchgeführt.

\section{Metagenomanalyse einer Bodenprobe des Avachinsky-Kraters}

Die in dieser Arbeit analysierte metagenomische Fosmidgenbank wurde von Jörg Schuldes (Institut für Mikrobiologie und Genetik, Universität Göttingen) im Rahmen einer Doktorarbeit aus DNA aus einer Bodenprobe des Avachinsky-Kraters konstruiert. Aus 5200 E. coli Fosmidgenbankklonen mit insgesamt $182 \mathrm{Mbp}$ klonierter metagenomischer DNA konnten elf hydrolytisch aktive E. coliGenbankklone detektiert werden, welche letztlich sechs putative (Hemi-)CellulaseORFs trugen.

Zwei dieser ORFs wurden in E. coli BL21 exprimiert. Die Sequenzanalyse des ersten ORFs xyn1015 (1332 bp) ergab eine Sequenzidentität des Genproduktes (Xyn1015) von $40 \%$ zu einer Glycosidhydrolase der Familie 10 (Xylanase) aus Caldicellulosiruptor saccharolyticus (ABP65852). Das durch Hitzefällung und einer Affinitätschromatographie gereinigte, rekombinante etwa $50 \mathrm{kDa}$ große Enzym zeigte vorwiegend hydrolytische Aktivität mit Substraten mit einem B-1,4-glycosidisch verknüpten Xyloserückgrat (Xylane aus Haferspelzen, Lärchen-, Birken- und Buchenholz), spaltete innerhalb der Xylosekette und konnte daher als Endo-ß-1,4-Xylanase (3.2.1.8) klassifiziert werden.

Xyn1015 zeigt maximale hydrolytische Aktivität bei $95{ }^{\circ} \mathrm{C}$ (15 min Enzymassay), einem $\mathrm{pH}$ Wert von 7 und einer $\mathrm{NaCl}$-Konzentration von $1 \mathrm{M}$ im Testansatz. Das Enzym ist außergewöhnlich beständig gegen Hitzeinaktivierung: Nach 24 Stunden Inkubation bei $95{ }^{\circ} \mathrm{C}$ konnten noch $50 \%$ der Ausgangsaktivität nachgewiesen werden. Mit Buchenholzxylan als Substrat wurden ein $\mathrm{K}_{\mathrm{m}}$-Wert von $2 \mathrm{mg} / \mathrm{ml}$ und ein $V_{\max }-$ Wert von $400 \mathrm{U} / \mathrm{mg}$ ermittelt (bei $\mathrm{pH} 7,95{ }^{\circ} \mathrm{C}$ und $1 \mathrm{M} \mathrm{NaCl}$ im Testansatz).

Das Genprodukt des zweiten ORFs (bga48) zeigte 38\% Sequenzähnlichkeit zu einer nicht charakterisierten Glycosidhydrolase aus Thermotoga petrophila 
(YP_001244493). Abschnitte der Primärstruktur wiesen schwache Sequenzähnlichkeiten zur Glycosidhydrolase-Familie 42 und zur Familie CBM4_9 der Kohlenhydratbindemodule auf. Das heterolog exprimierte Protein (Bga48) mit einer Größe von etwa 100 kDa konnte mittels Hitzefällung mesophiler Wirtsproteine und Kationenaustauschchromatographie aufgereinigt werden. Bga48 hydrolysierte vorwiegend B-1,3-ß-1,4-Glucane wie ß-Glucan aus Gerste und Lichenan und kann daher als Lichenase (3.2.1.73) bezeichnet werden. Es besteht jedoch keine Aminosäuresequenzähnlichkeit zu anderen beschriebenen Lichenasen, so das Bga48 eventuell in eine neue Glycosidhydrolase-Familie eingeordnet werden muss. Bga48 zeigte die höchste hydrolytische Aktivität bei $90{ }^{\circ} \mathrm{C}$ (25 min Enzymassay) und einem pH-Wert von 6. Das Enzym erwies sich als sehr thermostabil und wies nach fünf Stunden Inkubation bei $75^{\circ} \mathrm{C}$ fast $60 \%$ der Ausgangsaktivität auf. Bga48 spaltet zunächst innerhalb der Glucosekette und ist somit eine Endolichenase. Als $\mathrm{K}_{\mathrm{m}}$ - bzw. $\mathrm{V}_{\max }-$ Werte wurden 0,24 mg/ml bzw. 200 $\mathrm{U} / \mathrm{mg}$ ermittelt (Gersten-ß-Glucan, $\mathrm{pH} 6,90^{\circ} \mathrm{C}$ ).

\section{Untersuchung der mikrobiellen Diversität in verschiedenen Bereichen des Intestinaltraktes des Elbebibers}

Die bakterielle Diversität in dem vorderen und hinteren Bereich des Caecums (Blinddarm) und im Colon (Dickdarm) eines im Herbst gestorbenen Tieres wurde untersucht. In dieser Jahreszeit ernähren sich Biber vorwiegend von schwer verdaulicher Nahrung wie Rinden von Weichholzbäumen, die von von (ligno-)cellulolytischen Mikroorganismen im gut ausgebildeten Caecum degradiert werden können. Aus insgesamt 696 rRNA-Gensequenzen wurden phylogenetische Stammbäume der bakteriellen Diversität in den verschiedenen Intestinaltrakten auf Artenebene erstellt. Ein Anteil von 99,4\% dieser Sequenzen zeigte keine Identität zu 16S rRNA-Gensequenzen von kultivierten Bakterien. Die 696 16S rRNA Gensequenzen wurden in 39 operational taxonomic units (OTUs) für den vorderen Caecumbereich, in 44 OTUs für den hinteren Caecumbereich und 31 OTUs für den Colon eingeteilt (genetische Distanz $1 \%$ ). Zudem wurden mit insgesamt über 121.600 454-Pyrosequenzierungsdaten von amplifizierten $16 \mathrm{~S}$ rRNA-Gensequenzen Untersuchungen zur bakteriellen Diversität auf Phylumebene durchgeführt. 
Durch die Erstellung der phylogenetischen Stammbäume und durch die Auswertung der 454-Pyrosequenzierungsdaten konnten in den untersuchten Proben Vertreter der Phyla Proteobacteria, Verrucomicrobia, Firmicutes, Bacteroidetes, Fusobacteria, Cyanobacteria und Actinobacteria nachgewiesen werden. Ein Unterschied der Diversität konnte besonders zwischen Caecum und Colon festgestellt werden.

Während das Phylum Firmicutes in den Caecumabschnitten mit 63,4 \% bzw $65,9 \%$ dominierte, war dieses Phylum im Colon nur durch $37,4 \%$ aller $16 \mathrm{~S}$ rRNAGensequenzen vertreten. Im Gegenzug enhielt der Colon zu 43,5\% Vertreter der Verrucomicrobia, während dieses Phylum nur durch 7,7 \% bzw 17,4 \% der 16S rRNA-Gensequenzdaten in den Blinddarmbereichen nachgewiesen werden konnten. Wenn man annimmt, dass eine Korrelation besteht zwischen der Phylumzugehörigkeit der im Caecum am zahlreichsten vorhandenen Bakterien und der Fähigkeit zum (Hemi)Celluloseabbau, so kann vermutet werden, dass die (ligno-)cellulolytischen Bakterien vorwiegend den Firmicutes zugehörig sind.

Die phylogenetischen Stammbäume der bakteriellen Diversitäten in den Caecumbereichen zeigten, dass die Vertreter der Firmicutes fast ausschließlich in die Klasse der Clostridia und hier vorwiegend den Familien Ruminococcaceae und Lachnospiraceae zuzuordnen waren. Viele Vertreter dieser Familien sind (ligno-)cellulolytische Bakterien.

Weiterhin wurde untersucht, ob die bakterielle Diversität im Caecum eines im Sommer gestorbenen Bibers (Ernährung vorwiegend von unverholzten Pflanzen wie z.B. Gräser oder Wasserpflanzen) sich von der bakteriellen Diversität im Caecum des im Herbst gestorbenen Tieres unterschied. Für die Analyse wurden Pyrosequenzierungsdaten partiell amplifizierter 16S rRNA-Gene verwendet, die eine Einordnung auf Phylumebene erlaubten. Ein Unterschied zu dem im Herbst gestorbenen Tier konnte hauptsächlich bei den Phyla Actinobacteria und Cyanobacteria festgestellt werden. Während $10,9 \%$ der $16 \mathrm{~S}$ rRNAGensequenzen der Probe des im Herbst gestorbenen Tieres den Actinobacteria zugeordnet wurden, waren es bei dem im Sommer gestorbenen Tier nur 5,2\%. Im Gegenzug wurden 13,2 \% der 16S rRNA-Gensequenzen bei dem im Sommer gestorbenen Tier den Cyanobacteria zugeteilt, während es bei dem im Herbst gestorbenen Tier nur 3,1\% waren. 


\section{Literaturverzeichnis}

Abecia, L., Fondevila, M., Balcells, J., Edwards, J. E., Newbold, C. J. und McEwan, N. R., (2005). Molecular profiling of bacterial species in the rabbit caecum. FEMS microbiology letters, 244, 111-115

Amann, R. I., Ludwig, W. und Schleifer, K. H., (1995). Phylogenetic identification and in situ detection of individual microbial cells without cultivation. Microbiol. Rev., 59, 143-169

Anderson, R. C., Rasmussen, M. A., Jensen, N. S. und Allison, M. J., (2000). Denitrobacterium detoxificans gen. nov., sp. nov., a ruminal bacterium that respires on nitrocompounds. Int J Syst Evol Microbiol, 50, 633-638

Angelov, A., Mientus, M., Liebl, S. und Liebl, W., (2009). A two-host fosmid system for functional screening of (meta) genomic libraries from extreme thermophiles. Systematic and Applied Microbiology, 32, 177-185

Anish, R. und Rao, M., (2007). Biochemical characterization of a novel -1-3, 1-4 glucan 4-glucanohydrolase from Thermomonospora sp. having a single active site for lichenan and xylan. Biochimie, 89, 1489-1497

Aubert, D., Naas, T., Heritier, C., Poirel, L. und Nordmann, P., (2006). Functional Characterization of IS1999, an IS4 Family Element Involved in Mobilization and Expression of \{beta\}-Lactam Resistance Genes. Journal of Bacteriology, 188, 6506

Bataillon, M., Nunes Cardinali, A. P., Castillon, N. und Duchiron, F., (2000). Purification and characterization of a moderately thermostable xylanase from Bacillus sp. strain SPS-0. Enzyme and microbial technology, 26, 187-192

Beg, Q. K., Kapoor, M., Mahajan, L. und Hoondal, G. S., (2001). Microbial xylanases and their industrial applications: a review. Applied Microbiology and Biotechnology, 56, 326-338

Bell, P. J. L., Sunna, A., Gibbs, M. D., Curach, N. C., Nevalainen, H. und Bergquist, P. L., (2002). Prospecting for novel lipase genes using PCR. Microbiology, 148, 2283-2291

Bennegadi, N., Fonty, G., Millet, L., Gidenne, T. und Licois, D., (2003). Effects of age and dietary fibre level on caecal microbial communities of conventional and specific pathogen-free rabbits. Microbial Ecology in Health and Disease, 15, 23-32

Bergquist, P., Moreland D. Gibbs Daniel D. Morris V. S. Junior Te'o David J. Saul Hugh W. Morgan, (1999, Molecular diversity of thermophilic cellulolytic and hemicellulolytic bacteria, 28, 99-110

Bhat, M. K., (2000). Cellulases and related enzymes in biotechnology. Biotechnology Advances, 18, 355-383 
Blanco, A., Diaz, P., Zueco, J., Parascandola, P. und Pastor, F. I. J., (1999). A multidomain xylanase from a Bacillus $\mathrm{sp}$. with a region homologous to thermostabilizing domains of thermophilic enzymes. Microbiology, 145, 2163-2170

Bonfield, J. K., Smith, K. F. und Staden, R., (1995). A new DNA sequence assembly program. Nucl. Acids Res., 23, 4992-4999

Boraston, A. B., Bolam, D. N., Gilbert, H. J. und Davies, G. J., (2004). Carbohydrate-binding modules: fine-tuning polysaccharide recognition. Biochem. J, 382, 769-781

Bouvet, P. J. M. und Grimont, P. A. D., (1986). Taxonomy of the genus Acinetobacter with the recognition of Acinetobacter baumannii sp. nov., Acinetobacter haemolyticus sp. nov., Acinetobacter johnsonii sp. nov., and Acinetobacter junii sp. nov. and emended descriptions of Acinetobacter calcoaceticus and Acinetobacter Iwoffii. International Journal of Systematic and Evolutionary Microbiology, 36, 228

Bradford, M. M., (1976). A rapid and sensitive method for the quantitation of microgram quantities of protein utilizing the principle of protein-dye binding. Analytical Biochemistry, 72, 248-254

Breccia, J. D., Sineriz, F., Baigori, M. D., Castro, G. R. und Hatti-Kaul, R., (1998). Purification and characterization of a thermostable xylanase from Bacillus amyloliquefaciens. Enzyme and Microbial Technology, 22, $42-49$

Brennan, Y. L., Callen, W. N., Christoffersen, L., Dupree, P., Goubet, F., Healey, S., Hernandez, M., Keller, M., Li, K. und Palackal, N., (2004). Unusual microbial xylanases from insect guts. Applied and Environmental Microbiology, 70, 3609-3617

Cantarel, B. L., Coutinho, P. M., Rancurel, C., Bernard, T., Lombard, V. und Henrissat, B., (2009). The Carbohydrate-Active EnZymes database (CAZy): an expert resource for glycogenomics. Nucleic acids research, 37, D233

Carere, C. R., Sparling, R., Cicek, N. und Levin, D. B., (2008). Third Generation Biofuels via Direct Cellulose Fermentation. Int J Mol Sci, 9, 1342-60

Chen, J. und Weimer, P. J., (2001). Competition among three predominant ruminal cellulolytic bacteria in the absence or presence of non-cellulolytic bacteria. Microbiology, 147, 21-30

Chernoglazov, V. M., Jafarova, A. N. und Klyosov, A. A., (1989). Continuous photometric determination of endo-1,4-[beta]-d-glucanase (cellulase) activity using 4-methylumbelliferyl-[beta]-d-cellobioside as a substrate. Analytical Biochemistry, 179, 186-189

Chou, J. H., Sheu, S. Y., Lin, K. Y., Chen, W. M., Arun, A. B. und Young, C. C., (2007). Comamonas odontotermitis sp. nov., isolated from the gut of the termite Odontotermes formosanus. International Journal of Systematic and Evolutionary Microbiology, 57, 887 
Cohen, Y. und Gurevitz, M., (2006). The cyanobacteria-ecology, physiology and molecular genetics. Prokaryotes, 4, 1074-1098

Collins, T., Gerday, C. und Feller, G., (2005). Xylanases, xylanase families and extremophilic xylanases. FEMS microbiology reviews, 29, 3-23

Corfield, T., (1992). Bacterial sialidases-roles in pathogenicity and nutrition. Glycobiology, 2, 509-521

Cotta, M. und Forster, R., (2006, The Family Lachnospiraceae, Including the Genera Butyrivibrio, Lachnospira and Roseburia,1002-1021

Coughlan, M. und Hazlewood, G., (1993). beta-1, 4-D-xylan-degrading enzyme systems: biochemistry, molecular biology and applications. Biotechnology and applied biochemistry, 17, 259-289

Daly, K., Stewart, C. S., Flint, H. J. und Shirazi-Beechey, S. P., (2001). Bacterial diversity within the equine large intestine as revealed by molecular analysis of cloned 16S rRNA genes. FEMS Microbiology Ecology, 38, 141-151

Daniel, R., (2004). The soil metagenome--a rich resource for the discovery of novel natural products. Curr Opin Biotechnol, 15, 199-204

Derewenda, U., Swenson, L., Green, R., Wei, Y., Morosoli, R., Shareck, F., Kluepfel, D. und Derewenda, Z. S., (1994). Crystal structure, at 2.6-A resolution, of the Streptomyces lividans xylanase A, a member of the $\mathrm{F}$ family of beta-1, 4-Dglycanases. Journal of Biological Chemistry, 269, 20811-20814

DeSantis, T. Z., Hugenholtz, P., Larsen, N., Rojas, M., Brodie, E. L., Keller, K., Huber, T., Dalevi, D., Hu, P. und Andersen, G. L., (2006). Greengenes, a chimera-checked 16S rRNA gene database and workbench compatible with ARB. Applied and environmental microbiology, 72, 5069

Ellis, R. J., Morgan, P., Weightman, A. J. und Fry, J. C., (2003). CultivationDependent and -Independent Approaches for Determining Bacterial Diversity in Heavy-Metal-Contaminated Soil. Appl. Environ. Microbiol., 69, 3223-3230

Erfle, J. D., Teather, R. M., Wood, P. J. und Irvin, J. E., (1988). Purification and properties of a 1, 3-1, 4-beta-D-glucanase (lichenase, 1, 3-1, 4-beta-D-glucan 4glucanohydrolase, EC 3.2. 1.73) from Bacteroides succinogenes cloned in Escherichia coli. Biochemical Journal, 255, 833

Feng, Y., Duan, C.-J., Pang, H., Mo, X.-C., Wu, C.-F., Yu, Y., Hu, Y.-L., Wei, J., Tang, J.-L. und Feng, J.-X., (2007). Cloning and identification of novel cellulase genes from uncultured microorganisms in rabbit cecum and characterization of the expressed cellulases. Applied Microbiology and Biotechnology, 75, 319-328

Ferrer, M., Golyshina, O. V., Chernikova, T. N., Khachane, A. N., ReyesDuarte, D., Martins Dos Santos, V. A. P., Strompl, C., Elborough, K., Jarvis, G. und Neef, A., (2005). Novel hydrolase diversity retrieved from a metagenome library of bovine rumen microflora. Environmental Microbiology, 7, 1996 
Fontes, C. M., Hazlewood, G. P., Morag, E., Hall, J., Hirst, B. H. und Gilbert, H. J., (1995, Evidence for a general role for non-catalytic thermostabilizing domains in xylanases from thermophilic bacteria,307 ( Pt 1), 151-8

Frey, J. C., Rothman, J. M., Pell, A. N., Nizeyi, J. B., Cranfield, M. R. und Angert, E. R., (2006). Fecal bacterial diversity in a wild gorilla. Applied and Environmental Microbiology, 72, 3788

Fu, L., Xu, Z., Shuai, J., Hu, C., Dai, W. und Li, W., (2008). High-Level Secretion of a Chimeric Thermostable Lichenase from Bacillus subtilis by Screening of SiteMutated Signal Peptides with Structural Alterations. Current Microbiology, 56, 287292

Gibbs, M. D., Reeves, R. A. und Bergquist, P. L., (1995, Cloning, sequencing, and expression of a xylanase gene from the extreme thermophile Dictyoglomus thermophilum Rt46B.1 and activity of the enzyme on fiber-bound substrate,61, 4403-4408

Gilkes, N. R., Henrissat, B., Kilburn, D. G., Miller, R. C., Jr. und Warren, R. A., (1991). Domains in microbial beta-1, 4-glycanases: sequence conservation, function, and enzyme families. Microbiol. Mol. Biol. Rev., 55, 303-315

Grant, S., Sorokin, D. Y., Grant, W. D., Jones, B. E. und Heaphy, S., (2004). A phylogenetic analysis of Wadi el Natrun soda lake cellulase enrichment cultures and identification of cellulase genes from these cultures. Extremophiles, 8, 421429

Haki, G. D. und Rakshit, S. K., (2003). Developments in industrially important thermostable enzymes: a review. Bioresource Technology, 89, 17-34

Hakulinen, N., Turunen, O., Janis, J., Leisola, M. und Rouvinen, J., (2003). Three-dimensional structures of thermophilic [beta]-1, 4-xylanases from Chaetomium thermophilum and Nonomuraea flexuosa: Comparison of twelve xylanases in relation to their thermal stability. European Journal of Biochemistry, 270, 1399

Handelsman, J., (2004). Metagenomics: Application of Genomics to Uncultured Microorganisms. Microbiol. Mol. Biol. Rev., 68, 669-685

Handelsman, J., Rondon, M. R., Brady, S. F., Clardy, J. und Goodman, R. M., (1998). Molecular biological access to the chemistry of unknown soil microbes: a new frontier for natural products. 5, R245-R249

Hildén, L. und Johansson, G., (2004). Recent developments on cellulases and carbohydrate-binding modules with cellulose affinity. Biotechnology Letters, 26, 1683-1693

Hirakawa, H., (2001). Coprophagy in leporids and other mammalian herbivores. Mammal Review, 31, 61-80 
Hirofumi, H., (2001). Coprophagy in leporids and other mammalian herbivores. Mammal Review, 31, 61-80

Holmes, M. L., Scopes, R. K., Moritz, R. L., Simpson, R. J., Englert, C., Pfeifer, F. und Dyall-Smith, M. L., (1997). Purification and analysis of an extremely halophilic -galactosidase from Haloferax alicantei. Biochimica et Biophysica Acta (BBA)/Protein Structure and Molecular Enzymology, 1337, 276-286

Hoover, W. H. und Clarke, S. D., (1972). Fiber Digestion in the Beaver. J. Nutr., 102, 9-15

Jenkins, S. H., (1979). Seasonal and year-to-year differences in food selection by beavers. Oecologia, 44, 112-116

Johansson, L., (2006). Structural analyses of $(1 \rightarrow 3),(1 \rightarrow 4)-\beta$-D-glucan of oats and barley. Dissertation, Universität Helsinki, Abteilung für angewandte Chemie und Mikrobiologie

Khan, M. A. S., Akbar, M., Kitaoka, M. und Hayashi, K., (2007). A unique thermostable lichenase from Thermotoga maritima MSB 8 with divergent substrate specificity. Indian Journal of Biotechnology, 6, 315-320

Koike, S., Yoshitani, S., Kobayashi, Y. und Tanaka, K., (2003). Phylogenetic analysis of fiber-associated rumen bacterial community and PCR detection of uncultured bacteria. FEMS microbiology letters, 229, 23-30

Kulkarni, N., Shendye, A. und Rao, M., (1999). Molecular and biotechnological aspects of xylanases. FEMS Microbiology Reviews, 23, 411-456

Kumar, S., Tsai, C.-J. und Nussinov, R., (2000). Factors enhancing protein thermostability. Protein Eng., 13, 179-191

Laemmli, U. K., (1970). Cleavage of Structural Proteins during the Assembly of the Head of Bacteriophage T4. Nature, 227, 680-685

Larsen, N., Olsen, G. J., Maidak, B. L., McCaughey, M. J., Overbeek, R., Macke, T. J., Marsh, T. L. und Woese, C. R., (1993). The ribosomal database project. Nucl. Acids Res., 21, 3021-3023

Lee, C. C., Kibblewhite-Accinelli, R. E., Wagschal, K., Robertson, G. H. und Wong, D. W. S., (2006). Cloning and characterization of a cold-active xylanase enzyme from an environmental DNA library. Extremophiles, 10, 295-300

Lee, S.-T. und Lee, J. J., (1997). Insoluble dye substrate for screening and assay of xylan-degrading enzymes. Journal of Microbiological Methods, 29, 1-5

Lee, Y. E., Lowe, S. E., Henrissat, B. und Zeikus, J. G., (1993). Characterization of the active site and thermostability regions of endoxylanase from Thermoanaerobacterium saccharolyticum B6A-RI. J. Bacteriol., 175, 5890-5898 
Lefebvre, T., Miambi, E., Pando, A., Diouf, M. und Rouland-Lefèvre, C., (2009). Gut-specific actinobacterial community structure and diversity associated with the wood-feeding termite species, Nasutitermes corniger (Motschulsky) described by nested PCR-DGGE analysis. Insectes Sociaux, 56, 269-276

Ley, R. E., Bäckhed, F., Turnbaugh, P., Lozupone, C. A., Knight, R. D. und Gordon, J. I., (2005). Obesity alters gut microbial ecology. Proceedings of the National Academy of Sciences, 102, 11070

Ley, R. E., Hamady, M., Lozupone, C., Turnbaugh, P. J., Ramey, R. R., Bircher, J. S., Schlegel, M. L., Tucker, T. A., Schrenzel, M. D. und Knight, R., (2008). Evolution of mammals and their gut microbes. Science, 320, 1647

Li, L. L., McCorkle, S. R., Monchy, S., Taghavi, S. und van der Lelie, D., (2009). Bioprospecting metagenomes: glycosyl hydrolases for converting biomass. Biotechnology for Biofuels, 2, 10

Li, N., Shi, P., Yang, P., Wang, Y., Luo, H., Bai, Y., Zhou, Z. und Yao, B., (2008). Cloning, Expression, and Characterization of a New Streptomyces sp. S27 Xylanase for Which Xylobiose is the Main Hydrolysis Product. Applied Biochemistry and Biotechnology, online,

Li, R., Kibblewhite, R., Orts, W. J. und Lee, C. C., (2009). Molecular cloning and characterization of multidomain xylanase from manure library. World Journal of Microbiology and Biotechnology, online publiziert, 1-8

Liolios, K., Mavromatis, K., Tavernarakis, N. und Kyrpides, N. C., (2008). The Genomes On Line Database (GOLD) in 2007: status of genomic and metagenomic projects and their associated metadata. Nucl. Acids Res., 36, D475479

Louw, M. E., Reid, S. J. und Watson, T. G., (1993). Characterization, cloning and sequencing of a thermostable endo- $(1,3-1,4) \beta$-glucanase-encoding gene from an alkalophilic Bacillus brevis. Applied Microbiology and Biotechnology, 38, 507-513

Lynd, L. R., Weimer, P. J., van Zyl, W. H. und Pretorius, I. S., (2002). Microbial Cellulose Utilization: Fundamentals and Biotechnology. Microbiol. Mol. Biol. Rev., 66, 506-577

Marchler-Bauer, A., Anderson, J. B., Cherukuri, P. F., DeWeese-Scott, C., Geer, L. Y., Gwadz, M., He, S., Hurwitz, D. I., Jackson, J. D. und Ke, Z., (2005). CDD: a Conserved Domain Database for protein classification. Nucleic Acids Research, 33, D192

Marchler-Bauer, A., Panchenko, A. R., Shoemaker, B. A., Thiessen, P. A., Geer, L. Y. und Bryant, S. H., (2002). CDD: a database of conserved domain alignments with links to domain three-dimensional structure. Nucleic Acids Research, 30, 281 
Martinez, A., Kolvek, S. J., Yip, C. L. T., Hopke, J., Brown, K. A., MacNeil, I. A. und Osburne, M. S., (2004). Genetically modified bacterial strains and novel bacterial artificial chromosome shuttle vectors for constructing environmental libraries and detecting heterologous natural products in multiple expression hosts. Applied and Environmental Microbiology, 70, 2452-2463

Maruo, T., Sakamoto, M., Ito, C., Toda, T. und Benno, Y., (2008). Adlercreutzia equolifaciens gen. nov., sp. nov., an equol-producing bacterium isolated from human faeces, and emended description of the genus Eggerthella. Int J Syst Evol Microbiol, 58, 1221-1227

Mielenz, J. R., (2001). Ethanol production from biomass: technology and commercialization status. Current Opinion in Microbiology, 4, 324-329

Monteils, V., Cauquil, L., Combes, S., Godon, J. J. und Gidenne, T., (2008). Potential core species and satellite species in the bacterial community within the rabbit caecum. FEMS Microbiology Ecology, 66, 620

Monteiro, L., Bonnemaison, D., Vekris, A., Petry, K. G., Bonnet, J., Vidal, R., Cabrita, J. und Megraud, F., (1997). Complex polysaccharides as PCR inhibitors in feces: Helicobacter pylori model. Journal of Clinical Microbiology, 35, 995

Nolet, B. A., Hoekstra, A. und Ottenheim, M. M., (1994). Selective foraging on woody species by the beaver Castor fiber, and its impact on a riparian willow forest. Biological Conservation (United Kingdom)

Pauly, M. und Keegstra, K., (2008). Cell-wall carbohydrates and their modification as a resource for biofuels. Plant Journal, 54, 559

Planas, A., (2000). Bacterial 1, 3-1, 4- -glucanases: structure, function and protein engineering. Biochimica et Biophysica Acta (BBA)/Protein Structure and Molecular Enzymology, 1543, 361-382

Rees, H. C., Grant, S., Jones, B., Grant, W. D. und Heaphy, S., (2003). Detecting cellulase and esterase enzyme activities encoded by novel genes present in environmental DNA libraries. Extremophiles, 7, 415-421

Riesenfeld, C. S., Schloss, P. D. und Handelsman, J., (2004). METAGENOMICS: Genomic Analysis of Microbial Communities. Annual Review of Genetics, 38, 525-552

Roberge, M., Shareck, F., Morosoli, R., Kluepfel, D. und Dupont, C., (1999). Characterization of active-site aromatic residues in xylanase A from Streptomyces lividans. Protein Eng., 12, 251-257

Roggentin, P., Schauer, R., Hoyer, L. L. und Vimr, E. R., (1993). The sialidase superfamily and its spread by horizontal gene transfer. Molecular Microbiology, 9, 915-921 
Ruttersmith, L. D. und Daniel, R. M., (1991). Thermostable cellobiohydrolase from the thermophilic eubacterium Thermotoga sp. strain FjSS3-B. 1. Biochem. J, 277, $887-890$

Salzman, N. H., de Jong, H., Paterson, Y., Harmsen, H. J. M., Welling, G. W. und Bos, N. A., (2002). Analysis of $16 \mathrm{~S}$ libraries of mouse gastrointestinal microflora reveals a large new group of mouse intestinal bacteria. Microbiology, 148, 3651

Sanger, F., Nicklen, S. und Coulson, A. R., (1977). DNA sequencing with chainterminating inhibitors. Proceedings of the National Academy of Sciences, 74, 5463

Saul, D. J., Williams, L. C., Reeves, R. A., Gibbs, M. D. und Bergquist, P. L., (1995). Sequence and expression of a xylanase gene from the hyperthermophile Thermotoga sp. strain FjSS3-B. 1 and characterization of the recombinant enzyme and its activity on kraft pulp. Applied and Environmental Microbiology, 61, 41104113

Schimming, S., Schwarz, W. H. und Staudenbauer, W. L., (1991). Properties of a thermoactive beta-1, 3-1, 4-glucanase (lichenase) from Clostridium thermocellum expressed in Escherichia coli. Biochemical and biophysical research communications, 177, 447

Schlesner, H., Jenkins, C. und Staley, J. T., (2006). The phylum Verrucomicrobia: a phylogenetically heterogeneous bacterial group. The Prokaryotes, 7, 881-896

Schloss, P. D. und Handelsman, J., (2005). Introducing DOTUR, a Computer Program for Defining Operational Taxonomic Units and Estimating Species Richness. Appl. Environ. Microbiol., 71, 1501-1506

Schmeisser, C., Steele, H. und Streit, W., (2007). Metagenomics, biotechnology with non-culturable microbes. Applied Microbiology and Biotechnology, 75, 955962

Schomburg, I., Chang, A. und Schomburg, D., (2002). BRENDA, enzyme data and metabolic information. Nucleic acids research, 30, 47

Schuldes, J., (2008). Charakterisierung und Nutzung der mikrobiellen Diversität extremer Habitate der Kamtschatka-Region. Doktorarbeit, angefertigt im Institut für Mikrobiologie und Genetik, Universität Göttingen

Schwarz, W. H., (2001). The cellulosome and cellulose degradation by anaerobic bacteria. Applied microbiology and biotechnology, 56, 634-649

Scott, R. W., (1972). The viscosity of worts in relation to their content of $\beta$-glucan. J. Inst. Brew, 78, 179-186

Severi, E., Hood, D. W. und Thomas, G. H., (2007). Sialic acid utilization by bacterial pathogens. Microbiology, 153, 2817-2822 
Shinzato, N., Muramatsu, M., Matsui, T. und Watanabe, Y., (2007). Phylogenetic analysis of the gut bacterial microflora of the fungus-growing termite Odontotermes formosanus. Bioscience, biotechnology, and biochemistry, 71, 906

Shoseyov, O., Shani, Z. und Levy, I., (2006). Carbohydrate binding modules: biochemical properties and novel applications. Microbiology and Molecular Biology Reviews, 70, 283

Simpson, H. D., Haufler, U. R. und Daniel, R. M., (1991). An extremely thermostable xylanase from the thermophilic eubacterium Thermotoga. Biochemical Journal, 277, 413

Sinnott, M. L., (1990). Catalytic mechanism of enzymic glycosyl transfer. Chemical Reviews, 90, 1171-1202

Sommer, P., Georgieva, T. und Ahring, B., (2004). Potential for using thermophilic anaerobic bacteria for bioethanol production from hemicellulose. Biochemical Society Transactions, 32, 283-289

Staden, R., Beal, K. F. und Bonfield, J. K., (2000). The Staden package, 1998. Methods Mol Biol, 132, 115-130

Stevenson, B. S., Eichorst, S. A., Wertz, J. T., Schmidt, T. M. und Breznak, J. A., (2004). New strategies for cultivation and detection of previously uncultured microbes. Applied and environmental microbiology, 70, 4748

Streit, W. R. und Schmitz, R. A., (2004). Metagenomics--the key to the uncultured microbes. Curr Opin Microbiol, 7, 492-8

Strickeberger, M. W., (1996). In: Evolution. Johnes \& Bartlett Publishers, Boston, USA.,

Sunna, A. und Bergquist, P. L., (2003). A gene encoding a novel extremely thermostable 1,4-beta-xylanase isolated directly from an environmental DNA sample. Extremophiles, 7, 63-70

Sunna, A., Gibbs, M. D. und Bergquist, P. L., (2000, A novel thermostable multidomain 1,4-\{beta\}-xylanase from 'Caldibacillus cellulovorans' and effect of its xylan-binding domain on enzyme activity,146, 2947-2955

Sunna, A., Gibbs, M. D. und Bergquist, P. L., (2000). The thermostabilizing domain, XynA, of Caldibacillus cellulovorans xylanase is a xylan binding domain. BIOCHEMICAL JOURNAL-LONDON-, 346, 583-586

Ten, L. N., Im, W. T., Kim, M. K. und Lee, S. T., (2005). A plate assay for simultaneous screening of polysaccharide- and protein-degrading microorganisms. Letters in Applied Microbiology, 40, 92-98 
Teng, D., Wang, J.-h., Fan, Y., Yang, Y.-I., Tian, Z.-g., Luo, J., Yang, G.-p. und Zhang, $F_{\text {., }}$ (2006). Cloning of $\beta-1,3-1,4-$ glucanase gene from Bacillus licheniformis EGW039 (CGMCC 0635) and its expression in Escherichia coli BL21 (DE3). Applied Microbiology and Biotechnology, 72, 705-712

Torsvik, V. und Øvreås, L., (2002). Microbial diversity and function in soil: from genes to ecosystems. Current Opinion in Microbiology, 5, 240-245

Towner, K. J., Bergogne-Bérézin, E. und Fewson, C. A., (1991, The biology of Acinetobacter

Tull, D., Withers, S. G., Gilkes, N. R., Kilburn, D. G., Warren, R. A. und Aebersold, R., (1991). Glutamic acid 274 is the nucleophile in the active site of a "retaining" exoglucanase from Cellulomonas fimi. J. Biol. Chem., 266, 1562115625

Valérie, M., Laurent, C., Sylvie, C., Jean-Jacques, G. und Thierry, G., (2008). Potential core species and satellite species in the bacterial community within the rabbit caecum. FEMS Microbiology Ecology, 66, 620-629

Van Laere, K. M. J., Abee, T., Schols, H. A., Beldman, G. und Voragen, A. G. J., (2000). Characterization of a novel -galactosidase from Bifidobacterium adolescentis DSM 20083 active towards transgalactooligosaccharides. Applied and Environmental Microbiology, 66, 1379-1384

Venter, J. C., Remington, K., Heidelberg, J. F., Halpern, A. L., Rusch, D., Eisen, J. A., Wu, D., Paulsen, I., Nelson, K. E. und Nelson, W., (2004). Environmental genome shotgun sequencing of the Sargasso Sea. Science, 304, $66-74$

Voget, S., Leggewie, C., Uesbeck, A., Raasch, C., Jaeger, K. E. und Streit, W. R., (2003). Prospecting for novel biocatalysts in a soil metagenome. Applied and Environmental Microbiology, 69, 6235-6242

Voget, S., Steele, H. L. und Streit, W. R., (2006). Characterization of a metagenome-derived halotolerant cellulase. Journal of biotechnology, 126, 26-36

Wainwright, T., (1999). Enzymes in brewing. Ferment, 12, 30-34

Wang, J. L., Ruan, H., Zhang, H. F., Zhang, Q., Zhang, H. B., He, G. Q. und Shen, S. R., (2007). Characterization of a Thermostable and Acidic-Tolerable Glucanase from Aerobic Fungi Trichoderma koningii ZJU-T. Journal of Food

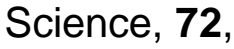

Wang, Y., Yuan, H., Wang, J. und Yu, Z., (2009). Truncation of the cellulose binding domain improved thermal stability of endo-beta-1,4-glucanase from Bacillus subtilis JA18. Bioresour Technol, 100, 345-9

Warren, R. A. J., (1996). MICROBIAL HYDROLYSIS OF POLYSACCHARIDES. Annual Review of Microbiology, 50, 183-212 
Wen, T. N., Chen, J. L., Lee, S. H., Yang, N. S. und Shyur, L. F., (2005). A Truncated Fibrobacter succinogenes 1, 3-1, 4-[beta]-d-Glucanase with Improved Enzymatic Activity and Thermotolerance†. Biochemistry, 44, 9197-9205

Whitman, W. B., Coleman, D. C. und Wiebe, W. J., (1998, Prokaryotes: the unseen majority,95, 6578-6583

Willems, A., De Vos, P. und De Ley, J., (1992). The genus Comamonas. The Prokaryotes, 3, 2583-2590

Wilson, E. O., (1992). In: The diversity of life. W.W. Norton \& Co. New York, USA, 131-162

Wilson, I. G., (1997). Inhibition and facilitation of nucleic acid amplification. Applied and Environmental Microbiology, 63, 3741-3751

Winterhalter, C., Heinrich, P., Candussio, A., Wich, G. und Liebl, W., (1995). Identification of a novel cellulose-binding domain the multidomain $120 \mathrm{kDa}$ xylanase XynA of the hyperthermophilic bacterium Thermotoga maritima. Molecular Microbiology, 15, 431-444

Winterhalter, C. und Liebl, W., (1995). Two Extremely Thermostable Xylanases of the Hyperthermophilic Bacterium Thermotoga maritima MSB8. Appl. Environ. Microbiol., 61, 1810-1815

Woese, C. R., (1987). Bacterial evolution. Microbiol. Mol. Biol. Rev., 51, 221-271

Worthington, J. M. und Fulghum, R. S., (1988). Cecal and fecal bacterial flora of the Mongolian gerbil and the chinchilla. Applied and Environmental Microbiology, 54,1210

Wu, S., Liu, B. und Zhang, X., (2006). Characterization of a recombinant thermostable xylanase from deep-sea thermophilic Geobacillus sp. MT-1 in East Pacific. Applied microbiology and biotechnology, 72, 1210-1216

Xiong, H., Fenel, F., Leisola, M. und Turunen, O., (2004). Engineering the thermostability of Trichoderma reesei endo-1, 4-ß-xylanase II by combination of disulphide bridges. Extremophiles, 8, 393-400

Yang, S., Qiaojuan, Y., Jiang, Z., Fan, G. und Wang, L., (2008). Biochemical Characterization of a Novel Thermostable -1, 3-1, 4-Glucanase (Lichenase) from Paecilomyces thermophila. Journal of Agricultural and Food Chemistry, 56, 53455351

Yoo, D. H., Lee, B. H., Chang, P. S., Lee, H. G. und Yoo, S. H., (2007). Improved quantitative analysis of oligosaccharides from lichenase-hydrolyzed water-soluble barley beta-glucans by high-performance anion-exchange chromatography. Journal of agricultural and food chemistry, 55, 1656 
Zhang, Y.-H. P. und Lynd, L. R., (2004). Toward an aggregated understanding of enzymatic hydrolysis of cellulose: Noncomplexed cellulase systems. Biotechnology and Bioengineering, 88, 797-824

Zhou, J., Bruns, M. A. und Tiedje, J. M., (1996). DNA recovery from soils of diverse composition. Appl. Environ. Microbiol., 62, 316-322 


\section{Anhang}

\section{Nukleotidsequenz und die abgeleitete Aminosäuresequenz von Xyn1015}

Die dem Signalpeptid entsprechende Sequenz ist blau hinterlegt. Die entsprechende Aminosäuresequenz ist im Ein-Buchstabencode unter der DNA Sequenz dargestellt. Die an der katalytischen Diade beteiligten Glutamatreste sind rot hinterlegt. Die vier Aminosäurereste, die für die Substratbindung verantwortlich sind, sind gelb hinterlegt.

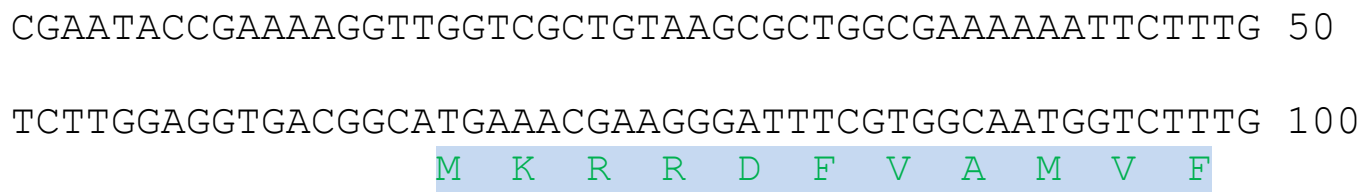


$\begin{array}{lllllllllllllllll}V & R & E & I & V & Q & R & F & A & G & R & I & D & I & W & D & V\end{array}$

GGTCAATGAGCCAACTCACCTGTCACCGAAAAGCCCGAACAAGACGAAGA 700

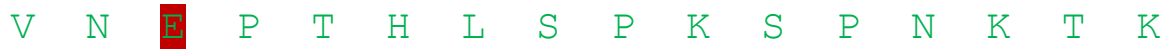

TGGCAGAATGGGGCATGGCGATCGGACCGGTCGCTTACACGGCTTTGCAC 750

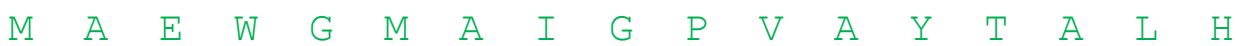

CTAAAGGTCGCCCGAGAGGCTAATCCCAAGGCGATTTTGCTCGTCAACGA 800

$\begin{array}{lllllllllllllllll}\mathrm{L} & \mathrm{K} & \mathrm{V} & \mathrm{A} & \mathrm{R} & \mathrm{E} & \mathrm{A} & \mathrm{N} & \mathrm{P} & \mathrm{K} & \mathrm{A} & \mathrm{I} & \mathrm{L} & \mathrm{L} & \mathrm{V} & \mathrm{N} & \mathrm{D}\end{array}$

CTACCGAACAGACGAAGCCTACAGGAAAATCCTGCAGCAACTGAAAGACG 850

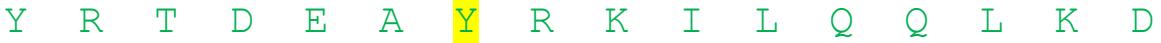

AAAGCGGTCGCTGGCTTTTTGATGTCATCGGGATTCAAAGCCACATGCAC 900 $\begin{array}{lllllllllllllllllllll}E & S & G & R & W & L & F & D & V & I & G & I & Q & S & H & M & H\end{array}$

GGCGGTGTTTGGACGGCTCAAAGGACATGGGAAATTTGCGAGCGATTTGC 950

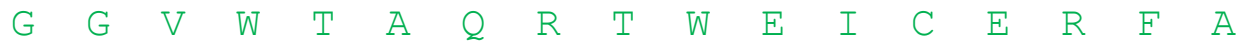

CCAACTCGGTCTGCCTTTGCATTTTACCGAAACGACCATCGTGAGTGGCT 1000

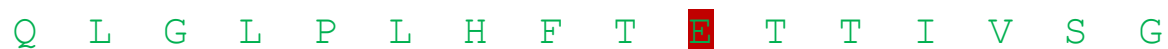

CACCAGCAGGGTTTGGAAAGTGGGGACCAACAACGCCCGAAGGTGAGGAG 1050 $\begin{array}{lllllllllllllllll}S & P & A & G & F & G & K & W & G & P & T & T & P & E & G & E & E\end{array}$

AGACAAGCGGAAGCGACAGCGTCGTTTTACACCCTCTTGTTCTCCCATCC 1100 $\begin{array}{lllllllllllllllll}R & Q & A & E & A & T & A & S & F & Y & T & L & L & F & S & H & P\end{array}$

CGCAGTTGAAGCGATCACATGGTGGGACTTTTCTGACGACGGTGCGTGGC 1150 $\begin{array}{llllllllllllllll}A & V & E & A & I & T & W & W & D & F & S & D & D & G & A & W\end{array}$

TGGGAGCGCCTGCAGGTTGGCTCAGACGAGATATGTCGCCAAAGCCCGTC 1200 $\begin{array}{llllllllllllllllll}L & G & A & P & A & G & W & L & R & R & D & M & S & P & K & P & V\end{array}$

TATGAACGCATGCTTGAACTCATCAAAGGAAAATGGTGGACGAAAGCGGA 1250

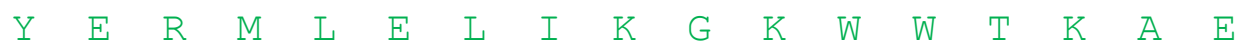

AGGCGAAACCGACAAGGAGGGCAAGTGGCAAGCGAAAGCGTTCTACGGAG 1300

$\begin{array}{llllllllllllllll}G & E & T & D & K & E & G & K & W & Q & A & K & A & F & Y & G\end{array}$

AGCACGAATTGACAATTCGCACTCAAGACGGTCGCAAAGTAGCGCAAAAA 1350

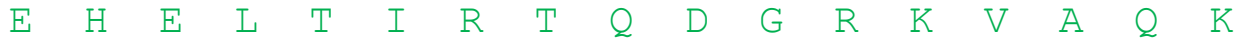

ATCATGCTCCGAAAAGAGGAGAAAAACATCGTTGAAATCCGACTGCCGTG 1400 $\begin{array}{lllllllllllllllllllllllll}I & M & L & R & K & E & E & K & N & I & V & E & I & R & I & P & *\end{array}$

A 


\section{Nukleotidsequenz und die abgeleitete Aminosäuresequenz von Bga48}

Die dem Signalpeptid entsprechende Sequenz ist blau hinterlegt. Die entsprechende Aminosäuresequenz ist im Ein-Buchstabencode unter der DNA Sequenz dargestellt.

CAAAAGTGAGGTTTTTGAATAGTCCGTCTCATCAGAGCTCAGGGGGCGAT 50

$\mathrm{M}$

GGAAATGCGATGGTGGTTGGTTGTTATTTGGGCGTTCATCTCAGGAATGG 100

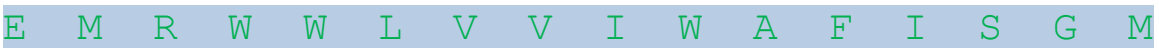

GAGGCTGGTGGTCTATGCGTTGCGGTCTGACACAGGAAGGGAGTTTCAAG 150

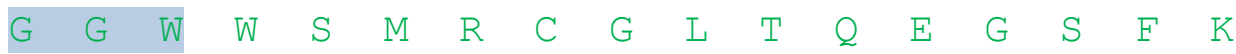

TCACCGCTTTTTTCCTTCGTTTTGCCTTGGGACGACGCTTCCCTCTCAGT 200

$\begin{array}{lllllllllllllllll}S & P & L & F & S & F & V & L & P & W & D & D & A & S & L & S & V\end{array}$

CACCAACATCAGCCACTGGCTTCACAAACCTGCAGGTAAGTTCGGACACA 250

$\begin{array}{llllllllllllllll}\mathrm{T} & \mathrm{N} & \mathrm{I} & \mathrm{S} & \mathrm{H} & \mathrm{W} & \mathrm{L} & \mathrm{H} & \mathrm{K} & \mathrm{P} & \mathrm{A} & \mathrm{G} & \mathrm{K} & \mathrm{F} & \mathrm{G} & \mathrm{H}\end{array}$

TTCGGGCTGGCGCCGACGGTCACCTTTACGCAGGCAAGCAGCGCATCCGT 300 $\begin{array}{lllllllllllllllll}I & R & A & G & A & D & G & H & L & Y & A & G & K & Q & R & I & R\end{array}$

TTTCTCGGAGTGAACTTGTGTTTCGGCGCTTGCTTCCCCCGCAAAGAAGA 350 $\begin{array}{llllllllllllllllll}\mathrm{F} & \mathrm{L} & \mathrm{G} & \mathrm{V} & \mathrm{N} & \mathrm{L} & \mathrm{C} & \mathrm{F} & \mathrm{G} & \mathrm{A} & \mathrm{C} & \mathrm{F} & \mathrm{P} & \mathrm{R} & \mathrm{K} & \mathrm{E} & \mathrm{D}\end{array}$

CGCCGAAAAGATTGCCGCTCGGATGGCAAAGTTTGGCATCAACATCGTCC 400

$\begin{array}{lllllllllllllllll}\mathrm{A} & \mathrm{E} & \mathrm{K} & \mathrm{I} & \mathrm{A} & \mathrm{A} & \mathrm{R} & \mathrm{M} & \mathrm{A} & \mathrm{K} & \mathrm{F} & \mathrm{G} & \mathrm{I} & \mathrm{N} & \mathrm{I} & \mathrm{V}\end{array}$

GATTCCATCACATGGACATGCAAGAGTTTCCCAACGGAATCCGCCGTCGG 450 $\begin{array}{lllllllllllllllll}\mathrm{R} & \mathrm{F} & \mathrm{H} & \mathrm{H} & \mathrm{M} & \mathrm{D} & \mathrm{M} & \mathrm{Q} & \mathrm{E} & \mathrm{F} & \mathrm{P} & \mathrm{N} & \mathrm{G} & \mathrm{I} & \mathrm{R} & \mathrm{R} & \mathrm{R}\end{array}$

GGTGCCCCACACACTCGAGACCTTGACCCTGAAGCCCTTGACCGACTGGA 500 $\begin{array}{lllllllllllllllll}G & A & P & H & T & R & D & L & D & P & E & A & L & D & R & L & D\end{array}$

CTACCTGATTGCCCAACTGAAACGCAACGGCATCTATGTCAACTTGAACT 550

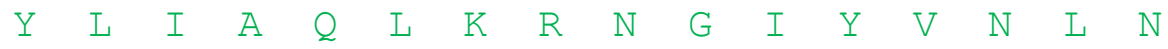

TGCTCGTCTCCCGCCCCTTCAACGCCGCCGACGGTTTGCCCAAAGAGATT 600 $\begin{array}{lllllllllllllllll}\mathrm{L} & \mathrm{V} & \mathrm{S} & \mathrm{R} & \mathrm{P} & \mathrm{F} & \mathrm{N} & \mathrm{A} & \mathrm{A} & \mathrm{D} & \mathrm{G} & \mathrm{L} & \mathrm{P} & \mathrm{K} & \mathrm{E} & \mathrm{I}\end{array}$

GAACAACTTGGTTGGAAGGAGCGTCACATTGTCGGTTTCTTCTACGAGCC 650

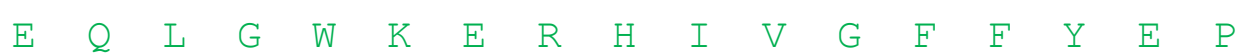

ATGCCTTGAGTTGCAAAAGGAGTATGCCCGAAAGTTGTTGACGCACCGCA 700

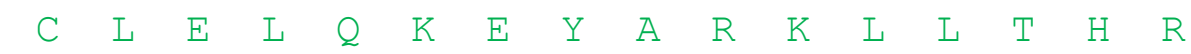


ACAAATACACAGGATTGACTTATGCTGAAGACCCTGCAATTGCCTTTGTG 750 $\begin{array}{lllllllllllllllll}N & K & Y & T & G & L & T & Y & A & E & D & P & A & I & A & F & V\end{array}$

GAAATCAACAACGAAAACGGTCTCGTTCACGCTTGGCTTGGTAACGATAT 800

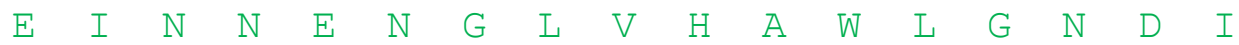

TGACAACATGCCGAAAGTTTTTCTGGACGAGTTGCAGCGTCAGTGGAACG 850

$\begin{array}{llllllllllllllll}D & N & M & P & K & V & F & \text { L } & D & E & L & \varrho & R & \varrho & W & N\end{array}$

AATGGTTGAGAGCCCGCTACGGCACAACGGAGAAACTGCGAAAGGCTTGG 900

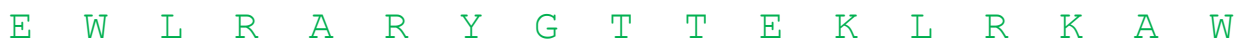

GGCGTTCGGGAAGAACCTTTGGGCGAAGAGATGTTGCGCAACGCCAACTT 950 $\begin{array}{lllllllllllllllll}G & V & R & E & E & P & L & G & E & E & M & L & R & N & A & N & F\end{array}$

TGAGGCGGGGTTGCAAAACTGGGTTTTGGAGAGGCACGCCGGGGCAGAAG 1000 $\begin{array}{llllllllllllllll} & \mathrm{A} & \mathrm{G} & \mathrm{L} & \mathrm{Q} & \mathrm{N} & \mathrm{W} & \mathrm{V} & \mathrm{L} & \mathrm{E} & \mathrm{R} & \mathrm{H} & \mathrm{A} & \mathrm{G} & \mathrm{A} & \mathrm{E}\end{array}$

CGGATGCTGAAGTTATCGCGGAACCTATCCCAGAACTCAAGGGCGTCCGA 1050 $\begin{array}{lllllllllllllllll}A & D & A & E & V & I & A & E & P & I & P & E & L & K & G & V & R\end{array}$

TTTGTCCGAATAACTGTCAAGAAGAAAGGTCAAGCAGGTTGGCATGTTCA 1100

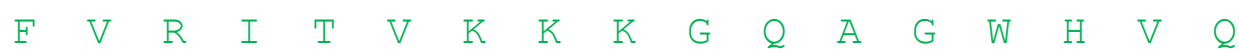
GTTCAGCCAACCGAACTTGAAGGTTCAAGCCGATAAGCCTTACACGCTCT 1150

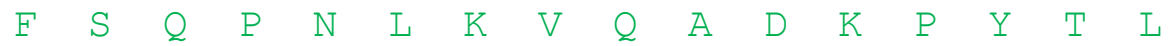
CCTTCTGGGCAAAAGCGGAACAACCTTGCACCATCAGCGTTGGTGTTTCT 1200 $\begin{array}{lllllllllllllllll}S & F & W & A & K & A & E & \& & P & C & T & I & S & V & G & V & S\end{array}$

CAAGCCCATGAACCCTGGCAGAACTTGGGCTTCAGCGCAAATGTTCGGTT 1250

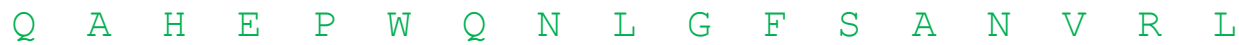

GACGCAAGAATGGCGCGAGTATCGCTTTACCTTTGTCCTCGCAAGGGGCG 1300 $\begin{array}{llllllllllllllll}T & \mathrm{Q} & \mathrm{E} & W & \mathrm{R} & \mathrm{E} & \mathrm{Y} & \mathrm{R} & \mathrm{F} & \mathrm{T} & \mathrm{F} & \mathrm{V} & \mathrm{I} & \mathrm{A} & \mathrm{R} & \mathrm{G}\end{array}$

ATGATAACGCACGGGTCATATTCAGCAACTTGGGGGCACAGACGATAACT 1350 $\begin{array}{lllllllllllllllll}D & D & N & A & R & V & I & F & S & N & L & G & A & \bigcirc & T & I & T\end{array}$

TACTGGTTTGCGATGCCTTCATTGCGCTACGGTGGCATCGTCGGCTTGGC 1400 $\begin{array}{lllllllllllllllll}Y & W & F & A & M & P & S & L & R & Y & G & G & I & V & G & L & A\end{array}$ GGCAAGTGAGCGTCTTGAAGATGGCAATGTGCCAATTTTCCTGCGGGGTT 1450 $\begin{array}{lllllllllllllllll}A & S & E & R & L & E & D & G & N & V & P & I & F & L & R & G\end{array}$

GTTTTGGAGAACGAACGCCTGAAGCGCAAAGGGATTGGATTCGGTTTTTG 1500 $\begin{array}{lllllllllllllllll}C & F & G & E & R & T & P & E & A & Q & R & D & W & I & R & F & L\end{array}$

TGGGAGACGGAAAACCGTTACTGGCAAACGATTTACCGCTACTTGAAAGA 1550 $\begin{array}{lllllllllllllllll}W & E & T & E & N & R & Y & W & Q & T & I & Y & R & Y & L & K & D\end{array}$ 
CGAACTGAAAGTCAAGGCTTTGGTCATCGGCACAATCGTTGGCTGCAGCA 1600 $\begin{array}{llllllllllllllll}E & I & K & V & K & A & L & V & I & G & T & I & V & G & C & S\end{array}$

CCCCCAACATGATGGCTCAACTTGACTGTGTTGACACCCACAGTTACTGG 1650 $\begin{array}{lllllllllllllllll}\mathrm{T} & \mathrm{P} & \mathrm{N} & \mathrm{M} & \mathrm{M} & \mathrm{A} & \mathcal{Q} & \mathrm{L} & \mathrm{D} & \mathrm{C} & \mathrm{V} & \mathrm{D} & \mathrm{T} & \mathrm{H} & \mathrm{S} & \mathrm{Y} & \mathrm{W}\end{array}$

CAACACCCAATGTTCCCATCGCGACCTTGGGACCCTGAAGACTGGATTGT 1700 $\begin{array}{lllllllllllllllll} & \mathrm{H} & \mathrm{P} & \mathrm{M} & \mathrm{F} & \mathrm{P} & \mathrm{S} & \mathrm{R} & \mathrm{P} & \mathrm{W} & \mathrm{D} & \mathrm{P} & \mathrm{E} & \mathrm{D} & \mathrm{W} & \mathrm{I} & \mathrm{V}\end{array}$

GCCTAACCGGACAATGGTCAATGAGAGAGGGGGAACTCTGCCCGGATTAG 1750 $\begin{array}{lllllllllllllllll}P & N & R & T & M & V & N & E & R & G & G & T & L & P & G & L\end{array}$

TCTTGCGAAGCGTTCTGGGTAAACCCTTCTCGGTTACAGAATACAACCAT 1800 $\begin{array}{lllllllllllllllll}V & L & R & S & V & L & G & K & P & F & S & V & T & E & Y & N & H\end{array}$

TCTGCTCCGAACACTTACAGCAGTGAAGCCTTCTTGTTGCTCGCAGCCTA 1850 $\begin{array}{lllllllllllllllll}S & A & P & N & T & Y & S & S & E & A & F & L & L & L & A & A & Y\end{array}$

CGCAGCCCTTCAGGACTGGGACGCAATTTACGCCTTCAGTTACTCGCACC 1900 $\begin{array}{llllllllllllllll}A & A & L & Q & D & W & D & A & I & Y & A & F & S & Y & S & H\end{array}$

GAAGGGACGATTGGGATTTGAGACGCATTCCCAACTTCTTTGATATTGAC 1950 $\begin{array}{lllllllllllllllll}R & R & D & D & W & D & L & R & R & I & P & N & F & F & D & I & D\end{array}$

CAGCACCCAACGAAGATGGTCACACTCCCACCTGCTGCAGCGATTTTCGT 2000 $\begin{array}{lllllllllllllllll}2 & H & P & T & K & M & V & T & L & P & P & A & A & A & I & F & V\end{array}$

TCGCGGCGATGTCAAACCTGCAAAGCGTCAAGTGGTTGTCAGGTTGACGA 2050 $\begin{array}{llllllllllllllll}R & G & D & V & K & P & A & K & R & Q & V & V & V & R & L & T\end{array}$

AAGAGCAAGAAATTGATTTGCTGCGAAGGAGTTGGGCGTGGCTGCTTGTC 2100

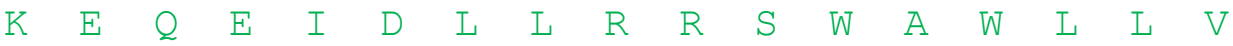

CATGCAGGTCATGTCGGTGTCAGGGATGAAACAGCGCTCATTCACAAGGT 2150 $\begin{array}{lllllllllllllllll}H & A & G & H & V & G & V & R & D & E & T & A & L & I & H & K & V\end{array}$

TGCAATTGTCACTGAGGGCAAACGAATTCCTCCAACAGCGCTTAAACCCG 2200 $\begin{array}{llllllllllllllll}A & I & V & T & E & G & K & R & I & P & P & T & A & L & K & P\end{array}$

AACAAGTGAAGATTGAAGGCAGCAAGTTTGTCTCTGACACTGGCGAGTTG 2250

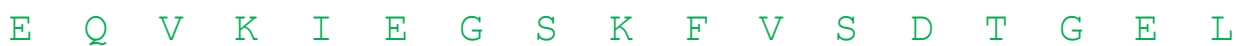

GTTTGGGACTTGACGGAAAAGGGGCGTGGCGTCGTCACCGTCAATGCGCA 2300 $\begin{array}{lllllllllllllllll}V & W & D & L & T & E & K & G & R & G & V & V & T & V & N & A & Q\end{array}$

AAACAGCAAAGCGGTCGTCGGTTTTGCAGGAGGCAAGCGTTTTGAATTAG 2350 $\begin{array}{llllllllllllllll}N & S & K & A & V & V & G & F & A & G & G & K & R & F & E & L\end{array}$

GCAGCGTGGTCATTGAACCAGGGCAAACGGTGCAAGATGGTTGGTGCACC 2400 $\begin{array}{lllllllllllllllll}G & S & V & V & I & E & P & G & Q & T & V & Q & D & G & W & C & T\end{array}$ 
$\begin{array}{lllllllllllllllll}\text { I } & \mathrm{T} & \mathrm{V} & \mathrm{T} & \mathrm{A} & \mathrm{M} & \mathrm{E} & \mathrm{G} & \mathrm{N} & \mathrm{L} & \mathrm{P} & \mathrm{T} & \mathrm{R} & \mathrm{P} & \mathrm{S} & \mathrm{S} & \mathrm{R}\end{array}$

CGTCCCTCGTCCCGTCCGTTTGCTCATCACGGCGACAGGTTATGCTGAGA 2500 $\begin{array}{llllllllllllllll}V & \mathrm{P} & \mathrm{R} & \mathrm{P} & \mathrm{V} & \mathrm{R} & \mathrm{I} & \mathrm{I} & \mathrm{I} & \mathrm{T} & \mathrm{A} & \mathrm{T} & \mathrm{G} & \mathrm{Y} & \mathrm{A} & \mathrm{E}\end{array}$

ACACCGAAATGGGTTGGAAAGAAGTTCCGGGTTATCCGCCCAAGTCCAGT 2550 $\begin{array}{llllllllllllllllllllllll}N & \mathrm{~T} & \mathrm{E} & \mathrm{M} & \mathrm{G} & \mathrm{W} & \mathrm{K} & \mathrm{E} & \mathrm{V} & \mathrm{P} & \mathrm{G} & \mathrm{Y} & \mathrm{P} & \mathrm{P} & \mathrm{K} & \mathrm{S} & \mathrm{S}\end{array}$

TGCGGTCGCAACTGGGGCAAACCGCCATCGCTCGTTGAGGGCATTACCGC 2600 $\begin{array}{llllllllllllllllllllllllll}C & G & R & N & W & G & K & P & P & S & L & V & E & G & I & T & A\end{array}$ AAAAATCGCTTTGCCCTTCCCCGCAAAGCGGGTGCAGGCTTGGGCGCTTG 2650 $\begin{array}{llllllllllllllll}K & I & A & L & P & F & P & A & K & R & V & Q & A & W & A & L\end{array}$ ACGAAAAAGGACAACGCAAAGAACAAATCCCCGTTGACTCTGACCCCAAC 2700 $\begin{array}{lllllllllllllllll}D & E & K & G & Q & R & K & E & Q & I & P & V & D & S & D & P & N\end{array}$

GGCAATGCCATCCTCCAAATCGGACCGCAATGGCGAACGCTTTGGTATGA 2750

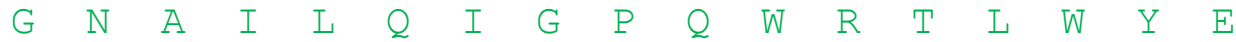
AGTTGTGGTGCAATGA 2766 
Tabelle 20: Phylogenetische Einordnung der 16S rRNA-Gensequenzen des Habitats „Caecum vorderer Bereich“ anhand ihrer nächsten

Verwandten aus der Datenbank der NCBI.

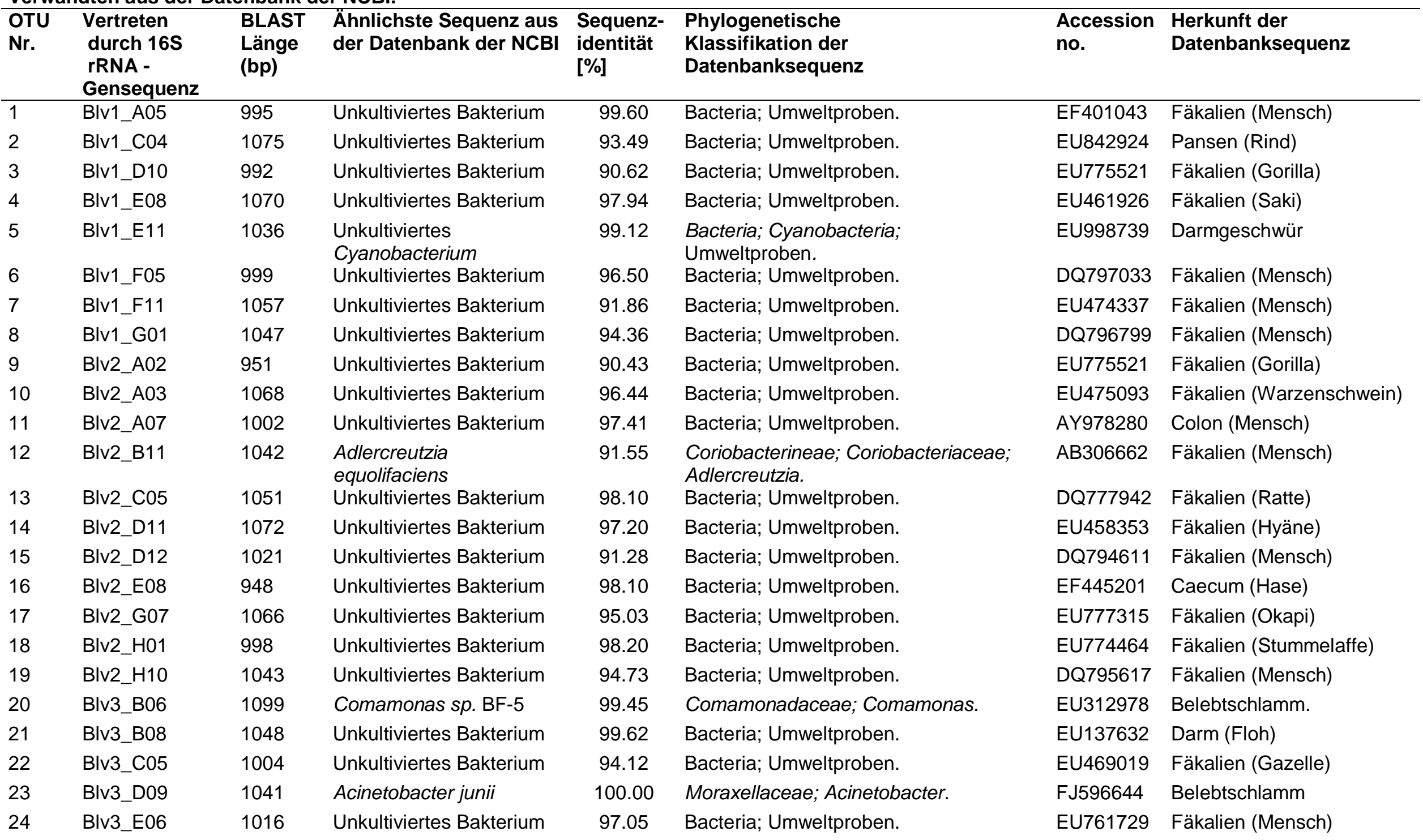




\begin{tabular}{|c|c|c|c|c|c|c|c|}
\hline $\begin{array}{l}\text { OTU } \\
\text { Nr. }\end{array}$ & $\begin{array}{l}\text { Vertreten } \\
\text { durch 16S } \\
\text { rRNA - } \\
\text { Gensequenz }\end{array}$ & $\begin{array}{l}\text { BLAST } \\
\text { Länge } \\
\text { (bp) }\end{array}$ & $\begin{array}{l}\text { Ähnlichste Sequenz aus } \\
\text { der Datenbank der NCBI }\end{array}$ & $\begin{array}{l}\text { Sequenz- } \\
\text { identität } \\
\text { [\%] }\end{array}$ & $\begin{array}{l}\text { Phylogenetische } \\
\text { Klassifikation der } \\
\text { Datenbanksequenz }\end{array}$ & $\begin{array}{l}\text { Accession } \\
\text { no. }\end{array}$ & $\begin{array}{l}\text { Herkunft der } \\
\text { Datenbanksequenz }\end{array}$ \\
\hline 25 & Blv3_E07 & 1083 & Unkultiviertes Bakterium & 95.75 & Bacteria; Umweltproben. & EU465584 & Fäkalien (Schaf) \\
\hline 26 & Blv3_G07 & 1071 & Unkultiviertes Bakterium & 94.21 & Bacteria; Umweltproben. & DQ795617 & Fäkalien (Mensch) \\
\hline 27 & Blv3_G09 & 1030 & Unkultiviertes Bakterium & 97.48 & Bacteria; Umweltproben. & EU507073 & Caecum (Maus) \\
\hline 28 & Blv3_H09 & 1083 & Unkultiviertes Bakterium & 90.58 & Bacteria; Umweltproben. & EU509084 & Caecum (Maus) \\
\hline 29 & Blv3_H12 & 1034 & Unkultiviertes Bakterium & 97.29 & Bacteria; Umweltproben. & AY979133 & Colon (Mensch) \\
\hline 30 & Blv4_A01 & 975 & Unkultiviertes Bakterium & 98.87 & Bacteria; Umweltproben. & DQ805867 & Fäkalien (Mensch) \\
\hline 31 & Blv4_B05 & 1067 & Unkultiviertes Bakterium & 95.97 & Bacteria; Umweltproben. & EU771855 & Fäkalien (Elefant) \\
\hline 32 & Blv4_B07 & 1081 & Unkultiviertes Bakterium & 97.41 & Bacteria; Umweltproben. & DQ796689 & Fäkalien (Mensch) \\
\hline 33 & Blv4_B09 & 806 & Unkultiviertes Bakterium & 94.91 & Bacteria; Umweltproben. & EU773141 & Fäkalien (Schaf) \\
\hline 34 & Blv4_C08 & 1069 & Unkultiviertes Bakterium & 95.51 & Bacteria; Umweltproben. & DQ456442 & Caecum (Truthahn) \\
\hline 35 & Blv4_C09 & 1053 & Unkultiviertes Bakterium & 92.31 & Bacteria; Umweltproben. & EU474337 & Fäkalien (Gorilla) \\
\hline 36 & Blv4_E03 & 1053 & Unkultiviertes Bakterium & 96.96 & Bacteria; Umweltproben. & EU761729 & Fäkalien (Mensch) \\
\hline 37 & Blv4_E05_ & 962 & Unkultiviertes Bakterium & 94.18 & Bacteria; Umweltproben. & DQ796268 & Fäkalien (Mensch) \\
\hline 38 & Blv4_E08 & 1066 & Unkultiviertes Bakterium & 99.62 & Bacteria; Umweltproben. & AF371795 & Darm (Schwein) \\
\hline 39 & Blv4_F05 & 1037 & Unkultiviertes Bakterium & 95.47 & Bacteria; Umweltproben. & EU763205 & Fäkalien (Mensch) \\
\hline
\end{tabular}


Tabelle 21: Phylogenetische Einordnung der 16S rRNA-Gensequenzen des Habitats „Caecum hinterer Bereich“ anhand ihrer nächsten Verwandten aus der Datenbank der NCBI.

\begin{tabular}{|c|c|c|c|c|c|c|c|}
\hline $\begin{array}{l}\text { OTU } \\
\text { Nr. }\end{array}$ & $\begin{array}{l}\text { Vertreten durch } \\
\text { 16S } \\
\text { rRNA } \\
\text {-Gensequenz }\end{array}$ & $\begin{array}{l}\text { BLAST- } \\
\text { Länge } \\
\text { (bp) }\end{array}$ & $\begin{array}{l}\text { Ähnlichste Sequenz aus } \\
\text { der Datenbank der NCBI }\end{array}$ & $\begin{array}{l}\text { Phylogenetische } \\
\text { Klassifikation der } \\
\text { Datenbanksequenz }\end{array}$ & $\begin{array}{l}\text { Sequenz- } \\
\text { Identität } \\
\text { [\%] }\end{array}$ & $\begin{array}{l}\text { Accession } \\
\text { no. }\end{array}$ & $\begin{array}{l}\text { Herkunft der } \\
\text { Datenbanksequenz }\end{array}$ \\
\hline 1 & C09_Cbm10 & 1089 & Unkultiviertes Bakterium & Bacteria; Umweltproben. & 97.98 & EF445201 & Caecum (Ratte) \\
\hline 2 & Cbm10_A02 & 995 & Unkultiviertes Bakterium & Bacteria; Umweltproben. & 96.28 & DQ777947 & Fäkalien (Ratte) \\
\hline 3 & Cbm10_A09 & 1091 & Unkultiviertes Bakterium & Bacteria; Umweltproben. & 94.78 & DQ824049 & Fäkalien (Mensch) \\
\hline 4 & Cbm10_B07 & 964 & Unkultiviertes Bakterium & Bacteria; Umweltproben. & 91.60 & DQ794611 & Fäkalien (Mensch) \\
\hline 5 & Cbm10_B09 & 977 & Unkultiviertes Bakterium & Bacteria; Umweltproben. & 97.65 & EU458353 & Fäkalien (Hyäne) \\
\hline 6 & Cbm10_B10 & 1045 & Unkultiviertes Bakterium & Bacteria; Umweltproben. & 92.63 & EU773141 & Fäkalien (Schaf) \\
\hline 7 & Cbm10_D03 & 1096 & Unkultiviertes Bakterium & Bacteria; Umweltproben. & 97.35 & EU776475 & Fäkalien (Känguru) \\
\hline 8 & Cbm10_D07 & 982 & Unkultiviertes Bakterium & Bacteria; Umweltproben. & 97.35 & EU509267 & Caecum (Maus) \\
\hline 9 & Cbm10_D09 & 1069 & Unkultiviertes Bakterium & Bacteria; Umweltproben. & 94.95 & EU777315 & Fäkalien (Okapi) \\
\hline 10 & Cbm10_E11 & 1095 & Unkultiviertes Bakterium & Bacteria; Umweltproben. & 96.99 & EU779326 & $\begin{array}{l}\text { Fäkalien } \\
\text { (Warzenschwein) }\end{array}$ \\
\hline 11 & Cbm7_A05 & 1028 & Unkultiviertes Bakterium & Bacteria; Umweltproben. & 94.46 & EF401391 & Fäkalien (Mensch) \\
\hline 12 & Cbm7_A08 & 1048 & Unkultiviertes Bakterium & Bacteria; Umweltproben. & 95.80 & DQ105657 & Fäkalien (Schwein) \\
\hline 13 & Cbm7_B01 & 980 & Unkultiviertes Bakterium & Bacteria; Umweltproben. & 96.84 & DQ456423 & Caecum (Truthahn) \\
\hline 14 & Cbm7_B12 & 943 & Unkultiviertes Bakterium & Bacteria; Umweltproben. & 93.74 & EU474537 & Fäkalien (Schaf) \\
\hline 15 & Cbm7_C10 & 1019 & Adlercreutzia equolifaciens & $\begin{array}{l}\text { Coriobacterineae; } \\
\text { Coriobacteriaceae; } \\
\text { Adlercreutzia. }\end{array}$ & 91.17 & AB306662 & Fäkalien (Mensch) \\
\hline 16 & Cbm7_D07 & 872 & Unkultiviertes Bakterium & Bacteria; Umweltproben. & 93.00 & DQ803711 & Fäkalien (Mensch) \\
\hline 17 & Cbm7_D09 & 1048 & Unkultiviertes Bakterium & Bacteria; Umweltproben. & 93.70 & DQ796943 & Fäkalien (Mensch) \\
\hline 18 & Cbm7_D10 & 829 & Unkultiviertes Bakterium & Bacteria; Umweltproben. & 94.33 & AY993741 & Caecum (Maus) \\
\hline 19 & Cbm7_E05 & 1008 & Unkultiviertes Bakterium & Bacteria; Umweltproben. & 97.82 & FJ365033 & Fäkalien (Mensch) \\
\hline 20 & Cbm7_F01 & 1027 & Unkultiviertes Bakterium & Bacteria; Umweltproben. & 94.64 & DQ795617 & Fäkalien (Mensch) \\
\hline 21 & Cbm7_H09 & 1049 & Unkultiviertes Bakterium & Bacteria; Umweltproben. & 97.04 & AY978280 & Fäkalien (Mensch) \\
\hline 22 & Cbm8_A02 & 1007 & Unkultiviertes Bakterium & Bacteria; Umweltproben. & 90.86 & EU509712 & Caecum (Maus) \\
\hline
\end{tabular}




\begin{tabular}{|c|c|c|c|c|c|c|c|}
\hline $\begin{array}{l}\text { OTU } \\
\text { Nr. }\end{array}$ & $\begin{array}{l}\text { Vertreten durch } \\
\text { 16S } \\
\text { rRNA } \\
\text {-Gensequenz }\end{array}$ & $\begin{array}{l}\text { BLAST- } \\
\text { Länge } \\
\text { (bp) }\end{array}$ & $\begin{array}{l}\text { Ähnlichste Sequenz aus } \\
\text { der Datenbank der NCBI }\end{array}$ & $\begin{array}{l}\text { Phylogenetische } \\
\text { Klassifikation der } \\
\text { Datenbanksequenz }\end{array}$ & $\begin{array}{l}\text { Sequenz- } \\
\text { Identität } \\
\text { [\%] }\end{array}$ & $\begin{array}{l}\text { Accession } \\
\text { no. }\end{array}$ & $\begin{array}{l}\text { Herkunft der } \\
\text { Datenbanksequenz }\end{array}$ \\
\hline 23 & Cbm8_A04 & 917 & Unkultiviertes Bakterium & Bacteria; Umweltproben. & 98.36 & EU470226 & Fäkalien (Steppenschaf) \\
\hline 24 & Cbm8_A06 & 947 & Unkultiviertes Bakterium & Bacteria; Umweltproben. & 92.71 & DQ777942 & Fäkalien (Ratte) \\
\hline 25 & Cbm8_A08 & 985 & Unkultiviertes Bakterium & Bacteria; Umweltproben. & 92.18 & EF404072 & Fäkalien (Mensch) \\
\hline 26 & Cbm8_A11 & 1038 & Unkultiviertes Bakterium & Bacteria; Umweltproben. & 96.82 & DQ800380 & Fäkalien (Mensch) \\
\hline 27 & Cbm8_A12 & 1066 & Unkultiviertes Bakterium & Bacteria; Umweltproben. & 97.75 & EU766578 & Fäkalien (Mensch) \\
\hline 28 & Cbm8_B02 & 846 & Unkultiviertes Bakterium & Bacteria; Umweltproben. & 94.68 & EU777315 & Fäkalien (Okapi) \\
\hline 29 & Cbm8_C02 & 1057 & Unkultiviertes Bakterium & Bacteria; Umweltproben. & 98.01 & DQ777942 & Fakalien (Ratte) \\
\hline 30 & Cbm8_C05 & 895 & Unkultiviertes Bakterium & Bacteria; Umweltproben. & 92.63 & AY993741 & Caecum (Maus) \\
\hline 31 & Cbm8_C08 & 1072 & Unkultiviertes Bakterium & Bacteria; Umweltproben. & 97.39 & AY979133 & Fäkalien (Mensch) \\
\hline 32 & Cbm8_C11 & 826 & Unkultiviertes Bakterium & Bacteria; Umweltproben. & 94.43 & DQ795738 & Fäkalien (Mensch) \\
\hline 33 & Cbm8_C12 & 1104 & $\begin{array}{l}\text { Unkultiviertes Pansen } \\
\text { Bakterium }\end{array}$ & Bacteria; Umweltproben. & 97.55 & DQ394604 & Pansen (Rentier) \\
\hline 34 & Cbm8_D07 & 1001 & Unkultiviertes Bakterium & Bacteria; Umweltproben. & 97.50 & EU458353 & Fäkalien (Hyäne) \\
\hline 35 & Cbm8_E01 & 986 & Unkultiviertes Bakterium & Bacteria; Umweltproben. & 96.35 & DQ805867 & Fäkalien (Mensch) \\
\hline 36 & Cbm8_E02 & 1023 & Unkultiviertes Bakterium & Bacteria; Umweltproben. & 94.53 & DQ795617 & Fäkalien (Mensch) \\
\hline 37 & Cbm8_F06 & 1064 & Unkultiviertes Bakterium & Bacteria; Umweltproben. & 95.49 & EU775456 & Fäkalien (Gorilla) \\
\hline 38 & Cbm8_G12 & 1058 & Unkultiviertes Bakterium & Bacteria; Umweltproben. & 97.07 & FJ365126 & Fäkalien (Mensch) \\
\hline 39 & Cbm8_H01 & 1049 & Unkultiviertes Bakterium & Bacteria; Umweltproben. & 94.38 & DQ796268 & Fäkalien (Mensch) \\
\hline 40 & Cbm8_H03 & 1059 & $\begin{array}{l}\text { Unkultiviertes Clostridiales } \\
\text { Bakterium }\end{array}$ & Bacteria; Umweltproben. & 97.83 & EF434365 & Stuhl (Mensch) \\
\hline 41 & Cbm9_C02 & 1079 & Unkultiviertes Bakterium & Bacteria; Umweltproben. & 93.42 & EU842924 & Pansen (Rind) \\
\hline 42 & Cbm9_D04 & 1087 & Unkultiviertes Bakterium & Bacteria; Umweltproben. & 97.24 & EU466245 & Fäkalien (Schaf) \\
\hline 43 & Cbm9_F04 & 1089 & Unkultiviertes Bakterium & Bacteria; Umweltproben. & 88.15 & EF099724 & Caecum (Maus) \\
\hline 44 & Cbm9_H08 & 960 & Unkultiviertes Bakterium & Bacteria; Umweltproben. & 96.46 & AY989930 & Caecum (Maus) \\
\hline
\end{tabular}


Tabelle 32: Phylogenetische Einordnung der 16S rRNA-Gensequenzen des Habitats „Colon“ anhand ihrer nächsten Verwandten aus der Datenbank der NCBI

\begin{tabular}{|c|c|c|c|c|c|c|c|}
\hline $\begin{array}{l}\text { OTU } \\
\text { Nr. }\end{array}$ & $\begin{array}{l}\text { Vertreten durch } \\
\text { 16S rRNA - } \\
\text { Gensequenz }\end{array}$ & $\begin{array}{l}\text { BLAST- } \\
\text { Länge } \\
\text { (bp) }\end{array}$ & $\begin{array}{l}\text { Ähnlichste Sequenz aus } \\
\text { derDatenbank der NCBI }\end{array}$ & $\begin{array}{l}\text { Phylogenetische } \\
\text { Klassifikation der } \\
\text { Datenbanksequenz }\end{array}$ & $\begin{array}{c}\text { Sequenz- } \\
\text { identität } \\
{[\%]} \\
\end{array}$ & $\begin{array}{l}\text { Accessio } \\
\text { n no. }\end{array}$ & $\begin{array}{l}\text { Herkunft der } \\
\text { Datenbanksequenz }\end{array}$ \\
\hline 1 & Co1_A09 & 994 & Unkultiviertes Bakterium & Bacteria; Umweltproben. & 96.48 & EU774380 & Fäkalien (Schimpanse) \\
\hline 2 & Co1_B02 & 1004 & Unkultiviertes Bakterium & Bacteria; Umweltproben. & 96.12 & EU762918 & Fäkalien (Mensch) \\
\hline 3 & Co1_B12 & 1078 & $\begin{array}{l}\text { Clostridiales } \\
\text { Bakterium,unkultiviert }\end{array}$ & $\begin{array}{l}\text { Bacteria; Firmicutes; } \\
\text { Clostridia; Clostridiales. }\end{array}$ & 94.81 & EU728715 & Darm (Schwein) \\
\hline 4 & Co1_C10 & 1113 & Unkultiviertes Bakterium & Bacteria; Umweltproben. & 94.61 & EF405224 & Fäkalien (Mensch) \\
\hline 5 & Co1_D06 & 952 & Unkultiviertes Bakterium & Bacteria; Umweltproben. & 98.11 & EU461926 & Fäkalien (Saki) \\
\hline 6 & Co1_D12 & 883 & Unkultiviertes Bakterium & Bacteria; Umweltproben. & 92.53 & EU511408 & Caecum (Maus) \\
\hline 7 & Co1_F06 & 1047 & Unkultiviertes Bakterium & Bacteria; Umweltproben. & 92.07 & EU474337 & Fäkalien (Gorilla) \\
\hline 8 & Co1_F12 & 1074 & Unkultiviertes Bakterium & Bacteria; Umweltproben. & 95.81 & EU469921 & Fäkalien (Gorilla) \\
\hline 9 & Co1_G03 & 1066 & Unkultiviertes Bakterium & Bacteria; Umweltproben. & 96.81 & EU778755 & Fäkalien (Springbock) \\
\hline 10 & Co1_G04 & 995 & Unkultiviertes Bakterium & Bacteria; Umweltproben. & 94.87 & EU772848 & Fäkalien (Buschhund) \\
\hline 11 & Co1_H01 & 1061 & Unkultiviertes Bakterium & Bacteria; Umweltproben. & 96.42 & EU462142 & Fäkalien (Stummelaffe) \\
\hline 12 & Co1_H02 & 1028 & Unkultiviertes Bakterium & Bacteria; Umweltproben. & 94.26 & EU456712 & Caecum (Maus) \\
\hline 13 & Co1_H12 & 1067 & Unkultiviertes Bakterium & Bacteria; Umweltproben. & 93.63 & EU779316 & $\begin{array}{l}\text { Fäkalien } \\
\text { (Warzenschwein) }\end{array}$ \\
\hline 14 & Co2_A02 & 919 & Unkultiviertes Bakterium & Bacteria; Umweltproben. & 91.51 & EU511816 & Caecum (Maus) \\
\hline 15 & Co2_B01 & 1035 & Unkultiviertes Bakterium & Bacteria; Umweltproben. & 89.37 & EU775521 & Fäkalien (Gorilla) \\
\hline 16 & Co2_B07 & 1005 & Unkultiviertes Bakterium & Bacteria; Umweltproben. & 97.71 & AY979133 & Colon (Mensch) \\
\hline 17 & Co2_B10 & 938 & Unkultiviertes Bakterium & Bacteria; Umweltproben. & 94.24 & EU656107 & Fäkalien (Maus) \\
\hline 18 & Co2_C01 & 803 & Unkultiviertes Bakterium & Bacteria; Umweltproben. & 92.28 & EU507578 & Caecum (Maus) \\
\hline 19 & Co2_D06 & 1021 & Unkultiviertes Bakterium & Bacteria; Umweltproben. & 99.80 & FJ365778 & Fäkalien (Mensch) \\
\hline 20 & Co2_D09 & 981 & Unkultiviertes Bakterium & Bacteria; Umweltproben. & 91.54 & DQ478748 & Brauerei-Abwasser \\
\hline 21 & Co2_F11 & 1081 & Unkultiviertes Bakterium & Bacteria; Umweltproben. & 95.28 & EF097941 & Caecum (Maus) \\
\hline 22 & Co2_G06 & 1014 & Unkultiviertes Bakterium & Bacteria; Umweltproben. & 98.92 & DQ455830 & Caecum (Truthahn) \\
\hline 23 & Co2_G11 & 1108 & Unkultiviertes Bakterium & Bacteria; Umweltproben. & 95.31 & EU459956 & Fäkalien (Eichhörnchen) \\
\hline 24 & $\mathrm{Co} 2 \mathrm{H} 12$ & 1107 & Unkultiviertes Bakterium & Bacteria; Umweltproben. & 99.64 & AJ487021 & Darm Zopholas mori \\
\hline 25 & Co3_B09 & 1118 & Unkultiviertes Bakterium & Bacteria; Umweltproben. & 97.67 & EU842232 & Pansen (Rind) \\
\hline
\end{tabular}




\begin{tabular}{lllllcll}
\hline $\begin{array}{l}\text { OTU } \\
\text { Nr. }\end{array}$ & $\begin{array}{l}\text { Vertreten durch } \\
\text { 16S rRNA - } \\
\text { Gensequenz }\end{array}$ & $\begin{array}{l}\text { BLAST- } \\
\text { Länge } \\
\text { (bp) }\end{array}$ & $\begin{array}{l}\text { Ähnlichste Sequenz aus } \\
\text { derDatenbank der NCBI }\end{array}$ & $\begin{array}{l}\text { Phylogenetische } \\
\text { Klassifikation der } \\
\text { Datenbanksequenz }\end{array}$ & $\begin{array}{l}\text { Sequenz- } \\
\text { identität } \\
{[\%]}\end{array}$ & $\begin{array}{l}\text { Accessio } \\
\text { n no. }\end{array}$ & $\begin{array}{l}\text { Herkunft der } \\
\text { Datenbanksequenz }\end{array}$ \\
\hline 26 & Co3_C08 & 1076 & Unkultiviertes Bakterium & Bacteria; Umweltproben. & 97.12 & EU458353 Fäkalien (Hyäne) \\
27 & Co3_E06 & 1061 & Unkultiviertes Bakterium & Bacteria; Umweltproben. & 94.91 & DQ795617 Fäkalien (Mensch) \\
28 & Co3_E07 & 1084 & Unkultiviertes Bakterium & Bacteria; Umweltproben. & 97.51 & AY976010 Colon (Mensch) \\
29 & Co3_E12 & 883 & Unkultiviertes Bakterium & Bacteria; Umweltproben. & 91.96 & DQ777940 Fäkalien (Ratte) \\
30 & Co3_F08 & 1055 & Unkultiviertes Bakterium & Bacteria; Umweltproben. & 92.70 & EU474337 Fäkalien (Gorilla) \\
31 & Co3_H02 & 1080 & Unkultiviertes Bakterium & Bacteria; Umweltproben. & 97.13 & EU776475 Fäkalien (Känguru) \\
\hline
\end{tabular}




\section{Danksagung}

Ich möchte mich recht herzlich bei Herrn Prof. Dr. Wolfgang Liebl für die Bereitstellung des interessanten Themas und die Betreuung meiner Arbeit bedanken. Weiterhin möchte ich mich dafür bedanken, dass er mir die Möglichkeit gegeben hat, meine Doktorarbeit in Göttingen zu beenden.

Rolf Daniel danke ich nicht nur für die unkomplizierte Übernahme des Korreferats, sondern auch für die Unterstützung jeglicher Art in den letzten Monaten.

Dem Biosphärenreservat Mittelelbe, besonders Herrn Peter lbe, danke ich für die Bereitstellung der Biber. Dr. Inger Völkel vom tierärztlichen Institut danke ich für die fachgerechte Sektion.

Allen jetzigen und ehemaligen Mitgliedern der Arbeitsgruppen Liebl, Daniel und Ehrenreich - Angel, Andrea, Sonja, Marc, Christel, Meike, Daniela, Jörg S., Jörg K., Katharina, Jessika, Juli, Jennifer, Caro, Bernd, Boris, Dominik, Birgit, Carola, Christiane, Marco, Christina, Melanie, Michael R., Michael V.,Anja, Desirée, Claudia, Markus, Heiko, Julia, Carola, Steffi, Tanja, Volker und Milad - danke ich für die tolle Arbeitsatmosphäre.

Ein besonderer Dank geht an Angel und Markus für die nette Zusammenarbeit im „Cellulase-Projekt“. Vielen Dank Angel, für Alles!

Carola und Dominik danke ich für die Einweisung in die Welt der $16 \mathrm{~S}$ rRNAGensequenzanalyse.

Ein Extra-Dank geht an Christiane, Carola, Angel, Birgit, Christina Heiko und Andrea für das Korrekturlesen dieser Arbeit.

Unserer „Laborperle“ Mechthild danke ich für ihren tollen Einsatz im Labor und der geduldigen Beantwortung meiner „Wo ist ....?-Fragen“

Meinen Eltern möchte ich für die finanzielle und moralische Unterstützung vor und während meiner Promotion danken.

Vielen Dank auch an Andrea für die Spaziergänge um den „Block“, das Teilen von Cappuccinopulver und die vielen witzigen Gespräche über das Leben innerhalb und außerhalb des Labors.

Marc danke ich für die Freundschaft und den Beistand in den letzten Jahren.

And last but not least spezial thanks to my favourite person. Thank you Michael for your support and understanding in the last months. And for your love. I can't wait to say "YARP" in the church. :) 


\section{Lebenslauf}

09.11 .1978

Geburt in Goslar

\section{Schulbildung}

1985- 1989

Besuch der Grundschule, Altenau

$1989-1991$

Besuch der Orientierungsstufe Clausthal-Zellerfeld

$1991-1999$

Besuch des Robert-Koch-Gymnasiums

Clausthal-Zellerfeld

Juli 1999

Abitur

\section{Studium}

September 1999

Februar 2002

Mai 2005

März 2006

Juli 2006

Dezember 2009
Immatrikulation an der Georg-August Universität

Göttingen im Fach Biologie

Vordiplom in den Fächern

Mikrobiologie, Zoologie, Physik und Chemie

Diplom in den Fächern Mikrobiologie, Genetik und Botanik

Abgabe der Diplomarbeit unter Anleitung von Prof. Dr. Liebl mit dem Titel: „Untersuchung von Hydrolasen des thermophilen Bakteriums Thermus thermophilus"

Beginn der experimentellen Arbeiten zur vorliegenden Dissertation

Abgabe der vorliegenden Dissertation 